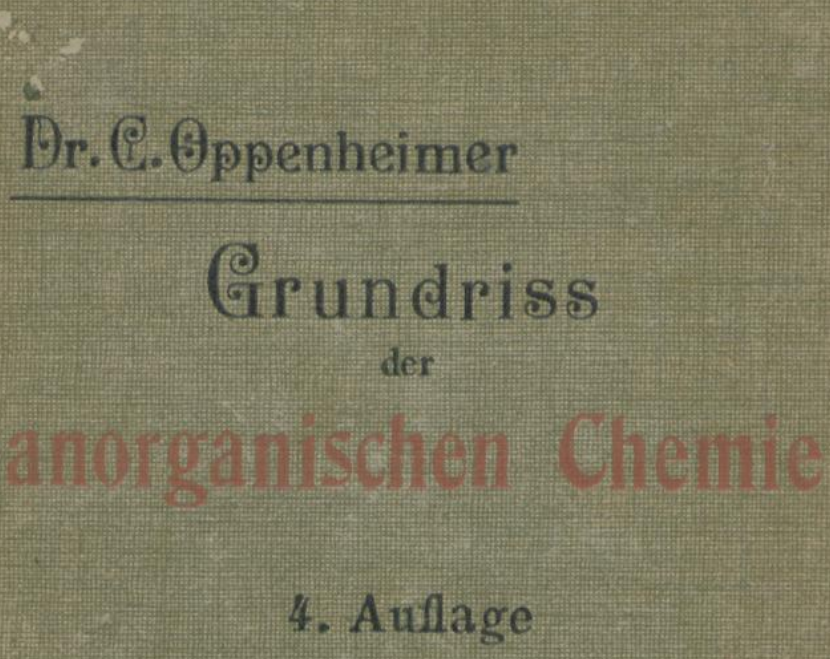

4. Auflage

Leipzig

Verlagron Georg Thieme 



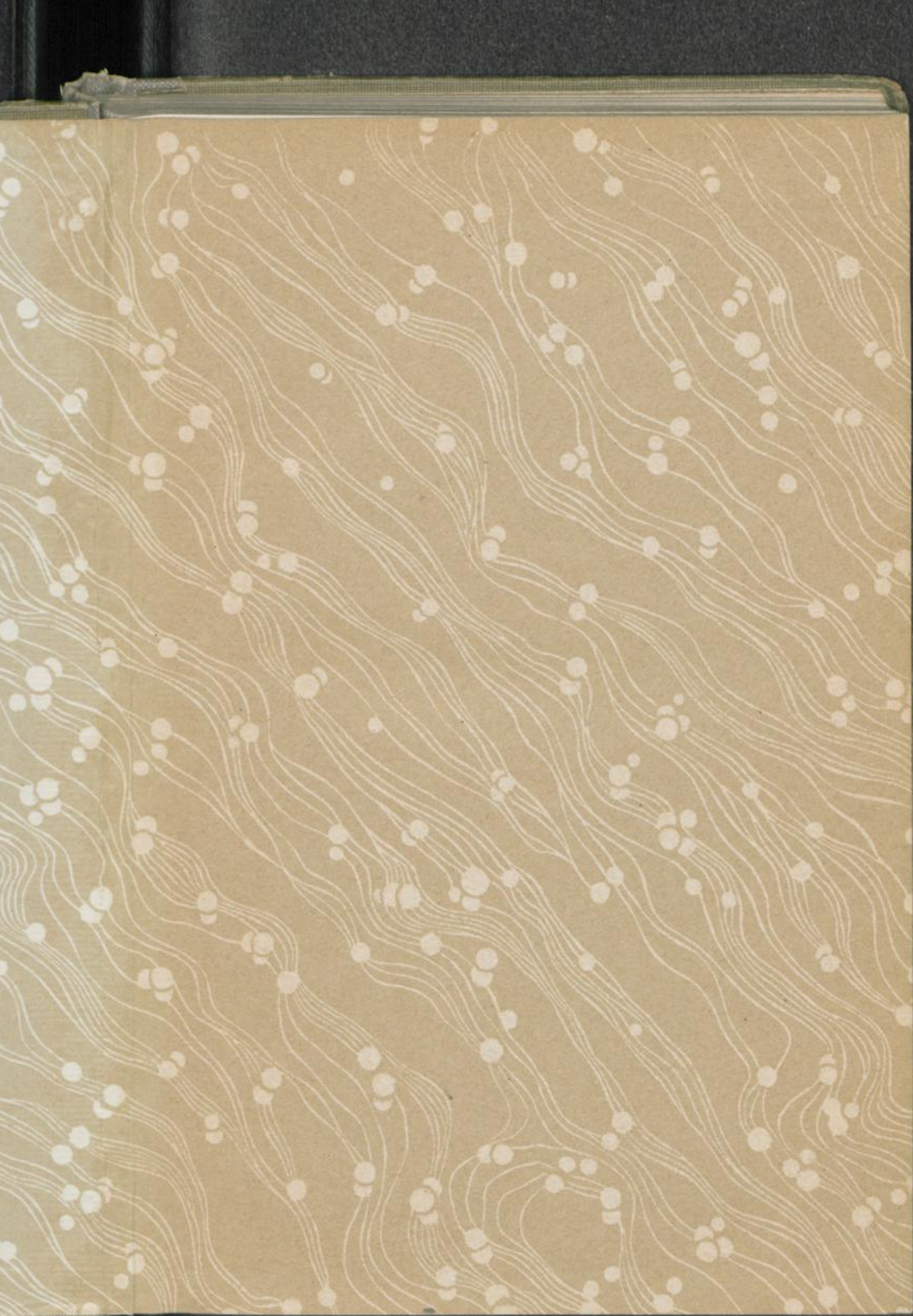




$$
3.50
$$




\section{Verlag von Georg Thieme in Leipzig.}

\section{Grundriss}

\section{der \\ organischen Chemie \\ Von}

\section{Carl Oppenheimer}

Dr. phil. et med.

Assist. \&. tierphysiol. Inst. d. Landw. Hochschul. Berlin.

Vierte Auflage.

geb. M. 2.40 .

Auf einem kleinen Raum hat der Verfasser mit einer Klarheit, die das Büchelchen durchaus für jeden, der das Gebäude der organischen Chemie kennen lernen will, empfehlenswert macht, die Grundgesetze derselben und die für den Mediziner wichtigen Stoffe ihrem Aufbau und ihren wesentlichen Eigenschaften nach beschrieben. Ein Durcharbeiten dieser Darstellung wird denjenigen, der auch moderne chemische Forschungsergebnisse leicht verstehen möchte, zu diesem Ziele führen.

(Deutsche medizin. Wochenschrift).

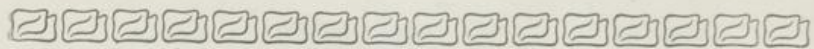




\section{Vuigel दि? \\ Grundriss

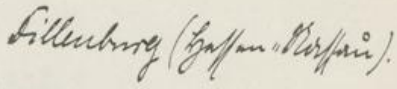

der

anorganischen Chemie

von

\section{Carl Oppenheimer}

Dr. phil. et med.

Assist. a. tierphysiol. Inst. d. Landw. Hochseh. Berlin.

Vierte Auflage.

LEIPZIG

Verlag von Georg Thieme

1907. 


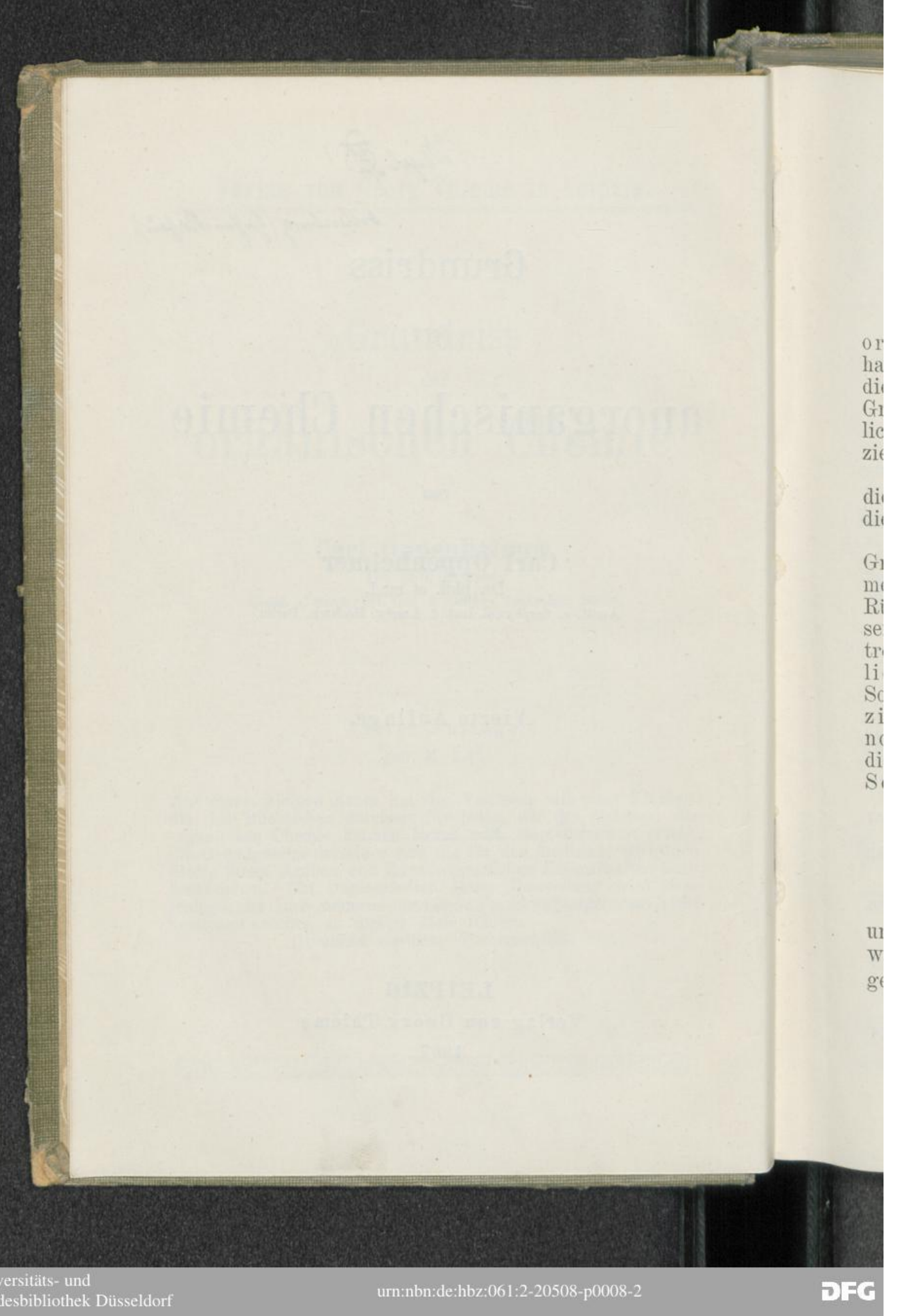




\section{Vorwort.}

Die Prinzipien, die ich in meinem "Grundriß der orga nis chen Ch e mie" durchzuführen versucht habe, haben mir auch in diesem Büchlein als Leitfaden gedient. Auch hier ist der Hauptwert darauf gelegt, die Grundgesetze in breiter Form darzulegen, um ein möglichst eingehendes Verständnis vor Aufnahme der speziellen Tatsachen zu erzielen.

Demgemäß ist also der , allgemeine Teil“, der die Grundlagen unsererWissenschaft behandelt, auch in diesem Büchlein relativ umfangreich.

Der "spezielle Teil" ist im wesentlichen auf der Grundlage des „periodischen Systems“ der Elemente aufgebaut. Die Auswahl wurde mit besonderer Rücksicht auf die Wichtigkeit der Stoffe für die Praxis, sei es in der Industrie oder als Heilmittel, getroffen. Daneben ist indessen auch der wissenschaftlichen Bedeutung der Stoffe ihr Recht geworden. So, hoffe ich, wird das Büchlein nicht nur für Mediziner, sondern auch für Pharmazeuten, Agronomen, Architekten, Ingenieure, kurz für alle die Chemie als Nebenfach treiben, sowie für den Schulunterricht geeignet sein.

Berlin, Dezember 1896.

\section{Der Verfasser.}

Die vorliegende vierte Auflage ist im wesentlichen unverändert, nur in Einzelheiten durchgesehen und die wichtigsten neuen Entdeckungen, z. B. Radium, nachgetragen.

Berlin, Oktober 1903.

Der Verfasser. 


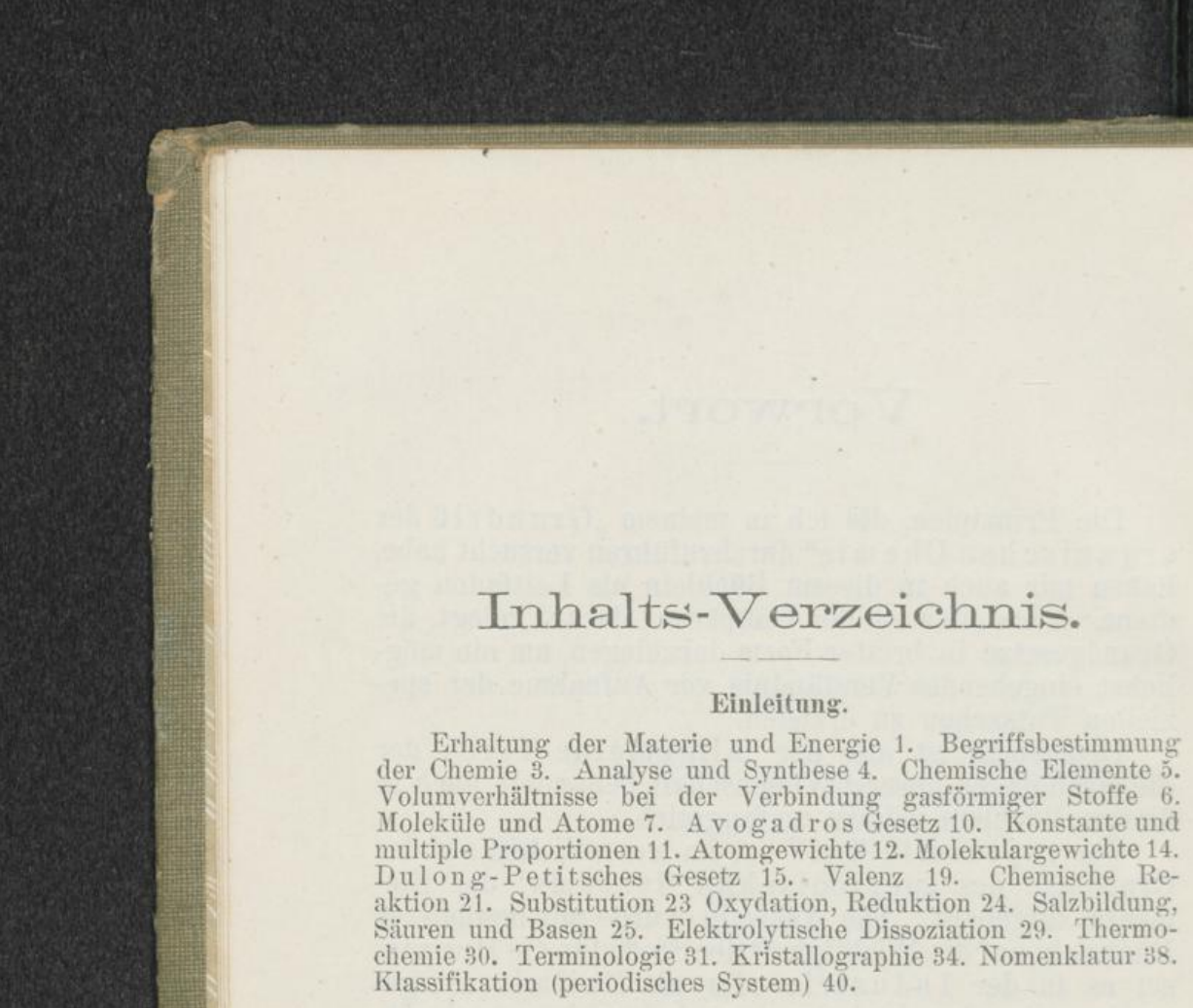

Arse

Antil

Kohl

Siliz

Über

Allge

Spezieller Teil.

A. Metalloïde.

Kalzi

Wasserstoff

Die Halogene. . . . . . . . . . . . . . 47

Fluor 48. Chlor 48. Brom 50, Jod 51. Fluorwasserstoff 52 . Chlorw assers to ff 52 . Brom-Jodwasserstoff 53 . Sauerstoffverb. d. Halogene 53.

Sauerstoff. 54 Ozon 56. Wasser 56. Wasserstoffsuperoxyd 58.

Schwefel . . . . . * 59 Schwefelwasserstoff 60 . Schwefeldioxyd 61 . Schwefelsäure 63 . Thioschwefelsäure 65 . Selen, Tellur

Elemente der Stickstoffgruppe.

Stickstoff . A tmosphärische Luft 67 . Edelgase 68. Ammoniak 69. Hydroxylamin, Hydrazin 70. Stickoxydul 71.

Stickoxyd 71. Stickstoffdioxyd Salpetersäure 72

Phosphor . . . . . . . . . . 74 Phosphorwasserstoff 75. Säuren des Phosphors 77.

Stro

Bary

Mag

Zink

Quec

Kupf

Silbe

Gold 
Arsen

Antimon . . . . . . . . . . . .

Vanadin, Niob, Tantal . . . ..... 84

Kohlenstoff . . . . . . . . . . . . 84

Kohlenoxyd 86. Kohlensäure 86. Leuchtgas 87.

Verbrennung und Flamme 88.

Silizium .

Titan, Zirkonium, Thorium . . . . . . . . 93

Übergang zu den Metallen ... . . . . . . . . . . 93

B or 94.

\section{B. Metalle.}

Allgemeines

Alkalimetalle.

Natrium

Lithium . . . . . . . . . . . 100

Chlornatrium. Natriumsulfat 101. Natriumkarbonat, Sodaprozesse 102. Natriumnitrat 104.

Kalium Ätzkali 105. Chlorkalium, chlorsaures Kalium i06.

Salpeter, Schießpulver 107. Pottasche 107. Rubidium. Caesium 108.

Ammoniumverbindungen

Alkalische Erdmetalle.

Kalzium Kalk, Mörtei, Zement 110. Chlorkalk, Gips 111.

Kalziumkarbonat 112. Glas 112 .

Strontium

Baryum

Metalle der Magnesiumgruppe.

Beryllium . . . . . . . . . . . . . 114

Magnesium . . . . . . . . . . . . . . . . 114

Zink

Kadmium . . . . . . . . . . . . 116

Quecksilber . . . . . . . 117

Kalomel 118. Sublimat 118. Quecksilberoxyd 119.

Zinnober 119 .

Kupfer, Silber, Gold.

Kupfer Kupfervitrioi 122.

Silber . . . . . . . 123

Höllenstein 125. Photographie 125. 


\section{- VIII -}

Gruppe des Aluminiums.

Aluminium

Alaun 129. Porzellan 130. Ultramarin 130.

Seltene Erdmetalle

Gruppe des Galliums .

Gallium, Indium, Thallium.

\section{Eisengruppe.}

Eisen

HochofenprozeB 132. Schmiedeeisen und

Stahl, BessemerprozeB 133. Ferroverbindungen 134.

Ferriverb. 135.

Nickel .

Kobalt

Chrom 139. Chromsäure 140. Molybdän 141.

Wolfram 141. Uran 141. Radium 142.

Zinn-Bleigruppe.

Germanium 143. Zinn 143. Blei 145. Wismut. 147

\section{Platingruppe.}

Rutenium 149. Osmium 149. Rhodium, Iridium 150.

Palladium 150. Platin 150.

Qualitative Analyse . . . . . . . . . . . . . 151

Spektralanalyse .....

Geschichtlicher Rüickblick 


\section{Einleitung.}

Auf zwei fundamentalen Gesetzen baut sich unsere gesamte moderne Naturwissenschaft auf: Dem Gesetze von der Erhaltung der Materie und dem von der Erhaltung der Energie.

Das Gesetz von der Erhaltung des Stoffes oder der Materie sagt aus, daß der Gesamtvorrat des Universums an Materie unveränderlich ist. Von dem vorhandenen Stoffe kann nichts vernichtet, nichts kann ihm hinzugefügt werden. Was uns in unseren Beobachtungen als Neuschaffung, als Vernichtung erscheint, ist nichts als eine Umwandlung, eine Veränderung der Form. Der Kristall, der wächst und sich vergrößert, en ts te h t nicht, sondern bildet sich nur aus den uns vorher unsichtbaren Partikeln der Flüssigkeit, in der er wächst, zu neuer Form um; die Kerze, die verbrennt, verbrennt nur für unser Auge zu einem Nichts; aus der in ihr enthaltenen Kohle entsteht durch die Verbrennung gasförmiges, für uns nicht wahrnehmbares Kohlendioxyd. Aber was unser Auge nicht sieht, zeigen uns andere Mittel. Leiten wir die Luft, in der eine Kerze verbrannt ist, in Kalkwasser, so trübt es sich, indem sich das Kohlendioxyd mit dem Kalziumhydroxyd verbindet, und sich kohlensaurer Kalk abscheidet. Das Gewicht des Gefäßes mit Kalkwasser wird vermehrt. Für die Chemie ist die Gewißheit dieser Unvergänglichkeit der Materie von der allergrößten Bedeutung; nur diese feste Basis, daß bei allen chemischen Reaktionen das Gesamtgewicht sich nicht verändert, erlaubt ihr, die

Oppen heimer, Grundriss d. anorg. Chemie, 4. Aufl. 1 
chemischen Prozesse mit der Wage zu untersuchen und damit ihre Ergebnisse auf feste, zahlenmäßig belegbare Fundamente zu stellen.

Nicht minder wichtig ist das zweite Fundamentalgesetz, das wir dem Genie Julius Robert Mayers ${ }^{1}$ ) und dessen Ausbau wir Helmholtz verdanken, das Gesetz der Erhaltung der Kraft oder besser der Energie. Energie ist die Fähigkeit, Arbeit zu leisten. Der menschliche Muskel, der einen Stein hebt, leistet Arbeit, der fallende Dampfhammer, der eine Panzerplatte schmiedet, der überhitzte Dampf, der die Lokomotive treibt, der elektrische Strom, der das Wort über Tausende von Meilen trägt, das Licht, das auf der photographischen Platte malt, sie alle leisten Arbeit und setzen dabei Energie um. Und dafür gilt das Gesetz:Die Ges a m tmenge derEnergieändert sich niemals, nur ihre Erscheinungsform wechselt. Unter den uns bekannten Energieformen: Mechanische Energie ${ }^{2}$ ), Wärme, Licht, Elektrizität, chemische Energie, herrscht ein fortwährender Umtausch, bei dem scheinbar Energiemengen verschwinden; der genauesten Untersuchungen hat es bedurft, nachzuweisen, daß dieses Verschwinden eben nur scheinbar ist. Ein Beispiel möge das erläutern. In der Kohle ist chemische Energie aufgespeichert. Ein Funke setzt die Kohle in Brand: ihre chemische Energie setzt sich in Wärmeenergie um, die nun imstande ist, Wasser in Dampf zu verwandeln und damit eine Dampfmaschine zu treiben, also mechanische Arbeit zu leisten, Bewegungsenergie, lebendige Kraft zu erzeugen. An die Dampfmaschine ist ein Dynamo gekuppelt, der die Bewegungsenergie in elektrische umwandelt, die nun ihrerseits vielleicht Glühlampen speist, also Lichtenergie liefert, oder zur elektrischen Heizung dient, also wieder Wärme produziert, oder Metalle aus ihren Salzen ausscheidet, also wieder chemische

1) Arztes in Heilbronn, der um 1844 zuerst das Gesetz aufstellte und dafür' fast ins Irrenhaus gesperrt worden wäre.

2) Näheres hierüber s. in den Lehrbüchern der Physik. 
Energie erzeugt. Bei allen diesen zahlreichen Umwandlungen bleibt die Energiemenge konstant. In der Praxis entstehen freilich Verluste, indem sich ein Teil der vorhandenen Energie in Formen umsetzt, welche dem Nutzeffekt nicht zu gute kommen, wie z.B. Reibung, Strahlung, Stromverluste. Diese beiden Gesetze bilden also das Fundament der ganzen Naturwissenschaft. Wodurch ist nun die Sonderstellung der Chemie begründet, worin liegen ihre Grenzen gegen andere Wissenschaften?

Begriff und Inhalt des Namens "Chemie" heute scharf $\mathrm{zu}$ umgrenzen, ist eine fast unlösbare Aufgabe. Die Grenzlinien, welche unsere Wissenschaft von der Physik scheiden, sind heute so verwischt, so viele Erscheinungen lassen sich ohne Zwang in beiden Disziplinen behandeln, ja m üsss en sogar in beiden behandelt werden, daß eine wirklich exakte Bestimmung des Begriffes "Chemie" undenkbar ist. Gerade die Grundlagen unseres Lehrgebäudes, die Atomtheorie und die Theorie der chemischen Affinität, gehören so gut wie völlig dem Gebiet an, das wir als "physikalische Chemie" bezeichnen. Sehen wir indessen von diesen Grenzfällen ab, so läßt sich allerdings noch leicht der Unterschied zwischen physikalischen und chemischen Vorgängen konstruieren. Physikalische Vorgänge sind solche, die nur in der Anordnung der kleinsten Elemente eines Körpers Änderungen bewirken, nicht aber diese kleinsten Partikeln selbst einem sie verändernden Prozesse unterwerfen. Die Physik beschäftigt sich mit den Änderungen des $\mathrm{Zu}$ standes der Stoffe, die Chemie mit den Anderungen der St offe selbst. Magnetisiertes Eisen bleibt Eisen, zur Weißgut erhitztes Platin ändert seine innerste Natur nicht, Eis ist Wasser.

Beim Aufhören der die physikalische Änderung bedingenden Ursache geht ferner der Körper wieder in den alten Zustand zurück. Anders bei einem chemischen Vorgang. Wenn wir Eisenfeile und pulverisierten Schwefel mischen, so erhalten wir ein Gemenge beider 
Stoffe, in dem Eisen- und Schwefelteilchen leicht von einander getrennt werden können; z. B. läßt sich das Eisen mit Hilfe des Magneten entfernen, der Schwefel in einigen Lösungsmitteln auflösen. Bleibt das Gemisch trocken, so läßt es sich Jahre lang unverändert aufbewahren; sobald es aber feucht wird, oder noch schneller beim Erhitzen, verwandelt es sich in eine homogene schwarze Masse, in der durch keinerlei ph ys i kalische Nethoden mehr Eisen und Schwefel nachweisbar sind. Ein völlig neuer Körper, eine chemische Verbind ung, das Schwefeleisen, ist das Resultat des Prozesses, entstanden durch Vereinigung der Bestandteile des Gemenges von Schwefel mit Eisen, die es also gebunden enthält.

Für die physikalischen Vorgänge, bei denen das Schwefeleisen etwa eine Rolle spielt, ist das völlig gleichgültig. Die Physik rechnet mit ihm als einem einheitlichen Körper, dessen Farbe, Glanz, Dehnbarkeit, Leitungsvermögen für Wärme und Elektrizität, Durchsichtigkeit, Brechungsexponenten etc. etc. als "physikalische Konstanten" sie bestimmt. Für sie ist es ein "Individuum". Nicht so für die Chemie. Sie schant tiefer, sie entdeckt, daß dieser scheinbar homogene Körper aus zwei verschiedenen einfacheren Körpern zusammengesetzt ist.

Zwei Methoden hat die Chemie, nm diesen Nachweis zu führen, die Analyse und die Synthese. Erstere sucht ein gegebenes physikalisches Individuum zu sprengen, es in seine Bestandteile zu zerlegen; glückt dies, so ist der Beweis geführt, daß der Körper aus den gewonnenen Bruchstücken bestanden hat; die Synthese hat nachzuprïfen, ob es gelingt, durch Aufbau, durch Vereinigung der Bruchstücke den ursprünglichen Körper wiederherzustellen. Natürlich kann auch die Synthese das primäre sein, den Aufbau bewirken, und Aufgabe der Analyse ist es dann, zu kontrollieren, ob das gewonnene Produkt sich in der Tat wieder in die alten Komponenten spalten läßt. So haben wir durch Erhitzen des Gemenges von Schwefel und Eisen synthe- 
tisch ein Produkt erhalten, das wir Schwefeleisen benannt und als chemische Verbindung hingestellt haben; den Beweis für die Richtigkeit dieser Behauptung können wir dadurch erbringen, daß wir durch geeignete a n a lytische Methoden aus dem Schwefeleisen Schwefel und Eisen darstellen.

Schwefel und Eisen sind also chemisch einfacherer Natur als Schwefeleisen. Sind sie aber absolut einfach? A priori ist sehr wohl denkbar, dab nun auch diese beiden Körper nicht chemische Individua, sondern noch weiter zerlegbar oder aus anderen einfacheren synthetisch erhältlich sind. Soweit aber unsere Kenntnisse reichen, sind sie es nicht: Schwefel und Eisen sind chemisch einfache Körper, die nicht weiter zerlegt werden können. Wir nennen solche einfachen Körper chemische Elemente. Threr sind heute ca. 70 bekannt, von denen die wichtigsten Sauerstoff, Kohlenstoff, die Metalle sind. Aus diesen 70 Elementen in mannigfachsten Kombinationen setzen sich sämtliche Stoffe der Erde zusammen, indem immer 2, 3 oder mehr Elemente sich miteinander verbinden.

Der Bequemlichkeit halber hat man für die einzelnen Elemente Symbole eingeführt, z. B. Wasserstoff $($ Hydrogenium $)=H$, Sauerstoff $($ Oxygenium $)=0$, Chlor $=$ Cl etc. Die Kombinationen dieser Elemente in den Verbindungen bezeichnen die sog. ch emischen F ormeln, z. B. Fe Eisen, S Schwefel, also FeS Schwefeleisen.

Bei diesen Kombinationen spielen nun nicht nur die Art und Zahl der sich verbindenden Elemente eine Rolle, sondern vor allem die Mengenverhältnisse der einzelnen. Komponenten. So konnte eine fruchtbringende Forschung erst dann beginnen, als die Wissenschaft anfing, mit Wage und Maß an das Studium der chemischen Verbindungen heranzugehen; und Laurent La v o isier $\mathbf{s}^{1}$ ) unsterbliches Verdienst ist es, der quantitativen Forschung durch seine Arbeiten.

1) Hingerichtet 1792 . 
über das Wasser den Weg gewiesen zu haben, der allein zum Ziele führte.

Wasserstoff und Chlor vereinigen sich im Licht zu Chlorwasserstoff. Man mag nun die Versuchsbedingungen modifizieren, soviel man will: Stets vereinigen sich genau .1 Volum Wasserstoff mit 1 Volum Chlor. Jedweder Überschuß des einen oder anderen Elementes bleibt unangetastet. Bei dieser Vereinigung bleibt das frühere Gesamtvolnm ungeändert. 1 Liter Chlor + 1 Liter Wasserstoff geben 2 Liter Chlorwasserstoff.

Nehmen wir an Stelle des Chlors Sauerstoff, so verläuft der Vorgang anders. Es vereinigen sich stets und unabänderlich 2 Volume Wasserstoff mit 1 Volum Sauerstoff zu Wasser. Hierbei werden aber auch nur 2 Volume Wasserdampf gebildet.1) Das Gesamtvolumen vermindert sich also um $1 / 3$, aus 2 Litern Wasserstoff +1 Liter Sauerstoff werden 2 Liter Wasserdampf. Genau so ergeben 1 Liter Stickstoff und 3 Liter Wasserstoff ebenfalls nur 2 Liter Ammoniak; und genau so verläuft bei allen Gasen der Prozeb: Es werden unter allen Umständen 2 Volume der neuen Verbindung gebildet.

Zur Ausführung dieses Versuches füllt man einen graduierten Glaszylinder bis an den Rand mit Quecksilber, stülpt ihn unter Quecksilber um und läßt nun die gewünschten Gasvolume in den Zylinder eintreten. Vereinigt man nun die Gase, z. B. durch den elektrischen Funken, so kann man das neugebildete Volumen an der Stellung des Quecksilbers ablesen.

Wohin verschwinden die scheinbar verloren gegangenen Gasvolume? Oder vielmehr wohin verbergen sie sich, denn daß sie de facto vorhanden sind, zeigt jede Wage, die das unveränderte Gewicht des Ganzen angibt. Zur Erklärung dienen folgende theoretische

1) Natürlich oberhalb $100^{\circ} \mathrm{C}$, weil sonst das Wasser sich verdichten würde. 
Betrachtungen, die die Grundlage unseres ganzen Lehrgebäudes bilden:

Wir nehmen eine gewisse Quantität einer chemischen Verbindung, sagen wir Chlor wasserstoff(Salzsäure). Wir können nun diese Quantität verkleinern, in beliebige Teile teilen, diese Teile weiter teilen und so fort. Diese Teilung muß ein Ende nehmen; wir müssen schließlich auf eine Grenze kommen, wo ein weiteres Teilen nicht mehr möglich ist.

Dies muß der Fall sein, da bis in die Unendlichkeit fortgesetzte Teilung zu Partikeln von unendlicher Kleinheit führen würde; und diese könnten niemals endliche Massen bilden.

Wir finden also, daß die Salzsäure - und ebenso natürlich alle andern Substanzen - aus einer Anzahl kleinster, unteilbarer Partikelchen besteht; und diese mechanischen Urbestandteile der Körper nennen wir Moleküle ${ }^{1}$ ). Die Salzsäure also besteht aus Molekülen, von denen jedes einzelne Träger der Eigenschaften der Salzsäure ist. Jedes dieser MIoleküle ist noch Salzsäure; nun wissen wir aber, daß Salzsäure aus Chlor und Wasserstoff besteht; ergo mul auch das Salzsäuremolekül aus Chlor und Wasserstoff bestehen: das unzerlegliche Molekül besteht doch noch ans zwei Teilen. Um dieses Dilemma zu lösen, hat man angenommen, daß die Moleküle zwar m echan isch unteilbar sind, daß sie aber doch noch chemisch teilbar sind. Diese chemischen Grundpartikeln bezeichnen wir als Atome $^{2}$ ). Freie Atome sind im allgemeinen nicht existenzfähig, also wird man auch in den Elementen selbst ihren Zusammenschluß zu Molekülen annehmen. Bei vielen Elementen, z. B. den meisten gasförmigen, läßt sich in der Tat nachweisen, daß ihre Moleküle aus zwei Atomen bestehen. Das Resultat unserer Betrachtung ist also folgendes:

Alle Körper bestehen aus mechanisch un-

1) Moleculum v. moles die Masse.

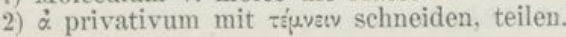


teilbaren kleinsten Teilchen, den Molekülen; diese sind wieder zusammengesetzt aus den chemischen Grundeinheiten, den Atomen. Bei chemischen Elementen sind die Atome gleich, bei Verbindungen verschieden.

Nach diesen Auseinandersetzungen müssen wir auch unseren schon des öfteren gebrauchten Symbolen für die Elemente einen anderen Sinn unterlegen. Sie bedeuten uns nicht mehr bloß das Vorhandensein des Elementes, sie haben nicht mehr bloß qualitative Bedeutung; sie versinnbildlichen jetzt eine Quantität, nämlich ein Atom des Elementes; 0 ist also ein Atom Sauerstoff, $\mathrm{H}$ ein A tom Wasserstoff, $\mathrm{Cl}$ ein A tom Chlor. Und wir schreiben sie in den sogenannten chemischen Formeln nur in diesem Sinne. Also bedeutet z. B. die Formel HCl eine Verbind ung eines A toms $\mathrm{H}$ mit einem A to $\mathrm{m} \mathrm{Cl}$ zu einem Molekül $\mathrm{HCl}, \mathrm{H}_{2} \mathrm{O}$ diejenige von zwei Atomen $\mathrm{H}$ mit einem Atom $\mathrm{O}$ zu einem Molek ül $\mathrm{H}_{2} \mathrm{O}$. So muß die che$m$ ische Formel eines Elementes auch die Molekularformel sein, z. B. $\mathrm{O}_{2}, \mathrm{Cl}_{2}$, da ja auch diese Moleküle 2 Atome enthalten.

Wie haben wir uns nun denVorgang einer chemischen Reaktion vorzustellen, z. B. zwischen Chlor und Wasserstoff? Wir haben ein Chlormolekül, das aus 2 Chloratomen besteht, und ein Wasserstoffmolekül, das aus 2 Wasserstoffatomen besteht:

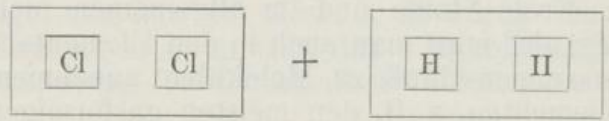

Jetzt tritt die „Reaktion“ ein. Zu diesem Zweck müssen die Moleküle sich spalten; momentan werden die Atome frei, um sich sofort in anderer Weise wieder zusammenzuschließen, sodaß Ch lorwas se rst of fmoleküle entstehen. 


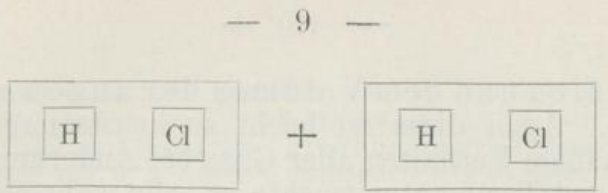

Zwei Moleküle sind in Reaktion getreten, zwei andere sind das Resultat. Ihre Anzahl bleibt unverändert. Ein anderes Beispiel!

Aus 2 Molekülen Wasserstoff und einem Molekül Sauerstoff bilden sich 2 Moleküle Wasser nach folgendem Schema :

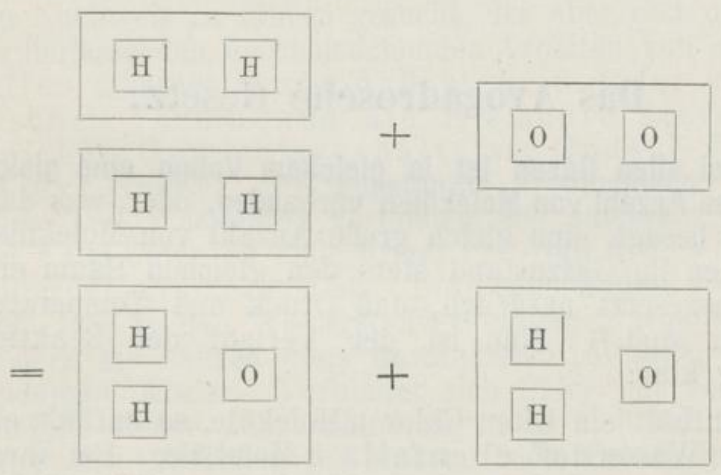

Die Zahl der Moleküle ist während der Reaktion nich t unverändert geblieben: aus drei ursprünglich vorhandenen Molekülen sind zwei geworden. Die Anzahl der A tome ist unverändert, nur ihre Anord$\mathrm{nung}$ in den Molekülen hat sich geändert.

Was wir hier mit einem oder wenigen Molekülen vorgenommen haben, vollzieht sich in derselben Weise mit Tausenden und Millionen von Molekülen.

Nur ein Glied der Kette zwischen unseren letzten Molekularbetrachtungen und der vorhin empirisch konstatierten Tatsache, daß 2 Volume Wasserstoff mit 1 Volum Sauerstoff 2 Volume Wasserdampf geben, fehlt uns noch: die Beziehung zwischen den 
Molek ülen und dem Volumen der angewand ten Stoffe. Auch diese ist leicht zu konstatieren: Das gleichmäßige Verhalten aller Gase bei Änderungen von Druck und Temperatur machte es sehr wahrscheinlich, daß bei allen Gasen die Elementarteilchen sich in gleichen Entfernungen befinden, und dies in Verbindung mit der Molekulartheorie drückt jene berühmte Hypothese aus, die fast sicher erwiesen ist, da sie sich mit allen chemischen Vorgängen vorzüglich deckt, die Avogadrosche Hypothese, oder wie man sie jetzt meist nennt:

\section{Das Avogadrosche Gesetz:}

Bei allen Gasen ist in gleichem Volum eine gleich grosse Anzahl von Molekülen vorhanden, oder, was dasselbe besagt, eine gleich große Anzahl von Molekülen nehmen im Gaszustand stets den gleichen Raum ein, vorausgesetzt natürlich, daß Druck und Temperatur gleich sind. 1) Nun ist der Verlauf der Reaktion völlig klar:

Enthält ein Liter Chlor nMoleküle, so enthält ein Liter Wasserstoff ebenfalls n Moleküle. Bei ihrer Vereinigung erhalten wir 2 n Moleküle $=2$ Liter Chlorwasserstoff. Dagegen ergeben 2 Liter Wasserstoff = 2 n Moleküle +1 Liter Sauerstoff $=n$ Moleküle nur 2 n Moleküle. Diese 2 n Moleküle können also auch nur den Raum von 2 Litern einnehmen.

Und nun sehen wir, warum es notwendig war, auch in den Elementarmolekülen noch eine Zusammensetzung aus Atomen anzunehmen, anzunehmen, daß freie A tome nicht existenzfähig sind ${ }^{2}$ ). Gesetzt, die elementaren Gase beständen aus freien Atomen, so würden z. B. ein Liter Chlor p Atome und ein Liter Wasserstoff ebenfalls $\mathrm{p}$ Atome enthalten. Vereinigen sich nun diese beiden, so würden im ganzen p Moleküle Chlorwasserstoff entstehen, die

1) Man berechnet alle Vorgänge in Gasen auf $0^{\circ}$ und den Normaldruck einer Atmosphäre, $760 \mathrm{~mm}$ Quecksilber.

2) Eine Ausnahme stellt z. B. das Quecksilber im Gaszustande dar, s. d. 
nun auch nur einen Liter ausfüllen würden. Da dies aber nicht der Fall ist, sondern es 2 Liter bleiben, so ergibt sich daraus, daß auch Chlor und Wasserstoff nicht in freien Atomen, sondern in Molekülen mit je 2 Atomen vorhanden sein müssen.

Haben wir so einen direkten Zusammenhang zwischen Anzahl der Moleküle und Volumen der Gase gefunden, so bleibt uns noch die viel wichtigere Aufgabe, die Beziehungen zwischen den Molekülen resp. Atomen und den Gewichtsverhältnissen der chemischen Verbindungen aufzuklären.

Schon im Anfange dieses Jahrhunderts hatte Proust den Nachweis zu führen gesucht, der aber erst durch die umfassenden, epochemachenden Arbeiten von Berzelius erbracht wurde, daß sich in jeder chemischen Verbindung die Elemente stets in gleichem Gewichtsverhältnisse finden. Dies ist das Gesetz der konstanten Proportionen. Mit einem Teil Wasserstoff verbinden sich unfehlbar stets 35,5 Teile Chlor, 80 Teile Brom, 127 Teile Jod, 8 Teile Sauerstoff, 4,7 Stickstoff etc. Doch spielen diese Zahlen nicht blob in den Wasserstoffverbindungen eine Rolle, sondern sie kehren stets unwandelbar in allen Verbindungen wieder. Verbindet sich Chlor mit Jod, so entsteht wieder eine Verbindung, in der sich 35,5 Teile Chlor mit 127 Teilen Jod binden. Diese Zahlen stellen die Verbindungsgewichte der Elemente dar. Solche hat man auch früh schon für viele Elemente gefunden.

Doch ist das Gesetz, das man auch so formulieren kann: die Elemente verbinden sich stets im Verhältnis ihrer Verbindungsgewichte, in dieser Form zu eng. Denn es gibt Elemente, die untereinander mehrere Verbindungen eingehen, z. B. Schwefel und Sauerstoff, Stickstoff und Sauerstoff. In diesen Fällen sind natürlich die Proportionen nicht konstant, aber sie stehen dann in einem einfachen Verhältnis miteinander, im Verhältnis der Vielfachen einer rationalen Zahl. So binden z. B. 127 Teile Jod sowohl 35,5 Teile Chlor, als auch $3 \times 35,5$ Teile Chlor; Schwefel (32 Teile) sowohl $2 \times 16$, als $3 \times 16$ Teile 
Sauerstoff. Dies Gesetz heißt das Gesetz der m ultiple m Proportionen.

Die Atomtheorie erklärtall dies ohne weiteres. Wenn sich eben stets ein Atom, also ein unveränderlich festgelegter Massenteil eines Elementes mit einem andern Atom vereinigt, so $\mathrm{mu}$ B die Gewichtsproportion eine k onsta nte sein. Die multiplen Proportionen erklären sich dadurch, daß z. B. ein Atom Schwefel sowohl zwei Atome Sauerstoff, als auch drei Atome Sauerstoff binden kann. Esentstehen dabei zwei ganz verschiedene Körper, Schwefeldioxyd und Schwefeltrioxyd, in denen natürlich die Gewichtsmengen des Sauerstoffs sich wie 2:3 verhalten. Durch die Atomtheorie wird aus dem vagen Begriff des Verbindungsgewichtes das feststehende $\mathrm{Ma}$ des A tomgewichtes, denn mit der Vorstellung eines Atoms als eines Massenteils ist notwendig die Vorstellung eines Gewichtsteils verbunden. Es handelt sich jetzt also um die Aufgabe, für diese Gewichtsverhältnisse wirklich vergleichbare Werte zu schaffen. Dazu brauchen wir vor allem einen Einheitswert und ferner Methoden, um die Gewichte der übrigen Atome, bezogen auf diesen Einheitswert, zu ermitteln, also Methoden zur Bestimmung der Atomgewichte.

Der Weg nun, der zu dem Ziele führt, die Atomgewichte einiger Elemente in bezug auf eine Einheit zu finden, ist einzig die Untersuchung gasförmiger Stoffe. Zwei Gesetze gelten für alle Gase:

1) Das Boyle-Mariotte-Gay Lussacsche Gesetz: Das Volumen aller Gase ist direkt proportional der Temperatur und umgekehrt proportional dem auf ihnen lastenden Druck.

2) Das Avogadrosche Gesetz (s. 0.). Bei allen Gasen enthalten gleicheVolumina eine gleiche Anzahl von Molekülen.

Wenn nun alle Gase in gleichen Raumteilen gleich viel Moleküle enthalten, sogelten alleBeziehungen, die wir zwischen den Volumverhältnissen der Gase feststellen, ohne Änderung auch für jedes einzelne Molekül. 
Nun lassen sich unter Berücksichtigung des gleichen Verhaltens der Gase gegen Druck und Temperatur durch Wägung leicht ihre Gewichtsverhältnisse feststellen.

Das leichteste aller Gase ist der Wasserstoff. Deshalb beziehen wir auf ihn die übrigen Gasgewichte, die spezifischen Gewichte, die sog. "Dampfdichten"1) oder Gasdichten der Gase.

Wiegt also 1 Liter Wasserstoff „1", so wiegt nach den Resultaten der Untersuchungen:

$\begin{array}{cccc}1 & \text { Liter } & \text { Sauerstoff } & 16^{2} \text { ) } \\ 1 & \# & \text { Stickstoff } & 14 \\ 1 & " & \text { Chlor } & 35,5\end{array}$

Hiermit ist nun ohne weiteres das Atomgewicht des Elementes gefunden. Wiegt ein Liter Sauerstoff 16 mal so viel als ein Liter Wasserstoff, so wiegt ein Molekül Sauerstoff 16 mal so viel als ein Molekül Wasserstoff (nach dem A vogadroschen Gesetz); und da wir sahen, daß die Moleküle zweiatomig sind, auch jedes A tom Sauerstoff 16 mal so viel als ein Atom Wasserstoff. Das Atomgewicht des Sauerstoffes, berechnet auf Wasserstoff $=1$, ist also 16; genau so das des Stickstoffs $=14$, des Chlors $=35,5$.

Das Atomgewicht der gasförmigen Elemente ist gleich dem spezifischen Gewicht derselben, bezogen auf Wasserstoff $=1$.

Nun sind wir aber auch in der Lage, gasförmige Verbindungen zu untersuchen. Auch für sie gelten die Gasgesetze. Nur lassen sich bei ihnen aus den spezifischen Gewichten natürlich keine Atomgewichte ableiten, denn Verbindungen haben keine Atome, also keine Atomgewichte, wohl aber die Molekulargewichte, d. h. das Gewicht der Moleküle, bezogen

1) Ich muB leider dies allgemein gebräuchliche Wort auch hier anführen, obgleich es nicht das richtige trifft.

2) In runden Zahlen. 
auf ein Mol ekül Wasserstoff. Ein MolekülW asserstoff wiegt aber, "zwei", da es zwei A tomeder Gewichtseinheiten enthält.

Ein Liter Chlor wiegt 35,5, 1 Liter Wasserstoff 1, daraus entstehen 2 Liter Chlorwasserstoff, welche also 36,5 wiegen. Das spez. G. also des Chlorwasserstoffs, d. h. das Gewicht eines Liters, bezogen auf einen Liter Wasserstoff, ist $=18,25$. Das Chlorwasserstoffmolekül ist also $18,25 \mathrm{mal}$ schwerer als das Wasserstoffmolekül: dieses wiegt 2, also ist das Molekulargewicht des Chlorwasserstoffs $=36,5$, d. h. gleich dem doppelten spez. G.

2 Liter Wasserstoff wiegen 2, 1 Liter Sauerstoff 16. Die sich daraus ergebenden 2 Liter Wasserdampf (s. 0.) wiegen also 18 . Das spez. G. des Wasserdampfes ist also 9, das Molekulargewicht 18.

Natürlich lassen sich auch ohne weiteres die Molekulargewichte der gasförmigen Elemente aus den spez. G. durch Verdoppelung ableiten, da ja alle Gase denselben Gesetzen unterliegen. Wir finden also:

Die Molekulargewichte aller gasförmigen Stoffe (Elemente und Verbindungen) sind gleich dem doppelten spezifischen Gewicht derselben.

Ein zweiter Satz, giltig für alle Verbindungen, folgt aus der Definition des Moleküls:

\section{Die Molekulargewichte der Verbindungen sind gleich der Summe der Atomgewichte.}

Die Methode der Bestimmung der Atomgewichte aus den Gasdichten, die völlig eindeutige Resultate liefert, ist nur bei vergasbaren Elementen durchführbar. Bei der großen Mehrzahl der Elemente versagen sie. Hier muß man zu anderen Methoden seine Zuflucht nehmen. Man kann das Atomgewicht eines unvergasbaren Elements unter Umständen finden, wenn es mit 
einem vergasbaren Elemente eine Verbindung eingeht. Man ermittelt zunächst durch quantitative Analyse den Prozentgehalt der Verbindung an beiden Stoffen; man kennt die Gasdichte und damit das Atomgewicht des gasförmigen Elementes und kann nun durch Rechnung das Atomgewicht des anderen Elementes finden, vorausgesetzt, daß man auch noch weiß, wieviel Atome eines jeden Elementes die Verbindung enthält. Weiß man z. B., daß in einer Verbindung des Chlors mit dem Silber je ein Atom beider Elemente vorhanden ist, so läßt sich leicht das Atomgewicht des Silbers finden. Für viele Verbindungen ist dies möglich 1), für andere hingegen nicht. Hier hilft nun ein Gesetz weiter, das die französischen Forscher Dulong und Petit gefunden haben:

\section{Das Produkt aus Atomgewicht und spezifischer Wärme ist konstant ${ }^{2}$ ) (ungefähr 6 ). \\ Die spezifische Wärme ist eine physikalische Kon- stante, die sich leicht bestimmen läßt. Es ist nämlich diejenige Wärmemenge, die nötig ist, um $1 \mathrm{~kg}$ eines Körpers um $1^{0} \mathrm{zu}$ erwärmen, wenn wir als Einheit diejenige Wärmemenge betrachten, die $1 \mathrm{~kg}$ Wasser um 10 erwärmt. Die Anwendung dieses Gesetzes ge- staltet sich nun folgendermaßen:}

Mit 16 Teilen Sauerstoff, also mit einem Atom, verbinden sich 63,5 Teile Kupfer. Ist nun diese Menge ebenfalls einem Atom entsprechend? Oder entspricht sie mehreren Atomen, oder ist erst mit mehreren Atomen ein Atom Kupfer verbunden? Das DulongPetitsche Gesetz gibt uns Antwort. Die spez. Wärme des Kupfers ist 0,0951. Diese Zahl mit 63,5, dem mutmaßlichen Amtomgewicht, multipliziert, gibt 6,0388, also ca. 6. Damit ist gezeigt, daß 63,5 das

1) Aus Analogien mit anderen Elementen, durch Isomorphismus ete. Näheres ist in Ostwalds Allg. Chemie Kap. I einzusehen.

2) Oder anders ausgedrückt: „Die Atomwärme der Elemente ist konstant." 


\section{- $16-$}

wirkliche Atomgewicht des Kupfers ist, daß auf ein Atom $\mathrm{O}$ ein Atom Cu entfällt, daß der Verbindung also die Formel CuO zukommt.

Mit 16 Teilen Sauerstoff sind ferner 216 Teile Silber verbunden. Die spez. Wärme des Silbers ist 0,0570 , das Produkt beider Zahlen 12,312. Also ist 216 doppelt so groß, als für das einfache Verhältnis $\mathrm{AgO}$ stimmen würde: das wahre Atomgewicht ist 108. Die Formel der Verbindung muß $\mathrm{Ag}_{2} \mathrm{O}$ sein.

Mit Hilfe dieses Gesetzes, das übrigens bei einigen Elementen, z. B. Kohlenstoff, völlig im Stich läßt, und einiger anderer Hilfsmittel ist es gelungen, die Atomgewichte sämtlicher bekannten Elemente zu finden. Die folgende Tabelle gebe einen Überblick über die bis jetzt bekannten: ${ }^{1}$ )

$\begin{array}{llc}\text { Aluminium } & \mathrm{Al} & 26.9 \\ \text { Antimon (Stibium) } & \mathrm{Sb} & 119.5 \\ \text { Argon } & \mathrm{Ar} & 39.7 \\ \text { Arsen } & \mathrm{As} & 74.45 \\ \text { Baryum } & \mathrm{Ba} & 136.4 \\ \text { Beryllium } & \mathrm{Be} & 9.0 \\ \text { Blei (Plumbum) } & \mathrm{Pb} & 205.36 \\ \text { Bor } & \mathrm{B} & 10.86 \\ \text { Brom } & \mathrm{Br} & 79.34 \\ \text { Cadmium } & \mathrm{Cd} & 111.55 \\ \text { Caesium } & \mathrm{Cs} & 131.9 \\ \text { Calcium } & \mathrm{Ca} & 39.76 \\ \text { Cer } & \mathrm{Ce} & 138.0\end{array}$

1) Ich führe in dieser Übersichtstabelle die Atomgewichte in genauen Zahlen (nach Erdmann) an. Bei der Besprechung der einzelnen Elemente werde ich sie nur in abgerundeten Zahlen wiederholen. Was die Wichtigkeit der einzelnen Elemente anbetrifft, so ist sie durch den Druck bezeichnet. Von den fett gedruckten muß Symbol und A tomgewicht (mit abgerundetet Ziffer) jedem bekannt sein : von den gesperrt gedruckten mindestens das $\mathrm{Sy} \mathrm{mbol}$. Die klein gedruckten kann der Anfänger füglich vernachlässigen. In praktischen Rechnungen werden jetzt offiziell die Atomgewichte nicht mehr auf $H=1$, sondern auf $0=16,00$ berechnet, wodurch geringe, für uns unwesentliche Verschiebungen nach oben eintreten $(\mathrm{H}=1,002)$. 


\section{$-17-$}

\begin{tabular}{|c|c|c|}
\hline Chlor & $\mathrm{Cl}$ & 35.18 \\
\hline Chrom & $\mathrm{Cr}$ & 51.7 \\
\hline Eisen (Ferrum) & $\mathrm{Fe}$ & 55.47 \\
\hline Erbium & $\mathrm{Er}$ & 164.70 \\
\hline Fluor & $\mathrm{F}$ & 18.9 \\
\hline Gadolinium & Gd & 155.6 \\
\hline Gallium & $\mathrm{Ga}$ & 69.5 \\
\hline Germanium & Ge & 71.9 \\
\hline Gold (Aurum) & $\mathrm{Au}$ & 195.74 \\
\hline Helium & $\mathrm{He}$ & 4.0 \\
\hline Indium & In & 113.1 \\
\hline Jod & $\mathrm{J}$ & 125.9 \\
\hline Jridium & $\mathrm{Jr}$ & 191.66 \\
\hline Kalium & $\mathrm{K}$ & 38.82 \\
\hline Kobalt (Cobaltum) & $\mathrm{Co}$ & 58.80 \\
\hline Kohlenstoff (Carbonium) & C & II.9I \\
\hline Krypton & $\mathrm{Kr}$ & 81.0 \\
\hline Kupfer (Cuprum) & $\mathrm{Cu}$ & 63.1 \\
\hline Lanthan & $\mathrm{La}$ & 137.6 \\
\hline Lithium & $\mathrm{Li}$ & 6.97 \\
\hline Magnesium & $\mathrm{Mg}$ & 24.1 \\
\hline Mangan & $\mathrm{Mn}$ & 54.6 \\
\hline Molybdän & Mo & 95.2 \\
\hline Natrium & $\mathrm{Na}$ & 22.88 \\
\hline Neodym & $\mathrm{Nd}$ & 142.5 \\
\hline Neon & $\mathrm{Ne}$ & 19.86 \\
\hline Nickel & $\mathrm{Ni}$ & $5 \$ .3$ \\
\hline Niob & $\mathrm{Nb}$ & 93.0 \\
\hline Osmium & Os & 198.5 \\
\hline Palladium & $\mathrm{Pd}$ & 106 \\
\hline Phosphor & $\mathbf{P}$ & 30.75 \\
\hline Platin & $\mathrm{Pt}$ & 194.4 \\
\hline Praseodym & $\mathrm{Pr}$ & 139.4 \\
\hline Quecksilber (Hydrargyrum) & $\mathrm{Hg}$ & 199.5 \\
\hline Radium & $\mathrm{Ra}$ & 225 \\
\hline Rhodium & Rh & 102.2 \\
\hline Rubidium & $\mathrm{Rb}$ & 84.7 \\
\hline
\end{tabular}




\begin{tabular}{|c|c|c|}
\hline Ruthenium & $\mathrm{Ru}$ & 100.9 \\
\hline Samarium & $\mathrm{Sa}$ & 149.2 \\
\hline Sauerstoff (Oxygenium) & 0 & 15.88 \\
\hline Seandium & $\mathrm{Sc}$ & 43.8 \\
\hline Schwefel (Sulfur) & S & 31.83 \\
\hline Selen & $\mathrm{Se}$ & 78.58 \\
\hline Silber (Argentum) & $\mathrm{Ag}$ & 107.11 \\
\hline Silicium & $\mathrm{Si}$ & 28.18 \\
\hline Stickstoff (Nitrogenium) & $\mathbf{N}$ & 13.93 \\
\hline Strontium & $\mathrm{Sr}$ & 86.95 \\
\hline Tantal & Ta & 181.45 \\
\hline Tellur & $\mathrm{Te}$ & 126.73 \\
\hline Terbium & $\mathrm{Te}$ & 158.8 \\
\hline Thallium & $\mathrm{Tl}$ & 202.61 \\
\hline Thorium & $\mathrm{Th}$ & 230.8 \\
\hline Thulium & $\mathrm{Tu}$ & 16940 \\
\hline Titan & $\mathrm{Ti}$ & 47.79 \\
\hline Uran & $\mathrm{U}$ & 237.77 \\
\hline Vanadin & V & 50.99 \\
\hline Wasserstoff (Hydrogenium) & $\mathrm{H}$ & 1.00 \\
\hline Wismut (Bismutum) & $\mathrm{Bi}$ & 206.54 \\
\hline Wolfram & W & 182.6 \\
\hline Xenon & $\mathrm{Xe}$ & $12 \pi .1$ \\
\hline Ytterbium & $\mathrm{Tb}$ & 171.88 \\
\hline Yttrium & Y & $\$ 8.35$ \\
\hline Zink & $\mathrm{Zn}$ & 64.91 \\
\hline Zinn (Stannum) & Sn & 118.1 \\
\hline Zirkonium & $\mathrm{Zr}$ & 89.72 \\
\hline
\end{tabular}

Die eben entwickelten Gesetze bilden die Grundlage der modernen Chemie. Auf Grund dieser Gesetze wurde es möglich, chemische Formeln und chemische Gleichungen zu bilden. Nun sehen wir noch einmal eine solche Formel an:

\section{$\mathrm{HCl}$ Chlorwasserstoff.}

1) Einige andere „Elemente“ wie z. B. Victorium, Holmium usw. scheinen keine Elemente, sondern Gemische verschiedener Elemente $\mathrm{zu}$ sein. 
Diese Formel sagt aus:

1) Es liegt ein Stoff vor, der Chlor und Wasserstoff enthält.

2) Ein Atom Chlor und ein Atom Wasserstoff binden sich gegenseitig. Diese Tatsache führt man zurück auf eine supponierte chemische Verwandtschaft (Affinität, Bindungskraft).

3) Die Verbindung enthält auf 35,5 Teile Chlor 1 Teil Wasserstoff.

4) Sie hat das Molekulargewicht 36,5.

All dies ist durch die einfache Formel ausgedrückt. Sehen wir nun andere Verbindungen des Wasserstoffs an: Wir kennen schon zwei, das

Wasser $\mathrm{H}_{2} \mathrm{O}$ und das Ammoniak $\mathrm{NH}_{3}$.

Betrachten wir nun diese Formel genauer, so fällt es auf, daß dem Chlor zu seiner Verbindung ein Atom $\mathrm{H}$ genügt, während der Sauerstoff zwei und der Stickstoff gar drei verlangt; denn es gibt keine Verbindung $\mathrm{OH}$ oder $\mathrm{NH}$. Und wenn wir weiter sehen, daß das Kohlenstoffatom C zu seiner Sättigung 4 Wasserstoffatome braucht, so erkennen wir, daß es sich um tiefgreifende Unterschiede in der chemischen Anziehungskraft handelt. Man bezeichnet das Maß dieser chemischen Bindungskraft als Wertigkeit oder Valenz.

Als Einheit der Valenz dient wiederum der Wasserst off, da er die niedrigste Valenz hat, indem er höchstens ein Atom eines anderen Elementes binden kann. Er und diejenigen Elemente, die nur ein Atom Wasserstoff binden können, sind die einwertigen Elemente. Hierher gehören z. B. Chlor, Brom, Jod, Fluor, die Alkalimetalle und Silber.

Zweiwertig sind die Elemente, deren Atom zwei einwertige oder ein anderes zweiwertiges A tom zu binden vermag. Die wichtigsten sind: Sauerstoff, Schwefel, die alkalischen Erdmetalle, Zink, Magnesium, die Metalle der Eisengruppe.

Dreiwertig sind u. a. Stickstoff, Phosphor, Gold, Eisen, Chrom. 
Vierwertig Kohlenstoff, Schwefel, Silicium, Platin. F ünfwertig Stickstoff, Arsen, Antimon, Phosphor. Sechswertig Schwefel, Wolfram, Molybdän.

Siebenwertig Chlor, Mangan.

Schon aus dieser ganz oberflächlichen Übersicht läßt sich erkennen, daß die Valenz kein feststehender Wert ist, sondern daß viele Elemente wechselnde Wertigkeit besitzen. Die interessantesten Beispiele von Vielwertigkeit sind z. B. Sch wefel, der 2, 4, 6 wertig, Mangan, das 2, 3, 4, 6, 7wertig, Stickstoff, der 1, 2, 3, 4, 5wertig ist. Aus dieser Verschiedenheit folgt das Gesetz der multiplen Proportionen (s. o.).

Die Bezeichnung der Wertigkeit geschient durch Striche oder Zahlen an dem Symbol des Elementes,

$$
\text { z. B. } \stackrel{\mathrm{I}}{\mathrm{C}} \mathrm{l}-\stackrel{\mathrm{II}}{\mathrm{O}}=, \stackrel{\mathrm{III}}{\mathrm{N}} \equiv, \stackrel{\mathrm{IV}}{\mathrm{C}} \equiv
$$

Mit Hilfe unserer gewonnenen Anschauungen über Wertigkeit etc. können wir nun auch in unseren Formeln außer dem Atomverhältnis noch der Art und Weise der Bindung der Atome Rechnung tragen. Wir versinnbildlichen in den sog. Strukturformeln nicht nur die im Molekül vorhandene Zahl der Atome, sondern auch ihre Verteilung nach der Valenzlehre. Diese Formeln, die in der organischen Chemie eminente Bedeutung haben, werden wir in der anorganischen verhältnismäßig selten gebrauchen. Doch kommen sie auch hier vor. So ist die Strukturformel der Schwefelsäure $\left(\mathrm{H}_{2} \mathrm{SO}_{4}\right)$

$$
\stackrel{\mathrm{SI}}{\mathrm{v} \leqslant} \mathrm{O}_{\mathrm{O}-\mathrm{H}}^{\mathrm{O}-\mathrm{H}} \text { oder kürzer } \mathrm{SO}_{2}<\mathrm{OH}
$$

Wir wissen nach den vorangegangenen Erörterungen, was eine chemische Formel ist, was sie ausdrückt. Wir müssen nun lernen, wie man sie anwendet. Zur Darstellung chemischer Prozesse bedient man sich der sog. 
chemischen Gleichungen. Man schreibt z. B. den Prozeb der Entstehung von Chlorwasserstoff folgendermaßen:

$$
\mathrm{H}_{2}+\mathrm{Cl}_{2}=2 \mathrm{HCl}
$$

Ein Mol. (2 Atome) $\mathrm{H}+$ ein Mol. (2 Atome) $\mathrm{Cl}=2$ Mol. HCl. Oder die Entstehung von Wasser:

$$
2 \mathrm{H}_{2}+\mathrm{O}_{2}=2 \mathrm{H}_{2} \mathrm{O} \text {. }
$$

Dasjenige, was durch diese Gleichungen ausgedrückt wird, ist eine chemische Reaktion.

Wodurch aber kommt denn überhaupt eine solche Reaktion zu stande?

Zwei Dinge muß man hier streng unterscheiden: die Ursache einer chmischen Reaktion und die Veranlassung zu einer solchen. Es können zwei chemische Stoffe, die die größte Neigung haben, mit einander zu reagieren, unter gewissen Bedingungen unbegrenzte Zeit in engem Gemisch mit einander ruhen, ohne in Reaktion zu treten, bis endlich die Bedingungen günstig werden, die Veranlassung zur Reaktion vorliegt. Namentlich zwei Faktoren sind es, die meist die Veranlassung zum Eintritt der Reaktion bilden, die Lösung und die Wärme. Die in festen Gemischen, mögen sie noch so fein sein, stets noch durch weite Zwischenräume getrennten Moleküle werden in der flüssigen Lösung einander genähert und erhalten so die Gelegenheit, auf einander einzuwirken. So hat der Spruch der alten Chemiker: "Corpora non agunt, nisi fluida" in vielen Fällen eine Berechtigung.

Ein nicht minder wichtiger Faktor beider chemıschen Reaktion ist die Wärme. Bei den niedrigen Temperaturen, die die moderne Technik hat erzielen können, ca. von $1000 \mathrm{C}$ abwärts, reagieren die chemischen Körper nicht mehr mit einander; und im Laboratorium sind wir es täglich gewohnt, reaktionsträge Körper mit Hilfe von Erhitzung zur Reaktion zu bringen. 
Andere reaktionsauslösende Mittel sind der elektrische Funke, die Glimmentladung, Druck, (Erhitzen im geschlossenen Glasrohr), das Sonnenlicht u. a. m. Eine sehr interessante Erscheinung ist es ferner, daß Körper, die in fertigem Zustande nicht mit einander reagieren, sich dann beeinflussen, wenn einer im Momente des Entstehens (in statu nascendi) in Reaktion tritt. Arsentrioxyd und Wasserstoff reagieren nicht miteinander. Läßt man aber den Wasserstoff direkt in Berührung mit dem Arsentrioxyd (aus Zink und Salzsäure) entstehen, so resultiert Arsenwasserstoff. ${ }^{1}$ ) Die Erklärung ist folgende: Bei der Einwirkung von Zink auf Salzsäure bilden sich freie Wasserstoffatome. Bevor diese nun sich zu festen Molekülen zusammenschließen, greifen sie schon das Arsentrioxyd an, da sie noch frei und reaktionskräftig sind; sind sie erst einmal im Molekularverband, so gehört eine gewisse Energie dazu, sie erst aus diesem Verbande loszureißen. Und diese Energie ist bei der Reaktion zwischen Arsenoxyd und Wasserstoff nicht vorhanden. Diese Energie ist eben der Ausdruck der mehr oder minder großen chemischen Verwandtschaft oder Affinität. Damit kommen wir zum zweiten Punkt, der eigentlichen Ursach e der chemischen Reaktionen. Im Grunde ist uns jedoch das innere Wesen der chemischen Affinität ein völliges Rätsel, wenn man auch ihre Gesetze aufsuchen kann, wie es die moderne physikalische Chemie tut.

Wir wissen nur, daß wir in der chemischen Affinität eine Energieform vor uns haben, die in die gleiche Kategorie wie die übrigen Energieformen : Licht, Wärme, Elektrizität, mechanische Energie, gehört. Wir wissen, daß die chemischen Reaktionen völlig den Gesetzen von der Erhaltung der Energie folgen, wir wissen, daß wir die chemische Energie gewisser Verbindungen, z. B. der Kohle, in Licht, Wärme, Elektrizität umsetzen können, daß die Energie der Zersetzung der Sprengstoffe mechanische Arbeit leistet.

1) $\mathrm{As}_{2} \mathrm{O}_{3}+12 \mathrm{H}=2 \mathrm{AsH}_{3}+3 \mathrm{H}_{2} \mathrm{O}$. 
Andererseits gibt es Reaktionen, bei denen man Energie in Form von Wärme, Licht, Elektrizität von außen zuführen muß, die bei der Reaktion in chemische Energie verwandelt wird und dann in diesen Verbindungen aufgespeichert liegt.

Wir haben uns gewisse Schemata zurechtgelegt, um darin die vorkommenden Erscheinungen einzureihen. Und diese sind mannigfacher Art: Wir leiten durch eine Lösung von Bromkalium einen Chlorstrom. Sofort scheidet sich braunschwarzes Brom aus und in der Lösung haben wir Chlorkalium:

$$
2 \mathrm{KBr}+\mathrm{Cl}_{2}=2 \mathrm{KCl}+\mathrm{Br}_{2} \text {. }
$$

Das Chlor hat das Brom also einfach verdrängt: Es hat eine größere "Affinität" zum Kalium als das Brom. Dieser Ausdruck ist keine Erklärung, sondern nur eine Konstatierung der Tatsache durch einen dafür eingeführten Terminus technicus.

Wir übergießen kohlensaures Kalzium (Marmor) mit Schwefelsäure: Die Kohlensäure entweicht; es resultiert schwefelsaures Kalzium (Gips). Warum? Die Schwefelsäure ist eine „stärkere Säure" als die Kohlensäure.

Im wesentlichen können wir folgende Reaktionen als die "typischen" hinstellen, d. h. als diejenigen, nach deren Schema mehr oder weniger alle verlaufen:

1) Die Substitution: Der Ersatz von Atomen oder Atomgruppen durch andere von gleicher Wertigkeit. So kann z.B. das einwertige Chlor durch das einwertige Brom oder aber das einwertige Radikal ${ }^{1}$ ) $\mathrm{OH}$ (Hydroxyl) ersetzt werden; der zweiwertige

1) Unter Radikal versteht man einen Atomkomplex, dessen einzelne Valenzen nicht aneinander gesättigt sind, sondern bei dem eine oder mehrere Valenzen noch frei sind. So ist in dem einwertigen Radikal - OH noch die eine Valenz des Sauerstoffes frei; in dem Radikal $=\mathrm{SO}_{4}$, das zweiwertig ist, die beiden Valenzen, die sonst in der Schwefelsäure $\mathrm{H}_{2} \mathrm{SO}_{4}$ Wasserstoff binden usw. Freie Radikale sind ebenso wenig existenzfähig wie freie Atome. 


\section{$-24-$}

Sauerstoff durch zweiwertigen Schwefel etc. Namentlich gleichwertige Metalle können sich so in ihren Salzen vertreten, z. B. die einwertigen Kalium und Natrium, die zweiwertigen Kupfer und Zink etc. So scheidet z. B. Eisen aus Kupferlösungen das Kupfer ab und setzt sich an seine Stelle,

$$
\mathrm{CuSO}_{4}+\mathrm{Fe}=\mathrm{FeSO}_{4}+\mathrm{Cu} .
$$

od

We

Auch die Salze untereinander setzen sich um. Ein Gemisch einer Kochsalz-(Chlornatrium)-Lösung (NaCl) mit einer Lösung von schwefelsaurem Kalium $\left(\mathrm{K}_{2} \mathrm{SO}_{4}\right)$ reagiert scheinbar nicht miteinander: in Wirklichkeit indessen stellt sich ein Gleichgewichtszustand in der Weise her, daß schließlich alle 4 möglichen Salze friedlich nebeneinander in Lösung sind: Chlornatrium, Chlorkalium, schwefelsaures Natrium, schwefelsaures Kalium ( $\mathrm{NaCl}, \mathrm{KCl}, \mathrm{Na}_{2} \mathrm{SO}_{4}, \mathrm{~K}_{2} \mathrm{SO}_{4}$ ). In die Erscheinung tritt die Reaktion erst, wenn z. B. einer der Substituenten mit irgend einem andern eine unlösliche Verbindung ergibt. Dann binden sich diese völlig aneinander und fallen als Niederschlag aus. So z. B. geben Chlornatrium und salpetersaures Silber eine weiße Fällung von Chlorsilber, während salpetersaures Natrium in Lösung verbleibt:

$$
\mathrm{NaCl}+\mathrm{AgNO}_{3}=\mathrm{NaNO}_{3}+\mathrm{AgCl}
$$

Hierher gehören auch die oben erwähnten Verdrängungsreaktionen der Metalle.

2) Oxydationnennt man die Zuführung von Sauerstoff oder die Entzieh ung von Wasserst off: ${ }^{1}$ ) z. B. die Verbrennung von Schwefel zu. Schwefeldioxyd:

$$
\mathrm{S}_{2}+2 \mathrm{O}_{2}=2 \mathrm{SO}_{2} \text {. }
$$

3) Reduktion ist Entziehung von Sauerstoff

1) Im weiteren Sinne nennt man Oxydationsvorgänge chemische Reaktionen, bei denen die Wertigkeit des Elementes sich erhöht. Wie man z. B. durch wirkliche Sauerstoffzufuhr Fe0 (Eisenoxydul) $\mathrm{zu} \mathrm{Fe}_{2} \mathrm{O}_{3}$ (Eisenoxyd) oxydiert, so kann man in übertragenem Sinne auch $\mathrm{FeCl}_{2}$ (Eisenchlorür) zu $\mathrm{FeCl}_{3}$ (Eisenchlorid) „oxy dieren ", ohne daß dabei Sauerstoff eine Rolle spielt. Auch bezeichnet man den diesem reziproken Prozeb als „Reduktion" in übertragenem Sinne. 
oder Zuführung von Wasserstoff: z. B. die Verwandlung der Metalloxyde in Metalle durch Wasserstoff:

$$
\mathrm{CuO}+\mathrm{H}_{2}=\mathrm{Cu}+\mathrm{H}_{2} \mathrm{O} \text {. }
$$

4) Die Salzbildung aus Basen und Säuren. Eine absolut scharfe Definition der Begriffe: „Base" und „Säure" an und für sich ist rein chemisch nicht zu geben; denn wenn man sagt: Eine Base ist eine Oxydationsstufe eines Metalles, die laugenhaft schmeckt und Lakmuspapier 1) blau färbt; oder: eine Säure ist eine Oxydationsstufe eines Metallö̈des, die sauer schmeckt und Lakmuspapier rot färbt, so ist dies zwar für die meisten Säuren und Basen richtig, aber für manche auch nicht; es gibt Basen und Säuren, die auf Lakmuspapier nicht reagieren, es gibt Metalloïdbasen und Metallsäuren, kurz, diese Definitionen und alle ähnlichen sind unzulänglich. Versuchen wir, den Begriff Base und Säure von ihrem Vereinigungsprodukt, dem Salz aus zu analysieren: Ein Salz ist ein chemischer Körper, der sich durch Einzwängung von Wasser $\mathrm{H}-\mathrm{OH}$ in zwei verschiedene, in ihrer chemischen Natur diametral entgegengesetzte Verbindungen spalten lässt. Und zwar spaltet es sich so, daß ein Bruchstück das Hydroxyl OH des Wassers aufnimmt, das andere den Einzelwasserstoff des Wassers. Nun nennen wir den Teil des ursprünglichen Salzes, zu dem das Hydroxyl tritt, den Basenrest, den andern den Säurerest. Der Basenrest plus dem Hydroxyl ist nun die Base, der Säurerest plus dem Wasserstoff die Säure. Beide, Base wie Säure, tragen meist die Kennzeichen der oben gegebenen Definition. Der Basenrest ist meist ein Metall, die Base dann also das Hydroxyl eines Metalles; der Säurerest meist das Oxydationsprodukt eines Nichtmetalles, enthält also meist 0.2) Bei der Bildung der Säure durch Anlagerung von $H$ tritt das $\mathrm{H}$ an das vorhandene $\mathrm{O}$ und bildet mit ihm ebenfalls

1) Ein mit dem Farbstoff der Flechte Rocella tinctoria getränktes Papier.

2) Nur die Halogenwasserstoffsäuren und die Cyanwasserstoffsäure sind sauerstofffrei. 


\section{$-26-$}

Hydroxyl, sodab in diesem Fall beide Teile, sowohl die Base als die Säure, Hydroxyl enthalten. Doch ist für die Säure nur das Wasserstoffatom kennzeichnend, für die Base das ganze Hydroxyl.

Hieraus ergibt sich, daß, wenn umgekehrt eine Säure und eine Base zusammentreten, ein Salz und Wasser entstehen mul. Das Charakteristische bei den Reaktionen der Basen und Säuren ist die Rolle des Wassers: Bei der Zerlegung wird Wasser aufgenommen; bei der Bildung der Salze aus Säure und Base wird Wasser frei.

Einige Beispiele mögen den Vorgang erläutern: $\mathrm{NaCl}$ ist zusammengesetzt aus dem Basenrest $\mathrm{Na}$, der beim Eintritt von Wasser durch die Anlagerung von $\mathrm{OH}$ in die $\mathrm{Base} \mathrm{NaOH}$ übergeht, und dem Säurerest $\mathrm{Cl}$, der durch $\mathrm{H}$ in die Säure $\mathrm{HCl}$ übergeht.

$$
\mathrm{NaCl}+\mathrm{H}-\mathrm{OH}=\mathrm{NaOH}+\mathrm{HCl} \text {. }
$$

Dies ist der einfachste Fall. Etwas komplizierter ist folgender: $\mathrm{Na}_{2} \mathrm{SO}_{4}$ (schwefelsaures Natrium) besteht aus dem Basenrest $\mathrm{Na}_{2}$, der nachher, um in die Base $\mathrm{NaOH}$ übergehen zu können, $2 \times \mathrm{OH}$ braucht, und dem Säurerest $\mathrm{SO}_{4}$, der ebenfalls, um in Schwefelsäure $\mathrm{H}_{2} \mathrm{SO}_{4}$ überzugehen, $2 \mathrm{H}$ braucht. Hier müssen also zwei Mol. Wasser eintreten, um das Salz zu sprengen:

$$
\mathrm{Na}_{2} \mathrm{SO}_{4}+2 \mathrm{H}_{2} \mathrm{O}=\mathrm{H}_{2} \mathrm{SO}_{4}+2 \mathrm{NaOH} .
$$

Die beiden Bruchstücke des Salzes (Säurerest und Basenrest) müssen stets gleiche Valenz haben,

$$
\begin{aligned}
& \mathrm{Na}--\mathrm{O} \\
& \mathrm{Na}-\mathrm{O}>\mathrm{SO}_{2}
\end{aligned}
$$

um sich sättigen zu können. In den Basen resp. Säuren sind eben diese Valenzen durch OH resp. H abgesättigt, die dann bei der Vereinigung sich als Wasser abscheiden:

$$
\begin{aligned}
& \mathrm{Na}-(\mathrm{OH}) \\
& \mathrm{Na}-(\mathrm{OH})
\end{aligned}+\stackrel{(\mathrm{H})-\mathrm{O}}{(\mathrm{H})-\mathrm{O}}>\mathrm{SO}_{2}=\begin{aligned}
& \mathrm{Na}-\mathrm{O} \\
& \mathrm{Na}-\mathrm{O}
\end{aligned}>\mathrm{SO}_{2}+2 \mathrm{H}_{2} \mathrm{O} .
$$

Wir sehen ferner, daß in den Salzen der Wasser- 
stoff der Säuren durch den Basenrest (meist ein Metall) ersetzt ist (Substitution).

Wir gelangen aus all diesen Betrachtungen zu folgenden Definitionen:

Eine Säure ist eine (meist das Oxydationsprodukt eines Nichtmetalles darstellende) chemische Verbindung, die mindestens ein Wasserstof fato $\mathrm{m}$ durch Metall ersetzen kann und dadurch, sowie ferner durch Vereinigung mit einer Base unter Wassera ustritt ein Salz zu bilden vermag.

Eine Base ist eine (meist das Oxydationsprodukt eines Metalles darstellende) chemische Verbindung, die mindestens ein Hydroxyl $\mathrm{OH}$ enthält und befähigt ist, mit einer Säure unter Abspaltung dieses Hydroxyls und W a sseraustritt ein Salz zu erzeugen.

Das Wesentliche ist die Verbindung unter W asser a ustritt. Metalle lösen sich zwar auch in Säuren unter Bildung von Salzen; doch sind darum nicht die Metalle Basen, da sie kein $\mathrm{OH}$ enthalten und somit bei dieser Reaktion kein Wasser austritt, sondern nur Wasserstoff; es ist eine einfache Substitution des Säurewasserstoffes durch Metall.

$$
\mathrm{Zn}+\mathrm{H}_{2} \mathrm{SO}_{4}=\mathrm{ZnSO}_{4}+\mathrm{H}_{2} \text {. }
$$

Was nun die Verwandtschaft der Basen und Säuren unter sich betrifft, so haben wir bereits gelernt, dab es stärkere und schwächere Säuren gibt; ebenso gibt es stärkere und schwächere Basen: Die stärkere Säure ver drängt die schwächere aus ihren Salzen, die starke Base die schwache, z. B.:

$$
\underset{\text { Salpeters. Natron }}{\mathrm{NaNO}_{3}+\mathrm{HCl}}=\mathrm{NaCl}+\underset{\text { Salpetersäure, }}{\mathrm{HNO}_{3}}
$$

so vertreibt Kalilauge das Ammoniak, Schwefelsäure die Salzsäure, Salzsäure die Salpetersäure, letztere die Kohlensäure. Ein weiteres Charakteristikum einer , starken" Base oder Säure ist es ferner, daß sie auch mit den schwächsten "Antipoden" noch Verbindungen eingeht, während die "Schwachen" sich nur mit den „Starken" fest verbinden; die Salze schwacher Basen 
mit schwachen Säuren sind gewöhnlich unbeständig, leicht zersetzlich.

Die eigentlichen Reaktionsträger von Säuren und Basen sind die sog. "typischen" Wasserstoffatome, resp. Hydroxyle, d. h. diejenigen, die bei der Salzbildung zur Bildung von Wasser benutzt und in diesem abgeschieden werden. Je nach der Zahl dieser "typischen" Wasserstoffatome gibts es einbasische, zweibasische, mehrbasische Säuren, nach der Zahl der Hydroxyle einsäurige, zweisäurige, mehrsäurige Basen, z. B.:

$\mathrm{NO}_{2} \mathrm{OH}$ einbasisch (Salpetersäure)

$\mathrm{SO}_{2}<\underset{\mathrm{OH}}{\mathrm{OH}} \mathrm{zw}$ eibasisch (Schwefelsäure)

$\mathrm{NaOH}$ einsäurig (Natriumhydrat)

$\mathrm{Ca}<\mathrm{OH}_{\mathrm{OH}}^{\mathrm{OH}}{ }^{\mathrm{O}}$ eisäurig (Kalziumhydrat).

Bei der Salzbildung muß man unterscheiden zwischen neutralen Salzen, d. h. solchen, wo die völlige Verschmelzung von Base und Säure stattgefunden, und unvollk o mmen en Salzen, wo eine der beiden Parteien ihre Individualität nicht völlig aufgegeben hat. Solehe Salze sind nur möglich, wenn die Säure zwei- oder mehrbasisch ist; dann reagiert nur das eine "typische Wasserstoffatom", das oder die anderen nicht. Diese unvollkommenen Salze enthalten noch ein oder mehrere typische Wasserstoffatome, haben also noch sauren Charakter, sie heißen also saure Salze. Es gibt auch Salze, in denen mehr von der Base, als zur Neutralisierung erforderlich, vorhanden ist, die sog. ba sischen Salz e. Einige Beispiele werden dies schnell verständlich machen:

$$
\mathrm{SO}_{2}<\underset{\mathrm{OH}}{\mathrm{OH}}+\mathrm{NaOH}=\mathrm{SO}_{2}<\mathrm{OH}+\mathrm{ONa}_{2} \mathrm{O} .
$$

Schwefelsäure +1 Natriumbydrat $=$ saures schwefels. Natron.

Das eine typische Säurewasserstoffatom steht noch, also ist die Salzbildung unvollkommen.

$$
\mathrm{SO}_{2}<\underset{\mathrm{OH}}{\mathrm{OH}}+\underset{\mathrm{NaOH}}{\mathrm{NaOH}}=\mathrm{SO}_{2}<\underset{\mathrm{ONa}}{\mathrm{ONa}}+2 \mathrm{H}_{2} \mathrm{O} \text {. }
$$

rea

nel

gen

unt

$\mathrm{Me}$

W

Sä

du

st:

se

üb

Th

A 1

dif

$\mathrm{Di}$

lös

ist

$\mathrm{Kt}$

po

(K

ge

$\mathrm{Pc}$

tir

un

sti

ko

ist

eir 
Bei Anwendung von 2 Molekülen Natriumhydrat reagiert auch dieses zweite $\mathrm{H}$-Atom; es resultiert ein neutrales Salz.

Die Darstellung der Salze geschieht nach zwei allgemeinen Methoden:

1) Durch direkte Vereinigung von Base und Säure unter Wasseraustritt.

$$
\begin{aligned}
& \mathrm{Ca}(\mathrm{OH})_{2}+\mathrm{H}_{2} \mathrm{SO}_{4}=\mathrm{CaSO}_{4}+2 \mathrm{H}_{2} \mathrm{O} \\
& \text { Kalziumhydrat Schwefels. }=\text { schwefels. Kalk. }
\end{aligned}
$$

2) Durch Einwirkung des der Base entsprechenden Metalls auf die Säure. (Substitution des typischen Wasserstoffs durch Metall.)

$$
\begin{aligned}
& \mathrm{Zn}+\mathrm{H}_{2} \mathrm{SO}_{4}=\mathrm{ZnSO}_{4}+\mathrm{H}_{2} \\
& \text { Zink Schwefels. }=\text { schwefels. Zink. }
\end{aligned}
$$

Die allgemeine Darstellungsweise von Säuren und Basen ist die Zersetzung ihrer Salze durch stärkere Säuren, um die Säure, durch stärkere Basen, um die Base in Freiheit zu setzen.

Eine wesentliche Änderung haben unsere Ansichten über Basen, Säuren und Salze durch hochwichtige Theorien erfahren, die namentlich von van t'Hoff, Arrhenius und Ostwald aufgebaut sind. Es ist dies hauptsächlich die Theorie der elektroly tischen Dissoziation in verdünnten Lösungen. Daß Salzlösungen durch den elektrischen Strom zerlegt werden, ist längst hekannt. Schickt man z. B. durch eine Kupferchloridlösung den Strom, so scheidet sich am positiven Pol (Anode) das Chlor, am negativen Pol (K a thode) das Kupfer aus. So tritt stets das positiv geladene Jon ') (Metalle, Wasserstoff) an den negativen Pol (Kation), das negative (Chlor, Säuren) an den positiven Pol (Anion). Nun behaupten die neueren Anschauungen, auf theoretische und experimentelle Gründe gestützt, daß nicht erst der Strom diese Sprengung der

1) Jonen sind mit Elektrizität geladene Atome oder Atomkomplexe. Näheres über die Theorie der Elektrolyse mitzuteilen. ist hier nicht der Ort. Dies muß in einem Lehrbuch der Physik eingesehen werden. 
Salzmoleküle bewirke, sondern daß in genügend verdünnten Lösungen die Teilung schon aus freien Stücken sich vollzieht, daß in verdünnten Lösungen keine Salze, sondern deren Bruchstücke, ihre Jon en, sich finden. So enthält eine Chlorkaliumlösung keine festen $\mathrm{KCl}-$ Moleküle, sondern die Jon en $\mathrm{K}$ und Cl. Den Einwurf, daß freie Kaliumatome resp. Chloratome sich im Wasser nicht halten könnten, widerlegt die Theorie durch den Nachweis starker elektrischer Ladungen der Jonen, die ihre chemische Affinität so verändern, daß eben das Kaliumion nicht das Wasser so zersetzt, wie es das Kaliumatom ohne elektrische Ladung tut. Ganz ähnliche Gesetze gelten für Basen und Säuren. So zerfällt z. B. $\mathrm{HCl}$ in die beiden Jonen $\mathrm{H}$ und $\mathrm{Cl}, \mathrm{H}_{2} \mathrm{SO}_{4}$ in die beiden Jonen $\mathrm{H}_{2}$ und $\mathrm{SO}_{4}$. Alle gebräuchlichen Reaktionen der anorganischen Chemie sind Jonenreaktionen. Wenn sich z. B. Silbernitrat mit Chlornatrium umsetzt, so treten dabei die Jonen $\mathrm{Ag}, \mathrm{K}$, $\mathrm{NO}_{3}$ und $\mathrm{Cl}$ in Aktion. Die "Stärke" einer Base und Säure ist ebenfalls abhängig von ihrem "Dissoziationsgrad" d. h. von ihrem Gehalt an freien H-Jonen bei Säuren, OH-Jonen bei Basen. Wir haben also in dieser Anschauung eine präzisere Umformung der oben gegebenen Darstellung, daß für die Säuren das H, für die Basen das $\mathrm{OH}$ charakteristisch ist. Wir sehen, wie diese Anschaumgen die alten Ansichten über Säuren und Basen vom Grund auf umändern, da es danach nur Jonenwirkungen gibt. Ich muß es mir leider versagen, auf diese hochinteressanten Verhältnisse hier einzugehen. Wer sich dafür interessiert, findet in größeren Werken alles Wünschenswerte. ${ }^{1)}$

\section{Thermochemie.}

Haben wir in der Tat keine sichere Vorstellung davon, wie eigentlich ein chemischer Vorgang sich vollzieht, welcher Art die dabei in Tätigkeit tretenden Kräfte sind, so haben wir doch ein Mittel, ungefähr

die

me:

bei

Rea

scht

dem

eine

En

gef

in 1

Fine

in u

Ene

wi ]

En

wer

ind

ist

und

Del

ihn

Sin

bre

st \&

ist

ein

gle

die

der

ist

fiir

br

jed

Ei

nö

15

1) Ostwald, Grundriß der allgemeinen Chemie. IX. LotharMeyer-Rimbach, Theoret. Chemie usw.
Os we 
die dabei in Tätigkeit tretenden Energiemengen zu messen, und zwar durch die Wärmemengen, welche bei chemischen Reaktionen umgesetzt werden. Bei jeder Reaktion vollzieht sich diese Umwandlung von chemischer Energie in Wärmeenergie, oder umgekehrt, nach dem Gesetze der Erhaltung der Energie. Es gibt nämlich einerseits „en d o thermische“ Reaktionen, bei denen Energie in Form von Wärme von außen zugeführt werden muß. Diese Energie bleibt dann, in den so entstandenen Verbindungen als chemische Energie aufgespeichert, bis einmal sich die Reaktion in umgekehrtem Sinne vollzieht; dann geht die chemische Energie wieder in Wärme über. Bei dieser Reaktion wird Wärme frei, sie ist „exothermisch".

Um das Wasser zu zersetzen, brauchen wir Energie. Diese kann in Form von Wärme zugeführt werden. So zersetzt z. B. glühendes Eisen das Wasser, indem es daraus den Wasserstoff frei macht. In diesem ist nun die umgesetzte Wärmeenergie aufgespeichert und kann leicht wieder in Wärme übergeführt werden: Der Wasserstoff ist brennbar; ein Funke genügt, um ihn in Brand zu setzen. Verbrennung im chemischen Sinne ist Verbindung mit Sauerstoff. Beim Verbrennen des Wasserstoffs entsteht unter sehr starker Wärmeentwicklung wieder Wasser. Damit ist der Kreislauf geschlossen. Die Wärmeentwicklung einer bestimmten Quantität Wasserstoff ist stets die gleiche, und zwar ist sie genau gleich groß derjenigen, die zur Erzeugung derselben Menge Wasserstoff a us dem Wasser zugeführt werden mußte. Diese Größe ist meßbar; damit haben wir also zugleich ein Maß für die chemische Energie. Das Maß für die "Verbrennungswärme" der chemischen Stoffe, wie für jede Wärmemenge überhaupt, ist die Kalorie (Cal.). Eine Kalorie ist diejenige Wärmemenge, die nötig ist, um ein Kilogramm Wasser von $15^{\circ}$ auf $160 \mathrm{zu}$ erwärmen. ${ }^{1)}$ Ebenso wie für

1) Der tausendste Teil davon ist die sog. kleine Kalorie (cal.). 0 stwalds K. ist die Wärmemenge, die ein gr Wasser abgibt, wenn man es von $100^{\circ}$ auf $0^{\circ}$ abkühlt; sie ist ungef ähr $=100$ cal. 


\section{2}

den Wasserstoff, der die größte Verbrennungswärme besitzt, ist auch für viele andere Stoffe die "Verbrennungswärme", d. h. die Wärmemenge, die bei der Verbindung mit Sauerstoff frei wird, gemessen worden. Doch nicht nur bei der Verbindung mit Sauerstoff, sondern auch bei vielen anderen Reaktionen wird Wärme frei, so z. B. bei der Vereinigung von Säuren und Basen; da hierbei die neutralen Salze entstehen, so spricht man von "Neutralisationswärme". Alle diese Beobachtungen und Messungen machen das Gebiet der ,Thermochemie" aus, die nicht nur wissenschaftlich, sondern auch in der Technik von allergrößter Wichtigkeit ist. Ebenfalls von hoher Bedeutung, doch ganz jenem Grenzgebiet der "physikalischen Chemie" angehörig, ist das Stadium der Wärmemengen, welche nötig sind, um feste Körper in den flüssigen Zustand und flüssige in den gasförmigen Zustand überzuführen. Daß man Eisen erhitzen muß, um es zu schmelzen, Wasser, um es zu verdampfen, sind Erfahrungen des täglichen Lebens. Die Wärmemengen, die zu diesen Prozessen nötig sind, sind ebenfalls für viele Körper bestimmt und werden als "Schmelzwärme" resp. "Verdampfungswärme" bezeichnet.

\section{Ä ßere Eigenschaften der Körper. Terminologie.}

Um einen chemischen Körper zu bestimmen, müssen wir 2 Reihen von Eigenschaften angeben: Die physikalischen, äußeren Eigenschaften und die chemischen Eigenschaften: Die Formel und das Verhalten gegen andere chemische Körper: seine Reaktionen.

\section{Physikalische Eigenschaften.}

Die Stoffe kommen in drei verschiedenen, sog. Aggregat-Zuständen vor, dem festen, flüssigen und gasförmigen. Fest nennt man diejenigen Körper, die jederzeit eine bestimmte Form haben, und deren Teile nur durch Aufwendung einer gewissen 
Kraft getrennt werden können. Flüssige Körper haben keine Form, aber ein gegebenes Volumen, Gase endlich haben keine Form und kein gegebenes Volumen, sondern nehmen jeden gebotenen Raum ein. Diese drei Zustände sind nicht völlig voneinander getrennt, sondern sind durch Veränderung der Temperatur und des Druckes mehr oder minder leicht ineinander überzuführen. Bei Temperaturen unter $0^{0}$ ist Wasser fest: Eis, bei Temperaturen über $100^{\circ}$ ist es gasförmig: Dampf. Eisen schmilz bei ca. $1600^{\circ}$ (Schmiedeeisen) und ist durch die Temperatur des elektrischen Ofens zu vergasen. Quecksilber schmilzt bei ca. $-40^{\circ}$ und siedet etwa bei $360^{\circ}$. Körper, die bei gewöhnlicher Temperatur gasförmig sind, lassen sich mehr oder minder leicht durch Erniedrigung der Temperatur und Erhöhung des Druckes verflüssigen, leicht z. B. Kohlensäure, schweflige Säure, schwerer schon Stickoxyd u. a. Bei einigen Gasen schlugen lange Zeit alle Versuche fehl, sie zu verflüssigen, z. B. bei Stickstoff, Wasserstoff und Sauerstoff. Man nannte sie deswegen permanente Gase. Endlich gelang es doch, mit Hilfe sehr niedriger Temperatur (ca. $-150^{\circ}$ C) und hoher Drucke. Jetzt kann man mit Hilfe verbesserter Methoden alle diese Gase in größeren Mengen verflüssigen. Am schwersten gelingt es bei Wasserstoff.

Die Versuche, diese Gase bei höheren Temperaturen unter Anwendung kolossaler Drucke zu kondensieren, mußten fehlschlagen. Es hat sich nämlich ergeben, daß es für jedes Gas eine Temperatur gibt, über die hinaus es selbst bei der Anwendung geradezu ungeheuerlicher Drucke - man hat bis zu 20000 Atmosphären angewendet - nicht gelingt, es zu verflüssigen. Diese Temperatur nennt man die kritische Temperatur. Sie liegt für Kohlensäure z. B. bei $31^{\circ}$, d. h. nur bei Temperaturen unter $31^{0}$ läßt sich die Kohlensäure durch Druck kondensieren, während sie bei $31^{0}$ auch dem stärksten Druck zum Trotz wieder vergast. Nun liegt diese kritische Temperatur bei Samerstoff, Wasserstoff etc. ungemein tief, bei Wasser-

0 ppen heimer, Grundriss der anorg. Chemie, 4. Aufl. 
stoff z. B. unter $-200^{\circ}$, sodaß man sie nur bei diesen Temperaturen kondensieren kann.

Wenn man flüssige Kohlensäure schnell verdunsten läßt, so verbraucht diese verdunstende Menge so viel Wärme, daß ein Teil der Masse gefriert und so feste Kohlensäure entsteht.

Den Übergang vom festen in den flüssigen Zustand nennen wir schmelzen, in umgekehrtem Sinne erstarren. Dieser Punkt liegt für jeden Körper bei einer ganz bestimmten Temperatur, dem Schmelzp unkt. (Sp.) Ein flüssiger Körper verwandelt sich in einen gasförmigen entweder ohne direktes Erhitzen, er verdunstet, oder beim gelinden Erwärmen: er verdampft, oder endlich, wenn ihm ein Überschuß von Wärme zugeführt wird, so siedet der Körper, indem er dabei in heftige Bewegung gerät. Hierbei erreicht die Flüssigkeit die höchste Temperatur, die zu erreichen ihr möglich ist, die Siedetemperatur. Auch dieser Punkt ist für jeden Körper, der überhaupt ohne Zersetzung zum Sieden gebracht werden kann, sicher bestimmt: der Sied ep unkt. 1) (Kp.) Wenn ein flüssiger Stoff in den gasförmigen und dann wieder in den flüssigen übergeführt wird, so nennen wir diesen Prozeß destillieren; geht ein fester Körper ohne vorherige Verflïssigung direkt in den Gaszustand und aus diesem wieder direkt in den festen Zustand über, so sublimiert der Stoff. Je nach der Siedetemperatur unterscheidet man wohl auch leicht flüchtige und schwer flüchtige Stoffe.

Wir charakterisierten oben einen festen Körper als einen solchen, der eine bestimmte Form besitzt. Unter günstigen Umständen treten nun die meisten festen Körper in Formen auf, die von ebenen Flächen begrenzt sind, und die wir Kristalle nennen. Die Kristalle eines jeden Körpers zeigen nun ganz bestimmte Flächen und Winkel, nach denen man eine große Anzahl von Kristallformen unterscheiden gelernt hat. Thre genaue Bestimmung ist Aufgabe eines

1) Er schwankt nur in geringen Grenzen mit dem Luftdruck. 
besonderen Zweiges unserer Wissenschaft, der Kris tallographie. Hier können nur die Hauptformen kurz skizziert werden. Denkt man sich gegenüberliegende Ecken, oder die Mittelpunkte von gegenüberliegenden Flächen oder Kanten durch Linien verbunden, so stellen diese Linien die Achsen des Kristalles dar. Man pflegt bei jedem Kristall 3 Linien als Achsen im engeren Sinne hinzustellen, als diejenigen, die seine Ausdehnung nach drei Dimensionen des Raumes bezeichnen. Die drei Ebenen durch je zwei dieser drei Achsen sind die Hauptachsenschnitte. Jeder Hauptachsenschnitt, der auf der dritten Achse senkrecht steht, teilt den Kristall in zwei symmetrische (spiegelgleiche) Hälften und heißt deshalb eine Symmetrieebene. Nach den Beziehungen der Achsen zueinander hat man sechs Kristallsysteme unterschieden:

\section{Reguläres System.}

Die drei Achsen sind gleich lang und stehen aufeinander senkrecht.

Diese Kristalle sind nach allen Richtungen hin (oben, unten, vorn, hinten, rechts, links) ganz gleich ausgebildet.

Würfel und Oktaëder (Achtflächner).
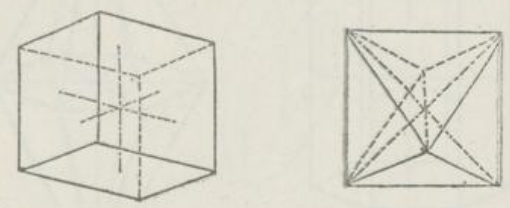

II. Tetragonales oder quadratisches System.

Alle drei Achsen stehen aufeinander senkrecht. Doch sind nur zwei Achsen gleich lang (die Nebenachsen); die dritte (die Ha utachse) ist verschieden. 


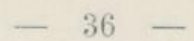

Tetragonale Pyramide, Tetragonales Prisma.
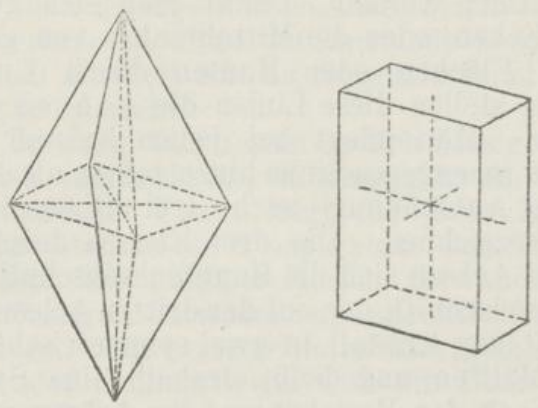

III. Hexagonales System.

Eine Hauptachse. Dazu senkrecht drei in einer Ebene liegende, sich unter $60^{\circ} \mathrm{schnei-}$ dende Nebenachsen.

Hexagonale Pyramide, Hexagonales Prisma.
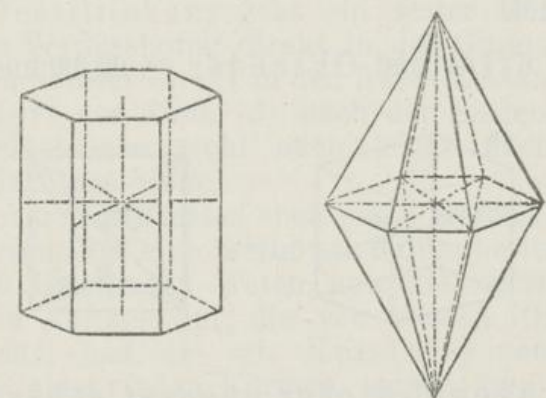

IV. Rhombisches System.

Drei senkrecht aufeinander stehende Achsen, die alle drei verschieden lang sind. 


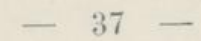

Rhombische Pyramide.

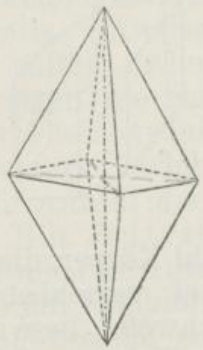

V. Monoklines System.

Diedrei Achsen sind verschieden lang: zwei schneiden sich in beliebigem Winkel, die dritte steht auf ihrer Ebene senkrecht.

Diese Kristalle haben nur eine Symmetrieebene, d. h. es gibt nur eine Möglichkeit, eine Ebene durch sie so hindurchzulegen, daß zwei symmetrische Hälften entstehen, z. B. die Kristallform des Gipses:

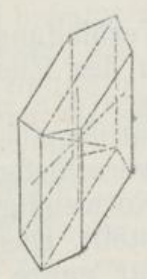

VI. Asymmetrisches System.

Drei ungleiche, sich in beliebigem Winkel schneidende Achsen.

Die Kristalle haben keine Symmetrieebene, sind also von allen Seiten ungleich. 
Kristallform des Kupfervitriols:

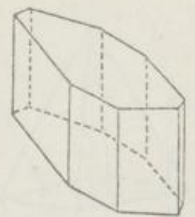

Es gibt eine Anzahl Körper, die unter verschiedenen Bedingungen in zwei verschiedenen Kristallformen kristallisieren, z.B. Schwefel; diese nennt man dim or ph.

Andererseits kristallisieren oft verschiedene Körper von ähnlicher Zusammensetzung in gleicher Kristallform, ja sogar mitunter in einem Kristall zusammen; diese Erscheinung nennt man Isomorphismus.

Sind bei einem festen Körper die Kristalle so schlecht ausgebildet und ineinander geschoben, daß ihre einzelnen Flächen nicht deutlich erkennbar sind, so nennt man einen solchen Körper $\mathrm{kr}$ istallin is ch. Körper, die auch bei näherer Untersuchung keine Kristallformen zeigen, heißen amor ph.

\section{Nomenklatur.}

Die Namen vieler Verbindungen bildet man einfach, indem man die Namen der Elemente aneinanderfügt: Chlorsilber, Schwefeleisen u. a. m. Doch hat sich aus vielen Gründen, namentlich aber wegen des häufigen Vorkommens von zwei verschiedenen Verbindungen derselben Elemente die Notwendigkeit einer besonderen Nomenklatur herausgestellt. Das Prinzip dieser Nomenklatur ist, daß man für ganze Gruppen von Verbindungen desselben Elementes eine Grundform der Benennung gewählt hat, indem man z. B. für alle Chlorverbindungen das Chlor als das Wesentliche für die Benennung ansieht und nun den Namen so bildet, daß der andere Grundstoff vorangesetzt und dann das Chlor mit der Endung -id angehängt wird. Sind zwei Verbindungen desselben Elementes vorhanden, so 
bezeichnet man die weniger von diesem Element enthaltende als - ür. So bezeichnet - chlorid und - chlor ür Chlorverbindungen, z. B. Eisenchlorid $\mathrm{FeCl}_{3}$ and Eisenchlorïr $\mathrm{FeCl}_{2}$. Analog Bromid, Bromür, Jodid, Jodür, Sulfid, Sulfür. Ahnlich bildet man für die Sauerstoffverbindungen die Endungen Oxyd und $\mathrm{Oxydul}$, z. B. FeO Eisenoxydul und $\mathrm{F}_{2} \mathrm{O}_{3}$ Eisenoxyd. Sind noch mehrere Verbindungen vorhanden, so bezeichnet man die Anzahl der Atome durch griechische Zahlen, z. B. $\mathrm{JCl}_{3}$ Jodtrichlorid. $\mathrm{NO}_{2}$ Stickstoff di oxyd, $\mathrm{P}_{2} \mathrm{O}_{5}$ Phosphor pentoxyd. Kompliziertere Verbindungen werden mit kombinierten Namen belegt, z. B. COS Kohlenstoffoxysulfid etc. Tritt zu einer Sauerstoffverbindung noch Wasser hinzu, so bezeichnet man sie als Hydrat, z. B.

Kalziumoxydhydrat $\mathrm{Ca}<\mathrm{OH}\left(\mathrm{OHO}+\mathrm{H}_{2} \mathrm{O}\right)$. Eisenoxydulhydrat $\mathrm{Fe}<\mathrm{OH}$ u. Eisenoxydhydrat $\mathrm{Fe}(\mathrm{OH})_{3}$. Manche Elemente bilden mit Sauerstoff Verbindungen, die mehr $O$ enthalten, als ihrer sonstigen Wertigkeit entspricht; diese heißen dann Peroxyde, z. B. $\mathrm{H}_{2} \mathrm{O}_{2}$ Wasserstoffperoxyd (Hydroperoxyd). Viel rationeller ist eine andere Methode der Benennung, die für die Metallverbindungen viel benutzt wird. Man bezeichnet danach alle Verbindungen, die das Metall in seiner niedrigeren Valenzstufe bildet, mit - 0 , die der höheren mit -i, und hängt daran die gebräuchlichsten Enden, wie Chlorid, Oxyd etc. z. B.

$$
\begin{array}{ll}
\text { Ferrochlorid } \mathrm{FeCl}_{2}=\text { Eisenchlorür } \\
\text { Ferrichlorid } \mathrm{FeCl}_{3}=\text { Eisenchlorid } \\
\text { Ferrooxyd } & \mathrm{FeO}=\text { Eisenoxydul } \\
\text { Ferrioxyd } & \mathrm{Fe}_{2} \mathrm{O}_{3}=\text { Eisenoxyd }
\end{array}
$$

damit ist auch Ferrokarbonat, Ferrisulfat etc. ohne weiteres verständlich.

Eine besondere Nomenklatur erfordern die Säuren und Salze. Die Säuren empfangen ihren Namen im allgemeinen von den Elementen, von denen sie sich ableiten, z. B. Schwefelsäure $\mathrm{H}_{2} \mathrm{SO}_{4}$; mitunter jedoch 
auch von einem besonders wichtigen ihrer Salze, aus denen sie dargestellt werden, z. B. Salpetersäure $\mathrm{HNO}_{3}$, die aus dem Salpeter; Salzsäure $\mathrm{HCl}$, die aus dem Kochsalz dargestellt wird. Bildet das Element außer dieser Säure noch eine mit geringerem Sauerstoffgehalt, so heißt diese die _-ige Säure. So z. B.:

$\begin{array}{ll}\text { Schwefelsäure } & \mathrm{H}_{2} \mathrm{SO}_{4} \\ \text { schweflige Säure } & \mathrm{H}_{2} \mathrm{SO}_{3} \\ \text { Chlorsäure } & \mathrm{HClO}_{3} \\ \text { chlorige Säure } & \mathrm{HClO}_{2} .\end{array}$

Viele Säuren sind imstande, Wasser abzuspalten und in ihre Anhydride ${ }^{1}$ ) überzugehen.

$$
\mathrm{SO}_{2}<\mathrm{OH}-\mathrm{H}_{2} \mathrm{O}=\mathrm{SO}_{3} \text {. }
$$

Schwefelsäure - Anhydrid.

Die Salze werden gewöhnlich einfach durch Zusammenstellung der Namen ihrer Komponenten bezeichnet, z. B. schwefelsaures Natrium, salpetersaures Kalzium, kohlensaures Kupfer. Doch haben auch die Salze jeder Säure ihre vom lateinischen Namen der Säure hergeleitete besondere Bezeichnung, die dem Metallnamen angehängt wird. So heißen die Salze der

Kohlensäure (acidum carbonicum)

Salpetersäure (acidum nitricum)

Schwefelsäure (acidum sulfuricum)

salpetrigen Säure (acidum nitrosum)

schwefligen S. (ac. sulfurosum)

Chlorsäure (ac. chloricum)

Phosphorsäure (ac. phosphoricum)

phosphorigen S. (ac. phosphorosum)

Kieselsäure (silex der Kiesel)

Essigsäure (ac. aceticum)

Oxalsäure (ac. oxalicum)

Weinsäure (ac. tartaricum)
Karbonate,

Nitrate,

Sulfate,

Nitrite,

Sulfite,

Chlorate,

Phosphate,

Phosphite,

Silikate,

Acetate,

Oxalate,

Tartrate

usw., also z.B. Kupfersulfat, Baryumnitrat, Magnesiumsilikat.

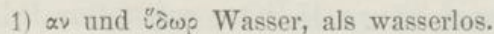

$\mathrm{J}_{0}$

Wi 
Besondere Benemnung erfordern die Salze der Chlor-, Brom-, Jod-, Fluorwasserstoffsäure. Weil bei ihnen der „Säurerest" keinen Sauerstoff enthält, sondern das Element selbst ist, fallen sie mit den Chloriden, Bromiden, Jodiden, Fluoriden der betr. Metalle zusammen und werden demgemäß so bezeichnet. Salzsaures Natron ist gleich Chlornatrium.

$$
\mathrm{NaOH}+\mathrm{HCl}=\mathrm{NaCl}+\mathrm{H}_{2} \mathrm{O} \text {. }
$$

Man faßt auch diese Verbindungen, da man die vier obengenannten Elemente als Halogene (Salzbildner) bezeichnet, als Halogenide zusammen.

\section{Klassifikation der Elemente.}

Das Bedürfnis, die große Anzahl der Elemente zu ordnen, in größere Gruppen zusammenzufassen, hat sich schon früh gezeigt. Zwei große Gruppen scheinen sich von selbst darzubieten. Auf der einen Seite die Metalle, ihnen entgegengestellt die Nichtmetalle oder Metalloïde. So einleuchtend auf den ersten Blick diese Einteilung ist, so mangelhaft ist sie in wissenschaftlicher Beziehung. Denn es ist völlig unmöglich, die "Metalle" einwandsfrei abzugrenzen. Nimmt man ihre äußeren Eigenschaften, ihren Glanz, ihre Dehnbarkeit etc. als Grundlage, so schließt man damit eine Anzahl von Elementen ein, die in chemischer Beziehung eng mit Nichtmetallen zusammengehören, z.B.Antimon, das zweifellos äußerlich ein „Metall“ ist, aber chemisch zum Stickstoff zu stellen ist, andererseits schließt man den Wasserstoff aus, der zwar kein „Metall" ist, aber chemisch sicher zu ihnen gehört. Und macht man den chemischen Unterschied zur Grundlage, daß die Metalle basenbildende, die Nichtmetalle säurebildende Elemente sind, so fällt eigentlich die ganze Klassifikation zusammen, denn so zweifellose Metalle wie das Mangan, das Gold, das Chrom sind Säurebildner. Trotz alledem hat diese Einteilung in Metalle und Metallö̈de, wenn man sie mit den Beschränkungen an- 


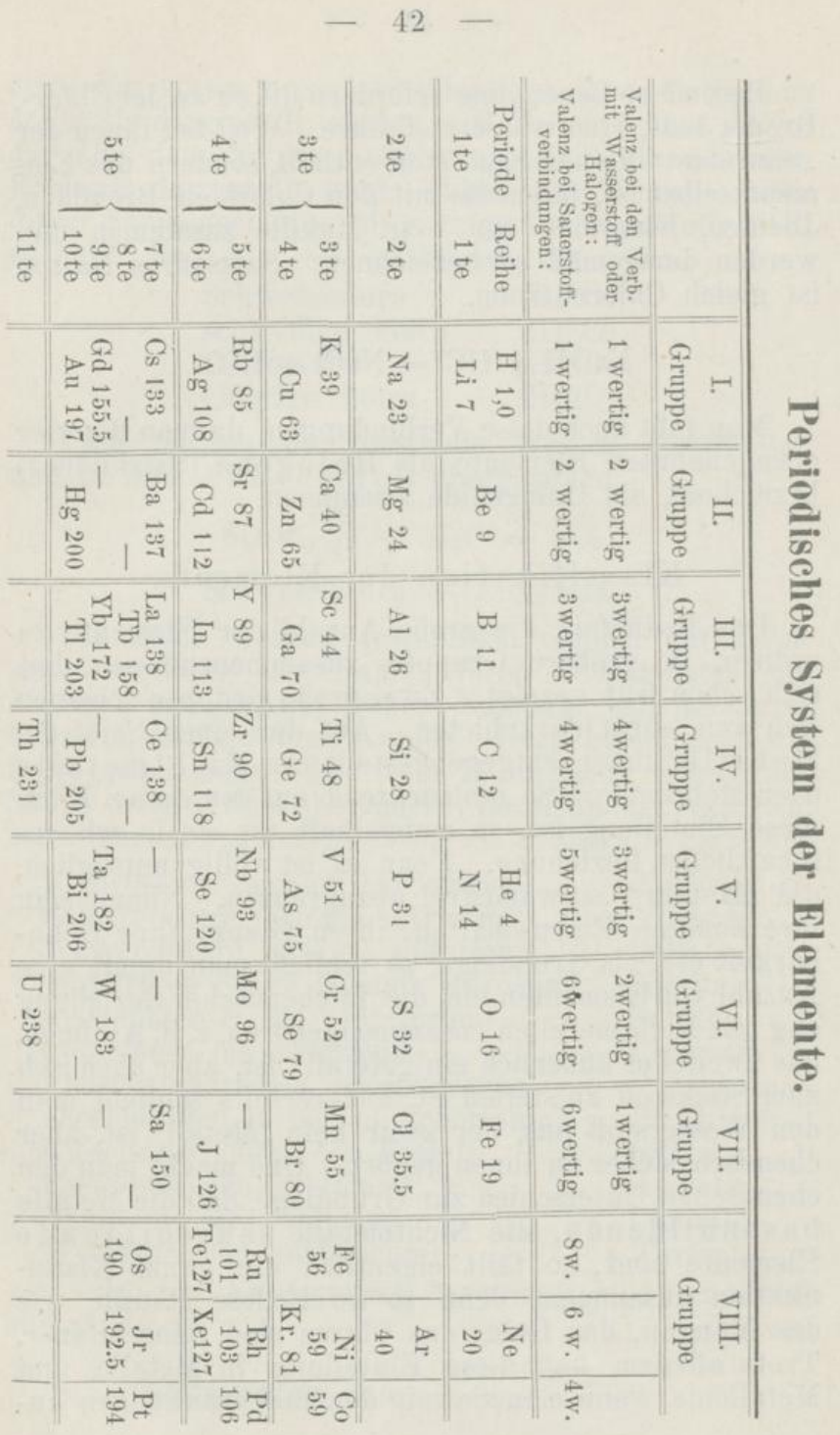

we

Eir dal

uns

fiki

dis

Sys:

Ats

doc

ver

ein

unc

ger

$\mathrm{ma}$

an

na

E1

stir

unc

(2) 1

teil

Atc

B01

Flo

7

Res

Sat

der

dar

die

Gr'

nic

ord

dec

auc

dal

fols 
wendet, daß sie eben nur im allgemeinen, nicht in allen Einzelheiten Wert hat, großen praktischen Nutzen, so daß auch wir uns ihrer noch bedienen wollen, obwohl uns heute eine wissenschaftlich unanfechtbare Klassifikation der Elemente zur Verfügung steht, das periodische System der Elemente. Der Gedanke, der diesem System zugrunde liegt: die Elemente mit Hilfe ihrer Atomgewichte zu ordnen, ist ebenfalls ziemlich alt, doch seine konsequente Durchführung in einem System verdanken wir zwei Forschern, die unabhängig von einander ihre Gedanken entwickelten: Mendele jeff und L othar Meyer. Der Grundgedanke des jetzt allgemein angenommenen Systems ist folgender: Wenn man alle Elemente nach ihrem Atomgewicht anordnet, so ergibt sich, daß jedem Element nach je 7 Gliedern ein ihm nahe verwandtes Element folgt. Noch prägnanter ist die Übereinstimmung, wenn man die beiden ersten Siebenerreihen und dann immer Reihen von je 17 untereinander stellt ( 2 kleine, 3 große Perioden). Doch muß bei dieser Einteilung der Wasserstoff fortfallen. Die sieben kleinsten Atomgewichte haben dann Lithium (7), Beryllium (9), Bor (11), Kohlenstoff (12), Stickstoff (14), Sauerstoff (16), Fluor (19). Das sind also die Anfangsglieder der 7 Gruppen, die die Tabelle auf Seite 42 zeigt.

Dies System zeigt uns vor allem die eigentümliche Regelmäßigkeit der Valenzverteilung. Die Valenz zum Sauerstoff nimmt stetig zu, die zum Wasserstoff resp. den Halogenen nimmt bis zur vierten Gruppe zu, um dann wieder zu sinken. Schwierig zu beurteilen ist die Stellung der Elemente, die wir in der achten Gruppe untergebracht haben, weil sich diese Gruppen nicht ganz zwanglos in den Rahmen der Perioden einordnen lassen. Die von Ramsay in jüngster Zeit entdeckten neuen Gase der atmosphärischen Luft bilden auch eine Reihe: Helium (4), Neon (20), Argon (40), dann noch Krypton (81) und Xenon (127).

Nach dem periodischen System ergeben sich nun folgende Gruppen von Elementen, nach denen wir 
innerhalb der beiden großen Hauptabteilungen der Metalle und Metalloïde unseren Stoff einteilen wollen:

\section{A. Nichtmetalle.}

I. Wasserstoff.

II. Die Halogene: Fluor, Chlor, Brom, Jod.

III. Sauerstoff, Schwefel, Selen, Tellur.

IV. Stickst off, Phosphor, Arsen, Antimon, Vanadin, Niob, Tantal.

V. Die Edelgase (Neon, Argon etc.).

VI. Kohlenst off, Silicium, Titan, Zirkonium, Thorium.

VII. Bor (Übergang zu den Metallen).

\section{B. Metalle.}

I. Alkalimetalle: Lithium, Natrium, Kalium, Rubidium, Caesium.

II. Alkalische Erden: Kalzium, Strontium, Baryum.

III. Beryllium, Magnesium, Zink, Kadmium, Quecksilber.

IV. Kupfer, Silber, Gold.

V. Aluminium, Gallium, Indium, Cerium, Thallium, Scandium, Yttrium, Ytterbium.

VI. Germanium, Zinn, Blei; - Wismut.

VII. Eisen, Nickel, Kobalt, Nangan.

VIII. Chrom, Molybdän, Wolfram, Uran.

IX. Platinmetalle: Platin, Iridium, Osmium, Palladium, Rhodium, Ruthenium. 


\section{Spezieller Teil.}

\section{A. Nichtmetalle. \\ Wasserstoff (Hydrogenium).}

Symbol: H; Atomgewicht 1, Molekulargewicht 2.

Historisches: Entdeckt 1766 von Caven dish. Lavoisier erkannte ihn als Bestandteil des Wassers.

Vorkommen: Nur selten in freiem Zustande. Gebunden hauptsächlich im Wasser, ferner in fast allen pflanzlichen und tierischen Stoffen.

Darstellung: 1) Aus dem Wasser:

a) durch Metalle. Kalium und Natrium zersetzen Wasser schon bei gewöhnlicher Temperatur, andere Metalle, z. B. Eisenspäne, in Rotglut.

b) durch Zersetzung mittels des elektrischen Stroms (

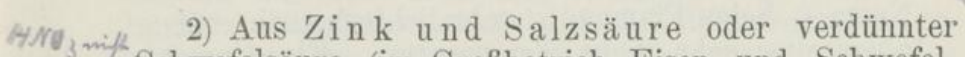
Schwefelsäure (im Großbetrieb Eisen und Schwefelsäure):

$$
\text { mis } \mathrm{H}_{2} \mathrm{P}_{\mathrm{TCC}} \mathrm{Zn}+\mathrm{H}_{2} \mathrm{SO}_{4}=\mathrm{H}_{2}+\mathrm{ZnSO}_{4}
$$

(Substitution des Säurewasserstoffs durch Metall). 


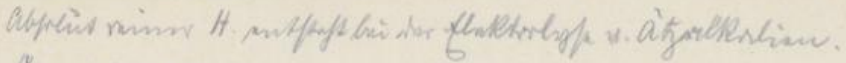

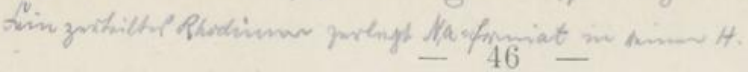
Apparates:

Im Laboratorium bedient man sich des sog. Kippschen

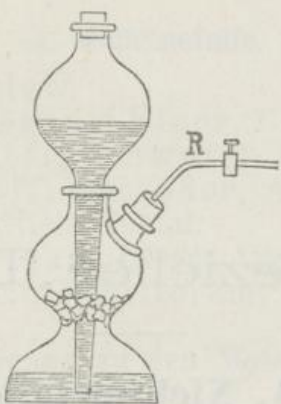

Ist der Apparat offen, so strömt die Salzsäure nach unten und gelangt mit dem Zink in Berührung; es entwickelt sich Wasserstoff. Schließt man den Hahn R, so drängt der Druek des Gases die Salzsäure in das obere Gefäß und die Entwickelung hört auf.

Eigenschaften: Farbloses, geruchloses, geschmackloses Gas. Von allen Gasen außer Helium am schwierigsten zu verflüssigen (kritische Temp. gegen $-240^{\circ}$ ). Wenig löslich in Wasser.

Das leichteste aller Gase. 1 Liter wiegt bei 00 und $760 \mathrm{~mm} 0,089551 \mathrm{gr} ., 14,44 \mathrm{mal}$ weniger als Luft. Ein mit Wasserstoff gefüllter Ballon steigt also in die Höhe. Der Wasserstoff dringt sehr leicht durch poröse Körper und Kautschuk (Diffusion).

Chemisches Verhalten: Brennbar an der Luft und in Sauerstoff zu Wasser, daher sein griechischer Name. ${ }^{1}$ ) Seine Flamme ist sehr lichtschwach, erzeugt aber eine sehr hohe Temperatur. Ein Gemenge von Wasserstoff und Luft explodiert sehr heftig; deshalb Vorsicht bei der Entwickelung des Gases. Die Vereinigung von $\mathrm{H}$ und $\mathrm{O}$ geschieht auch durch

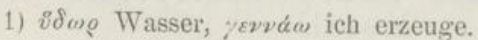


den elektrischen Funken. Wasserstoff entzündet sich ferner durch fein verteiltes Platin (Platinschwamm). (Döbereinersche Zündmaschine.)

Mit Palladium geht der Wasserstoff eine Verbindung ein, in dem das erstere sein 900 faches Volumen Wasserstoff absorbiert.

Verwendung: Er kommt in eiserne Ballons komprimpiert in den Handel. Wegen seiner Leichtigkeit als Füllungsmittel von Luftballons. Reductionsuital

Den ersten Luftballon konstruierten in der zweiten Hälfte des vorigen Jahrhunderts die Gebrüder Montgolfier, die erwärmte Luft als Füllungsmittel benutzten. Wasserstoff verwandte zuerst Charles. Der erste Mensch, der in einem Luftballon aufstieg, war Pilâtre de Rozier. Man verwendet jetzt neben Wasserstoff zuweilen auch Leuchtgas.

Ferner benutzt man ein Gemenge von zwei Teilen Wassersoff und einem Teile Sauerstoff, das sog. Knallgas, zur Erzielung sehr hoher Temperaturen (Knallgasgebläse). In diesem schmilzt z. B. Platin.

Man vereinigt die beiden Gase zur Vermeidung der Explosionsgefahr erst unmittelbar vor der Verbrennung. Man benutzt dazu eine doppelte Röhre, in deren inneren Teil Sauerstoff, in deren äußeren Wasserstoff geleitet wird, deren Gemisch an der Mündung beider Röhren entzündet wird. Richtet man die Knallgasflamme, die an und für sich fast nichtlenchtend ist, gegen einen Kalkkegel, so erzielt man durch das Glühen des Kalkes ein sehr helles Licht, das Drummondsche Kalklicht. Eventuell kann man den Wasserstoff auch durch Leuchtgas ersetzen.

\section{Die Halogene.}

Fluor, Chlor, Brom, Jod.

Die Halog ene oder Salzbildner haben ilıren Namen davon, daß ihre Verbindungen mit Metallen Salze darstellen. Dies rührt daher, daß ihre Wasserstoffverbindungen starke Säuren sind. Sie allein von allen anorganischen Säuren sind sa uerstofffrei. Die Halogene sind einwertig und untereinander nah verwandt.

Ihre Verwandtschaft zu Wasserstoff und den Metallen nimmt mit steigendem Atomgewicht ab, so daß sie beim Fluor am stärksten, beim Jod am schwächsten ist. Dies zeigt 


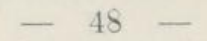

sich erstens in der Beständigkeit der Wasserstoffverbindungen.

Fluorwasserstoff ist am beständigsten, Jodwasserstoff zerfällt beim Stehen allmählich unter Abscheidung von Jod; ferner darin, daß Chlor das Brom, Brom das Jod aus seinen Wasserstoff- und Metallverbindungen verdrängt. Umgekehrt steigt die Affinität zum Sauerst off mit steigendem Atomgewicht, so daß hier die Jodverbindungen beständiger sind als die entsprechenden Bromund Chlorverbindungen; Sauerstoffverbindungen des Fluors sind garnicht bekannt. Auch verdrängt z. B. die Jodsäure die Bromsäure, diese die Chlorsäure aus ihren Salzen.

\section{Fluor.}

Symbol F. Atomgewicht 19. Mol. G. 38.

Historisches: Erst 1886 gelang es Moissan, das Fluor frei darzustellen. Alle früheren Versuche waren daran gescheitert, daß das Fluor eine zu große Verwandtschaft mit fast allen Körpern besitzt und sich deshalb mit ihnen verbindet, selbst noch bei sehr tiefen Temperaturen (bis $-187^{\circ}$ ).

Vorkommen: Hauptsächlich im Fluorkalzium $\mathrm{CaF}_{2}$, dem sog F'lu Bspat. Ferner in Verbindung mit Natrium und Aluminium als Kryolith (Grönland). Fluorkalzium findet sich auch in den Knochen und Zähnen.

Darstellung: Durch Elektrolyse von Fluorwasserstoff.

Eigenschaften: Schwach gelbgrünes Gas. Schwer kondensierbar, noch bei $-95^{\circ}$ gasförmig.

Chemisches Verhalten: Verbindet sich schon im Dunkeln mit Wasserstoff; ferner mit allen Metallen außer Platin und Gold.. $/ \&$ Zersetzt Wasser unter Bildung von Fluorwasserstoff.

$$
\mathrm{H}_{2} \mathrm{O}+\mathrm{F}_{2}=2 \mathrm{HF}+\mathrm{O} \text {. }
$$

\section{Chlor.}

Symbol Cl. Atomg. 35,5. Mol. G. 71.

Historisches: 1774 von Scheele entdeckt. 1810 durch Humphrey Davy als Element nachgewiesen.

Vorkommen: Nicht frei. In vielen Salzen: das wichtigste ist das Chlornatrium oder Kochsalz.

Darstellung: Aus dem Chlorwasserstoff: 
1) durch Elektrolyse (auch aus Chloriden).

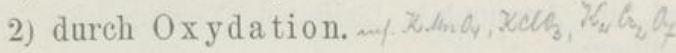

$$
2 \mathrm{HCl}+\mathrm{O}=\mathrm{Cl}_{2}+\mathrm{H}_{2} \mathrm{O} \text {. }
$$

Als oxydierende Mittel werden namentlich verwendet:

_. Salpetersäure: Ein Gemisch von 3 Teilen Salzsäure und 1. Teil Salpetersäure, das sog. Königswasser, wirkt durch seinen Gehalt an freiem Chlor sehr energisch, löst z. B. Gold und Platin. Ferner chlorsaures Kali, vor allem aber Braunstein, Mangansuperoxyd $\mathrm{MnO}_{2}$. Dies ist die gewöhnlich e Darstellung des Chlors: Kochen von Braunstein mit Salzsäure. Sie geht nach folgender Reaktion vor sich:

$$
\mathrm{MnO}_{2}+4 \mathrm{HCl}=\mathrm{MnCl}_{2}+\mathrm{Cl}_{2}+2 \mathrm{H}_{2} \mathrm{O} .
$$

Eigenschaften: Gelbgrünes, sehr heftig riechendes, die Schleimhäute angreifendes Gas, das bei $-40^{\circ}$ flüssig wird. Löst sich etwas im Wasser; die Lösung, die als Desinfektionsmittel benutzt wird, wirkt wie Chlor und heißt Chlorwasser (aq. chlori).

Che misches Verhalten: Verbindet sich mit fast allen Elementen; mit manchen, z. B. Antimon, Phosphor, unter Feuererscheinung. Zerstört organische Stoffe, entfärbt Farbstoffe.

Ein Gemenge von Wasserstoff und Chlor explodiert im Sonnenlicht (Chlorknallgas).

Anwendung: Wegen seiner heftigen Wirkung auf organische Stoffe als Desinficiens; Chlorkalk, der freies Chlor entwickelt, in Aborten, Chlor räucherungen in verseuchten Häusern, Chlorw asser als Augen- und Wundwasser. Ferner als Bleichmittel.

Oppen heimer, Grundriss der anorg. Chemie, 4. Aufl. 4 
Nachweis: Chloride geben mit Silbernitrat einen weißen, in Ammoniak löslichen Niederschlag von Chlorsilber :

$$
\text { z. B. } \mathrm{NaCl}+\mathrm{AgNO}_{3}=\mathrm{AgCl}+\mathrm{NaNO}_{3} \text {. }
$$

\section{Brom.}

Br. Atomg. 80. Mol. G. 160.

Historisches: 1826 von Balard in Meersalzmutterlaugen entdeckt.

Vorkommen: Nie frei; in vielen Salzen als Begleiter der Chlorverbindungen, aber in viel geringerer Menge, namentlich als Bromnatrium im Meerwasser und in den StaBfurter Abraumsalzen, den auf den Steinsalzschichten liegenden Salzen.

Darstellung: Aus dem Bromwasserstoff durch Braunstein ganz analog dem Chlor. Man stellt bei dem Prozeß den Bromwasserstoff erst aus Brom. natrium und Schwefelsäure her und zerlegt ihn dann sofort.

$$
\begin{gathered}
\mathrm{NaBr}+\mathrm{H}_{2} \mathrm{SO}_{4}=\mathrm{HBr}+\mathrm{NaHSO}_{4} \\
4 \mathrm{HBr}+\mathrm{MnO}_{2}=\mathrm{MnBr}_{2}+\mathrm{Br}_{2}+2 \mathrm{H}_{2} \mathrm{O} .
\end{gathered}
$$

Man erhitzt also Bromnatrium mit Braunstein und Schwefelsäure.

Eigenschaften: Schwere, rotbraune Flüssigkeit von

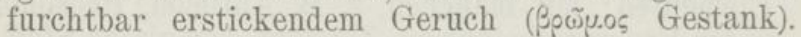
$3,18 \mathrm{mal}$ so schwer als Wasser. Sdp. $60^{\circ} \mathrm{C}$. Etwas löslich im Wasser (Bromwasser), leicht in Äther und Schwefelkohlenstoff.

Verwendung: Als Desinficiens. Bromverbindungen als Schlafmittel. Ferner in der Photographie (Bromsilber). In der Farbstofftechnik (Eosin).

Nachweis: Silbernitrat fällt gelblich weißes Bromsilber, löslich in Ammoniak. Bromverbindungen geben mit Chlorwasser Ausscheidung von Brom, das sich in Schwefelkohlenstoff mit brauner Farbe löst. 


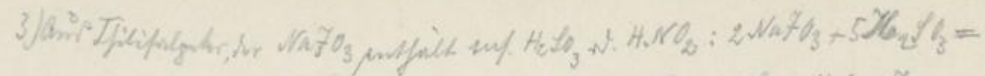

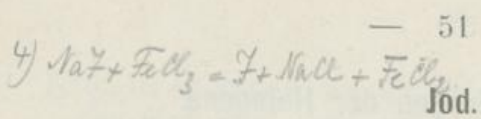$$
\text { J. Atomg. 126,5. Mol. G. } 253 .
$$

Historisches: Entdeckt von Courtois 1811 in der Asche von Algen.

Vorkommen: Im Meerwasser und in einigen Quellen, z. B. Kreuzn ach. In vielen Algen, aus deren Asche (Kelp, Varec) es gewonnen wird. Im Chilisalpeter als Natriumjodat $\mathrm{NaJO}_{3}$. In der Schilddrüse der Säugetiere als jodhaltige Eiweißverbindung (Thy reoglobulin).

Darstellung: 1) Aus Jodnatrium mit Braun-

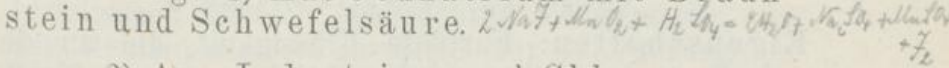

2) Aus Jodnatrium und Chlor:

$$
2 \mathrm{NaJ}+\mathrm{Cl}_{2}=2 \mathrm{NaCl}+\mathrm{J}_{2} \text {. }
$$

Eigenschaften: Grauschwarze rhombische Kristalle von starkem Metallglanz und eigentümlichem chlorähnlichen Geruch. Färbt die Haut braun, wirkt - schwach ätzend. Sdp. $184^{\circ}$, wobei es sich in einen violetten Dampf verwandelt (iosíंns veilchenblau). Sehr wenig löslich in Wasser, leicht (mit brauner Farbe) in Alkohol (Tinctura Jodi) und in Jodkaliumlösung, ferner mit violetter Farbe in Chloroform und Schwefelkohlenstoff.

Chemisches Verhalten: Ähnlich wie Chlor und Brom, aber viel schwächer. Bei $1500^{\circ}$ zerfallen die Jodmoleküle in freie Atome (V. Meyer).

Verwendung: Sehr wichtiger Arzneistoff. Jod selbst als Tinct. Jodi gegen Hautleiden, ferner als Jodkalium, vor allem gegen Syphilis; viele andere Jodverbindungen desgl. Ferner in der Photographie und Farbstofftechnik.

Nachweis: Selbst Spuren von freiem Jod färben Stärkekleister blau. (Beim Erwärmen verschwindet die Farbe, kehrt abę beim Erkalten zurück.) Schwefelkohlenstoff wird durch Jod tief violett gefärbt. Man muß zu beiden Reaktionen das Jod mittelst Chlorwasser freimachen. 


\section{Wasserstoffverbindungen der Halogene.}

Sie sind alle starke Säuren. Sie entstehen entweder durch direkte Vereinigung der Halogene mit Wasserstoff oder aus ihren Sa lzen durch stärkere Säuren.

\section{Fluorwasserstoff, Fluґssäure.}

HF. Mol. G. 20. Gasdichte 10.

Darstellung: Aus ihrem Kalksalz, dem Flußspat $\mathrm{CaF}_{2}$, durch Erwärmen mit Schwefelsäure:

$$
\mathrm{CaF}_{2}+\mathrm{H}_{2} \mathrm{SO}_{4}=2 \mathrm{HF}+\mathrm{CaSO}_{4}
$$

Eigenschaften: Farblose Flüssigkeit, die an der Luft stark raucht und Feuchtigkeit anzieht, leicht löslich in Wasser, Sdp. $19,4^{\circ}$ C. Heftig ätzend.

Chem isches Verhalten: Löst fast alle Metalle, außer Blei, Gold, Platin. Greift Glas an, muß deshalb in Platin-, Blei- oder Kautschukgefäßen aufbewahrt werden.

Verwendung: Zur Glasätzung. Man bedeckt das Glas mit einer dünnen Schicht Wachs oder Paraffin, graviert in dieses die Zeichnung ein und läßt dann Flußsäure darauf einwirken. Dann werden die freien Stellen geätzt.

Die Glasätzung mit Flußspat und Schwefelsäure war schon 1670 in Nürnberg bekannt.

\section{Chlorwasserstoff.}

HCl. Mol. G. 36,5. Gasdichte 18,25.

Entsteht bei der direkten Vereinigung von Chlor mit Wasserstoff, langsam im zerstreuten Tageslicht, im direkten Sonnenlicht unter Explosion (Chlorknallgas). Wasserstoff verbrennt in Chlorgas, und umgekehrt Chlor in Wasserstoff.

Darstellung: Durch Erhitzen von Kochsalz (Chlornatrium) mit Schwefelsäure.

$$
\mathrm{NaCl}+\mathrm{H}_{2} \mathrm{SO}_{4}=\mathrm{HCl}+\mathrm{NaHSO}_{4}
$$


Eigenschaften: Farbloses, an der Luft stark rauchendes Gas von stechendem Geruch. Sehr leicht löslich in Wasser zu der sog. "Salzsäure" (acidum hydrochloricum). Bei $110^{\circ}$ destilliert konstant eine wässerige Säure von ca. $20 \%$ Gehalt über, die im Handel die sog. konz. Salzsäure darstellt.

Chemisches Verhalten: Die wässerige Salzsäure löst sehr viele Metalle, z. B. Zink, Eisen; nicht Silber, Gold, Platin.

Verwendung: Die wässerige Salzsäure, die bei dem Leblancschen Sodaprozeß (s. d.) in großem Maßstabe als Nebenprodukt gewonnen wird, findet im technischen Betrieb ausgedehnte Verwendung. In der Medizin wird sie als Mittel zur Beförderung der Verdauung angewendet, da sie physiologisch im Magensaft vorkommt (ca. $0,2 \%$ ).

\section{Bromwasserstoff.}

$\mathrm{HBr}$. Mol G. S1. Gasdichte 40.5.

Entsteht aus Wasserstoff und Brom erst bei Rotglut.

Darstellung: Aus Phosphortribromid und Wasser:

$$
\mathrm{PBr}_{3}+3 \mathrm{H}_{2} \mathrm{O}=\mathrm{P}(\mathrm{OH})_{3}+3 \mathrm{HBr} \text {. }
$$

Eigensch. Farbloses, stark rauchendes Gas. Leicht löslich in Wasser.

\section{Jodwasserstoff.}

HJ. Mol. G. 1275 . Gasdichte 63.75.

Jod und Wasserstoff vereinigen sich sehr schwer.

Darstellung: Aus Phosphortrijodid und Wasser, auch aus Jod und Schwefelwasserstoff:

$$
\mathrm{H}_{2} \mathrm{~S}+\mathrm{J}_{2}=2 \mathrm{HJ}+\mathrm{S} \text {. }
$$

Eigensch. Farbloses, stark rauchendes Gas; leicht löslich in Wasser. Die wässerige Lösung zer setzt sich schnell, namentlich beim Erwärmen. Es wirkt stark reduzierend.

\section{Sauerstoffiverbindungen der Halogene.}

Fluorverbindungen sind unbekannt. Die Jodverbindungen sind beständiger als die Brom- und Chlorverbindungen. Man kennt je vier Oxydationsstufen, von denen drei säurebildend auftreten. In den Sauer- 
stoffverbindungen sind die Halogene nicht nur einwertig. sondern von wechselnder Valenz, bis zur Siebenwertigkeit.

$$
\text { Chlormonoxyd } \mathrm{Cl}_{2} \mathrm{O} \text {. }
$$

Aus Chlor und Quecksilberoxyd. Sehr unbeständig und explosiv. Ihm entspricht die

$$
\begin{aligned}
& \text { Unterchlorige Säure } \mathrm{HClO} \text {. } \\
& \qquad \mathrm{Cl}_{2} \mathrm{O}+\mathrm{H}_{2} \mathrm{O}=2 \mathrm{HClO} .
\end{aligned}
$$

Ihre Salze entstehen dureh ihre Einwirkung von Chlor auf starke Basen in der Kälte, z. B. das Kaliumsalz:

$$
2 \mathrm{KOH}+\mathrm{Cl}_{2}=\mathrm{KCl}+\mathrm{KClO}+\mathrm{H}_{2} \mathrm{O} \text {. }
$$

Chlortrioxyd $\mathrm{Cl}_{2} \mathrm{O}_{3}$ und chlorige $\mathrm{Säure} \mathrm{HClO}_{2}$ sind nur in den Salzen der letzteren bekannt.

Chlordioxyd $\mathrm{ClO}_{2}$. Entsteht aus chlorsaurem Kalium durch konz. Schwefelsäure. Entzündet Papier, Phosphor etc. Sehr explosiv.

Chlorsäure $\mathrm{HClO}_{3}=\mathrm{ClO}_{2} \mathrm{OH}$. Aus ihrem Baryumsalz durch Schwefelsäure. Zerfällt beim Erwärmen. Ihre Salze (Chlorate) entstehen durch Einleiten von Chlor in die heißen, konzentrierten Lösungen von Basen.

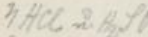

Überchlorsäure $\mathrm{HClO}_{4}$. Entsteht bei der Zersetzung G/ming ! ImG der Chlorsäure durch Erwärmen, ihre Salze durch Ergriv w hitzen der Chlorate. Stark ätzende, explosive Flüssig-

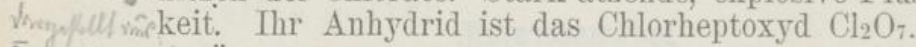

Âpoeshlmatum Ähnlich sind die Brom- und Jodverbindungen, doch $\mathrm{H}_{2} \mathrm{H}_{4}$ sind nicht alle entsprechenden bekannt.

\section{Sauerstofi (Oxygenium).}

\section{Symbol O. Atomg. Mol. G. 32.}

Historisches: Als besonderer Stoff erkannt von Priestley (1774) und gleichzeitig von Scheele. Doch erst Lavoisier studierte ihn genauer (1774 bis 81) und stellte seine große Wichtigkeit als Bestandteil des Wassers und seine Rolle bei der Atmung fest.

V ork ommen: Der Sauerstoff ist das verbreitetste aller Elemente. Er bildet einen wesentlichen Bestandteil 
der Luft und des Wassers, sowie der meisten mineralischen und organischen Stoffe.

Darstellung: 1) Aus Quecksilberoxyd durch Erhitzen anf $400^{\circ}$ (historische Darstellung):

$$
\mathrm{HgO}=\mathrm{Hg}+\mathrm{O} \text {. }
$$

2) Aus chlorsaurem Kalium durch Erhitzen (gew öhnliche Darstellung):

$$
\left.\mathrm{KClO}_{3}=\mathrm{KCl}+3 \mathrm{O} \cdot{ }^{1}\right)
$$

Eigenschaften: Farbloses, geruch- und geschmack-

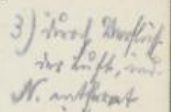
loses Gas. Wenig löslich in Wasser.

Kritische Temperatur - 118 . Flüssiger Sauerstoff siedet unter dem Druck einer Atmosphäre bei $-184^{\circ}$.

Chemisches Verhalten: Der Sauerstoff geht mit allen Elementen, außer dem Fluor, Verbindungen ein; mit den meisten läßt er sich direkt, und zwar häufig unter Licht- und Wärmeerscheinungen, vereinigen; die Stoffe verbrennen im Sauerstoff. Da die Luft $21 \%$ Sauerstoff enthält, so gehen diese Verbrennungserscheinungen vielfach, wenn auch mit geringerer Intensität, auch an der Luft vor sich. Andere "Verbrennungs"vorgänge vollziehen sich ohne Erwärmen, das Eisen verbindet sich z. B. an feuchter Luft mit Sauerstoff, es rostet. Auch die tierische Atmung ist ein solcher langsamer Verbrennungsprozeß. Die Vereinigung mit Sauerstoff nennt man Oxydation. Die Oxyde der Metalle bilden meist durch Wasseraufnahme Hydroxyde

1) Eigentlich $\mathrm{muß}$ man, da ja freie Sauerstoffatome nicht existenzfähig sind, so schreiben:

$$
2 \mathrm{KClO}_{3}=2 \mathrm{KCl}+3 \mathrm{O}_{2} .
$$

Doch schreibt man der Bequemlichkeit halber die Gleichungen oft in dieser einfacheren Form, wenn nur die Art der Reaktion und die relativen Gewichtsmengen ausgedrückt werden sollen. Diese Gleichungen sind also nur unter Vorbehalt richtig. 
oder Hydrate, die Basen sind. Man bezeichnet wohl auch diese Oxyde selbst als Basen in weiterem Sinne, zumal wenn sie keine Hydrate besitzen, wie z. B. Silberoxyd, da auch sie mit Säuren unter Wasserabspaltung Salze ergeben.

$$
\mathrm{Ag}_{2} \mathrm{O}+2 \mathrm{HNO}_{3}=2 \mathrm{AgNO}_{3}+\mathrm{H}_{2} \mathrm{O} \text {. }
$$

Die Sauerstoffverbindungen der Metalloïde bilden meist Säuren.

\section{Ozon,}

Das Ozon, 1840 von Schönbein entdeckt, bildet eine eigentümliche Modifikation des Sauerstoffs. Es ist, im Gegensatz zum Sauerstoff, stark riechend und hat sehr energisch oxydierende Eigenschaften. Es entsteht bei der Einwirkung von Sauerstoff auf manche Stoffe, z. B. Phosphor und Terpentinöl, sowie bei elektrischen Entladungen an der Luft. Beim Erhitzen verwandelt es sich in gewöhnlichen Sauerstoff. Es unterscheidet sich in seiner chemischen Natur dadurch vom Sauterstoff, daß sein Molekül aus drei Atomen besteht; es hat also die Formel

$$
\underset{\mathrm{O}}{\mathrm{V}}=\mathrm{O}_{3} \text { und das Mol. G. } 48 .
$$

Es findet sich in der Luft, namentlich nach dem Regen, und spielt als bakterientötendes Mittel in der Atmosphäre, sowie neuerdings auch zur künstlichen Sterilisierung von Trinkwasser eine große Rolle.

\section{Verbindungen des Sauerstoffs mit Wasserstoff.}

Es gibt deren zwei, das Wasser $\mathrm{H}_{2} \mathrm{O}$ und das Wasserstoffsuperoxy d $\mathrm{H}_{2} \mathrm{O}_{2}$.

\section{Wasser.}

\section{$\mathrm{H}_{2} \mathrm{O}$. Mol. 18. Gasdichte 9.}

Historisches: Der erste, der Wasser aus Wasserstoff und Sauerstoff darstellte, war Caven dis h, 
1781. Die quantitativeZusammensetzung des Wassers gab zuerst L a v o isier an. Die genauen Zahlen rühren von $\mathrm{Berzelius}$ her.

Darstellung: Chemisch reines Wasser erhält man durch Destillation des gewöhnlichen Wassers, das Salze aufgelöst enthält: destilliertes Wasser (aqua destillata).

Eigenschaften: Das Wasser spielt seine große Rolle in der Natur in allen drei Aggregatzuständen, als Eis, Wasser und Dampf. Das Wasser dient uns als Einheitskörper für viele physikalische Konstanten: Sein Schmelzpunkt ist gleich $0^{\circ}$, sein Siedepunkt gleich $100^{\circ}$ C. gesetzt. Sein spezifisches Gewicht, seine spezifische Wärme sind als Einheit genommen. Ein ccm Wasser bei $4^{0}$ ist die Gewichtseinheit $=1 \mathrm{Gramm}$.

Die größte Dichte hat das Wasser bei $4^{0}$. Oberhalb und unterhalb dieser Temperatur ist sie geringer. Auch das feste Wasser (Eis) hat ein geringeres spez. Gewicht als flüssiges Wasser. Es verhalten sich die spez. Gew. von Eis und Wasser ca. wie $9: 10$. Die kritische Temperatur ist $=370^{\circ}$, sein Dampfdruck bei dieser Temperatur 195,5 Atmosphären.

Chemisches Verhalten: Das Wasser ist ein chemisch indifferenter Körper, d. h. weder Base noch Säure, doch zur Bildung der meisten Basen und Säuren aus den Sauerstoffverbindungen der entsprechenden Elemente erforderlich. Es löst viele Stoffe in bestimmten Verhältnissen, z. B. S a l z e. G a s e lösen sich auch vielfach in Wasser. Diesen Vorgang nennt man "A bsor ption". Die Menge des gelösten Gases, die von Temperatur und Druck abhängig ist, ist der Absorptionskoeffizient. Manche Flüssigkeiten sind in jedem Verhältnis mit Wasser mischbar, z. B. Alkohol, Schwefelsäure, andere sind auch 
nur in bestimmten Verhältnissen in Wasser löslich, z. B. Äther in ca. 10 Teilen Wasser. Manche Stoffe, z. B. Natrium, zersetzen das Wasser, indem sie daraus Wasserst off frei machen; andere erst beim Erhitzen, z. B. Eisen. Chlor zersetzt Wasser im Sonnenlicht, macht aber Sauerst off daraus frei. Auch durch sehr starke Erhitzung, sowie durch den elektrischen Strom wird Wasser zersetzt.

Das reinste natürlich vorkommende Wasser ist das Regen- und Schneewasser, das etwas Luft und Kohlensäure, aber nur Spuren fester Körper enthält.

Fluß- und Quellwasser enthalten $0,1-2,0 \%$ feste Bestandteile. Wasser, das viele Kalksalze enthält, nennt man hartes Wasser; weiches Wasser enthält nur wenig Kalk. In manchen Wässern sind entweder ungemein reichlich feste Körper oder solche besonderer Art enthalten, z. B. Magnesiumsulfat, Arsen, Jod, Eisen. Derartige zu Heilzwecken verwandte Wässer heißen Mineralwässer.

Meerwasser enthält ca. $3,5^{\%} / 0$ feste Stoffe, darunter $2,7 \%$ Kochsalz.

Von den festen Partikeln, Sand,Pflanzenresten etc., wird das Wasser durch Filtration über Sand etc. befreit: geklärt. Von den gelösten Stoffen wird es durch Destillation getrennt.

Hydroperoxyd, Wasserstoffsuperoxyd $\mathrm{H}_{2} \mathrm{O}_{2}$ (Thénard 1818).

Vorkommen: In geringer Menge in der Luft und atmosphärischen Niederschlägen.

Darstellung: Aus Baryumperoxyd und Schwefelsäure.

$$
\mathrm{BaO}_{2}+\mathrm{H}_{2} \mathrm{SO}_{4}=\mathrm{H}_{2} \mathrm{O}_{2}+\mathrm{BaSO}_{4}
$$

Eigenschaften: Wasserhelle, dicke Flüssigkeit, mischbar mit Wasser. Ziemlich leicht zersetzlich. 
Chemisches Verhalten: Meist wirkt es ziemlich stark oxydierend, z. B. auf Arsen, auf Schwefelmetalle etc., indem es ein Atom Sauerstoff abgibt. Zuweilen indessen, z. B auf Oxyde des Silbers und Goldes, reduzierend, indem es Wasserstoff abgibt und die Oxyde zu Metallen reduziert.

$$
\mathrm{Ag}_{2} \mathrm{O}+\mathrm{H}_{2} \mathrm{O}_{2}=2 \mathrm{Ag}+\mathrm{H}_{2} \mathrm{O}+\mathrm{O}_{2} \text {. }
$$

Es wird durch ein in allen lebenden Geweben und Säften (Blut, Nilch ete.) vorkommendes Ferment, Katalase, in $\mathrm{H}_{2}$ und $\mathrm{O}_{2}$ gespalten.

Verwendung: Als Haarfärbemittel, als Desinfiziens.

\section{Schwefel.}

\section{S. Atomg. 32. Mol. G. (bei über $1000^{\circ}$ C) 64 .}

Seit uralten Zeiten bekannt.

Vorkommen: In freiem Zustande (gediegen) in vulkanischen Gegenden, z. B. Sizilien. Ferner in sehr vielen Mineralien (Erzen). Seine natürlich vorkommenden Metallverbindungen heißen meist Kiese, Glanze oder Blenden, z. B. Kupferkies, Bleiglanz, Zinkblende. Auch die Eiweißstoffe sind schwefelhaltig.

Darstellung: Der natürlich vorkommende Schwefel wird zur Reinigung mehrmals destilliert und dann in Stangen gegossen (Stan gen s ch wefel), oder, indem die Schwefeldämpfe sehr rasch abgekühlt werden, als feines kristallinisches Pulver, Schw efelb lum en (Flores Sulfuris) erhalten.

Eigenschaften: Der Schwefel tritt in mehreren allotropen Modifikationen auf:

1) der gewöhnliche oder r hombis che Schwefel ist rtaid: die Form, die in der Natur vorkommt und die beim Kristallisieren des Schwefels aus Lösungsmitteln (z. B. Schwefelkohlenstoff) entsteht. Er schmilzt bei $114^{\circ} \mathrm{zu}$ einer gelben Flüssigkeit, die bei höherem Erhitzen dunkel und dick, bei $250^{\circ}$ gummiartig und amorph wird und beim schnellen Abkühlen auch so 
bleibt: 2) a morp he Modifikation. Bei $300^{\circ}$ schmilzt er wieder und siedet bei $448^{\circ}$.

3) Der prismatische Schwefel entsteht beim Erstarren geschmolzenen Schwefels. Diese Modifikation geht leicht in die rhombische über.

Die Schwefelmilch entsteht aus Kaliumpolysulfid durch Salzsäure und stellt Schwefel als sehr feines, amorphes Pulver dar (Lac Sulfuris).

Der Schwefel ist von gelber Farbe, hart und spröde. Unlöslich in Wasser, löslich besonders leicht in Schwefelkohlenstoff.

chemisches Verhalten: Ähnlich dem Sauerstoff. Verbindet sich direkt mit vielen Elementen. Verbrennt an der Luft zu Schwefeldioxyd.

Verwendung: Als Bestandteil von Salben und Seifen gegen Hautleiden. Zu Streichhölzern, vor allem aber zu Schießpulver (s. d.).

\section{Schwefelwasserstoff.}

$\mathrm{H}_{2} \mathrm{~S}$. Mol. G. 34. Gasdichte 17.

Vorkommen: In vulkanischen Gasen. Entsteht bei Fäulnis von Eiweißstoffen.

Darstellung: Einwirkung von Säuren auf Schwefelmetalle, z. B. aus Schwefeleisen und Salzsäure:

$$
\mathrm{FeS}+2 \mathrm{HCl}=\mathrm{FeCl}_{2}+\mathrm{H}_{2} \mathrm{~S} \text {. }
$$

Eigenschaften: Farbloses, heftig nach faulen Eiern riechendes Gas, giftig. Löslich in Wasser (Schwefelwasserstoffwasser).

Chemisches Verhalten: Es ist brennbar zu Wasser und Schwefeldioxyd:

$$
\mathrm{H}_{2} \mathrm{~S}+3 \mathrm{O}=\mathrm{H}_{2} \mathrm{O}+\mathrm{SO}_{2} \text {. }
$$

Wird durch Oxydationsmittel, z. B. Salpetersäure, Chlor, leicht unter Abscheidung von Schwefel zer- 
setzt. Fällt aus fastallen Metallsalzlösungen Schwefelmetalle. Es wird auch zu Heilzwecken benutzt. Die Wirkung der sog. „Schwef elbäder" beruht nämlich im wesentlichen auf ihrem Gehalt an $\mathrm{H}_{2} \mathrm{~S}$. Natürliche Schwefelbäder sind z. B. Aachen, Leuk. Man stellt sie auch künstlich her.

Nachweis: Papier, das mit Bleiessig getränkt, wird schwarz gefärbt (Bildung von Schwefelblei). $\mathrm{SCl}_{2}, \mathrm{SCl}_{4}$.

Mit Chlor gibt der Schwefel drei Verbindungen, $\mathrm{S}_{2} \mathrm{Cl}_{2}$,

\section{Sauerstoffverbindungen des Schwefels.}

Der Schwefel bildet mit dem Sauerstoff vier Ox y dationsstufen, von denen indessen nur zwei als Anhydride der beiden wichtigsten Säuren des Schwefels von größerem Interesse sind:

$\mathrm{S}_{2} \mathrm{O}_{3} \mathrm{Sch}$ wefelsesquioxyd,

$\mathrm{SO}_{2}$ Schwefeldioxyd, Anhydrid der schwefligen Säure, $\mathrm{SO}_{3}$ Schwefeltrioxyd, Anhydrid der Schwefelsäure, $\mathrm{S}_{2} \mathrm{O}_{7}$ Schwefelheptoxyd.

Von Säuren des Schwefels sind zehn bekannt.

Thioschwefelsäure $\mathrm{H}_{2} \mathrm{~S}_{2} \mathrm{O}_{3}$

$\mathrm{Hydroschweflige} \mathrm{Säure} \mathrm{H}_{2} \mathrm{SO}_{2}$

Schweflige Säure $\quad \mathrm{H}_{2} \mathrm{SO}_{3}$

Schwefelsäure $\quad \mathrm{H}_{2} \mathrm{SO}_{4}$

Überschwefelsäure $\quad \mathrm{H}_{2} \mathrm{~S}_{2} \mathrm{O}_{8}$

Oxyschwefelsäure $\quad \mathrm{H}_{2} \mathrm{SO}_{5}$

Dithionsäure $\quad \mathrm{H}_{2} \mathrm{~S}_{2} \mathrm{O}_{6}$

Trithionsäure $\quad \mathrm{H}_{2} \mathrm{~S}_{3} \mathrm{O}_{6}$

Tetrathionsäure $\quad \mathrm{H}_{9} \mathrm{~S}_{4} \mathrm{O}_{6}$

Pentathionsäure $\quad \mathrm{H}_{2} \mathrm{~S}_{5} \mathrm{O}_{5}$

\section{Schwefeldioxyd $\mathrm{SO}_{2}$.}

Vorkommen: In Vulkangasen. 
Darstellung: Durch Verbrennen von Schwefel an der Luft. Ferner beim Erhitzen von Schwefelmetallen an der Luft (Rösten).

Eigenschaften: Farbloses, äußerst heftig riechendes Gas. Bei $-15^{0}$ flüssig. Leicht löslich in Wasser.

Chemisches Verhalten: Das Schwefeldioxyd nimmt sehr leicht noch ein Atom $\mathrm{O}$ auf und wird zu Schwefeltrioxyd. Deshalb wirkt es reduzierend. So entfärbt es z. B. Jodlösung, indem es das Jod zu Jodwasserstoff reduziert:

$$
\mathrm{SO}_{2}+2 \mathrm{H}_{2} \mathrm{O}+\mathrm{J}_{2}=\mathrm{H}_{2} \mathrm{SO}_{4}+2 \mathrm{HJ} \text {. }
$$

Es entfärbt auch organische Farbstoffe. Es ist ein exquisit fäulniswidriges Mittel; man benutzt es z.B.zum Desinfizieren der W einfässer (S ch w e feln), indem man in dem feuchten Fasse Schwefel verbrennt. Es zerstört auch den z. B. bei der Fäulnis tierischer Stoffe sich entwickelnden Schwefel wasserstoff:

$$
2 \mathrm{H}_{2} \mathrm{~S}+\mathrm{SO}_{2}=2 \mathrm{H}_{2} \mathrm{O}+3 \mathrm{~S}
$$

indem sich Schwefel abscheidet. Auf diese Weise sind vermutlich die großen Schwefelablagerungen in der Nähe der Vulkane entstanden.

Mit Chlor vereinigt es sich zu Sulfurylehlorid $\mathrm{SO}_{2} \mathrm{Cl}_{2}$. Es tauscht auch ein Atom $\mathrm{O}$ gegen $\mathrm{Cl}_{2}$ aus und bildet Thionylchlorid $\mathrm{SOCl}_{2}$.

Die wässrige Lösung des Schwefeldioxyds enthält wahrscheinlich die sonst nicht bekannte

$$
\text { Schweflige Säure } \mathrm{H}_{2} \mathrm{SO}_{3} \text {. }
$$

Die schweflige Säure ist zweibasisch; sie bildet deshalb zwei Reihen von Salzen: primäre (saure) und sekundäre (neutrale) Sulfite.

$$
\left.\begin{array}{l}
\mathrm{KHSO}_{3} \text { saures } \\
\mathrm{K}_{2} \mathrm{SO}_{3} \text { neutrales }
\end{array}\right\} \text { Kaliumsulfit. }
$$

Ihre Konstitution wird am einfachsten durch die Formel 


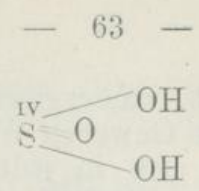

ausgedrückt.

Hydrosch w eflige Säure $\mathrm{H}_{2} \mathrm{SO}_{2}$ durch Auflösen von Zink in wässriger schwefliger Säure als Zinksalz. Sehr zersetzlich.

\section{Schwefeltrioxyd $\mathrm{SO}_{3}$.}

Anhydrid der Schwefelsäure $\mathrm{H}_{2} \mathrm{SO}_{4}$. Entsteht aus $\mathrm{SO}_{2}$ durch Aufnahme von 1 Atom Sauerstoff.

Wird dargestellt durch Erhitzen von wasserfreiem Eisenoxydsulfat:

$$
\mathrm{Fe}_{2}\left(\mathrm{SO}_{4}\right)_{3}=\mathrm{Fe}_{2} \mathrm{O}_{3}+3 \mathrm{SO}_{3} .
$$

An der Luft rauchende Flüssigkeit, die begierig Wasser anzieht und sich damit zu Schwefelsäure verbindet.

\section{Schwefelsäure $\mathrm{H}_{2} \mathrm{SO}_{4}$.}

Schon im 15. Jahrhundert, wahrscheinlich sogar noch früher bekannt. Wegen ihrer ausgedehnten technischen Verwendung die wichtigste aller Säuren.

Darstellung: Durch den Bleikammerprozeß (s. u.) oder aus dem Anhydrid mit Wasser. Neuerdings wird die Schwefelsäure im Großen durch das sog. "K ontaktverfahren" dargestellt. Man leitet ein Gemenge von $\mathrm{SO}_{2}$, Luft und Wasserdampf bei bestimmter Temperatur über eine platinierte Tonkugel. Durch den Kontakt mit dem Platin wird das $\mathrm{SO}_{2} \mathrm{zu} \mathrm{SO}_{3}$ oxydiert.

Eigenschaften: In reinem Zustande dicke, ölige Flüssigkeit vom spez. Gew. $1,8 \mathrm{Kp} .338^{\circ}$. Die bei dieser Temperatur destillierende Säure enthält noch immer $1,5 \%$ Wasser. Ganz wasserfrei erhält man die Schwefelsäure in Kristallen, wenn man die gewöhnliche $98 \%$ ige auf $-10^{\circ}$ abkühlt. Sie ist sehr 
hygroskopisch, d. h. wassergierig und wirkt heftig ätzend, weil sie den Geweben Wasser entzieht. Mit Wasser mischt sie sich in jedem Verhältnis unter starker Erwärmung, deshalb beim Mischen Versicht nötig.

Chemisches Verhalten: Infolge ihrer großen Verwandtschaft zum Wasser wirkt die Schwefelsäure sehr energisch auf viele Körper. Organische Stoffe verkohlt sie, z. B. Zucker. Sie ist eine der stärksten Säuren, vertreibt also die meisten anderen aus ihren Salzen. Sie ist $\mathrm{z}$ weibasisch, d. h. sie bildet $z w e i$ Reihen von Salzen, saure und neutrale $\mathrm{Sulf}$ a te. Thre Konstitution ist:

$$
\stackrel{\mathrm{vI}}{\mathrm{SO}_{2}} \underset{\mathrm{OH}}{\mathrm{OH}}
$$

Nachweis: Durch die Unlöslichkeit ihres Baryumsalzes in Wasser und Säuren (Fällung mit Chlorbaryum).

$$
\mathrm{BaCl}_{2}+\mathrm{H}_{2} \mathrm{SO}_{4}=\mathrm{BaSO}_{4}+2 \mathrm{HCl} .
$$

\section{Bleikammerprozess.}

Schwefel oder Schwefelerze (Schwefelkies, Kupferkies etc.) werden in Öfen verbrannt. Dabei entsteht $\mathrm{SO}_{2}$, das mit Luft vermischt in große aus Bleiplatten gebaute Kammern geleitet wird. Dort tritt es mit Salpetersäure und W as serdam pf in Berührung. Die Salpetersäure oxydiert das Schwefeldioxyd zu Sch we felsäure, und wird dabei selbst zu Stickoxyd reduziert, das durch Luft und Wasserdampf wieder zu Salpetersäure wird, so daß theoretisch unbegrenzte Mengen $\mathrm{SO}_{2}$ in Schwefelsäure übergeführt werden könnten, ohne daß die Salpetersäure erneuert zu werden brauchte. In den Bleikammern findet sich eine Schwefelsäure von ca. $60 \%$, die dann durch Eindampfen in Blei- und weiterhin in Platinpfannen konzentriert und schließlich durch Destillation gereinigt wird. 


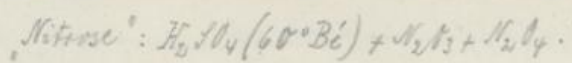

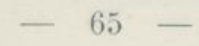

Der chemische Vorgang dieses Prozesses ist ein sehr komplizierter. Am einfachsten läßt er sich folgendermaßen darstellen:

Salpetersäure oxydiert bei Gegenwart von Wasse'r das Sehwefeldioxyd zu Schwefelsäure:

$$
3 \mathrm{SO}_{2}+2 \mathrm{HNO}_{3}+2 \mathrm{H}_{2} \mathrm{O}=3 \mathrm{H}_{2} \mathrm{SO}_{4}+2 \mathrm{NO} \text {. }
$$

Das Stickoxyd NO wird durch Luft und Wasser wieder in Salpetersäure verwandelt:

$$
2 \mathrm{NO}+30+\mathrm{H}_{2} \mathrm{O}=2 \mathrm{HNO}_{3}
$$

Doch ist diese Darstellung nur eine Anschauung, neben der auch noch andere bestehen.

Enthalten die Bleikammern nicht genügend Wasserdampf, so entstehen die sog. Bleikammerkristalle, die ihrer che-<smiles>O=[W]O[Na]</smilesmischen Natur nach Nitrosyls chw ef elsäure sind und durch Wasser in Sehwefelsäure übergehen.

Entzieht man 2 Mol. Schwefelsäure ein Mol. Wasser, so entsteht die sog. Pyroschwefelsäure $\mathrm{H}_{2} \mathrm{~S}_{2} \mathrm{O}_{7}$, die als ein unvollkommenes Anhydrid der Schwefelsäure aufzufassen ist und die Strukturformel

$$
\begin{aligned}
& \mathrm{SO}_{2}<{ }_{\mathrm{OH}}^{\mathrm{OH}} \\
& \mathrm{SO}_{2}<{ }_{\mathrm{OH}}
\end{aligned}
$$

hat, also zweibasisch ist. Sie entsteht durch Vereinigung von $1 \mathrm{Mol}$. Schwefelsäureanhydrid $\mathrm{SO}_{3}$ mit $1 \mathrm{Mol}$. Schwefelsäure.

$$
\mathrm{H}_{2} \mathrm{SO}_{4}+\mathrm{SO}_{3}=\mathrm{H}_{2} \mathrm{~S}_{2} \mathrm{O}_{7} \text {. }
$$

Sie ist in der sog. „rauchenden Schwefelsäure " enthalten, die durch Erhitzen von trockenem Eisenvitriol $\mathrm{FeSO}_{4}$ erhalten wird. Diese ist eine dicke, stark rauchende Flüssigkeit, die auch als „Nord$\mathrm{h}$ äuser Vitriol-öl" bezeichnet wird, da sie früher in Nordhausen a./H. dargestellt wurde:

Thioschwefeisäure $\mathrm{H}_{2} \mathrm{~S}_{2} \mathrm{O}_{3}$, häufig fälschlich unterschweflige Süure genannt, kann als Schwefelsäure betrachtet werden, in der ein Hydroxyl OH durch das gleichwertige Radikal SH ersetzt ist.

Op penheimer, Grundriss der anorg. Chemie, 4. Aufl. $\check{5}$ 


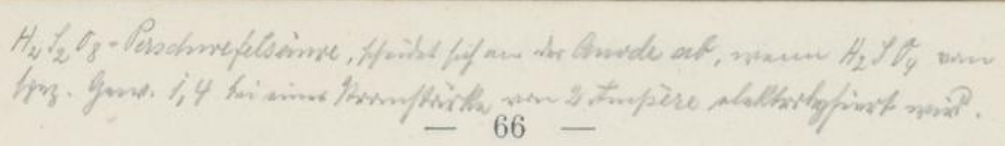

Ihre Konstitution ist also:<smiles>O=S(=O)(O)[Hg]</smiles>

Sie ist nur in ihren Salzen bekannt. Natriumthiosulfat, dastechnischeVerwendungz.B.in derPhotographie,findet, entsteht durch Kochen von schwefligsaurem Natron mit Schwefel:

$$
\mathrm{Na}_{2} \mathrm{SO}_{3}+\mathrm{S}=\mathrm{Na}_{2} \mathrm{~S}_{2} \mathrm{O}_{3} .
$$

Die übrigen Säuren des Schwefels sind von untergeordneter Bedeutung.

\section{Selen.}

Se. Atomgew. 79. Mol. Gew. 158 (bei $1400^{\circ}$ C.).

Als geringfügige Beimengung in einigen Schwefelerzen kommen Selenverbindungen vor. Beim Rösten soleher selenhaltiger Erze scheidet sich das Selen in den Ableitungsröhren, ev. in den Bleikammern (Selenschlamm) als rotes Pulver $a b$

Tellur.

Te. Atomgew. 127.

Selten; entweder gediegen oder mit Metallen, z. B. Gold und Wismut, verbunden.

Beide Elemente bilden dem Schwefel analoge Verbindungen, z. B. Selenwasserstoff, selenige Säure, Selensäure.

\section{Elemente der Stickstofigruppe.}

Die Elemente der Stickstoffgruppe können d re i - und fünfwertig auf treten.

$\mathrm{Zu}$ ihnen gehören Stickstoff, Phosphor, Arsen, Antimon, (Wismut). Die letzten Glieder der Gruppe nähern sich den Metallen, namentlich das Wismut, das z. B. keine Verbindung mit Wasserstoff eingeht, während die vier übrigen gasförmige Verbindungen mit je 3 Atomen Wasserstoff besitzen. Das Wismut wird deshalb bei den Metallen abgehandelt werden. 


\section{Stickstoff (Nitrogenium).}

Symbol: N. Atomg. 14. Mol. G. 28.

Historisches: Seine elementare Natur konstatierte Lavoisier

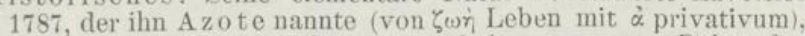
weil er die Atmung nicht zu unterhalten vermag. Daher das noch heute in Frankreich ïbliche Symbol Az. Den Namen

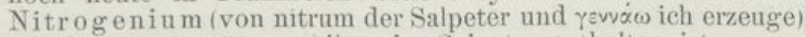
erhielt er erst später, weil er im Salpeter enthalten ist.

Vorkommen: In der atmosphärischen Luft, von deracterca: ffef er ca. $4 / 5$ des Volumens einnimmt. Außerdem als - $y$ f $/$ incos Ammoniak $\mathrm{NH}_{3}$ und Salpetersäure in deren Salzen.

Darstellung: 1) Aus der Luft durch Entziehung des Sauerstoffes. Läßt man in einem abgeschlossenen Raum z. B. Phosphor verbrennen, so wird der Sauerstoff verzehrt und der Stickstoff bleibt zurück.

2) Durch Erhitzen von Ammoniumnitrit:

$$
\mathrm{NH}_{4} \mathrm{NO}_{2}=\mathrm{N}_{2}+2 \mathrm{H}_{2} \mathrm{O}
$$

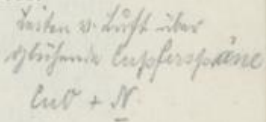

Eigenschaften: Farbloses, geruch- und geschmackloses Gas. Wenig löslich in Wasser, läßt sich erst bei - $146^{\circ}$ durch 35 Atmosphären Druck verflüssigen. Der flüssige Stickstoff siedet bei $-194^{\circ}$.

Chemisches Verhalten: Der Stickstoff zeichnet sich durch außerordentlich geringe Affinität gegen andere Elemente aus. Direkt verbindet es sich mit sehr

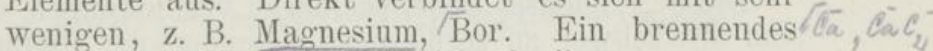
Licht erlischt, ein Tier erstickt in ihm.

\section{Die atmosphärische Luft}

besteht im wesentlichen aus einem Gemenge von ca $79 \%$ Stickstoff und ca. $20 \%$ Sauerstoff, ferner Wasserdampf, Kohlendioxyd und anderen unwesentlichen Bestandteilen, z. B. Wasserstoffsuperoxyd, Ozon, salpetrig $y_{O_{2}}$ saurem Ammoniak etc. Der Druck der Luft am Meeres. strande ist durchschnittlich gleich dem einer Quecksilbersäule von $760 \mathrm{~mm}$. Diesen Druck, der auf dem

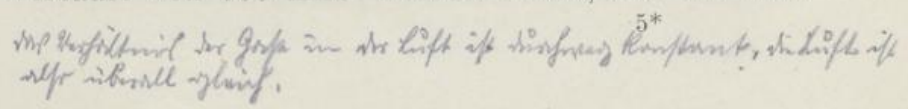


qcm rund $1 \mathrm{~kg}$ ausmacht, nennt man den „einer Atmosphäre".

Daß Luft nicht eine chemische Verbindung, sondern ein Gemenge von Sauerstoff und Stickstoff ist, zeigt die Tatsache, daß man die beiden Gase sowohl durch ihre verschiedene Löslichkeit in Wasser, als auch durch Diffusion durch Tonröhren leicht von einander scheiden kann. Durch die Wand tönerner Röhren geht Stickstoff leichter hindurch als Sauerstoff.

Einen neuen Bestandteil der Luft haben Lord Rayleigh und W. Ramsay aufgefunden, das Argon

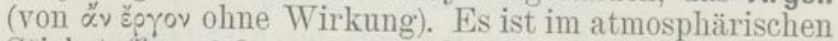
Stickstoff zu $0,8-0,9 \%$ enthalten. Man gewinnt es, indem man den Stickstoff mittelst glühenden Magnesiums oder durch elektrische Funkenentladung entfernt. Dann bleibt das Argon, das noch weit schwerer als der Stickstoff angegriffen wird, zurück. Seine Gasdichte ist $=$ ca. 20 , sein A tomgewicht $=$ ca. 40, sein Siedepunkt $-186^{\circ}$. Es hat ein wohlcharakterisiertes Spektrum. Es ist später auch als Bestandteil einiger Mineralien mit noch einem neuen Element, dem bis dahin nur auf der Sonne konstatierten Helium, zusammen nachgewiesen worden. Das Helium hat die Gasdichte 2, ist also nach Wasserstoff das leichteste Gas. Ferner hat Ramsay in der Luft noch mehrere andere Gase: Neon, Krypton, $\mathrm{X}$ enon, aufgefunden und näher untersucht.

Diese „Edelgase" geben keinerlei Verbindungen, sie sind alle schwer zu verflüssigen, besonders das Helium, das noch bei - $264^{0}$ und einer Atmosphäre Druck gasförmig bleibt. Es sind ein a t o mige Gase, bei denen also im Gegensatz zu den gewöhnlichen Elementargasen das Atomgewicht gleich dem Molekulargewicht ist. halten.

Sie sind in der Luft in sehr geringer Menge ent-

\section{Wasserstoffverbindungen des Stickstoffs.}

Ammoniak $\mathrm{NH}_{3}$.

$\mathrm{Hydrazin} \mathrm{NH}_{2}-\mathrm{NH}_{2}=\mathrm{N}_{2} \mathrm{H}_{4}$.

Stickstoffwasserstoffsäure $\mathrm{N}_{3} \mathrm{H}$. 


\section{Ammoniak.}

$\mathrm{NH}_{3}$. M. G. 17. Gasdichte 8,5.

$\mathrm{NAPH}_{4} \sqrt{\mathrm{C}} \mathrm{C}$.

Vorkommen: In der Luft und einigen Mineralien.

Es bildet sich bei der Fäulnis organischer Substanzen und als Nebenprodukt bei der Leuchtgasfabrikation.

Das Ammoniak liefert neben den salpetersauren Salzen des Bodens den Pflanzen den zum A ufbau der Eiweißst offe nötigen Stickstoff. Es ist deshalb ein unentbehrliches D u n g mitte l, wie es ja einen der wesentlichsten Bestandteile des tierischen Düngers darstellt. Das Tier nämlich verbrennt die Eiweißstoffe zu Harnstoff oder Harnsäure, die bei der Fäulnis in Ammoniak übergehen. Weder Tiere noch höhere Pflanzen können elementaren Stickstoff verwerten. Nur einige Bakterien haben die Fähigkeit, ihn in Ammoniaksalze überzuführen (Azotobakter). Andere verwandeln das Ammoniak im Boden in Salpetersäure, die die Pflanzen verwerten können (Nitrifikation).

Darstellung: Aus den „Gaswässern“ (s. L euchtgas) durch Eindampfen mit Salzsäure. Dabei entsteht Chlorammonium $\mathrm{NH}_{4} \mathrm{Cl}$, aus dem man mit gelöschtem Kalk das Ammoniak wieder in Freiheit setzt.

$$
2 \mathrm{NH}_{4} \mathrm{Cl}+\mathrm{Ca}(\mathrm{OH})_{2}=2 \mathrm{NH}_{3}+2 \mathrm{H}_{2} \mathrm{O}+\mathrm{CaCl}_{2} .
$$

Eigenschaften: Farbloses, eigenartig riechendes Gas, sehr leicht löslich in Wasser. Bei - $40^{\circ}$ flüssig. Die wässrige Lösung heißt Salmiakge ist (Liquor ammonii caustici).

Chemisches Verhalten: In reinem Sauerstoff ist Ammoniak brennbar. Es hat stark basische Eigenschaften; seine wässrige Lösung enthält wahrscheinlich eine Base von der Formel $\mathrm{NH}_{4} \mathrm{OH}$, das $\mathrm{Am}$ moniumhydroxyd. Man nennt nämlich das einwertige Radikal $\mathrm{NH}_{4}\left(-\stackrel{\mathrm{v}}{\mathrm{N}} \equiv \mathrm{H}_{4}\right)$ A mmonium, da 
es sich wie ein metallisches Element erhält. Als solches gibt es dann ein basisches Hydroxyd, das Salze bildet, z. B.:

$$
\left(\mathrm{NH}_{4}\right) \mathrm{OH}+\mathrm{HCl}=\left(\mathrm{NH}_{4}\right) \mathrm{Cl}+\mathrm{H}_{2} \mathrm{O} \text {. }
$$

Nachweis: Die Ammoniumverbindungen geben beim Kochen mit Natronlauge den charakteristischen Geruch des Ammoniaks.

Verwendung: In der Farbstofftechnik. Flüssiges Ammoniak zur Erzeugung von Kälte in Eismaschinen. In der Medizin.

Hydrazin $\mathrm{NH}_{2}-\mathrm{NH}_{2}$ hauptsächlich in seinen organ ischenDerivaten wichtig. Ist ebenfalls in seinem Hydrat $\mathrm{NH}_{2}-\mathrm{NH}_{3} \mathrm{OH}$ stark basischer Natur.

Stickstoffwasserstoffsäure $\mathrm{N}_{3} \mathrm{H}=\mathrm{N}>\mathrm{NH}$ ist eine starke Säure.

$$
\text { iximix }
$$

Stark riechende, sehr explosive Flüssigkeit.

Hydroxylamin $\mathrm{NH}_{2} \mathrm{OH}$. Entsteht durch Reduktion von Salpetersäure (oder besser ihrem Athylester) mit Zinn:

$$
\mathrm{HNO}_{3}+3 \mathrm{H}_{2}=\mathrm{NH}_{2} \mathrm{OH}+2 \mathrm{H}_{2} \mathrm{O} \text {. }
$$

Farblose Nadeln. Ziemlich leicht zersetzlich. Verbindet sich mit Säuren zu Salzen:

$$
\mathrm{NH}_{2} \mathrm{OH}+\mathrm{HCl}=\mathrm{NH}_{2} \mathrm{OH} . \mathrm{HCl} \text {. }
$$

Die Salze leiten sich von der Base: Oxyammonium her:

$$
\mathrm{NH}_{3}(\mathrm{OH}) \mathrm{OH}+\mathrm{HCl}=\mathrm{NH}_{3}(\mathrm{OH}) \mathrm{Cl}+\mathrm{H}_{2} \mathrm{O} .
$$

Chlorstickstoff, $\mathrm{NCl}_{3}$, aus Ammoniak und Chlor.

$$
\mathrm{NH}_{3}+6 \mathrm{Cl}=\mathrm{NCl}_{3}+3 \mathrm{HCl} \text {. }
$$

Ölige Flüssigkeit, schon bei leiser Berührung heftig explodierend.

Jodstickstoff $\mathrm{NJ}_{2} \mathrm{H}$, aus Jod und Ammoniak.

Schwarzes Pulver, noch explosiver als Chlorstickstoff. 


\section{- $71-$ \\ Stickstoff und Sauerstoff.}

Der Stickstoff bildet fünf verschiedene Sauerstoffverbindungen, von denen zwei Säureanhydride darstellen:

$\mathrm{N}_{2} \mathrm{O}$ Stickoxydul.

NO Stickoxyd.

$\mathrm{N}_{2} \mathrm{O}_{3}$ Stickstofftrioxyd (Salpetrigsäureanhydrid).

$\mathrm{NO}_{2}\left(\mathrm{~N}_{2} \mathrm{O}_{4}\right)$ Stickstoffdioxyd.

$\mathrm{N}_{2} \mathrm{O}_{5}$ Stickstoffpentoxyd (Salpetersäureanhydrid).

\section{Stickoxydul $\mathrm{N}_{2} \mathrm{O}$.}

Darstellung: 1) Durch Reduktion von Salpetersäure mit Zink neben Stickoxyd.

2) Rein aus Ammoniumnitrat durch Erhitzen:

$$
\mathrm{NH}_{4} \mathrm{NO}_{3}=\mathrm{N}_{2} \mathrm{O}+2 \mathrm{H}_{2} \mathrm{O} \text {. }
$$

Eigenschaften: Farbloses, süßlich schmeckendes Gas von schwachem Geruch. Ziemlich leicht löslich in Wasser.

Chemisches Verhal ten: Unterhält die Verbrennung, da es leicht Sauerstoff abgibt.

Verwend ung: Da es beim Einatmen erst einen rauschartigenZustand, dann Betäubung hervorruft, als leichtes Narkotikum für kleine Operationen (Lachgas).

\section{Stickoxyd NO.}

Darstellung: Aus Kupfer und Salpetersäure.(Reduntioiov!')

$$
3 \mathrm{Cu}+8 \mathrm{HNO}_{3}=3 \mathrm{Cu}\left(\mathrm{NO}_{3}\right)_{2}+2 \mathrm{NO}+4 \mathrm{H}_{2} \mathrm{O} \text {. }
$$

Farbloses Gas. Wenig löslich in Wasser. Schwer kondensierbar. Nimmt an der Luft sofort noch 1 Atom Sauerstoff auf und verbindet sich mit ihm zu $\mathrm{NO}_{2}$ (bra u ne Dämpfe). Ein Gemisch von Stickoxyd und Schwefelkohlenstoffdampf verbrennt mit blendender, prachtvoll blauer Flamme. 


\section{Stickstoffdioxyd $\mathrm{NO}_{2}$.}

el

gi

Entsteht durch direkte Vereinigung von $\mathrm{N}$ und $\mathrm{O}$ mittelst des elektrischen Funkens, sowie aus Stickoxyd an der Luft. Rotgelbe, erstickend riechende Dämpfe.

Bei niederer Temperatur hat es die Molekularformel $\mathrm{N}_{2} \mathrm{O}_{4}$ und läßt sich bei $-12^{\circ} \mathrm{zu}$ einer farblosen Flüssigkeit kondensieren, die indessen schon bei $0^{\circ}$ anfängt gelb zu werden, indem schon hier die Trennung der Moleküle in $\mathrm{NO}_{2}$ beginnt. Bei $26^{\circ}$ verwandelt sich die Flïssigkeit in einen gelben Dampf, der sich bei höherer Temperatur immer dunkler färbt, bis schließlich bei $150^{\circ}$ die Dissoziation in $\mathrm{NO}_{2}$ vollständig ist.

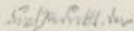

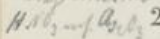

Salpetrigsäureanhydrid $\mathrm{N}_{2} \mathrm{O}_{3}$. Bei Temperaturen unter $21^{0}$ eine tiefblaue Flüssigkeit. Zersetzt sich beim Sieden (Sdp. $3.5^{0}$ ).

Gibt mit wenig Wasser wahrscheinlich die $\left\lceil/ \mathrm{m} / 2 \mathrm{Am} \mathrm{w}^{2}\right.$

Salpetrige Säure, $\mathrm{HNO}_{2}$. In freiem Zustande nicht bekannt. Thre Salze (Nitrite) entstehen durch Erhitzen von salpetersauren Salzen. Die aus ihren Salzen in Freiheit gesetzte Säure zerfällt in Wasser, $\mathrm{NO}_{2}$ und $\mathrm{NO}$; sie macht aus Jodverbindungen das Jod frei.

Salpetersäureanhydrid $\mathrm{N}_{2} \mathrm{O}_{3}$. Aus der Salpetersäure durch Wasserentziehung mittelst Phosphorpentoyd:

$$
2 \mathrm{HNO}_{3}+\mathrm{P}_{2} \mathrm{O}_{3}=2 \mathrm{HPO}_{3}+\mathrm{N}_{2} \mathrm{O}_{5} .
$$

Farblose, leicht zersetzliche Prismen.

\section{Salpetersäure $\mathrm{HNO}_{3}=\mathrm{NO}_{2} \mathrm{OH}$.}

Vorkommen: Salpetersaure Salze entstehen bei der Verwesung von organischen Stoffen meist durch die Tätigkeit von Bakterien (Nitrifikation). Hauptquelle ihrer Bereitung ist ihr Natriumsalz, das in grofen Lagern in Chile und Peru vorkommt (Chilisalpeter).

Darstellung: Aus Salpeter mit Schwefelsäure $\mathrm{NaNO}_{3}+\mathrm{H}_{2} \mathrm{SO}_{4}=\mathrm{NaHSO}_{4}+\mathrm{HNO}_{3}$. (min)

Neuerdings wird Salpetersäure (neben salpetriger S.) aus Luft durch Oxydation des Stickstoffs mittels sehr
Eis

$\mathrm{F}$

$\mathrm{B}$

ri

e

G 
energischer elektrischer Entladungen im großen hergestellt, und soll zu Düngerzwecken dienen.

Eigenschaften: Farblose, an der Luft rauchende Flüssigkeit von spez. G. 1,56. Mischbar mit Wasser. Beim Destillieren einer verdünnten Lösung geht erst reines Wasser über, dann destilliert bei $121^{\circ}$ konstant eine Salpetersäure von $68 \%$ Gehalt und dem spez. Gewicht 1,4. Dies ist die sog. konzentrierte Salpetersäure.

Chemisches Verhalten: Starke Säure ${ }_{1}$ löst fast alle Metalle (außer Gold und Platin). Oxydiert viele Elemente, z. B. Zinn, Kohle, Phosphor zu Säuren, zerstört organische Stoffe, färbt die Haut gelb. Wirkt überhaupt sehr energisch ox y dierend und reduziert sich dabei zu niedrigen Oxyden des Stickstoffs. Verdünnte Salpetersäure wird durch naszierenden Wasserstoff direkt zu Ammoniak reduziert.

$$
\begin{aligned}
& \mathrm{HNO}_{3}+8 \mathrm{H}=\mathrm{NH}_{3}+3 \mathrm{H}_{2} \mathrm{O} .
\end{aligned}
$$

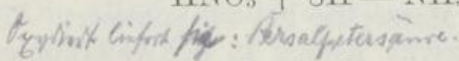

Rote rauchende Salpetersäure (acid. nitricum fumans) ist eine Salpetersäure, die Stickstoffdioxyd aufgelöst enthält. Man stellt sie durch Destillation von Salpetersäure mit konz. Schwefelsäure dar. Wirkt noch energischer als gewöhnliche Salpetersäure. Ein Gemenge von 3 Volumen Salzsäure und einem Volumen Salpetersäure heißt Königswasser. Es löst Gold und Platin.

Nach we is: Salpetersaure Salze mit Kupfer und Schwefelsäure erhitzt geben die roten Dämpfe des Stickstoffdioxyds.

Eine Lösung von Diphenylamin in konz. Schwefelsäure wird selbst durch Spuren von $\mathrm{HNO}_{3}$ blau gefärbt. Da das gewöhnliche Wasser fast stets Spuren von Salpetersäure enthält, reine Mileh dagegen nicht, so kann man dadurch Milch auf nachträglichen Wasserzusatz prüfen. 


\section{Phosphor.}

\section{P. Atomg. 31. Mol. G. 124.}

Historisches: Der Phosphor wurde fast gleichzeitig von Brand und K unkel aus Harn dargestellt. Sein Name rührt von seiner Fähigkeit her, im Dunkeln

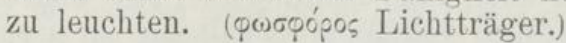

Vorkommen: Nur in Salzen; namentlich phosphorsaurer Kalk in manchen Mineralien, in der Ackererde, in Pflanzen und Tieren, besonders in den Knochen.

Darstellung: Aus Knochenasche, die tertiäres Kalziumphosphat enthält, durch Erhitzen mit Schwefelsäure, wodurch primäres Kalziumphosphat entsteht. Dies wird mit Sand und Kohle geglüht, wobei die Kohle das Kalziumphosphat zu Phosphor reduziert. Dieser entweicht gasförmig und wird unter Wasser aufgefangen.

Eigenschaften: Der so erhaltene Phosphor ist eine gelbe, wachsweiche Masse, die bei $44^{0}$ schmilzt. Unlöslich in Wasser, leicht löslich in Schwefelkohlenstoff. Äußerst giftig. $0,1 \mathrm{gr}$ sind für einen erwachsenen Menschen tödlich. Leuchtet im Dunkeln an der Luft. Wenn man Phosphor in luftleeren Gefäßen kurze Zeit auf $300^{\circ}$ erhitzt, geht er in eine andere Modifikation über, den roten $\mathrm{Phosphor.}$ Dieser hat ganz andere Eigenschaften: Er leuchtet nicht, bleibt an der Luft bis ca. $200^{\circ}$ unverändert, sublimiert ohne zu schmelzen, ist unlöslich in Schwefelkohlenstoff und ungiftig.

Eine dritte Modifikation ist der sog. metallische Phosphor, der entsteht, wenn man roten Posphor in geschmolzenem Blei löst und erstarren läßt; dann scheiden sich schwarze, metallglänzende Kristalle aus die noch beständiger sind als der rote Phosphor und vielleicht nur gut ausgebildete Kristalle der letzteren Modifikation darstellen.

Chemisches Verhalten: Der gelbe Phosphor verbindet sich sehr leicht mit Sauerstoff. An feuchtre 
Luft zerfließt er unter Bildung von phosphoriger Säure $\mathrm{H}_{3} \mathrm{PO}_{3}$; beim Erhitzen an trockener Luft (schon bei $60^{\circ}$ ) oder im Sauerstoffstrom verbrennt er mit helleuchtender Flamme zu Phosphorpentoxyd $\mathrm{P}_{2} \mathrm{O}_{5}$. Er verbindet sich schon bei gewöhnlicher Temperatur sehr lebhaft mit Chlor, Brom und Jod. Der rote Phosphor reagiert viel weniger energisch.

Der Phosphor zeigt in seinem Molekulargewicht eine Abweichung von der Regel, daß die Elemente im Gaszustand zweiatomige Moleküle besitzen. Seine G a s d i c h te beträgt 62 . Demnach ist sein Molekulargewicht $=124$. Nun ergibt sich aber aus den Verbindungen des Phosphors, daß man sein Atomgewicht zu 31 annehmen muß, folglich ist in diesem Falle das Mol. G. das vierfache des Atomgewichtes; das Phosphormolekül muß vieratomig sein.

Nachweis: Phosphor enthaltende Substanzen, z. B. vergiftetes Brot, Mageninhalt etc., geben beim Kochen mit Wasser im Dunkeln leuchtende Dämpfe. Man kann den Phosphor durch eine Röhre hindurch destillieren, wobei die Röhre zu leuchten beginnt.

Verwendung: In der Medizin. Zu Zündhölzern: Die alten Zündhölzchen bestanden aus einem Holzstäbchen, das an dem einen Ende in Schwefel gesteckt und dann noch mit einem aus Phosphor und Gummi arabicum bestehenden Köpfchen versehen wurde. Die sog.s ch we dischen $Z$ ünd hölzer haben statt dessen eine Zündmasse ohne Schwefel und Phosphor, die meist aus chlorsaurem Kali und Schwefelantimon besteht. Das Holz wird zur Erzielung größerer Leuchtkraft mit Paraffin getränkt. Die Streichmasse der Schachteln enthält u. a. roten Phosphor. Wegen der großen Gesundheitsschädlichkeit des Phosphors (Knochenerkrankungen) ist seine Verwendung wesentlich eingeschränkt worden. Er ist vielfach durch andere, wenig giftige Verbindungen ersetzt worden.

\section{Phosphor und Wasserstofi.}

Gasförmiger Phosphorwasserstoff $\mathrm{PH}_{3}$ entspricht dem Ammoniak. 
Darstellung: 1) Aus Phosphor und Natronlauge.

2) Aus Phosphorkalzium und Wasser:

$$
\mathrm{P}_{2} \mathrm{Ca}_{3}+6 \mathrm{H}_{2} \mathrm{O}=2 \mathrm{PH}_{3}+3 \mathrm{Ca}(\mathrm{OH})_{2} \text {. }
$$

Der so dargestellte Phosphorwasserstoff ist ein farbloses, widrig knoblauchartig riechendes, sehr giftiges Gas. Er enthält etwas flüssigen Phosphorwasserstoff $\mathrm{P}_{2} \mathrm{H}_{4}$ beigemengt und ist infolgedessen selbstentzündlich. Reiner $\mathrm{PH}_{3}$ ist nicht selbstentzündlich, aber brennbar.

Er ist ähnlich dem Ammoniak basenbildend, aber viel schwächer; die Base $\mathrm{PH}_{3}+\mathrm{H}_{2} \mathrm{O}=\mathrm{PH}_{4} \mathrm{OH}$ heißt Phosphoniumhydrat, der Basenrest $\mathrm{PH}_{4} \mathrm{Phos}_{-}$ phonium, gleich dem Ammonium $\mathrm{NH}_{4}$. Die Base bildet auch analoge Salze, z. B. Phosphoniumjodid $\mathrm{PH}_{4} \mathrm{~J}$ etc.

Die Gasdichte des $\mathrm{PH}_{3}$ ist $=17$, daraus folgt sein Mol. G. $=34$ und daraus, daß das Atomgewicht des Phosphors nicht $=62$ sein kann, sondern = 31 sein muß, da man dem Phosphorwasserstoff nach Analogie mit dem Ammoniak die Formel $\mathrm{PH}_{3}$ zuschreiben muß.

Flüssiger Phosphorw asserst off $\mathrm{P}_{2} \mathrm{H}_{4}$, entsprechend dem Hydrazin $\mathrm{N}_{2} \mathrm{H}_{4}$, scheidet sich beim Abkühlen des unreinen Gases (s. o.) ab. Er entzündet sich, sobald er mit Luft in Berührung kommt.

\section{Phosphor und Halogene.}

Die Verbindungen des Phosphors mit $\mathrm{Cl}, \mathrm{Br}, \mathrm{J}$ entstehen durch direkte Vereinigung der Elemente.

Phosphortrichloriđa $\mathrm{PCl}_{3}$. Farblose Flüssigkeit. Geht durch Wasser in phosphorige Säure über:

$$
\mathrm{PCl}_{3}+3 \mathrm{H}_{2} \mathrm{O}=\mathrm{H}_{3} \mathrm{PO}_{3}+3 \mathrm{HCl} \text {. }
$$

Phosphorpentach lorid $\mathrm{PCl}_{5}$ aus dem Trichlorid + Chlor. Kristallinischer gelblich weißer Körper. Geht mit wenig Wasser in $\mathrm{Phosph}$ oroxychlorid $\mathrm{POCl}_{3}$ über. Viel Wasser gibt $\mathrm{Phos}$ phorsäure:

$$
\mathrm{PCl}_{5}+4 \mathrm{H}_{2} \mathrm{O}=\mathrm{PO}(\mathrm{OH})_{3}+5 \mathrm{HCl} \text {. }
$$

Ähnlich sind die Brom- und Jodverbindungen.

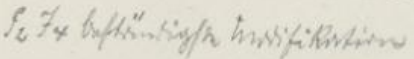




\section{7 \\ Sauerstoffverbindungen \\ des \\ Phosphors. \\ Der Phosphor bildet 3 Sauerstoffverbindungen: \\ Phosphorsuboxyd $\mathrm{P}_{4} \mathrm{O}$ \\ Phosphortrioxyd $\mathrm{P}_{4} \mathrm{O}_{6}$ \\ Phosphorpentoxyd $\mathrm{P}_{2} \mathrm{O}_{5}$ (Phosphorsäureanhydrid)}

und drei Säuren

$$
\begin{aligned}
& \mathrm{H}_{2} \mathrm{PO}-\mathrm{OH} \text { Unterphosphorige Säure } \\
& \stackrel{\stackrel{v}{H} O}{\mathrm{OH}}{ }_{\mathrm{OH}}^{\mathrm{OH}} \text { Phosphorige Säure } \\
& \mathrm{O}=\stackrel{\mathrm{r}}{\mathrm{P}}=\underset{\mathrm{OH}}{\mathrm{OH}} \text { Phosphorsäure. }
\end{aligned}
$$

Alle Säuren leiten sich vom fünfwertigen Phosphor ab. Die unterphosphorige Säure hat nur ein typisches (Hydroxyl-) Wasserstoffatom, ist also einbasisch; die phosphorige Säure hat zwei Hydroxyle, ist also zweibasisch; die Phosphorsäure mit drei Hydroxylen dreibasisch.

Die Phosphorsäure kann mehr oder weniger Wasser abspalten und bildet demgemäß mehrere Anhydride. Soweit diese noch Hydroxyl enthalten, sind sie noch Säuren und werden daher als Anhydrosäuren bezeichnet. Die Anhydride der Phosphorsäure sind folgende:

1) Aus zwei Molekülen Phosphorsäure spaltet sich ein Molekül Wasser ab: 

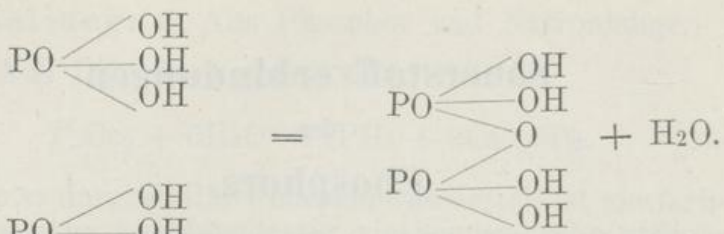<smiles>CCCOC1OC2COC1O2</smiles>

Diese Säure heißt Py roph osph orsäure $\left(\mathrm{H}_{4} \mathrm{P}_{2} \mathrm{O}_{7}\right)$. Sie enthält vier Hydroxyle, ist also vierbasisch.

2) Ein Molekül Phosphorsäure spaltet ein Molekül Wasser ab:

$$
\mathrm{PO} \underset{\mathrm{OH}}{\mathrm{OH}}=\mathrm{PO}_{2}-\mathrm{OH}+\mathrm{H}_{2} \mathrm{O} \text {. }
$$

Diese Säure heißt Metaphosphorsäure ( $\left.\mathrm{HPO}_{3}\right)$. Sie enthält ein Hydroxyl, ist also einbasisch. Sie entspricht der Salpetersäure $\mathrm{NO}_{2} \mathrm{OH}$.

3) Zwei Mol. Phosphorsäure spalten drei Mol. Wasser ab:

$$
2 \mathrm{H}_{3} \mathrm{PO}_{4}=\mathrm{P}_{2} \mathrm{O}_{5}+3 \mathrm{H}_{2} \mathrm{O} \text {. }
$$

Dieser Körper enthält kein Hydroxyl mehr, ist also keine Säure. Es ist das eigentliche Phosphorsäureanhydrid.

Hypophohite! Unterphosphorige Säure $\mathrm{H}_{3} \mathrm{PO}_{2}$. Das Baryumsalz resp. Natriumsalz entsteht durch Kochen von gelbem Phosphor mit Baryumhydroxyd oder Natriumhydroxyd in wässeriger Lösung, neben Phosphorwasserstoff:

Welucteh

$$
4 \mathrm{P}+3 \mathrm{NaOH}+3 \mathrm{H}_{2} \mathrm{O}=3 \mathrm{H}_{2} \mathrm{PO} . \mathrm{ONa}+\mathrm{PH}_{3} .
$$

Die freie Säure wird aus dem Baryumsalz durch Schwefelsäure

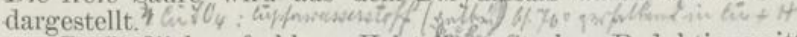

Zerfließliche, farblose Kristallê. Starkes Reduktionsmittel.

Phosphorige Säure $\mathrm{H}_{3} \mathrm{PO}_{3}$ entsteht durch Oxydation von Phosphor an feuchter Luft, ferner aus

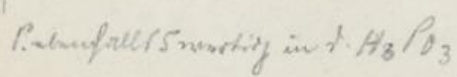




\section{- $79-$ \\ $\mathrm{PCl}_{3}+3 \mathrm{H}_{2} \mathrm{O}=\mathrm{H}_{3} \mathrm{PO}_{3}+\mathrm{HCl}$.}

Farblose, zerfließliche Kristallmasse. Wirkt stark reduzierend, indem sie sich zu Phosphorsäure oxydiert.

Phosphorsäure, auch Orthophosphorsäure (acidum phosphoricum) $\mathrm{H}_{3} \mathrm{PO}_{4}$ entsteht aus ihrem Ani) hydrid $\mathrm{P}_{2} \mathrm{O}_{5}$ durch heißes Wasser. Man stellt sie aus Knochenasche, die phosphorsaures Kalzium enthält,

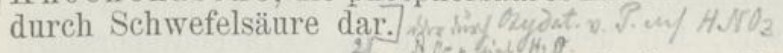

Farblose Prismen, die an der Luft zerfließen. Völlig ungiftig.

Sie bildet als dreibasische Säure drei Reihen von Salzen, die man als primäre, sekundäre und tertiäre $\mathrm{Ph}$ osphate bezeichnet.

$\mathrm{NaH}_{2} \mathrm{PO}_{4}$ primäres oder Mononatriumphosphat, $\mathrm{Ca}_{3}^{-}\left(\mathrm{H}_{2} \mathrm{P}_{4}\right)_{2}$

$\mathrm{Na}_{2} \mathrm{HPO}_{4}$ sekundäres oder Dinatriumphosphat,

$\mathrm{Na}_{3} \mathrm{PO}_{4}$ tertiäres oder Trinatriumphosphat.

Phosphorsäure spielt im Haushalt der organischen Wesen eine ungemein wichtige Rolle. Sie ist in der Substanz der Zellkerne, dem Nukleïn, enthalten, ferner im Zentralnervensystem als Lecithin (s. org. Chemie), bildet ferner als phosphorsaurer Kalk den Hauptbestandteil der Knochengrundsubstanz. Ebenso ist sie für die Pflanzen unentbehrlich. Man muß deshalb den Boden mit Phosphaten düngen. Darauf hingewiesen zu haben, ist das unsterbliche Verdienst Justus v. Liebigs, der zuerst die künstliche Düngung des Bodens inaugurierte.

N ach w e is: Molybdänsaures Ammonium gibt einen gelben Niederschlag, der in $\mathrm{HNO}_{3}$ nicht löslich ist. $\mathrm{AgNO} s$ gibt einen

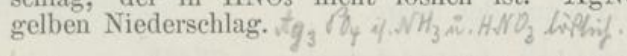

4 hyay: Pyrophosphorsäure $\mathrm{H}_{4} \mathrm{P}_{2} \mathrm{O}_{7}$ entsteht durch Er$\lim _{\rightarrow+\mathrm{H}_{2} \mathrm{OCO}_{3}}$

hitzen von Orthophosphorsäure auf $260^{\circ}$. sukwisahe . Gaxp.

Kristallinische, in Wasser leicht lösliche Masse.

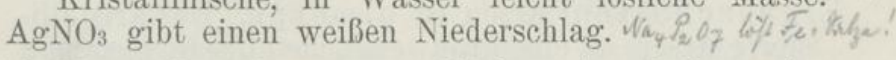

ifrpy Metaphosphorsäure $\mathrm{HPO}_{3}$. Aus Ortho- oder 


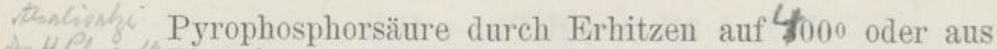

$4 / \mathrm{H}_{3} \mathrm{~S}_{2}$ mosphorpentoxyd $\mathrm{P}_{2} \mathrm{O}_{5}$ mit kaltem Wasser.

thim as. Throplate $\quad \mathrm{P}_{2} \mathrm{O}_{5}+\mathrm{H}_{2} \mathrm{O}=2 \mathrm{HPO}_{3}$.

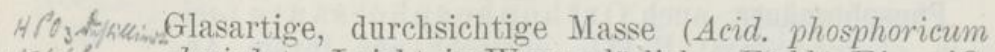
rerfigf. glaciale). Leicht in Wasser löslich. Fällt Eiweißlösungen (Unterschied gegen Ortho- und P yrophosphorsäure). Geht mit kaltem Wasser langsam, mit heißem schnell in Orthophosphorsäure

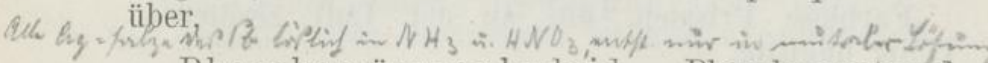

Phosphorsäureanhydrid, Phosphorpentoxyd $\mathrm{P}_{2} \mathrm{O}_{3}$ entsteht durch Verbrennen des Phosphors an. trockener Luft oder in Sauerstoff.

Weiße, sehr lebhaft Wasser anziehende Masse. Wird als sehr energisches Mittel zum Trocknen der Gase und zur Wasserentziehung aus Verbindungen angewendet.

Phosphor und Schwefel.

Durch Zusammenschmelzen von Phosphor und Schwefel entstehen mehrere Verbindungen, von denen das $\mathrm{Ph}$ os $p$ h ortrisulfid $\mathrm{P}_{2} \mathrm{~S}_{3}$ und das $\mathrm{P}$ entas ulfid $\mathrm{P}_{2} \mathrm{~S}_{5}$ die wichtigsten sind.

\section{Arsen.}

As. Atomg. 75. Mol. G. 300 .

Vorkommen: Selten gediegen. In vielen Mineralien an Metalle gebunden. Ferner als Arsenikblüte $\mathrm{As}_{4} \mathrm{O}_{6}$, Realgar $\mathrm{As}_{2} \mathrm{~S}_{2}$, Auripigment $\mathrm{As}_{2} \mathrm{~S}_{3}$.

Nach neueren Untersuchungen ist das Arsen in sehr geringen Mengen ein konstanter-Bestandteil sehr vieler tierischen Gewebe, besonders der Haut und der Haare.

ent:

Darstellung: Aus Arsentrioxyd mit Kohle:

$$
\mathrm{As}_{2} \mathrm{O}_{3}+3 \mathrm{C}=2 \mathrm{As}+3 \mathrm{CO} \text {. }
$$

Eigenschaften: Arsen ist dimorph. Das kristallisierte Arsen ist eine grauweiße, metallisch-glänzende Masse vom spez. G. 5.7; das amorphe ist schwarz, 
wenig glänzend, spez. G. 4.7. Verdampft bei $450^{\circ}$ ohne zu schmelzen.

Chemisches Verhalten: Die Gasdichte des Arsens ist $=150$, also ist sein Mol. G. 300. Sein Atomg. ist $=75$, also ist sein Molekül ebenfalls, wie das des Phosphors, vieratomig.

Arsen verbrennt beim Erhitzen an der Luft. Entzündet sich in Chlorgas.

Arsenwasserstoff $\mathrm{AsH}_{3}$. Entsteht bei der Einwirkung von naszierendem Wasserstoff (Zink und Salzsäure) auf Arsenverbindungen. Farbloses, widrig riechendes, enorm giftiges Gas. Wird beim Durchleiten durch eine glühende Glasröhre in Arsen und Wasserstoff zerlegt: Das Arsen setzt sich dann als schwarzer Belag auf dem Glase fest (A rsenspiegel).

Man benutzt dies zum Nachweis von Arsen, indem man die zu untersuchende Substanz, z. B. vergiftete Speisen, mit Zink und Salzsäure zusammenbringt und den sich entwickelnden Wasserstoff durch ein Glasrohr leitet, das an einer Stelle erwärmt wird. Dann scheidet sich an dieser Stelle schwarzes Arsen ab (Marsh scher A p parat). Sehr empfindlicher Nachweis.

Arsen und $\mathrm{Hal}$ ogene. Ähnlich den Phosphorverbindungen Das Pentachlorid, -bromid etc. ist indessen nicht bekannt. A rs en trichlorid $\mathrm{AsCl}_{3}$.

\section{Sauerstofiverbindungen des Arsens.}

Arsen hat zwei Oxydationsstufen, denen zwei Säuren entsprechen.
$\mathrm{As}_{2} \mathrm{O}_{3}$
Arsentrioxyd
$\mathrm{As}_{2} \mathrm{O}_{5}$
Arsenpentoxyd
$\mathrm{H}_{3} \mathrm{AsO}_{3}$ Arsenige Säure
$\mathrm{H}_{3} \mathrm{AsO}_{4}$
Arsensäure.

Arsentrioxyd, weißer Arsenik, Arsenigsäureanhydrid, gewöhnlich fälschlich als arsenige Säure (Aci-

Op penheimer, Grundriss d. anorg. Chemie, 4. Anfl. 6 


\section{$-82-$}

dum arsenicosum) bezeichnet, kommt in der Natur als Arsenikblüte vor. Es wird im großen bei der Verhüttung arsenhaltiger Erze gewonnen und zur Reinigung in eisernen Zylindern sublimiert. Weißes Pulver oder glasartige Masse, sehr giftig. Schwer löslich in Wasser. Wirkt reduzierend. Wird in der Medizin angewendet, besonders als Kaliumsalz (Liquor Fowleri).

Die arsenige Säure $\mathrm{H}_{3} \mathrm{AsO}_{3}$ ist in freiem $\mathrm{Zu-}$ stande nicht bekannt. In ihren Salzen ist sie dreibasisch.

Arsensäure $\mathrm{H}_{3} \mathrm{AsO}_{4}$ entsteht durch Oxydation von Arsen mit Salpetersäure. ZerflieBliche Kristalle. Dreibasische Säure. Die Arsensäure gibt wie die Phosphorsäure durch Wasserabspaltung zuerst $\mathrm{P}$ y r o arsen säure $\mathrm{H}_{4} \mathrm{As}_{2} \mathrm{O}_{7}$ und dann $\mathrm{Metarsensäure} \mathrm{HAsO}_{3}$, schließlich das A rsensäureanhydrid $\mathrm{A}_{2} \mathrm{O}_{5}$, weiße glasartige Masse.

A rsentrisulfid $\mathrm{As}_{2} \mathrm{~S}_{3}$. Schwefelwasserstoff fällt aus den Lösungen der arsenigsauren Salze gelbes Arsentrisulfid. Kommt in der Natur als A uripigment vor:

Arsenpentasulfid $\mathrm{As}_{2} \mathrm{~S}_{5}$. Durch Schwefelwasserstoff aus erwärmten sauren Lösungen von arsensauren Salzen. Gelbes Pulver.

Arsendisulfid $\mathrm{As}_{2} \mathrm{~S}_{2}$. Kommt in der Natur in rubinroten Kristallen als Realgar vor.

Ersetzt man in der arsenigen oder Arsensäure den Saner stoff durch Schwefel, so entstehen die sogenannten Sulfosäuren:

\section{$\mathrm{H}_{3} \mathrm{AsS}_{3}$ Sulfarsenige Säure}

$\mathrm{H}_{3} \mathrm{AsS}_{4}$ Sulfarsensäure.

Ihre Alkalisalze entstehen durch Auflösen von Sehwefelarsen in Schwefelkalium:

$$
\mathrm{AsS}_{3}+3 \mathrm{~K}_{2} \mathrm{~S}=2 \mathrm{~K}_{3} \mathrm{AsS}_{3} .
$$

\section{Antimon (Stibium). \\ Sb. Atomg. 120.}

Das Antimon nähert sich in seinem Verhalten bereits sehr den Metallen. 
Vorkommen: In der Natur hauptsächlich als Grauspießglanzerz $\mathrm{Sb}_{2} \mathrm{~S}_{3}$. Ferner in vielen anderen Mineralien.

Darstellung: Grauspießglanzerz wird an der Luft erhitzt (geröstet), wobei es in $\mathrm{Sb}_{2} \mathrm{O}_{3}$ übergeht. Dies wird dann mit Kohle reduziert. (Allgemeine Darstellungsweise der Metalle.)

Silberweißes, stark glänzendes Metall, spez. G. 6.7. Sehr spröde, läßt sich pulvern.

Verbrennt beim Erhitzen an der Luft, sowie in Chlorgas. Unlöslich in Salzsäure. Salpetersäure oxydiert zu Antimonsäure.

Antimonwasserstoff $\mathrm{SbH}_{3}$ völlig analog dem Arsenwasserstoff.

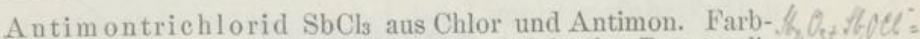
lose, weiche Masse (Butyrum Antimonii), wird in der Baumwollfärberei als Beize verwendet. Viel Wasser scheidet ein weißes Pulver ab: Algarotpulver (von dem italienischen Arzte Algarotus, der es als Heilmittel verwendete). 20 dec;

Antimonpentachlorid SbCls aus dem Trichlorid dureh Chlor. Gelbliche stark rauchende Flüssigkeit.

Die Sauerstoffverbindungen des Antimons entsprechen im wesentlichen denen des Arsens. Man kennt das Trioxyd $\mathrm{Sb}_{2} \mathrm{~S}_{3}$ (Antimonige Säure) und das Pentoxyd $\mathrm{Sb}_{2} \mathrm{O}_{5}$ (Antimonsäure). Indessen zeigt sich hier Alquetpontiver schon der metallische Charakter des Antimons. Das Trioxyd ist schon kaum noch eine Säure. Man kennt zwar einige Salze, z. B. das Kaliumsalz; doch sind auch diese sehr unbeständig. Degegen bildet das Antimon in dieser Oxydationsstufe mit starken Säuren Salze, fungiert also als Base.

$$
\mathrm{Sb}(\mathrm{OH})_{3}+3 \mathrm{NO}_{2} \mathrm{OH}=\mathrm{Sb}\left(\mathrm{NO}_{3}\right)_{3}+3 \mathrm{H}_{2} \mathrm{O}
$$

Antimontrioxydhydrat Salpetersäure Antimonnitrat.

Außerdem gibt es noch ein basisches Hydrat des Antimons, das die Formel $\mathrm{SbO}$. OH hat. Dies bildet Salze, in denen das einwertige Radikal SbO die Stelle 


\section{$-84-$}

eines Metalls vertritt. Es ist deshalb auch besonders als Antimonyl bezeichnet worden. Es bildet z. B.

( $\mathrm{SbO}) \mathrm{NO}_{3}$ Antimonylnitrat.

Das wichtigste Salz dieser Base ist der Brechweinstein, der ein weinsaures Antimonylkalium darstellt (s. org. Chemie).

Die Antimonsäure $\mathrm{H}_{3} \mathrm{SbO}_{4}$ ist eine schwache Säure, die ein $\mathrm{Anhydrid} \mathrm{Sb}_{2} \mathrm{O}_{5}$ bildet.

\section{Vanadin, Niob, Tantal}

sind drei seltene Elemente, die in naher Beziehung zur Phosphorgruppe stehen, der auch ihre Verbindungen entsprechen.

Das Tantal hat jüngstens dadurch Bedeutung erlangt, daß man das sehr schwer schmelzbare Metall als Fäden für elektrische Glühlampen benutzt.

\section{Kohlenstofi.}

Symbol: C. Atomg. 12. Vierwertig.

Vorkommen: In freiem Zustande als Diamant, Graphit und Kohle. Ferner stellt er den wesentlichen Bestandteil der ,organischen" Körper, d. h. der Stoffe des Tier - und Pflanzenreiches dar; außerdem bildet er in den kohlensauren Salzen sehr häufig vorkommende Mineralien; namentlich kohlensa urer Kalk ist ein sehr wichtiger gebirgsbildender Stoff (Kalkberge, Dolomite).

Eigenschaften: Der Kohlenstoff ist in drei Modifikationen bekannt:

1) als Diamant kristallisiert. Diamanten finden sich u. a. in Brasilien, Indien, Südafrika. Reguläre Kristalle von starkem Glanz, großem Lichtbrechungsvermögen und großer Härte; der Diamant ist der härteste Körper, den wir kennen. Er verbrennt im Sauerstoffstrom zu Kohlendioxyd. Neuerdings hat Moissan kleine Diamanten künstlich erhalten.

2) Graphit ist eine amorphe, grauschwarze, weiche Masse; findet sich z. B. in Sibirien. Völlig unschmelz- 
bar. Wird zu Bleistiften und zu feuerfesten Gefäßen und Anstrichfarben benutzt. Wenn man kohlenstoffhaltiges Eisen in Salzsäure löst, bleilbt der Kohlenstoff z. T. als Graphit zurück.

3) Amorphe Kohle entsteht durch Zersetzung (V e r kohlung) organischer Substanzen. Die reinste Kohle ist der KienruB, der durch unvollkommenes Verbrennen z. B. von Terpentinöl entsteht. Die Holzkohle, durch Verkohlen von Holz gewonnen, ist sehr porös; sie hat die Fähigkeit, Fäulnisstoffe und ähnliche Substanzen aufzunehmen; sie wird deshalb als Filter und zur Desinfektion benutzt. In noch höherem Maße hat diese Eigenschaften die Tierkohle, die man aus tierischen Geweben (Blut, Knochen) erhält, die außerdem viele Farbstoffe ihren Lösungen entzieht.

Gaskohle setzt sich bei der Leuchtgasfabrikation in den Röhren ab; sie ist sehr hart und leitet Elektrizität gut; sie wird deshalb zu galvanischen Batterien und Bogenlichtlampen benutzt. Koaks ist die geglühte Kohle der Gasfabriken, die in den Retorten zurïckbleibt. In der Natur findet sich fossile Ko h le aus alten Pflanzenbeständen gebildet: Braun kohle, T'orf, die verhältnismäßig wenig Kohlenstoff enthalten (bis 70\%); Steinkohle, die bis $90 \%$, und Anthracit, der $96-98 \%$ enthält. Sie enthalten außerdem noch Wasserstoff, Sauerstoff Stickstoff und andere feste Beimengungen, die sog. Asche.

Chemisches Verhalten: Der Kohlenstoff ist in jeder Form sehr beständig, nur die energischsten Mittel greifen ihn an, z. B. rauchende Salpetersäure. Er verbrenntzuKohlendioxyd. Er istvierwertig, doch haben seine Atome die Fähigkeit, sich gegenseitig zu langen Ketten zu binden und auch ringförmige Verbindungen zu schließen. Dadurch ist die Zahl der Kohlenstoffverbindungen eine ganz ungeheure, und man hat sich gewöhnt, ihr Studium einem besonderen Zweige der Chemie zu überweisen, der sog. organischen Chemie. 
Alter Gewohnheit folgend, besprechen wir hier nur die Sauerstoffverbindungen des Kohlenstoffs und einige andere einfachste Verbindungen.

Kohlenoxyd CO. Entsteht durch Verbrennen von Kohle bei höherer Temperatur, indem das zuerst entstehende Kohlendioxyd bei über 7000 durch die überschüssige Kohle reduziert wird.

$$
\mathrm{CO}_{2}+\mathrm{C}=2 \mathrm{CO} \text {. }
$$

Aus Wasser und glühenden Kohlen entsteht ein Gemisch von $\mathrm{CO}$ und Wasserstoff:

$$
\mathrm{C}+\mathrm{H}_{2} \mathrm{O}=\mathrm{CO}+\mathrm{H}_{2} .
$$

Dieses Gemisch findet zuweilen in der Technik Anwendung (Wassergas). Ähnliche Zusammensetzung zeigen Dowsongas und Regeneratorgas

Sie brennen mit sehr schwach leuchtender, aber sehr heißer Flamme. Der allgemeinen Verwendung steht ihre Giftigkeit bei völliger Geruchlosigkeit entgegen.

Farbloses, geruchloses Gas, schwer kondensierbar. Siedet bei -1900 , schmilzt bei $-211^{\circ}$. Heftiges Blutgift, indem es sich mit dem Blutfarbstoff verbindet und dadurch die Sauerstoffaufnahme verhindert (Kohlenoxydhämoglobin). Verbrennt mit bläulicher Flamme zu Kohlendioxyd $\mathrm{CO}_{2}$.

Kohlendioxyd $\mathrm{CO}_{2}$, vulgo Kohlensäure. Frei in der Luft (normal ca. 0,04\%) und in Quellen. Gebunden besonders an Kalk, als Kalziumkarbonat, das mächtige Gebirge bildet (Kalkstein, Kreide, Dolomit). Entsteht beim Verbrennen von Kohle, sowie aus den Salzen der Kohlensäure durch Salzsäure oder Schwefelsäure:

$$
\mathrm{CaCO}_{3}+\mathrm{H}_{2} \mathrm{SO}_{4}=\mathrm{CaSO}_{4}+\mathrm{CO}_{2}+\mathrm{H}_{2} \mathrm{O} \text {. }
$$

Es ist also das Anhydrid der $\mathrm{K}$ ohlensäure $\mathrm{H}_{2} \mathrm{CO}_{3}$. Farbloses, geruchloses Gas, ziemlich leicht löslich in Wasser. Es ist nicht giftig, verhindert aber, in größerer Menge der Atemluft beigemischt, die Atmung, man erstickt in Kohlendioxyd. Kritische Temperatur $30,9^{\circ} \mathrm{C}$. 


\section{$-87-$}

Bei dieser Temperatur läßt es sich durch 77 Atmosphären Druck verdichten. Läßt man flüssiges Kohlendioxyd schnell verdunsten, so erstarrt ein Teil zu fester Kohlensäure, die sehr langsam verdunstet, da sie die Wärme schlecht leitet. Es ist nicht brennbar, da es die letzte Oxydationsstufe des Kohlenstoffs darstellt, also keinen Sauerstoff mehr aufnehmen kann.

Kohlendioxyd spielt in der Natur eine große Rolle. Es ist in der Luft enthalten; aus ihr nehmen es die Pflanzen auf und bauen daraus die kompliziertesten Stoffe ihrer Zellen auf, besonders Kohlehydrate und Eiweißst offe. Dabei scheiden sie Sauerstoff aus. Die Tiere verbrennen in ihrem Organismus diese pflanzlichen Stoffe zu Kohlendioxyd, das sie ausatmen. So macht also das Kohlendioxyd einen großen Kreisprozeß durch.

Die dem Kohlendioxyd entsprechende Säure ist eine zweibasische, die Kohlensäure $\mathrm{H}_{2} \mathrm{CO}_{3}$ oder $\mathrm{CO}<\mathrm{OH}$.

Freie Kohlensäure ist nur bei $0^{\circ}$ und ca. 12 Atmosphären Druck beständig, zerfällt sonst sofort in $\mathrm{CO}_{2}$ und $\mathrm{H}_{2} \mathrm{O}$.

Schwefelkohlenstoff $\mathrm{CS}_{2}$ entsteht, wenn man Schwefeldämpfe über glühende Kohlen leitet. Farblose, faulig riechende, erst bei $-116^{\circ}$ erstarrende Flüssigkeit. Stark lichtbrechend. Sdp. 470. Brennt mit blänlicher Flamme. Löst viele Stoffe, z. B. Phosphor, Schwefel, Jod, Harze. Wird zum Vulkanisieren des Kautschuk verwendet. Die Dämpfe sind sehr giftig.

Kohlenoxysulfid COS. Unangenehm riechendes Gas, brennbar.

\section{Leuchtgas.}

Wenn man Steinkohle unter Luftabschluß erhitzt, so gibt sie die in ihr noch vorhandenen flüchtigen $\mathrm{Be}-$ standteile $\mathrm{ab}$, und es bleibt nur der Kohlenstoff und 
die nicht flüchtigen Aschenbestandteile zurück. Es geschieht dies in großen Retorten. Die entweichenden Bestandteile sind:

1) Ammoniak, resp. kohlensaures Ammonium, das in verdünnten Säuren aufgefangen wird. Diese "Gas wässer" werden auf Ammoniak verarbeitet (s. d.).

2) Der Steinkohlenteer ist ein Gemenge von einer groben Anzahl mehr oder minder flüchtiger flüssiger und fester Stoffe, das in gekühlten Vorlagen aufgefangen wird. Er ist in neuerer Zeit die Fundgrube sehr vieler wichtiger Stoffe geworden, die namentlich für die Farbstofftechnik von ungeheurem Werte geworden sind, wie z. B. Benzol, Anilin, Naphtalin, Anthracen, oder zu anderen Zwecken, z. B. denen der Heilkunde dienen, wie Karbolsäure etc.

3 ) Leuchtgas, ein Gemenge verschiedener Gase, das als Stoff für Heizung und Beleuchtung große Bedentung erlangt hat. Es besteht im wesentlichen aus W asserstoff (ca. 40\%) und Grubengas $\mathrm{CH}_{4}$, dem als eigentlich leuchtende Bestandteile Äthylen $\mathrm{C}_{2} \mathrm{H}_{4}$ und Azetylen $\mathrm{C}_{2} \mathrm{H}_{2}$ beigemengt sind. Seine Giftigkeit verdankt es einer Beimengung von $5-7 \%$ Kohlenoxyd, seinen Geruch dem Azetylen.

\section{Verbrennung und Flamme.}

Eine Verbrennung im chemischen Sinne ist eine Vereinigung eines Stoffes mit Sauerstoff. Eine Verbrennung im physikalischen Sinne ist ein Proze $\beta$, der unter Wärme-und Lichtentwickelung: vor sich geht, meist mit dem Bilde einer Flamm e. Eine Flamme entwickelt sich nur dort, wo ein Gas in einem anderen verbrennt. Feste Körper verbrennen wohl unter Er$g$ lühen, aber nie mit Flamme. Reiner Kohlenstoff verbrennt ohne Flamme, da er nicht in den gasförmigen Zustand übergeht. Gewöhnliche Kohle dagegen spaltet 
beim Erwärmen, wie wir sahen, gasförmige, bremnbare Substanzen ab, die dann mit Flamme verbrennen.

Die Verbrennung von Gasen in Sauerstoff ist die häufigste Ursache der Flammenbildung. Doch ist die Verbrennung eine relative Erscheinung. Wie Wasserstoff, Kohlenoxyd, Leuchtgas in Sauerstoff verbrennen, so verbrennt Sauerstoff umgekehrt in diesen Gasen, wie sich experimentell zeigen läßt, und zwar unter Bildung einer Sauerstofflamme.

Wenn ein Gas in einem anderen brennt, ist seine Flamme meist sehr schwach leuchtend, wie z. B. die Wasserstofflamme an der Luft. Stark leuchtend ist eine Flamme nur dann, wenn sie feste, nicht vergasbare Partikelchen enthält. Diese können entweder von den strömenden Gasen mechanisch mitgefülırt sein, wie z. B. Staub usw., oder sie können sich bei dem Prozeb der Verbrennung erst bilden. Während z. B. Methan $\mathrm{CH}_{4}$ an der Luft direkt $\mathrm{zu}$ Kohlensäure und Wasser verbrennt, also nicht leuchtet, scheidet sich beim Verbrennen von Azetylen $\mathrm{C}_{2} \mathrm{H}_{2}$, das beträchtlich mehr Kohlenstoff enthält, ein Teil dieses Kohlenstoffes in festen Partikelchen in der Flamme ab, die nun beginnen zu glühen: die Flamme leuchtet. Man kann dies nachweisen, indem man in die Flamme ein kaltes Stück Porzellan oder dergl. hält: es schlägt sich schwarzer Kohlenstoff, $R u B$, auf demselben nieder.

Das Bild einer solchen Flamme, z. B. einer Stearinkerze, ist also folgendes: Das Stearin zersetzt sich an dem heißen Docht in verschiedene Kohlenwasserstoffe, u. a. Äthylen. Dies wird also verbrannt. Die entstehende Flamme läßt deutlich drei Schichten unterscheiden:

1) den Kern. Dieser besteht aus unzersetztem Gas, das, vorläufig von der Luft abgeschlossen, nicht verbrennen kann.

2) die leuchtende Schicht. In dieser geht die Zersetzung des Äthylens unter Abscheidung von Kohlenstoff vor sich, der, zur Weißglut gebracht, leuchtet. 
3) den Mantel, eine kaum sichtbare, schwach bläulich leuchtende Schicht, in der die eigentliche Verbrennung auch des Kohlenstoffs beendigt wird, weil hier genügend Luft zugeführt wird. Hier ist die heibeste Stelle der Flamme.

Genau so verhält sich z. B. die Le uch tgasfla m me. Wenn man aber das Leuchtgas vor der Verbrennung mit so viel Luft mischt, daß jedes Kohlenstoffpartikelchen, das beim Verbrennen des Athylens entsteht, sofort damit in Berührung tritt, so hört das Leuchten auf: die Flamme wird aber dadurch viel heißer. Zu diesem Zwecke dient der viel benutzte Bunsen brenner.

Andererseits gibt es zahlreiche Mittel, um einer Flanme einen möglichst großen Leuch teffekt zu verleihen. Solche Brenner, welche eine möglichst große leuchtende Fläche zu erzielen suchen, sind z. B. der Argandbrenner, der Regenerativbrenner u. a. Auf der Einführung besonders stark leuchtender Stoffe beruht das Gas gl ühlicht (s. b. Thorium). In neuester Zeit benutzt man auch das Azetylen als Leuchtquelle (s. org. Chemie).

\section{Silizium.}

Si. Atomg. 28. Vierwertig.

Vorkommen: In der Natur als Kieselsäure und kieselsaure Salze sehr weit verbreitet. Es bildet den Grundstein der anorganischen Natur, wie der Kohlenstoff den der organischen. Denn fast alle gebirgsbildenden Gesteine enthalten Silizium: Granit, Gneis, Basalt, Ton, Schiefer u. a. Auch der Sand und die Ackererde bestehen hauptsächlich aus Kieselsäure. Nur dem Kalk ist eine annähernd so wichtige Rolle zuzuschreiben. Die Kieselsäure ist in diesen Gesteinen hauptsächlich an Kalzium, Kalium und Aluminium gebunden.

Darstellung: Aus Kieselfluorkalium mit Kalium.

$$
\mathrm{K}_{2} \mathrm{SiF}_{6}+4 \mathrm{~K}=6 \mathrm{KF}+\mathrm{Si} \text {. }
$$

Hierbei erhält man es als amorphes braunes Pulver. 


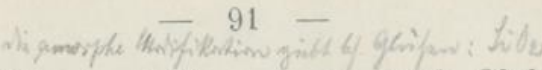

Kristallisiert erhält man es durch Glühen von Kieselfluorkalium mit Zink. Schwarze Oktaëder. Bleibt beim Glühen an der Luft unverändert, wird nicht durch Säuren angegriffen, löst sich aber in kochender Kalilauge zu Kaliumsilikat.

Siliziumwasserstoff $\mathrm{SiH}_{4}$. Ähnlich dem Methan $\mathrm{CH}_{4}$. Gas.

Silizi umehlorid $\mathrm{SiCl}_{4}$ aus Silizium und Chlor. Farblose Flüssigkeit. Ähnlich Bromid und Jodid.

Siliziumfluorid $\mathrm{SiF}_{4}$. Aus Kieselsäure $\mathrm{SiO}_{2}$ und Fluorwasserstoff HF. Gasförmig. Wiese Reaktion erklärt die Empfindlichkeit der Silikate, z. B. Glas, gegen Flußsäure.

Siliziumkarbid (Siliziumkohlenstoff, Karborundum) CSi. Ein Repräsentant einer in neuerer Zeit sehr wichtig gewordenen Klasse von Kohlenstoffverbindungen, die durch Erhitzen von Kohle mit Metalloxyden im elektrischen Ofen dargestellt werden. Das Siliziumkarbid entsteht aus Kohle und Sand bei $3500^{\circ}$. Es sind grünglänzende Kristalle von großer Widerstandsfähigkeit und Härte, die nur dem Diamanten und dem Borkarbid nachsteht; es wird deshalb als ausgezeichnetes Schleifmaterial verwendet.

Siliziumdioxyd $\mathrm{SiO}_{2}$, Kieselsäureanhydrid kommt in der Natur in mannigfachen Formen vor. Kristallisiert u. a. als: Quarz, Bergkristall ${ }^{1}$ ) (farblos), Ranchtopas (gelb), Amethyst (violett). Mikrokristallinisch u. a. als: Chalzedon, Achat, Chrysopras, Feuerstein. Amorph als Opal, Kieselsinter, Sand etc.

Ferner findet sich Kieselsäureanhydrid in den Panzern kleinster Lebewesen, der Dia to m een, die massenhafte Ablagerungen bilden (Kieselguhr, Infusorienerd e). Zur Darstellung von Dy nam it benutzt (s. org. Chemie). Auch manche höhere Pflanzen, z. B. B a mbus, häufen Kieselsäure auf, sowie ferner einige S c h wäm me

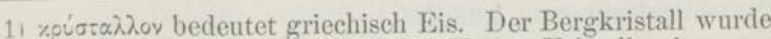
von den Griechen so genannt, und der Name „Kristall " ging von ilım aut die andern Körper über. 
(Kieselschwämme). Auch tierische Gewebe enthalten geringe Mengen Kieselsäure.

kie

Tro

Darstellung: Versetzt man kieselsaures Natrium oder Kalium mit Salzsäure, so scheidet sich eine Gallerte aus, die nach dem Trocknen ein feines Pulver darstellt und jetzt die Formel $\mathrm{H}_{2} \mathrm{SiO}_{3}$ besitzt, also eine Kieselsäure darstellt. Diese geht durch Glühen in $\mathrm{SiO}_{2}$ über. Amorphes, weißes Pulver, fast unschmelzbar. Künstlich dargestelltes $\mathrm{SiO}_{2}$ löst sich in Alkalien zu Alkalisilikat, das natürliche kristallisierte nicht.

Kieselsäure $\mathrm{Si}(\mathrm{OH})_{4}$. Eine Lösung von reiner Kieselsäure erhält man durch Dialyse einer Lösung von kieselsaurem Natrium, die überschüssige freie Salzsäure enthält. In dieser ist Kieselsäure löslich. Gießt man diese Lösung in ein Gefäß, das unten mit einem Pergamentpapier verschlossen ist, und setzt es in Wasser, so geht aus dem Gefäß (Dialysator) das Chlornatrium und die freie Salzsäure heraus und man behält eine reine Lösung von Kieselsäure. Die Salzsäure nämlich ist imstande, das Pergament zu durchdringen (Osmose), die Kieselsäure hingegen nicht.

Solche Körper, die durch Membranen zu dringen imstande sind, nannte Graham Kristalloide, die andern Kolloide. Doch sind dies relative Begriffe, die von der Art der Membran abhängen. Solche Diffusionsvorgänge spielen sowohl in der Pflanzen-, als anch in der Tierwelt eine große Rolle. Der ganze Saftkreislauf der Pflanzen ist dadurch bedingt. Auch im menschlichen Organismus spielen osmotische Vorgänge, z. B. im Darm und den Nieren, mit. Die wichtigsten Kolloide sind die Eiweißsubstanzen (s. org. Ch.).

$\operatorname{sch}$

Sie

nos

$\mathrm{Me}$

vo:

als

$\mathrm{Al}$

$\mathrm{mi}$

$\mathrm{Br}$

da

$\mathrm{Fc}$

in1

Le

E1

Wt

di

sie

di

Diese Lösung gerinnt sofort unter Abscheidung der oben genannten Gallerte, sobald man eine Spur Natriumkarbonat zusetzt.

Diese Gallerte stellt wahrscheinlich die Ortho- 
kieselsäure von der Formel $\mathrm{Si}(\mathrm{OH})_{4}$ dar. Beim Trocknen geht sie in die gewöhnliche Kieselsäure

$$
\mathrm{SiO}<\underset{\mathrm{OH}}{\mathrm{OH}}=\mathrm{H}_{2} \mathrm{SiO}_{3}
$$

über, die der Kohlensäure entspricht. Die Silika te leiten sich nur selten von der Orthokieselsäure ab, meist von der gewöhnlichen Kieselsäure $\mathrm{H}_{2} \mathrm{SiO}_{3}$, oder sie sind Abkömmlinge noch viel komplizierterer Säuren, die sich von der Orthokieselsäure durch mannigfaltige Wasserabspaltung aus mehreren Molekülen herleiten, den sog. Polykieselsäuren, z. B. $\mathrm{H}_{2} \mathrm{Si}_{2} \mathrm{O}_{5}, \mathrm{H}_{4} \mathrm{Si}_{3} \mathrm{O}_{8}$ usw.

Titan, Ti. Zirkonium, Zr. Thorium, Th.

Drei seltene Elemente, die sich an das Silizium anschließen, zu dem sie das periodische System stellt. Sie zeigen in ihren Oxydhydraten z. B. Ti $(\mathrm{OH})_{4}$ nur noch schwach sauren Charakter, nähern sich also den Metallen.

Das Thorium, das in einigen seltenen Mineralien vorkommt, hat in neuerer Zeit durch seine Anwendung als Glühkörper ungeahnte Bedeutung erlangt. Nach A uer v. Welsbach werden Baumwollstrümpfe, die mit Thoriumnitrat getränkt sind, der Flamme eines Bunsenbrenners ausgesetzt. Die Baumwolle verbrennt; das Gerüst der Thorerde behält seine feinmaschige Form und leuchtet beim Erhitzen mit ruhigem weißen, intensiven Licht. Doch muß zur Erzielung einer hohen Leuchtkraft ein Zusatz von Salzen anderer seltener Erden, besonders Cer- und Lanthansalzen, etc. gemacht werden.

Noch metallähnlicher sind die drei letzten Elemente dieser Gruppe des periodischen Systems. Wir wollen sie deshalb auch bei den Metallen behandeln. Es sind dies Germanium, Zinn, Blei.

\section{Übergang zu den Metallen.}

Nur die beiden ersten Gruppen des periodischen Systems, die Gruppe der Alkalimetalle und die der alkalischen Erden, sind rein metallischer Natur. Die 
übrigen Gruppen zeigen die Eigentümlichkeit, daß ihre niederen Glieder Metalloide sind, während die Elemente mit höherem Atomgewicht immer mehr metallischen Charakter tragen. Thre Verwandtschaft mit den Metalloiden zeigt sich dann nur noch darin, daß ihre höheren Sau ers to ffverbindungen Säuren bilden, die den Säuren der Metalloide derselben Gruppe analog sind. So findet sich in der siebenten Gruppe neben den Halogenen das Mangan, das als siebenwertiges Element eine Säure, die Übermang a n säure $\mathrm{HMnO}_{4}$ bildet, die der Überch lors äure $\mathrm{HClO}_{4}$ analog ist. Zur Schwefelgruppe gehören die Elemente Chrom, Wolfram, Molybdän, welche der Schwefelsäure analoge Säuren, die Chromsäure $\mathrm{H}_{2} \mathrm{CrO}_{4}$, Wolframsäure, Molybdänsäure bilden. An die Kohlenstoff-Siliziumgruppe schließen sich Zinn und Blei, die in der Zinnsäure und Bleisäure der Kohlensäure resp. Kieselsäure $\mathrm{H}_{2} \mathrm{SiO}_{3}$ analoge Säuren bilden. Zur Stickstoffgruppe gehört in ähnlicher Weise das Wismut. Doch sind andererseits die Eigenschaften der Elemente selbst, sowie die ihrer niederen Sauerstoffverbindungen ganz metallisch, so daß wir alle diese Elemente bei den Metallen abhandeln wollen. In der sonst ganz metallischen dritten Gruppe ist nur das Anfangsglied, das Bor, noch von nichtmetallischer Natur, doch auch schon in abgeschwächter Form, so daß es gewissermaßen einen Übergang zu den Metallen bildet. Es bildet zwar noch eine, wenn auch sehr unbeständige Wasserstoffverbindung; sein Chlorid ist durch Wasser zersetzlich Eigenschaften nichtmetallischer Natur; - doch nähert es sich auch in mancher Beziehung den Metallen, namentlich dem Aluminium, dadurch, daß sein Oxyd sowohl als Base, wie als Säure auftreten kann. Es möge deshalb gesondert besprochen werden.

\section{Bor}

B. Atomg. 11.

Vorkommen: In der Natur als Borsäure und deren Salze: Borax (borsaures Natrium). 


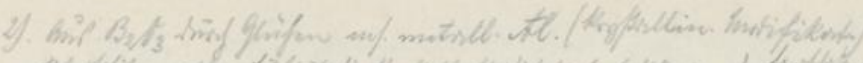

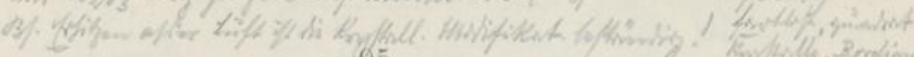 - $95-$}

$33^{32 / 3}$

Darstellung: Aus(Borsäure) durch Glühen mit Magne-

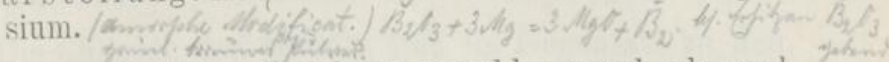

Eigenschaften: Bor kann sowohl amorph als auch kristallisiert erhalten werden. Die Borkristalle sind dem Diamanten sehr ähnlich, namentlich an Härte. Bor ist sehr beständig gegen chemische Einwirkungen, doch ist er eines der wenigen Elemente, die sich direkt mit Stickstoff verbinden, zu Bor sti ckst off BN.

Borwasserstoff $\mathrm{BH}_{3}$. Unangenehm riechendes Gas, unbeständig.

Borchlorid $\mathrm{BCl}_{3}$ aus Bor und Chlor. Farblose Flüssigkeit, durch Wasser zersetzt in Borsäure und Chlorwasserstoff.

$$
\mathrm{BCl}_{3}+3 \mathrm{H}_{2} \mathrm{O}=\mathrm{B}(\mathrm{OH})_{3}+3 \mathrm{HCl} \text {. }
$$

$\mathrm{B}(\mathrm{OH})_{3}$ kommt in einigen heißen $\mathrm{Quellen}$ frei vor. Fumarolen sind Wasserdämpfe, die in $/ \mathrm{G}_{2} \mathrm{H}_{2} \mathrm{~B}_{y} \mathrm{Cl}_{2}$ vulkanischen Gegenden aus der Erde strömen. Diese Dämpfe, welche Borsäure mitführen, werden dann in flache Becken mit Wasser (Lagoni) geleitet; aus

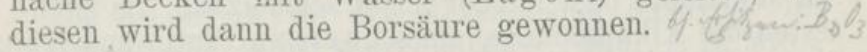

Darstellung: Aus Borax durch Salpetersäure.

Eigensch aften: Farblose Schüppchen, ziemlich leicht löslich in Wasser und Alkohol. Eine alkoholische Borsäurelösung brennt mit grüngesäumter Flamme. (Nachweis.) Leichtes Antisepticum. Die Salze der normalen Borsäure sind nicht bekannt. Der Borax leitet sich von einer anhydrierten Säure (Tetraborsäure oder Pyroborsäure) $\mathrm{H}_{2} \mathrm{~B}_{4} \mathrm{O}_{7}$ ab.

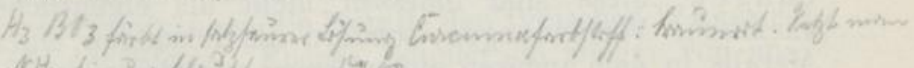

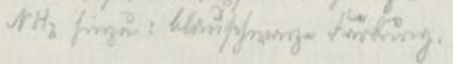

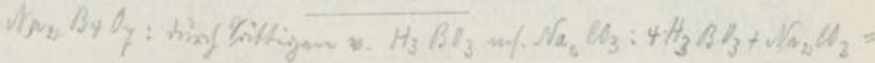

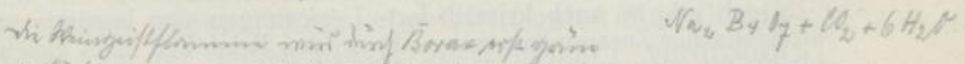

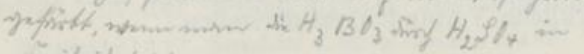

$$
\begin{aligned}
& \text { viniffit parte. }
\end{aligned}
$$




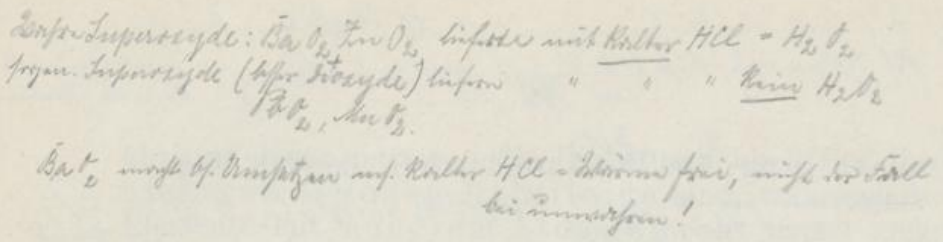

\section{B. Metalle.}

Die Metalle sind durch eine Reihe physika lischer und chemischer Eigenschaften charakterisiert. Sie sind mit Ausnahme des Quecksilbers feste Körper, während wir unter den Nichtmetallen alle drei Aggregatzustände vertreten finden. Sie zeigen meist eine weibgraue Farbe (außer Kupfer und Gold), den sog. Metallglanz, und sind gute Leiter für Wärme und Elektrizität.

Sie sind meist dehnbar und zähe. Nur die den Metalloiden noch nahe stehen, z. B. Zinn, sind spröde. Sie sind mehr oder minder leicht schmelzbar, am leichtesten die Alkalimetalle, am schwersten Platin und Iridium. Die leicht schmelzbaren Metalle sind auch leicht zu verflüchtigen, so siedet z. B. Kalium bei 6600 . Sie zeigen ein sehr verschiedenes spez. Gewicht. Das leichteste aller Metalle ist das Lithium: spez. Gewicht 0,59 ; das schwerste das Osmium: spez. Gewicht 22,5. Das chemische Verhalten der Metalle läßt sich durch folgende Hauptsätze illustrieren:

Die Metalle bilden zunächst unter sich sog. Le gierungen; diese sind indessen nicht als eigentliche chemische Verbindungen, sondern als Lösungen eines Metalls in dem anderen aufzufassen; man kann solche Legierungen in jedem beliebigen Mengenverhältnisse darstellen.

Doch gibt es auch kristallisierte Legierungen von bestimmter atomistischer Zusammensetzung, die in den Kristallen stets gleich bleibt, die also wirkliche Verbindungen darstellen. 
Legierungen mit Quecksilber nennt man Amalgame.

Die Chloride der Metalle sind im Gegensatz zu den Metalloidchloriden gegen Wasser beständig. Die Metalle bilden meist keine Wasserstoffverbindungen, wie dies alle Nichtmetalle tun.

Die Verbindungen des Sauerstoffs mit den Metallen sind mehr oder weniger basenbildender Natur, während die der Nichtmetalle säurebildend sind. Die Oxyde der Alkalimetalle und der alkalischen Erden zersetzen das Wasser unter Bildung von Hydroxyden oder Hydraten. Die meisten Metalloxyde zersetzen das Wasser in der Kälte nicht, indessen sind ihre Hydrate auf andere Weise, nämlich durch Fällen der Salze mit Kalilauge erhältlich, z. B.:

$$
\mathrm{FeCl}_{3}+3 \mathrm{KOH}=\mathrm{Fe}(\mathrm{OH})_{3}+3 \mathrm{KCl} .
$$

Einige Metalle haben kein e Hydroxyde, z.B. Silber, Gold. Diese vereinigen sich auch nicht direkt mit Sauerstoff. Man nennt sie wegen ihrer Beständigkeit gegen atmosphärische Einflüsse Edelm etalle.

Die Superoxyde der Metalle sind entweder indifferenter oder selbst säurebildender Natur, z. B. $\mathrm{MnO}_{3}$ Mangansäureanhydrid:

$$
\mathrm{MnO}_{3}+2 \mathrm{KOH}=\underset{\text { Mangans. Kali. }}{\mathrm{K}_{2} \mathrm{MnO}_{4}}
$$

Die Hydroxyde der Metalle sind Basen und geben mit Säuren Salze. Diese Salze entstehen auch, indem man die Metalle in den entsprechenden Säuren auflöst. Die meisten Metalle sind in Salpetersäure löslich, schon weniger in Salzsäure und Schwefelsäure. Hierbei verdrängen die Metalle den typischen Wasserstoff der Säure. Ebenso können sie wieder von anderen Metallen verdrängt werden. So scheidet Eisen oder Zink das Kupfer aus seinen Salzen aus, indem es sich an seine Stelle setzt, Kupfer wieder das Silber etc. Man kann folgende Reihe der wichtigsten Metalle aufstellen, in der jedes Metall die folgende I verdrängt:

Oppenheimer, Grundriss d. anorg. Chemie, 4. Anfl.

7 


\section{$-98-$}

$\mathrm{K} \mathrm{Fe} \mathrm{Zn} \mathrm{Sn} \mathrm{Pb} \mathrm{Cu} \mathrm{Hg} \mathrm{Ag} \mathrm{Pt} \mathrm{Au.}$

Kalium verdrängt also alle anderen Metalle aus ihren Lösungen.

Die Salze reagieren gewöhnlich neutral auf Lakmuspapier. Sie zeigen verschiedene Löslichkeitsverhältnisse. Die kohlensauren Salze (Karbonate) sind meist unlöslich (außer denen der Alkalimetalle); die Nitrate stets löslich, Chloride und Sulfate meist. Die Salze kristallisieren häufig unter Bindung von Wasser, das sie erst beim Erhitzen oder beim Liegenlassen an der Luft abgeben (Kristallwasser). Natriumkarbonat z. B. mit 10 Mol. Wasser. Man schreibt dies:

$$
\mathrm{Na}_{2} \mathrm{CO}_{3}+10 \mathrm{H}_{2} \mathrm{O} \text {. }
$$

Dies Wasser ist so fest gebunden, daß die Salze scheinbar trocken sind, erst beim Erwärmen werden sie feucht. Das Abgeben des Kristallwassers nennt man verwittern. 
ren

us-

ise.

in-

te

lze

las

ler

lat

in-

sie

an

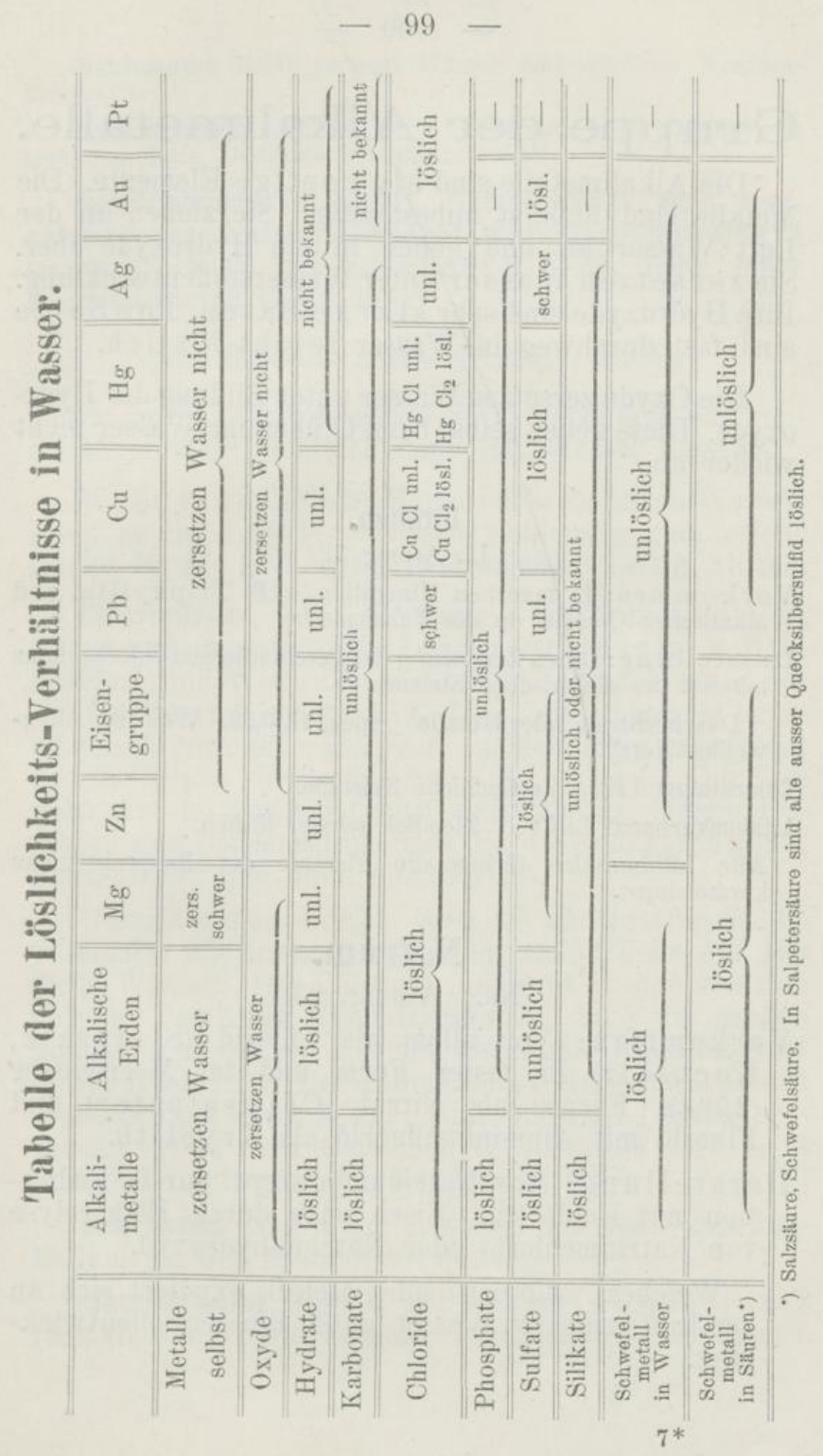




\section{Gruppe der Alkalimetalle.}

Die Alkalimetalle sind einw ertige Elemente. Die Metalle sind äußerst unbeständig. Sie ziehen an der Luft Wasser an und gehen in die Hydroxyde über. Sie zersetzen Wasser unter Wasserstoffentwicklung. Thre Hydroxyde sind sehr starke Basen. Thre Salze sind fast durchweg in Wasser leicht löslich.

Die Oxyde zersetzen Wasser unter Bildung der Hydroxyde. Diese geben selbst beim Glühen ihr Wasser nicht wieder ab.

\section{Lithium. \\ Li. Atomg. 7.}

Vorkommen: In manchen Mineralien, z. B. Triphyllin, und alkalischen Quellen; in der Tabaksasche.

D arstell u ng: Durch Zersetzung des geschmolzenen Chlorlithiums mittelst des elektrischen Stromes.

Das leichteste aller Metalle. Spez. G. 0,59. Weiches, silberweißes Metall.

Chlorlithium LiCl. Zerfließliche Kristalle.

Lithiumkarbonat $\mathrm{Li}_{2} \mathrm{CO}_{3}$. Ziemlich schwer löslich.

Alle Lithiumsalze färben die Flamme des Bunsenbrenners karmoisinrot.

\section{Natrum.}

\section{Na. Atomg. 23.}

Vorkommen: Vor allem als Chlorid (Steinsalz, Kochsalz) in fester Form und im Meerwasser $(2,7 \%)$. Ferner als Nitrat (Chilisalpeter) und Fluorid mit Aluminiumfluorid als Kryolith.

Darstellung: Ans Natriumhydroxyd durch Reduktion mit Kohle und Eisen oder durch Elektrolyse von Natriumchlorid oder Natriumhydroxyd.

Weiches, weißglänzendes Metall, oxydiert sich an der Luft, zersetzt Wasser unter Wasserstoffentwicklung. 
Natriumoxyd $\mathrm{Na}_{2} \mathrm{O}$ zersetzt Wasser und wird zu Natriumhydroxyd.

Natriumperoxyd $\mathrm{Na}_{2} \mathrm{O}_{2}$ durch Erhitzen von Natrium an trockener Luft. Kräftiges Oxydationsmittel.

Natriumhydroxyd NaOH, Natronhydrat oder Aetznatron, aus Natriumkarbonat und Kalziumhydroxyd (eventuell auch mit Eisenoxyd $\mathrm{Fe}_{2} \mathrm{O}_{3}$ nach einer komplizierteren Gleichung).

$$
\mathrm{Na}_{2} \mathrm{CO}_{3}+\mathrm{Ca}(\mathrm{OH})_{2}=2 \mathrm{NaOH}+\mathrm{CaCO}_{3}
$$

ferner durch Elektrolyse von $\mathrm{NaCl}$, wobei erst Natriummetall entsteht, das sich dann mit Wasser umsetzt.

Weiße, kristallinische Masse, leicht löslich in Wasser. Zieht an der Luft Wasser und Kohlensäure an. Sehr starke Base. In Lösung (Natronlauge) heftig ätzend.

Chlornatrium, NaCl, Kochsalz. Im Meerwasser (ca. $2,7^{\circ} \%$ ) und in gewaltigen Lagern (Steinsalz) z. B. in Staßfurt und Wieliczka in Galizien. Das Wasser des „Toten Meeres" enthält 270\% NaCl. Wird sowohl bergmännisch gewonnen, als auch aus dem Meerwasser und den natürlich vorkommenden Solquellen. Die Sole wird erst in den sog. Gradierhäusern, langen Gerüsten aus Dornenreisig, über die die Sole herabtropft, konzentriert und dann eingedampft.

Glasglänzende Würfel. Ziemlich gleichmäßig löslich in heißem wie in kaltem Wasser, ca. 36 Teile auf 100 Teile Wasser. Das Chlornatrium wird in der chemischen Technik (Sodafabrikation etc.) in großen Mengen verwendet. Für den tierischen Organismus ist es unentbehrlich. Der Jahresbedarf eines erwachsenen Nenschen ist etwa $8 \mathrm{~kg}$. Eine $0,9 \%$ ige Lösung entspricht etwa den tierischen Gewebsäften und heißt „physiologische Kochsalzlösung“.

Jodnatrium NaJ wird zuweilen an Stelle des Jodkaliums in der Medizin verwendet.

Natriumsulfat $\mathrm{Na}_{2} \mathrm{SO}_{4}$ ist das sog. Glaubersalz (mit $10 \mathrm{Mol}$. Kristallwasser). In vielen Mineralwässern. 
Entsteht als Nebenprodukt bei dem Leblancschen Sodaprozeb.

$\mathrm{mi}$

Läßt man eine bei $33^{\circ}$ gesättigte Lösung von Glaubersalz sich abkühlen, so scheidet sich nichts aus, so lange die Flüssigkeit in Ruhe bleibt. Sobald man aber einen festen Körper in die Lösung taucht, scheidet sich plötzlich ein fester Brei von Glaubersalz $a b$. Eine solche Lösung, die mehr von einem Salz enthält, als eigentlich möglich ist, nennt man eine üb ersättigte Lösung. Solche bilden auch andere Salze

Natriumthiosulfat, unterschwefligsaures Natron, $\mathrm{Na}_{2} \mathrm{~S}_{2} \mathrm{O}_{3}$, aus schwefligsaurem Natrium $\mathrm{Na}_{2} \mathrm{SO}_{3}$ durch Kochen mit Schwefel. Löst Chlor- und Bromsilber und findet deshalb in der Photographie Anwendung.

Whe $\mathrm{CO}_{3}+10 \mathrm{n}$ Natriumkarbonat, Soda $\mathrm{Na}_{2} \mathrm{CO}_{3}$. Kommt in der Natur in einigen Gegenden vor, z. B. in Ägypten, wo 37. num es Tro-Na heißt; und im Wasser einiger "Salzseen" asche, namentlich von Seepflanzen, z. B. Algen und Tangen (V arec in der Normandie, Kelp in England).

Darstellung: Außer den obengenannten Quellen für die Sodabereitung existieren heute drei wichtige Methoden:

\section{Der Leblancsche Sodaprozess.}

1) Chlornatrium wird mittelst Schwefelsäure in Natriumsulfat übergeführt:

$$
2 \mathrm{NaCl}+\mathrm{H}_{2} \mathrm{SO}_{4}=\mathrm{Na}_{2} \mathrm{SO}_{4}+2 \mathrm{HCl} \text {. }
$$

2) Das Natriumsulfat wird in Öfen mit Kalziumkarbonat (Kreide) und Kohle geglüht. Der Prozeß verläuft in zwei Phasen:

a) Die Kohle reduziert das Natriumsulfat zu Natriumsulfid :

$$
\mathrm{Na}_{2} \mathrm{SO}_{4}+2 \mathrm{C}=\mathrm{Na}_{2} \mathrm{~S}+2 \mathrm{CO}_{2} .
$$

b) Dies setzt sich mit Kalziumkarbonat zu Kalziumsulfid und Natriumkarbonat um:

$$
\mathrm{CaCO}_{3}+\mathrm{Na}_{2} \mathrm{~S}=\mathrm{CaS}+\mathrm{Na}_{2} \mathrm{CO}_{3} .
$$




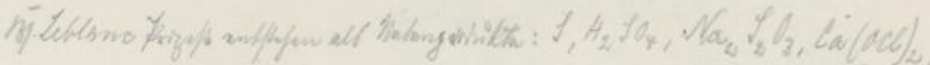 $-103-$

Das Natriumkarbonat wird aus der Schmelzmasse mit kaltem Wasser ausgelaugt und gereinigt. Es enthält immer etwas Atznatron. Das Kalziumsulfid wird auf Schwefel verarbeitet.

\section{Der Ammoniak-Soda (Solvay-)Prozess.}

In eine konzentrierte, mit Ammoniak gesättigte Kochsalzlösung wird Kohlendioxyd eingeleitet, das aus kohlensaurem Kalk durch Glühen gewonnen wird. Es entsteht AAmmoniumkarbonat, das sich sofort mit dem Kochsalz zu Ammoniumchlorid und saurem Natriumkarbonat umsetzt, das schwer löslich ist und ausfällt.

$$
\mathrm{NaCl}+\mathrm{NH}_{3}+\mathrm{CO}_{2}+\mathrm{H}_{2} \mathrm{O}=\mathrm{NaHCO}_{3}+\mathrm{NH}_{4} \mathrm{Cl} \text {. }
$$

Das saure Natriumkarbonat gibt beim Erhitzen Kohlendioxyd ab und geht in Soda über:

$$
2 \mathrm{NaHCO}_{3}=\mathrm{Na}_{2} \mathrm{CO}_{3}+\mathrm{CO}_{2}+\mathrm{H}_{2} \mathrm{O} \text {. }
$$

Das Kohlendioxyd wird wieder in den Betrieb zurückgeführt. Das Ammoniumchlorid wird durch Erhitzen mit gelöschtem Kalk in Ammoniak zurückgeführt,

$$
2 \mathrm{NH}_{4} \mathrm{Cl}+\mathrm{Ca}(\mathrm{OH})_{2}=\mathrm{CaCl}_{2}+2 \mathrm{NH}_{3}+2 \mathrm{H}_{2} \mathrm{O},
$$

das wieder in eine Kochsalzlösung eingeleitet wird. So sind die eigentliche Rohstoffe die denkbar billigsten: Kochsalz und kohlensaurer Kalk. Das Ammoniak wird stets regeneriert. Als Nebenprodukt entsteht Chlorkalzium. Der Solvayprozeß hat den Leblancschen schon zum größten Teil verdrängt.

\section{Der elektrolytische Prozess.}

Durch Elektrolyse einer wässerigen Kochsalzlösung entsteht an dem einen Pol Chlor, an dem andern $\mathrm{Na}-$ trium, das sich mit Wasser sofort in Ätznatron umwandelt. Beide Pole müssen durch eine poröse Scheidewand voneinander getrennt sein. Man gewinnt dabei Wasserstoff, Chlor und Ätznatron, das leicht durch Einleiten von Kohlendioxyd in Soda überführbar ist.

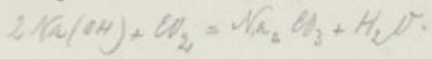




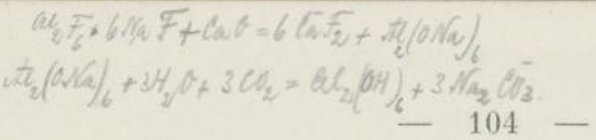

एా: Auch aus dem grönländischen Mineral Kryolith (s. o.) wird durch einen komplizierten Prozeb Soda darstellt. Diese Darstellung hat dort, wo der Kryolith häufig ist, z. B. in Amerika, ebenfalls eine große Bedeutung.

Saures Natriumkarbonat, doppelkohlensaures Natron $\mathrm{NaHCO}_{3}$. Wird in der Medizin verwendet (gegen Sod-

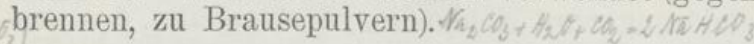

Natriumnitrat, Chilisalpeter findet sich in großen Lagern in Chile. Es dient hauptsächlich zur Darstellung. des Kalisalpeters und als Düngermittel.

Natriumphosphate. Es gibt drei:

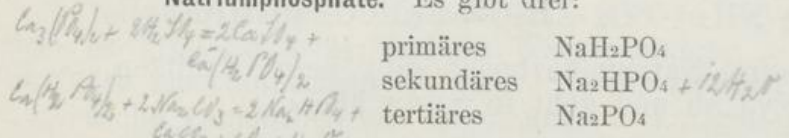

Das sekundäre ist das beständigste. Sie entstehen alle drei aus Phosphorsäure und Natronlange.

Natriumborat, borsaures Natrium. Es gibt mehrere, unter denen das wichtigste der Borax ist: $\mathrm{Na}_{2} \mathrm{~B}_{4} \mathrm{O}_{7}+$ $10 \mathrm{H}_{2} \mathrm{O}$. Findet sich. in Tibet in einigen Seen. Wird jetzt aus Borsäure und Natriumkarbonat hergestellt. Weiße Kristalle, leicht löslich in Wasser. Leichtes Desinfektionsmittel. Bläht sich beim Erhitzen stark auf und schmilzt zu einer glasartigen Masse. Diese löst beim Schmelzen viele Metalloxyde mit charakteristischen Farben (Boraxperle).

Natriumsilikat, kieselsaures Natron. Glasähnliche Masse, löslich in Wasser/(Natronwasserglas), s. b. Ka-

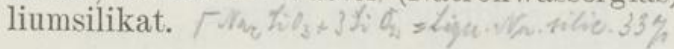

Nachweis: Alle Natriumverbindungen färben die Flamme intensiv gelb.

Das einzige in Wasser schwerlösliche Na-Salz, das mithin zum Nachweis verwendet werden kann, ist das Dinatriumpyroantimoniat $\mathrm{Sb}_{2} \mathrm{O}_{7} \mathrm{H}_{2} \mathrm{Na}+6 \mathrm{H}_{2} \mathrm{O}$. Bei Zusatz des entsprechenden löslichen Kaliumsalzes zu Natriumsalzlösungen entsteht der unlösliche Niederschlag. 


\section{Kalium.}

K. Atomg. 39.

Vorkommen: Sehr verbreitet, namentlich als Silikat (Feldspat, Glimmer). Chlorkalium in Staßfurt. Ein wichtiger Bestandteil der Pflanzenasche ist Kaliumkarbonat.

Historisches: Zuerst von Davy 1807 dargestellt.

Darstellung: Durch Glühen eines Gemisches von Kaliumkarbonat mit Kohle.

$$
\mathrm{K}_{2} \mathrm{CO}_{3}+2 \mathrm{C}=\mathrm{K}_{2}+3 \mathrm{CO} .
$$

Ein inniges Gemisch dieser beiden Stoffe erhält man am besten durch Erhitzen von weinsaurem Kalium (Weinstein).

Eigenschaften: Silberweißes Metall von wachsweicher Konsistenz. Schmilzt bei $62^{\circ}$.

Chemisches Verhalten: Wird an der Luft durch Oxydation matt. Zersetzt Wasser unter Bildung von Wasserstoff und so lebhafter Wärmeentwicklung, daß der Wasserstoff sich entzündet. Muß deshalb unter sauerstofffreien Flüssigkeiten, z. B. Petroleum aufbewahrt werden. Verbindet sich sehr energisch mit Chlor.

Kaliumoxyd $K_{2} O$. Durch Oxydation von Kalium an trockener Luft. Weiße Masse, die sich mit Wasser lebhaft verbindet. Kaliumperoxyd $\mathrm{K}_{2} \mathrm{O}_{2}$ und Kaliumsuboxyd $\mathrm{K}_{4} \mathrm{O}$. Sehr unbeständig.

Kaliumhydroxyd KOH, Kalihydrat oder Aetzkali (Kali causticum), entsteht durch Einwirkung von Wasser auf Kalium oder Kaliumoxyd.

Darstellung: Aus Kaliumkarbonat mit Kalziumhydroxyd (gelöschtem Kalk):

$$
\mathrm{K}_{2} \mathrm{CO}_{3}+\mathrm{Ca}(\mathrm{OH})_{2}=2 \mathrm{KOH}+\mathrm{CaCO}_{3},
$$

auch durch Elektrolyse von $\mathrm{KCl}$, (vgl. bei $\mathrm{NaOH}$ ). Weiße, kristallinische, zerfließliche Masse, die im Handel meist in Stangenform gegossen vorkommt. Sehr starke Base. Leicht löslich in Wasser und 
Alkohol. Seine Lösung, die Kalilauge, wirkt heftig ätzend. Zerstört viele organische Stoffe, z. B. Papier.

Kaliumchlorid (Kalium chloratum) $\mathrm{KCl}$ kommt in den Stabfurter Lagern als Sylvin oder mit Chlormagnesium als Carnallit vor. Wichtige Düngerstoffe, auch sonst im Großbetrieb vielfach verwendet. Glasglänzende Würfel.

Kaliumbromid KBr. Wichtiges Arzneimittel (gegen Schlaflosigkeit und Nervosität).

Kaliumjodid KJ. Weiße Würfel. Seine Lösung löst Jod (Lugolsche Lösung). Findet Verwendung in der Photographie und Medizin (z. B. gegen Spätformen der Syphilis).

Cyankalium KCN (blausaures Kalium), aus Kalilauge und Blausäure HCN oder durch Erhitzen von gelbem Blutlaugensalz dargestellt. Riecht nach Blausäure, ist ungemein giftig. Findet in der Photographie, sowie in der Galvanoplastik Anwendung, da es mit Schwermetallcyaniden leicht lösliche Doppelsalze bildet.

Chlorsaures Kalium, Kaliumchlorat, (Kali chloricum) $\mathrm{KClO}_{3}$. Durch Einleiten von Chlor in heiße konzentrierte Kalilauge. Gibt beim Erhitzen Sauerstoff ab, indem es in Chlorkalium und überchlorsaures Kali $\mathrm{KClO}_{4}$ zerfällt. Dies gibt bei stärkerem Erhitzen auch seinen Sauerstoff ab. Gibt mit Salzsäure Chlor (Oxydation der Salzsäure).

$$
\mathrm{KClO}_{3}+6 \mathrm{HCl}=\mathrm{KCl}+3 \mathrm{H}_{2} \mathrm{O}+3 \mathrm{Cl}_{2} .
$$

Es wird in der Medizin (als Gurgelwasser), zu Zündhölzern und in der Fenerwerkerei verwendet.

Unterchlorigsaures Kali KClO. Aus Chlor und kalter Kalilauge; ist in dem so dargestellten Eau de Javelle enthalten, das als Fleckenwasser dient.

Kaliumsulfat $\mathrm{K}_{2} \mathrm{SO}_{4}$

Saures Kaliumsulfat $\mathrm{KHSO}_{4}$ \}aus Chlorkalium mit 
Kaliumnitrat, Salpeter $\mathrm{KNO}_{3}$ (Kal.nitricum). Wittert an einigen Stellen aus der Erde. Wird gewonnen aus tierischen Abfällen, die, mit Holzasche und Kalk gemengt, sich selbst überlassen bleiben, wobei mit Hilfe gewisser Bakterien der Stickstoff oxydiert wird (Salpeterplantagen). Jetzt meist aus Chilisalpeter (Natriumnitrat) und Chlorkalium:

$$
\mathrm{NaNO}_{3}+\mathrm{KCl}=\mathrm{KNO}_{3}+\mathrm{NaCl}
$$

Es werden kochende gesättigte Lösungen beider Salze zueinander gegossen. Dann scheidet sich sofort das in der Hitze am schwersten lösliche $\mathrm{NaCl}$ aus. Beim Erkalten ist das $\mathrm{KNO}_{3}$ am wenigsten löslich, scheidet sich also ab. Große Prismen. Gibt leicht Sauerstoff ab. Kohle mit Salpeter erhitzt, verbrennt mit heller Flamme: Verwendung hauptsächlich als Düngermittel, zu Schiesspulver. Das Schießpulver ist ein Gemisch von $75 \%$ Salpeter, $12 \%$ Schwefel und $13^{\circ}{ }_{0}$ Kohle. Dies Gemisch entspricht nahezu der Formel

$$
2 \mathrm{KNO}_{3}+\mathrm{S}+3 \mathrm{C}
$$

und der Reaktion, die beim Entzünden eintritt:

$$
2 \mathrm{KNO}_{3}+\mathrm{S}+3 \mathrm{C}=\mathrm{K}_{2} \mathrm{~S}+3 \mathrm{CO}_{2}+\mathrm{N}_{2} .
$$

Die Explosion beruht also auf einer plötzlichen Entwickelung von Kohlensäure und Stickstoff.

Kaliumkarbonat, $\mathrm{K}_{2} \mathrm{CO}_{3}$, gewöhnlich Pottasche genannt, ist ein Bestandteil der Pflanzenasche, namentlich der der Runkelrüben. Wird daraus durch umständliche Reinigungsprozesse gewonnen. Heute fast ausschließlich aus Chlorkalium dargestellt (zum Teil nach dem Leblancschen Verfahren s. Soda). Chemisch rein durch Glühen von Weinstein.

Weißes, körniges Pulver. Verwendung in der Glasfabrikation.

Kaliumsilikat, Kaliwasserglas, durch Auflösung von Kieselsäure in Kalilauge. Glasartige, in Wasser lösliche Masse. Verwendet in der Medizin zu fixierenden 
Verbänden, zum Imprägnieren feuergefährlicher Stoffe, zum Fixieren von Farben.

Kaliumsulf hydrat KSH aus Kalilauge und Schwefelwasserstoff. Farblose, basisch reagierende, zerfließliche Kristalle. Kohle:

Kaliumsulfid $\mathrm{K}_{2} \mathrm{~S}$ durch Reduktion von Kaliumsulfat mit

$$
\mathrm{K}_{2} \mathrm{SO}_{4}+2 \mathrm{C}=\mathrm{K}_{2} \mathrm{~S}+2 \mathrm{CO}_{2} .
$$

Kocht man Kaliumsulfid mit Schwefel, so entsteht ein Gemenge von Polysulfiden, die sich mit Säuren unter Abscheidung von sehr fein verteiltem Schwefel (Schwefelmilch, Lac sulfuris, (Sulfur praecipitatum) zersetzen, der in der Medizin zu Salben verwendet wird. Ähnlich ist die, auch auf ähnliche Weise verwendete, Schwefelleber (Hepar sulfuris)

Nachwe is von Kalium: Weinsäure fällt aus Kaliumverbindungen in konzentrierter Lözung saures weinsaures Kali; Platinchlorid fällt Kaliumplatinchlorid. Sie färben die Flamme violett.

Rubidium Rb und Caesum Cs sind zwei seltene Elemente, die in jeder Beziehung dem Kalium gleichen. Sie wurden mit Hilfe der Spektralanalyse von Bunsen und Kirch hoff entdeckt. Ihre Salze kommen in vielen Quellen, doch stets in sehr geringer Menge vor.

\section{Ammoniumverbindungen.}

An die Alkalimetalle schließt man gewöhnlich die Besprechung der Salze, die sich von dem Radikal $\mathrm{NH}_{4}$, dem Ammonium, ableiten, das sich wie ein Alkalimetall verhält. Es bildet sogar ein Amalgam mit Quecksilber, das dem Natriumamalgam sehr ähnlich ist, das Ammoniumamalgam.

Chiorammonium $\mathrm{NH}_{4} \mathrm{Cl}$, Salmiak. Aus den Ammo(int wh niak enthaltenden Gaswässern durch Sättigung

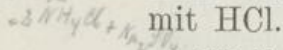

Weiße Würfel. Zersetzt sich beim Erhitzen in $\mathrm{NH}_{3}$ und $\mathrm{HCl}$, die sich beim Abkühlen wieder vereinigen.

Ammoniumsulfat $\left(\mathrm{NH}_{4}\right)_{2} \mathrm{SO}_{4}$ aus den Gaswässern mit Schwefelsäure.

Ammoniumnitrat $\left(\mathrm{NH}_{4}\right) \mathrm{NO}_{3}$ zerfällt beim Erhitzen in Stickoxydul und Wasser (s. S. 70).

Ammoniumnitrit $\left(\mathrm{NH}_{4}\right) \mathrm{NO}_{2}$ kommt in minimalen Mengen in 
der Atmosphäre vor. Spaltet sich beim Erhitzen in Stickstoff und Wasser.

Ammoniumkarbonat $\left(\mathrm{NH}_{4}\right) \mathrm{HCO}_{3}$ ist das sog. $\mathrm{Hirsch}$ hornsalz, das durch trockene Destillation von Knochen etc. dargestellt wurde. Jetzt stellt man es durch Erhitzen von Salmiak mit Kalziumkarbonat her. Weiße Masse.

Ammoniumsulfid $\left(\mathrm{NH}_{i}\right)_{2} \mathrm{~S}$, und

Ammoniumsulfhydrat $\left(\mathrm{NH}_{4}\right) \mathrm{HS}$ entstehen aus Ammoniak und $\mathrm{H}_{2} \mathrm{~S}$; sie werden in der analytischen Chemie verwendet.

Nachweis: Ammoniumverbindungen geben beim Kochen mit Kalilauge den charakteristischen Geruch des Ammoniaks.

\section{Alkaiische Erdmetalle.}

Kalzium, Strontium, Baryum. Zweiwertig.

Die Metalle zersetzen Wasser. Die Oxyde gehen durch Wasser in die $\mathrm{Hydroxyde} \mathrm{über.} \mathrm{Doch}$ geben diese beim Erhitzen ihr Wasser wieder ab. Von den Salzen sind die Karbonate, Phosphate und Silikate unlöslich. Die Sulfate sehr schwer oder auch unlöslich.

\section{Kalzium.}

\section{Ca. Atomg. 40.}

Vorkommen: Sehr weit verbreitet, namentlich als Karbonat (Kalkstein, Kreide), Sulfat (Gips), Fluorid (Flußspat).

Darstellung: Elektrolyse von geschmolzenem Chlorkalzium.

Gelbes, glänzendes Metall. An trockener Luft ziemlich beständig; an feuchter Luft oder durch Wasser zersetzt es sich schnell.

Kalziumoxyd CaO, gebrannter Kalk, wird aus dem Karbonat (Kalkstein, Marmor etc.) durch 
Glühen in Öfen gewonnen. Grauweiße Masse, schmilzt erst bei ca. $3000^{\circ}$.

Kalziumhydroxyd $\mathrm{Ca}(\mathrm{OH})_{2}$, gelöschter $\mathrm{Kalk}$, entsteht aus dem gebrannten Kalk unter starker Wärmeentwickelung, wenn man ihn mit Wasser anrührt (löscht). Er mischt sich mit wenig Wasser zu einem Brei (Kalkmilch) und löst sich in viel Wasser $(1: 760)$ zu Kalkwasser. Zieht an der Luft Kohlensäure an. In der Rotglut gibt er sein Wasser wieder ab.

Enthielt der Kalkstein viel andere Beimengungen, namentlich Ton, so ist der daraus gebrannte Kalk weniger wertvoll, er löscht sich nur teilweise und heißt magerer Kalk, der bessere, reinere fetter Kalk.

Mörtel ist ein breiiges Gemenge von Kalk, Wasser und feinem Sand. Es wird zum Verbinden von Ziegelsteinen verwendet. Sein Hartwerden beruht darauf, daß das in ihm enthaltene Kalziumhydroxyd zunächst aus der Luft Kohlendioxyd anzieht und zu Kalziumkarbonat wird. Dabei gibt es Wasser ab:

$$
\mathrm{Ca}(\mathrm{OH})_{2}+\mathrm{CO}_{2}=\mathrm{CaCO}_{3}+\mathrm{H}_{2} \mathrm{O} \text {. }
$$

(Feuchtigkeit von Neubauten; Beschleunigung des Trockenprozesses durch künstliche Zuführung von $\mathrm{CO}_{2}$ mittelst brennender Koakskörbe.) Im Laufe der Jahre verdrängt nun die Kieselsäure des Sandes die Kohlensäure, und es entsteht sehr fester kies sels a u r er Kalk.

Zement wird durch Brennen eines Gemenges von Kreide oder Kalkstein mit Sand und Ton (Aluminiumsilikat) gewonnen. Diese Masse erhärtet sehr rasch beim Anrühren mit Wasser und wird von diesem nicht angegriffen, wird deshalb bei Wasserbauten verwendet. Manche Kalksteine (z. B. der Trass) enthalten so viel Ton, daß sie ohne weiteres beim Brennen Zement ergeben. 
Kalziumchlorid $\mathrm{CaCl}_{2}$ aus Kalziumhydroxyd und Salzsäure. Kristallisiert mit 6 Mol. Kristallwasser, das es beim Erhitzen abgibt. Das entwässerte Chlorkalzium ist sehr hygroskopisch, d. h. es zieht lebhaft Wasser an, wird deshalb als Entwässerungsmittel vielfach benutzt.

Kalziamfluorid $\mathrm{CaF}_{2}$ bildet als Flußspat ein häufiges Mineral. Es ist ferner ein Bestandteil der Knochen und des Zahnschmelzes.

Kalziumhypochlorit, Unterchlorigsaures Kalzium $\mathrm{Ca}(\mathrm{ClO})_{2}$, ist der wirkende Bestandteil des sog. Chlorkalks, der nebenbei noch Chlorkalzium enthält. Man stellt ihn dar durch Einwirkung von Chlor auf gelöschten Kalk. Weißes, lockeres Pulver, von schwachem Chlorgeruch. Wichtiges Bleichmittel und billiges Desinfektionsmittel, besonders für Aborte etc. Gibt mit Salzsäure Chlor.

Kalziumsulfat $\mathrm{CaSO}_{4}$. Kommt kristallisiert mit $2 \mathrm{Mol}$. $\mathrm{H}_{2} \mathrm{O}$ als Gips, Alabaster, Marienglas vor.

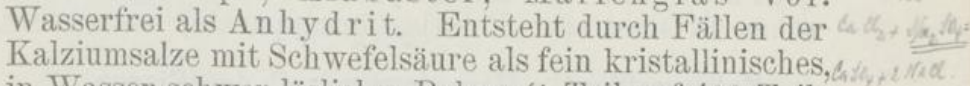
in Wasser schwer lösliches Pulver (1 Teil auf 400 Teile Wasser). Gibt bei $110^{\circ}$ sein Wasser ab (gebrannter Gips) und läßt sich nun mit Wasser zu einem Brei anrühren, der ohne Formänderung (plastisch) erstarrt und zu bildnerischen Zwecken und zu Verbänden benutzt wird. Wird der Gips über $160^{\circ}$ erhitzt, so läßt er sich nicht mehr anrühren (ist to tgebrann t). Wie totgebrannter Gips verhält sich der in der Natur vorkommende Anhydrit.

Kalziumnitrat $\mathrm{Ca}\left(\mathrm{NO}_{3}\right)_{2}$ kommt bisweilen als $\mathrm{M}$ a uersalpeter an alten Mauern etc. vor.

Kalziumphosphate. Das tertiäre $\mathrm{Ca}_{3}\left(\mathrm{PO}_{4}\right)_{2}$ kommt $\ell_{6} \mathrm{H} \mathrm{OO}_{4}+$ mit Fluorkalzium als Apatit vor. Außerdem rein als Phosphorit. Ferner in der Pflanzenasche, in den Knochen, deren Asche ca. $82 \%$ davon enthält.

Das primäre Phosphat $\mathrm{CaH}_{2}\left(\mathrm{PO}_{4}\right)_{2}$ entsteht aus dem tertiären durch Schwefelsäure; es wird in dem Gemenge mit Kalziumsulfat, wie es entsteht, als Superphosphat zum Düngen verwendet. 
Ebenfalls phosphorsauren Kalk enthält die bei der Verarbeitung des Eisens nach dem Thomasschen Verfahren als Nebenprodukt entstehende Thoma ss ch lacke; wiehtiges Düngermittel.

Kalziumkarbonat $\mathrm{aCO}_{3}$ findet sich in der Natur Limols kristallisiert als Kalkspat, Doppelspat und ArraFullow gonit; Kristallinisch als Marmor, Kalkstein, und in Verbindung mit Magnesiumkarbonat als Dolomit. Die Kreide besteht aus den Schalen kleiner Seetiere, der Foraminiferen.

Weißes Pulver, fast unlöslich in Wasser, etwas löslich in kohlensäurehaltigem Wasser. Findet sich deshalb in allen Quellen. Beim Stehenlassen oder langsamen Verdunsten dieser Wässer geht Kohlensäure fort und der kohlensaure Kalk seheidet sich ab. (Entstehung der Stalaktiten, des Kesselsteins etc.)

Es wird als Kreide (Schreibkreide, Malerfarbe), als Marmor und als Kalkspat (zu den sog. Nicolschen Prismen der Polarisationsapparate) verwendet.

Kalziumsilikat. Hauptbestandteil des Glases.

Zur Darstellung des Glases wird ein Gemisch von Kalk, Quarzsand und Soda oder Pottasche in Öfen zusammengeschmolzen. Zuweilen wird Bleioxyd zugesetzt (Bleiglas). Je nachdem man Soda oder Pottasche verwendet, entsteht Natronglas oder Kaliglas.

Natronglas ist leicht schmelzbar. Wird zu Fensterscheiben etc. benutzt.

Kaliglas, böhmisches Glas, Crowng las ist schwerer schmelzbar, härter und widerstandsfähiger gegen chemische Einflüsse.

Kristallglas oder Flintglas ist Kaliumbleisilikat. Stark lichtbrechend. Wird zu optischen Instrumenten verwendet. Der Straß, der zu Edelsteinimitationen dient, ist borhaltiges Bleiglas. Das Glas wird durch verschiedene Metalloxyde verschieden gefärbt. Gewöhn- 


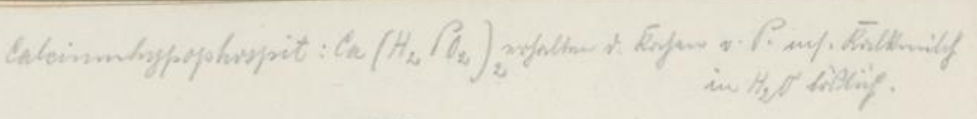

$-113-$

liches Glas ist meist durch Eisenoxydul grünlich gefärbt (Flaschenglas). Kupferoxyd färbt grün, Kupferoxydul rubinrot, Kobaltoxyd blau etc.

Die Glasfabrikation ist eine uralte, schon den Ägyptern ums Jahr 2000 v. Ch. bekannte Technik. Später war Byzanz und dann Venedig Hauptsitz der Glasfabrikation. Die Gl asmal e rei ist eine deutsche Erfindung. In neuerer Zeit ist die Technik des Glasgießens zu großer Wichtigkeit gediehen, während man früher hauptsächlich das Glasblasen übte.

Kalziumkarbid $\mathrm{CaC}_{2}$ aus gebranntem Kalk mit Kohle im elektrischen Ofen (Moissan):

$$
\mathrm{CaO}+3 \mathrm{C}=\mathrm{CaC}_{2}+\mathrm{CO} \text {. }
$$

Gibt mit Wasser Azetylen:

$$
\mathrm{CaC}_{2}+\mathrm{H}_{2} \mathrm{O}=\mathrm{CaO}+\mathrm{C}_{2} \mathrm{H}_{2} \text {. }
$$

(s. org. Chemie).

\section{Strontium.}

\section{Sr. Atomg. 87.}

Ziemlich selten als Karbonat (Strontianit) und Sulfat

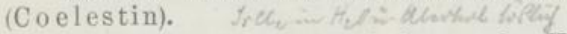

Seine Verbindungen sind denen des Kalziums sehr ähnlich

Strontiumsulfat $\mathrm{SrSO}_{4}$ schwerer löslich als Gips, leichter als Baryumsulfat.

Strontiumnitrat $\mathrm{S}_{\mathrm{r}}\left(\mathrm{NO}_{3}\right)_{2}$. Wird in der Feuerwerkerei verwendet. Ein Gemisch von Strontiumnitrat mit chlorsaurem Kali und Kohle ist das bengalische Rotlicht.

\section{Baryum.}

Ba. Atomg. 137.

Kommt in größerer Menge als Sulfat (Schwer- Yithrit: spat) vor. Seine Verbindungen haben alle ein hohes $\sqrt{3} e_{0} \mathrm{CO}_{3}$. spez. Gewicht. Daher der Name des Elementes ( $3 x p i s$ schwer).

Das Metall und seine Verbindungen sind denen des Kalziums sehr ähnlich.

Baryumhydroxyd $\mathrm{Ba}(\mathrm{OH})_{2}$ Ätzbaryt, starke Base leicht löslich in Wasser (Barytwasser).

\footnotetext{
Oppenheimer, Grundriss d. anorg. Chemie, 4. Aufl.
} 


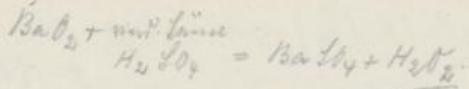

$$
\begin{aligned}
& -11 \overline{14}-
\end{aligned}
$$

Baryumsuperoxyd $\mathrm{BaO}$ 2 durch Erhitzen von Baryumoxyd BaO an trockener Luft auf $400^{\circ}$. Gibt bei $800^{\circ}$ den Sauerstoff wieder ab. Technische Darstellung von Sauerst off.

Baryumnitrat $\mathrm{Ba}\left(\mathrm{NO}_{3}\right)_{2}$ dient zur Darstellung des bengalischen Grünlichts (s. a. Strontiumnitrat). Baryumsulfat, $\mathrm{BaSO}_{4}$, Schwerspat. Weiße kristalli-
nische Masse, unlöslich in Wasser und Säuren. Wich-

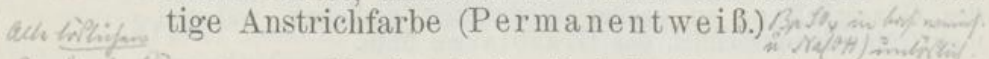
Burthokiman Nachwei's der Erdalkalimetalle:

fiv triflif ! Die Salze geben Niederschläge mit Lösungen von Karbonaten, Phosphaten und Sulfaten.

Be ithonit for Die Flamme des Bunsenbrenners färben

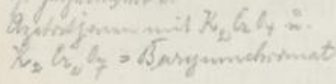

Kalziumverbindungen gelbrot,

Strontiumverb. rot,

Baryumverb. gelbgrün.

Metalle

\section{der Magnesiumgruppe.}

Beryllium, Magnesium, Zink, Kadmium.

$$
\text { Zweiwertig. }
$$

Die Metalle zersetzen in der Kälte Wasser nicht. Ihre Oxyde und Hydrate sind unlöslich. Die Hydrate geben ihr Wasser schon bei schwachem Erhitzen ab. Die Sulfate sind löslich.

\section{Beryllium.}

Be. Atomg. 9.

Kommt in der Natur selten vor. Der Beryll ist ein Beryllium-Aluminiumsilikat. Der Smaragd ist ein Beryll, der durch Chromoxyd grün gefärbt ist.

Es ist in seinen Verbindungen dem Magnesium sehr ähnlich, nähert sich aber auch etwas dem Aluminium.

\section{Magnesium.}

Mg. Atomg. 24.

Vorkommen: Als Karbonat (Magnesit), und mit Kalziumkarbonat (Dolomit). In fast allen Quellen

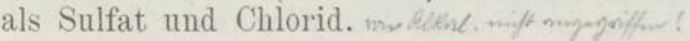




\section{$-115-$}

Darstellung: Durch Elektrolyse von geschmolzenem

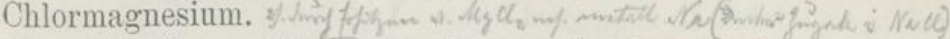
Ei gen sc h a f t en: Glänzendes, silberweißes Metall, sehr dehnbar. Verbrennt mit sehr intensivem Licht. Wird deshalb in der Photographie verwendet (Blitzlicht).

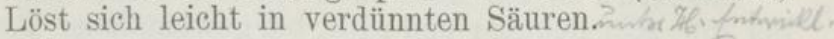

Magnesiumoxyd $\mathrm{MgO}$ wird durch Glühen des Karbonates erhalten. (Magnesia usta). Weißes, lockeres Pulver, in der Medizin gegen Sodbrennen verwendet.

Magnesiumchlorid $\mathrm{MgCl}_{2}$ findet sich mit Chlorkalium $\mathrm{MH}_{2} u_{2}+4_{2}=$ als Karnallit in Staßfurt.

Magnesiumsulfat $\mathrm{MgSO}_{4} ; \mathrm{Bittersalz}$, findet sich in ment manchen Quellen (Bitterwässern). Abführmittel.

Magnesiumphosphat kommt als Doppelsalz mit Ammoniumphosphat $\left(\mathrm{NH}_{4}\right) \mathrm{MgPO}_{4}$ im Harn und im Guano vor. Dieses Salz bildet im Organismus Blas en - und Nierensteine, da es schwer löslich ist.

Magnesiumkarbonat, $\mathrm{MgCO}_{3}$ Magnesit, Dolomit (mit Kalziumkarbonat).

Magnesiumsilikate sind u. a. Se rpentin, Talk und M eer s c ha u m. Ersterer wird als Material für architektonische Arbeiten benutzt, da er einen schönen grünlichen Ton hat. Der Talk dient als Streupulver. Der Meerschaum zu Schnitzereien.

Magnesiumkalziumsilikate sind u. a. Hornblende, ein Bestandteil des Granits, der außerdem noch Feldspat und Glimmer enthält, und der Asbest. Dieser kommt in fädigen Bündeln vor und wird als feuerfestes Material zu Anzügen etc. verarbeitet.

Nachweis: Ammoniakhaltige Magnesiumsalzlösungen geben mit Natriumphosphat einen Niederschlag von Ammoniummagnesiumphosphat (Phosphorsaure Ammoniakmagnesia).

\section{Zink.}

\section{Zn. Atomg. 65 .}

Die wichtigsten Zinkerze sind der Galmei (Zink-

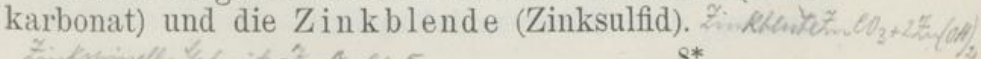


Die Erze werden an der Luft geröstet und gehen hresing: dabei in Zinkoxyd über. Dies wird mit Kohle geglüht. 32. cá, Das reduzierte Zink destilliert über und wird in Vorif : lagen aufgefangen.

Das Zink ist ein Metall von bläulich-weißer Farbe. Blotitgrid:

Bei $150^{\circ}$ sehr dehnbar und zähe, bei gewöhnlicher Tem. peratur spröde. Schmilzt bei $420^{\circ}$. Verbrennt mit sehr intensiver Flamme. Löst sich leicht in Säuren. Wird als Zinkblech etc., ferner zum Verzinken von Eisenblech (Weißble $\mathrm{ch}$ ) vielfach verwendet, da es an der Luft beständig ist.

Chion: in

Zinkoxyd ZnO. Aus dem Karbonat durch Glïhen. Wir. Wird als Malerfarbe (Zinkweiß) verwendet.

Zinkchlorid $\mathrm{ZnCl}_{2}$. Durch Auflösen von Zink in

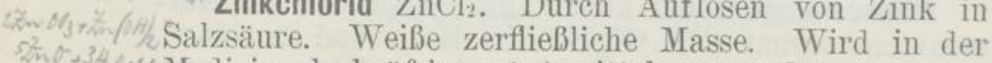
$52-34$ my Medizin als kräftiges Aetzmittel verwendet.

Zinksulfat $\mathrm{ZnSO}_{4}$, Zinkvitriol (Zincum sulfuricum). Aus Zink und Schwefelsäure. Rhombische Kristalle, leicht löslich in Wasser. Wird in der Medizin als adstringierendes, entzündungswidriges Mittel, z. B. gegen Augenentzündung verwendet.

Nachweis: $\mathrm{H}_{2} \mathrm{~S}$ fällt weißes $\mathrm{ZnS}$, das in Säuren außer Fssig-

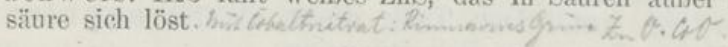

\section{Kadmium.}

Cd. Atomg. 112.

Findet sich als Regleiter des Zinks in seinen Erzen.

Ist dem Zink sehr ähnlich. Seine Verbindungen entsprechen vollkommen den Zinkverbindungen.

Dem periodischen System nach gehört zu dieser Gruppe noch das Quecksilber. In der Tat zeigen die Verbindungen des zweiwertigen Quecksilbers manche Ähnlichkeit mit denen des Zinks. Außerdem hat das Quecksilber noch eine Reihe Verbindungen, in denen es einwertig auftritt. In diesen nähert es sich, besonders durch die Unlöslichkeit der Chlorverbindung, dem Silber und Kupfer. 


\title{
Quecksilber (Hydrargyrum).
}

\author{
Hg. Atomg. 200. Mol. G. 200.
}

Das Quecksilber findet sich selten gediegen; meist als Sulfid, Zinnober, z. B. in Kalifornien, Mexiko. Idria in Krain.

Dargestellt wird es aus Zinnober, indem dieser in Öfen geröstet wird. Dabei verbrennt der Schwefel zu Schwefeldioxyd und das Quecksilber destilliert über. Zur Reinigung wird es durch Gemsleder gepreßt und dann nochmals destilliert. $H_{g} y_{+} C_{2}=\gamma_{2}+H_{2}$.

Das Quecksilber ist das einzige Metall, das bei gewöhnlicher Temperatur flüssig ist. Es erstarrt bei $-49^{\circ}$ und siedet bei 3600 . Seine Dämpfe sind sehr giftig. Spez. Gewicht 13,59. Seine Gas dichte ist 100. (Wasserstoff $=1$ ).

Folglich ist sein Molekulargewicht (Wasserstoff $=2$ ) $=200$ (s. S. 14), das heißt gleich dem Atomgewicht. Das Molekulargewicht des Quecksilbers ist also gleich dem Atomgewicht; d.h. das Quecksilbermolekül besteht nur aus einem A tom. Dasselbe gilt u. a. auch für Zink und Kadmium.

Es löst fast alle Metalle (Eisen nicht) zu sog. A malgamen. An der Luft bleibt es unverändert, bei höherer Temperatur oxydiert es sich zu rotem Oxyd. Es ist unlöslich in kalter Salzsäure und Schwefelsäure, leicht löslich in Salpetersäure. Das Quecksilber bildet zwei Reihen von Verbindungen, Merkuroverbindunge ${ }^{1}$ ) vom einwertigen $\mathrm{Hg}, \mathrm{z}$. B. $\mathrm{HgCl}$, und Merkuriverbindungen vom zweiwertigen $\mathrm{Hg}$, z. B. $\mathrm{Hg}\left(\mathrm{NO}_{3}\right)_{2}$. Die Quecksilberverbindungen sind g iftig, aber zugleich starke Heilmittel.

Sie wirken in kleinen Dosen abführend, in größeren Erbrechen und Speichelfluß erregend. Quecksilber und seine Verbindungen sind in der Heilkunde sehr wichtig als spezifische Heilmittel gegen konstitutionelle Syphilis. Quecksilber selbst in innigem Gemisch mit Fett bildet die bekannte graue Salbe (Unguentum cinereum).

1) Merkur ist der alte Name des Quecksilbers. 
Oxydulverbindungen des Quecksilbers.

Merkuroverbindungen.em/ $/ / H_{3}=/$ homg

Quecksilberchlorïr $\mathrm{HgCl}$, (Hydrargyrum chloratrim mite), Kalomel, entsteht als weißer amorpher Niederschlag beim Versetzen einer Lösung von Merkurosalzen

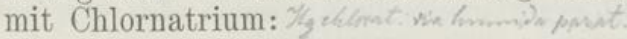

$$
\mathrm{Hg}_{2} \mathrm{SO}_{4}+2 \mathrm{NaCl}=2 \mathrm{HgCl}+\mathrm{Na}_{2} \mathrm{SO}_{4}
$$

Unlöslich in Wasser, Alkohol und verdünnten Säuren. Färbt sich beim Übergießen mit Ammoniak schwarz, indem sich eine komplizierte Verbindung bildet.

Wichtiges Arzneimittel. (Vorzügliches Desinfektionsmittel für den Darm).

Quecksilberjodïr HgJ (Protojoduretum Hydrargyri) aus Quecksilber und Jod, oder aus Merkuronitrat durch Jodkalium.

Quecksilberoxydul $\mathrm{Hg}_{2} \mathrm{O}$ entsteht aus den Salzlösungen dureh Kalilauge als schwarzes Pulver. Das Hydrat ist nicht bekannt.

$\left.\begin{array}{l}\text { Merkuronitrat } \mathrm{Hg}_{2} \mathrm{NO}_{3} \\ \text { Merkurosulfat } \mathrm{Hg}_{2} \mathrm{SO}_{4}\end{array}\right\}$ entstehen beim Auflösen von Quecksilber in den entsprechenden Säuren, verdünnter kalter Salpetersäure resp. konz. Schwefelsäure.

Oxydverbindungen des Quecksilbers. Merkuriverbindungen.

Quecksilberchlorid $\mathrm{HgCl}_{2}$, Sublimat, (Hydrargyrum V. bichloratum) entsteht durch Auflösen von Quecksilber-

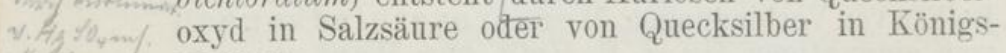
Whe wasser:

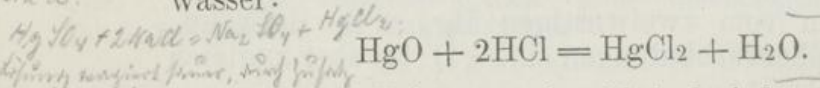

Farblose Prismen, ziemlich leicht löslich in Wasser und Alkohol. Sublimiert, ohne zu schmelzen. Ist ein heftiges Gift und ausgezeichnetes Antiseptikum.

Durch reduzierende Substanzen, z. B. Zinnchlorür, wird es zu Kalomel und schließlich sogar zu Quecksilber reduziert.

$$
\begin{aligned}
2 \mathrm{HgCl}_{2}+\mathrm{SnCl}_{2} & =2 \mathrm{HgCl}+\mathrm{SnCl}_{4} \\
2 \mathrm{HgCl} & +\mathrm{SnCl}_{2}=2 \mathrm{Hg}+\mathrm{SnCl}_{4}
\end{aligned}
$$




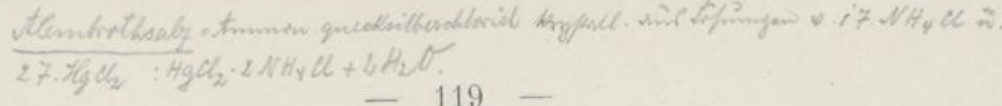

Ammoniak fällt einen weißen Niederschlag, dem die Formel $\mathrm{Hg}<\mathrm{NH}_{2}$, also eines Quecksilberamidochlorids, zukommt. Wenn man ihn als Abkömmling des Ammoniums $\mathrm{NH}_{4}$ auffaßt, kann man ihn als Merkuriammoniumehlorid bezeichnen. Die Substanz wird zu Salben verwendet und heibt weisser Präzipitat (Hydrargyrum praecipitatum album),

Quecksilberjodid HgJ aus Quecksilber und Jod. Rote Oktaëder, die sich beim Erwärmen zu gelben Nadeln umwandeln, die sehr leicht wieder in die roten Oktaëder übergehen.

Quecksilberoxyd HgO. Zwei Modifikationen:

in.

$\mathrm{cZ}$,

is-

k-

reh

nt.

ek-

er-

im

er-

gs-

in

en.

ti-

es

1) Rotes Quecksilberoxyd (Hydrargyrum oxydatum rubrum), durch Erhitzen des Quecksilbers an

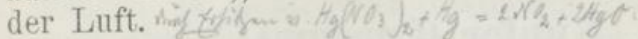

2) Gelbes Quecksilberoxyd (Hydr. oxyd. fla4h vum), durch Fällen der Salze mit Kalilauge. Beide Modifikationen geben bei $400^{\circ}$ ihren Sauerstoff ab.

Merkurinitrat $\mathrm{Hg}\left(\mathrm{NO}_{3}\right)_{2}$ \} entstehen durch Auflösen des MeMerkurisulfat $\mathrm{HgSO}_{4}$, entstehi talles in den heißen konz. Säuren.

Quecksilbersulfid $\mathrm{HgS}$ kommt in der Natur als Zinnober vor. Kristallinische Masse von dunkelroter wy Farbe. Unlöslich in allen Lösungsmitteln außer Königswasser. Das aus den Salzlösungen gefällte HgS ist oft schwarz, läßt sich aber destillieren und geht dabei in Zinnober über. Wichtige Malerfarbe.

Nachweis: Beim Erhitzen von Quecksilberverbindungen mit trockenem Natriumkarbonat entweicht metallisches Quecksilber, das sich im Reagensglas in Tropfen absetzt. In Oxydulver-

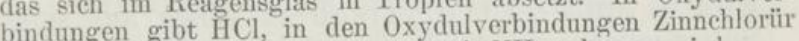
einen weißen Niederschlag, der durch $\mathrm{NH}_{3}$ schwarz wird.

\section{Kupfer, Silber, Gold.}

Diese drei Elemente gehören zwar der ersten Gruppe des periodischen Systems an, zeigen aber doch in ihren Eigenschaften so große Verwandtschaft mit den Schwermetallen, daß es nicht zweckmäßig wäre, sie im An- 
schluß an die Alkalimetalle zu behandeln. Diesen sind sie insofern ähnlich, als sie auch einwertig auftreten, außerdem durch ihre relativ niedrigen Schmelzpunkte und Siedepunkte. Sie haben von allen Elementen die größte Leitfähigkeit für Wärme und Elektrizität. Thre Chlorüre sind in Wasser unlöslich, wie das Quecksilberchlorür. Das Kupfer zeigt ferner in den Verbindungen, wo es zweiwertig auftritt, Verwandtschaft zur Magnesium-Zinkgruppe. Das Gold nähert sich dem Aluminium, indem es dreiwertig sein kann, und sein Oxyd als Säure fungiert.

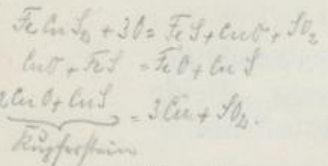

\section{Kupfer (Cuprum). \\ Cu. Atomg. 63.3.}

Ein- und zweiwertig.

Vorkommen: Häufig gediegen. Ferner als Rotkupfererz $\mathrm{Cu}_{2} \mathrm{O}$, Kupferglanz $\mathrm{Cu}_{2} \mathrm{~S}$, Kupferkies (Schwefelkupfer und Schwefeleisen), und als basisches Karbonat (Malachit und Lasurstein).

Darstellung: Aus den sauerstoff haltigen Erzen durch Reduktion mit Kohle. Der Kupferkies muß zur Gewinnung des Kupfers sehr umständlichen Röst- und Schmelzprozessen unterworfen werden. In neuerer Zeit beginnt eine entsprechende Modifikation des Bessemer-Verfahren (s. b. Eisen) auch bei der Bereitung des Kupfers eine Rolle zu spielen. Häufig wird es auf elektrolytischem Wege aus seinem Sulfat gewonnen. Auch die Reinigung des technischen Kupfers geschieht jetzt vielfach elektrolytisch. Man hängt Rohkupferplatten als Anode in ein Bad von Kupfersulfat und führt das Metall zu einer Kathode von reinem Kupfer herüber, wo es sich dann ebenfalls ganz rein absetzt. Alle Verunreinigungen fallen dabei zu Boden.

Eigenschaften: Das metallische Kupfer zeigt eine schöne rote Farbe und hohen Glanz; in dünnen 
Blättchen ist es durchscheinend grün. Es ist sehr weich und dehnbar, schmilzt bei $1054^{\circ}$.

Chemisches Verhalten: Löst sich nicht in verdünnter Salzsäure oder Schwefelsäure, leicht in Salpetersäure. An feuchter Luft bedeckt es sich mit einer Schicht von kohlensaurem Kupfer (Patina). Es bildet zwei Reihen von Verbindungen, in denen es einwertig und zweiwertig auftritt: Kuproverbindungen und Kupriverbindungen. Letztere sind die beständigeren und wichtigeren.

Verwendung: Das Kupfer für sich wird in großen Mengen zu elektrischen Leitungen verwendet, ist sonst aber für die Verwendung in der Technik im allgemeinen zu weich und läßt sich schlecht gießen; es wird deshalb mit anderen Metallen zu Legierungen verschmolzen. Die wichtigsten sind:

Zink und Kupfer: 1) Messing, 3 Teile Kupfer, 1 Teil Zink, meist unter Zusatz von $1-2 \%$ Blei. Es hat eine gelbe Farbe, läßt sich gut in Formen gießen und wird vielfach angewendet. Es ist viel härter als Kupfer. Das Tomback enthält nur $15 \%$ Zink und hat eine goldähnliche Farbe. Das unechte Blattgold und das Talmi haben ähnliche Zusammensetzung.

Zinn und Kupfer in verschiedenen Mischungen. die meist auch Zink, Blei, zuweilen auch Silber und Gold enthalten, bilden die verschiedenen Bronzen. Kanonenbronze besteht aus $90 \%$ Kupfer und $10 \%$ Zinn. Glockenmetall enthält $20-25 \%$ Zinn.

Neusilber ist eine Legierung von Kupfer, Zinn und Nickel. Die Kupfermünzen bestehen aus 95 Proz. Kupfer, 4 Proz. Zinn und 1 Proz. Zink.

Besondere Arten der Bronze sind die sehr widerstandsfähige Phosphorbronze, die 0,5 Proz. Phosphor enthält, und die Siliziumbronze. 
K uproverbindungen.

Kupferoxydul $\mathrm{Cu}_{2} \mathrm{O}$ als Rotkupfererz in der Natur. Bildet sich z. B. durch Reduktion von Kupferoxyd. (Erwärmen einer Kupfersulfatlösung mit Kalilauge und Traubenzucker: Trom. mersche Zuckerprobe). Hellrotes Pulver.

Kuprochlorid, $\mathrm{CuCl}$, aus $\mathrm{Kupfer}$ und Chlor, sowie aus Kupferchlorid durch Kochen mit Kupfer. Unlöslich in Wasser, löslich in Salzsäure und Ammoniak. Diese Lösungen absorbieren Kohlenoxyd. Kuprosulfid CuS ist der natürlich kristallisiert vorkommende Kupferglanz.

Es existiert auch eine Verbindung des Kupfers mit Wasserst o ff $\mathrm{CuH}$, die sehr leicht zerfällt.

\section{Kupriverbindungen.}

Kupferoxyd. Gewöhnlich durch Glühen von Kuprinitrat dargestellt. Schwarzes Pulver. Wirkt in der Hitze stark oxydierend. Deshalb seine Anwendung zur organischen Elementaranalyse (s. org. Ch.).

Es löst sich in Ammoniak mit tief dunkelblauer Farbe. Diese Lösung besitzt die eigentümliche Fähigkeit, Zellulose (Papier etc.) zu lösen (Schweizers Reagens).

Kupferhydroxyd $\mathrm{Cu}(\mathrm{OH})_{2}$ aus Kupfersalzen durch Kalilauge als bläulicher Niederschlag. Geht schon beim Kochen in das schwarze Oxyd über.

Kuprichlorid $\mathrm{CuCl}_{2}$, hellgrïnes Salz, leicht löslich in Wasser.

Kupfersulfat, $\mathrm{CuSO}_{4}^{+2}$, Kupfervitriol, durch Auflösen von $\mathrm{Cu}$ in kochender Schwefelsäure oder Oxydation von Schwefelkupfer. Große, blaue, asymmetrische Kristalle mit 5 Mol. Kristallwasser, die an der Luft verwittern. Das wasserfreie Kupfersulfat ist ein weißes Pulver, das begierig Wasser anzieht und z. B. zum Entwässern von Alkohol benutzt wird. Wird als Atzmittel in der Medizin und vor allem zur galvanischen Verkupferung angewendet.

Kup ferkarbonat, grünes Pulver; basische Karbonate als Malachit und Lasurstein in der Natur.

Kupferarsenit; arsenigsaures Kupfer, ist ein grünes Pulver von inkonstanter Zusammensetzung, das früher als Malerfarbe verwendet wurde (Scheeles Grün).

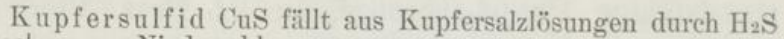

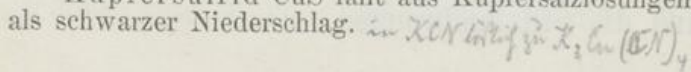




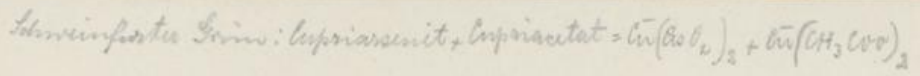

- $123-$

Nachwe is: Die Kupfersalze sind grün oder blau gefärbt. Sie lösen sich alle in Ammoniak mit tiefblauer Farbe zu den sog. Kuprammoniumverbindungen.

\section{Silber (Argentum).}

Ag. Atomg. 108. Einwertig.

Vorkommen: Meist gediegen. Ferner als Silber-Homoilba glanz AgS, und in vielen Erzen als Beimischung. Fast jeder Bleiglanz (Schwefelblei) enthält Silber.

Darstellung: I. Man schmilzt die silberhaltigen Erze mit Blei, um das Silber an dieses zu binden. Aus dem Blei gewinnt man es dann folgendermaßen:

1) Beim langsamen Erkalten von geschmolzenem silberhaltigen Blei scheidet sich zuerst reines Blei ab, das abgeschöpft wird. Zuletzt bleibt eine silberreiche Legierung zurück. (Pattinsonsches Verfahren.) )

Oder man setzt dem geschmolzenen Blei Zink zu. Dann bildet sich eine schwer schmelzbare Blei-Zink-Silberlegierung, die sich an der Oberfläche abscheidet und abgeschöpft wird. (Parke ssches Verfahren.)

T2) Das an Silber angereicherte Blei wird in Öfen geschmolzen, deren Boden aus porösem Material besteht. Dabei oxydiert sich das Blei zu Bleioxyd, das vor dem porösen Material eingesogen wird; das Silber bleibt als Metall zurück (Kupellation).

II. AmalgamierungsprozeB. Die Erze werden mit Kochsalz geschmolzen. Dabei entsteht Chlorsilber, das mittelst Eisen in metallisches Silber verwandelt wird. Dies wird mit Quecksilber aus der Masse herausgelöst (amalga miert). Das Quecksilber wird dann abdestilliert.

III. Das durch Rösten mit Kochsalz entstandene Chlorsilber wird mit Kochsalzlösung, in der $\mathrm{AgCl}$ löslich ist, ausgelaugt, und dann das Silber durch Kupfer abgeschieden.

Das gewöhnliche Silber ist nie rein, sondern enthält stets Kupfer und andere Metalle. Es ist ein weißes, glänzendes Metall vom spez. G. 10,5, ziemlich weich, sehr dehnbar, schmilzt bei $950^{\circ}$. Bleibt an der Luft unverändert, ist also ein Edelmetall. Sehr 
interessant ist die wasserlösliche Form des Silbers, das "kolloidale Silber" oder Kollargol, das nach verschiedenen Methoden, z. B. durch Erhitzen von zitronensaurem Silber im Wasserstoffstrom dargestellt werden kann. Es ist in Wasser mit tiefroter Farbe löslich und wird durch Salze daraus gefällt. Ganz ähnlich verhalten sich Gold und Platin.

Löst sich nicht in Salzsäure, in Schwefelsäure nur beim Kochen, leicht in Salpetersäure.

Verwendung hauptsächlich in seinen Legierungen mit Kupfer. Die meisten Silbermünzen enthalten 90 Proz. Silber und 10 Proz. Kupfer.

Man gibt den Gehalt an Silber, den sog. Feinge halt, in Tausendsteln an. Er ist also 900/1000 bei den gewöhnlichsten Münzen (Mark, Frank, Krone).

Die Silberverbindungen sind ferner äu Berst ener $\mathrm{g}$ ische Antiseptica. In neuerer Zeit sind eine ganze Reihe von möglichst wenig reizenden Silberverbindungen als Antiseptica empfohlen worden, von denen die Sil bereiweißverbindungen(Protargol, Albargin) die wichtigsten sind. Auch das kolloidale Silber wird zu ähnlichen Zwecken verwendet.

Silberoxyd $\mathrm{Ag}_{2} \mathrm{O}$ scheidet sich beim Versetzen einer Lösung von Silbernitrat mit Kalilauge als braunschwarzer Niederschlag aus. Das Hydroxyd ist nicht bekannt, doch reagiert feuchtes Silberoxyd ähnlich wie ein Hydrat.

asufymity Silberchlorid, Chlorsilber, $\mathrm{AgCl}$, in der Natur als H ornsilb er. Fällt aus Silbersalzlösungen durch Salzsäure als weißer, käsiger Niederschlag, unlöslich in Wasser und verdünnten Säuren, leicht löslich in Kochsalzlösung, Ammoniak, Natriumthiosulfatlösung und Cyankaliumlösung.

Silberbromid. $\mathrm{AgBr}$ : Ganz analog.

Silberjodid, AgJ, unterscheidet sich durch seine gelbe Farbe und Unlöslichkeit in Ammoniak. 


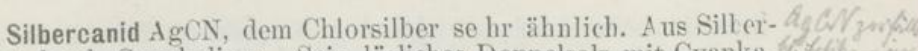
nitrat dureh Cyankalium. Sein lösliches Doppelsalz mit Cyankal-7.tgy in in lium dient zur elektrolytischen (galvanisehen) Versilberung.

Silbernitrat $\mathrm{AgNO}_{3}$ (Argentum nitricum). Durch Auflösen von Silber in Salpetersäure. Farblose Kristalle, sehr leicht löslich in Wasser und Alkohol. Ist leicht schmelzbar und wird in Stangen gegossen, die zum Aetzen in der Medizin angewendet werden (Ḧ̈llenstein). Schwärzt sich an der Luft, indem sich metallisches Silber abscheidet.

Silbersulfid $\mathrm{Ag}_{2} \mathrm{~S}$ in der Natur als Silberglanz. Fällt aus Silberlösungen durch $\mathrm{H}_{2} \mathrm{~S}$. Li 2 . 的就

Nachweis: Salzsäure fällt aus Silberlösungen weißes, käsiges Chlorsilber, das sich in Ammoniak löst.

\section{Photographie.}

Auf der Eigentïmlichkeit der Silberverbindungen, sich im Licht unter Abscheidung von geringen Mengen metallischen Silbers zu verändern, beruht die Photographie.

Das älteste Verfahren ist die von Daguerre erfundene D a gue rroty pi e: Eine Silberplatte wurde Joddämpfen ausgesetzt und dann das Bild der Camera obscura darauf projiziert. Die so behandelte Platte, auf der noch kein Bild zu sehen war, wurde Quecksilberdämpfen ausgesetzt, die sich an den belichteten Stellen, an denen Spuren von Silber ausgeschieden waren, stärker verdichteten als an den nicht belichteten. Diese Stellen erschienen dann heller, so daß auf der Platte das Bild sichtbar wurde.

Einen wesentlichen Fortschritt stellte das Kollodiumverfahren von Scott A reher dar. Eine Glasplatte wurde mit einer Schicht von jodkaliumhaltigem Kollodium überzogen und dann in eine Silbernitratlösung getaucht. Dadurch schlug sich auf der Glasplatte Jodsilber nieder. Wird eine solche Platte "belichtet", d. h. in die Camera obscura eingeführt, so wird an den belichteten Stellen das Jodsilber so verändert, daß sich bei der nachherigen Behandlung mit reduzierenden Mitteln, z. B. Eisenvitriol oder Pyrogallol, den sog. Entwicklern, an den belichteten Stellen ein stärkerer Niederschlag von metallischem Silber bildet, als an den nichtbelichteten. Wird nun das Jodsilber durch Cyankalium oder Natrium thiosulf at gelöst und entfernt, so bleibt das gefällte Slber auf der Platte und es entsteht so ein Bild, das an den belichteten Stellen dunkler, an den nicht be- 
lichteten heller erscheint, das sog. Negativ. Dies kann dann so „kopiert" werden, daß man durch dieses Negativ Licht auf lichtempfindliches Papier fallen läßt. Dann dringt natürlich mehr Licht durch die helleren Stellen des Negativs, färbt also das darunter liegende Papier dunkler, als an den dunklen Stellen. Die Lichtverhältnisse kehren sich also wieder um, und es wird ein Bild erzeugt, das die natürlichen Lichteffekte wiedergibt, das Positiv.

Einen ungeahnten Aufschwung nahm die Photographie dureh Einführung der Trocken platten, die vor den nassen Kollodiumplatten den Vorzug der Haltbarkeit besitzen. Sie bestehen aus einer Lösung von Gelatine, die fein verteiltes Brom- oder Jodsilber enthält. Die Lösung wird auf Glasplatten oder Celluloidplatten (Films) gegossen und dort angetrocknet. Diese „B romsilbergelatineplatten" sind sehr lichtempfindlich und, wenn sie dunkel und trocken aufbewahrt werden, von großer Dauerhaftigkeit. Sie werden genau so behandelt wie die Kollodiumplatten, also „entwickelt" und kopiert. Sie haben vor allem den Vorteil, daß man auch die belichteten Platten unter den nötigen Vorsichtsmaßregeln aufheben und transportieren kann, um sie bei Gelegenheit zu entwickeln. Die Zahl der Platten, Entwickler und Kopierpapiere ist heute eine ungemein große und ermöglicht mannigfache Nuancierungen des Tones herzustellen. Doch ist das Prinzip stets das gleiche.

In neuester Zeit ist es gelungen, durch eigentümliche Vorkehrungen Photographien in den natürlich en Farben aufzunehmen.

\section{Gold (Aurum).}

Au. Atomg. 197. Ein-und dreiwertig:

Das Gold kommt fast ausschließlich gediegen vor. Es enthält stets fremde Beimengungen (Silber, Kupfer etc.), von denen es durch Kochen mit Salpetersäure

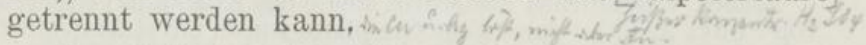

Das Gold ist ein weiches Metall von eigenartiger Farbe und hohem Glanz. Spez. G. 19,3. Es schmilzt bei $1035^{\circ} \mathrm{zu}$ einer grünlichen Flüssigkeit. Es ist an der Luft und gegen alle Säuren sehr beständig; löst sich nur in Königswasser zu Goldchlorid $\mathrm{AuCl}_{3}$.

Es wird in der Praxis seiner Weichheit wegen nur in Legierungen mit Silber und Kupfer benutzt. Die meisten Goldmünzen enthalten $90^{\circ}$ Gold und $10^{\circ} \%$ Kupfer. 
Man berechnete früher den Goldgehalt nach Karaten. Reines Gold war 24 karätig; 14 karätiges Gold entspricht also einem Goldgehalt von $58.3^{0} \%$. Jetzt gibt man meist den Feingehalt wie bei Silber in Tausendstel an.

Es tritt als einwertiges (A uroverbindungen) und dreiwertiges Element (Auriverbindungen) auf.

A uroverbindungen.

Goldchlorür $\mathrm{AuCl}$ durch Erhitzen von Goldehlorid. Unlöslich in Wasser.

Goldjodür AuJ, gelbes Pulver.

Goldcyanid-Cyankalium AuCN, KCN, in Wasser löslich, dient zur galvanischen Vergoldung. $\quad \mathrm{W}$ atie $(\mathrm{ON})_{2}$.

\section{Auriverbindungen.}

Goldchlorid $\mathrm{AuCl}_{3}$ durch Auflösen von Gold in Königswasser. Rotbraune, zerfließliche Masse, leicht löslich in Wasser. Gibt mit vielen Metallsalzen Doppelsalze, die schön kristallisieren, z. B. $\mathrm{AuCl}_{3}$,

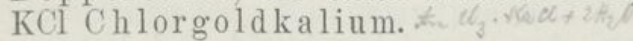

Goldoxyd $\mathrm{Au}_{2} \mathrm{O}_{3}$ und Goldhydroxyd $\mathrm{Au}(\mathrm{OH})_{3}$ sind schwache Säuren (Goldsäure), die mit Alkalien Salze (A urate) bilden, z. B. Kaliumaurat $\mathrm{KAuO}_{2}$.

Aus Goldehloridlösung und Zinnchlorür entsteht ein purpurbrauner Niederschlag, Cassius' Goldpurpur, der Glas schön rot färbt und in der Glas- und Porzellanmalerei Verwendung findet. Goldoxyd mit Ammoniak übergossen liefert einen bratnen Körper, der sehr explosiv ist (Knallgold).

\section{Gruppe des Aluminiums.}

Diese Gruppe des periodischen Systems enthält außer dem Aluminium noch eine Anzahl seltener Metalle. Das Anfangsglied dieser Gruppe, das Bor, zeigt ein von den übrigen abweichendes Verhalten; es hat nur geringe Beziehung zu den Metallen überhaupt und ist deshalb von ihnen getrennt besprochen worden. Das Aluminium schließt sich einerseits an das Gold durch 
seine Dreiwertigkeit und sein säureähnliches Hydra andererseits in vielen Salzen an das Eisen an.

\section{Aluminium.}

\section{Al. Atomg. 27. Dreiwertig.}

Vorkommen: Niemals gediegen; in seinen Verbindungen eins der wichtigsten, gesteinbildenden Elemente. Fast alle wichtigsten Gesteine, wie z. B. Granit, Porphyr, Gneis, Basalt, Schiefer etc. enthalten Aluminiumsilikat als wesentlichen Bestandteil neben anderen Silikaten. Der Ton ist vorwiegend Aluminiumsilikat. Ferner kommt es auch als Oxyd (Tonerde) vor, und zwar als Korund, Rubin, Saphir. Als Silikat bildet es auch mit anderen Silikaten den Feldspat und Glimmer.

Darstellung: Aus Aluminiumchlorid und Natrium. Heute wird es meist nach verschiedenen Methoden

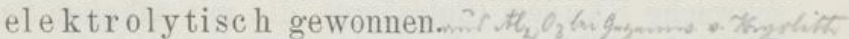

Weißes Metall von starkem Glanz. Sehr dehnbar. Es ist sehr leicht, sein spez. G. beträgt 2,58. Es schmilzt bei Rotglut. An der Luft ist es fast unveränderlich; löst sich in Salzsäure leicht, in Schwefelsäure schwer. Salpetersäure greift es nicht an. Dagegen löst es sich leicht in Kalilauge. Es wird wegen seiner Leichtigkeit und seines schönen Glanzes häufig zu Geschirren, Apparaten etc. angewendet. Die Verwendung des Aluminiums hat in neuerer Zeit infolge seiner wesentlich billigeren Darstellung einen großen Aufschwung genommen.

Eine Legierung von Kupfer mit 5-12\% Aluminium bildet die Aluminiumbronze, die goldähnliche Farbe besitzt, sehr hart und beständig ist und sich gut in Formen gießen läßt. 
Aluminiumchlorid $\mathrm{AlCl}_{3}$ aus Aluminium und Chlor. Weiße Blättchen, leicht sublimierbar. ZerflieBt an der Luft. Wird beim Erwärmen mit Wasser in Aluminiumoxyd und Salzsäure zerlegt.

$$
2 \mathrm{AlCl}_{3}+3 \mathrm{H}_{2} \mathrm{O}=\mathrm{Al}_{2} \mathrm{O}_{3}+6 \mathrm{HCl},
$$

eine Reaktion, die sonst den Chloriden der Metalloïde, und auch dem Borchlorid zukommt.

Aluminiumoxyd $\mathrm{Al}_{2} \mathrm{O}_{3}$, Tonerde, kommt vor als Korund, ein farbloser Edelstein, der auch blau gefärbt als Saphir und rot als Rubin gefunden wird, ferner in unreinem Zustande als S mirgel. Es ist sehr hart, fast wie Diamant, und wird als Schleifmittel benutzt. Man erhält es durch Glühen des Hydroxydes als ein in Wasser und Säuren unlösliches Pulver.

Aluminiumhydroxyd $\mathrm{Al}(\mathrm{OH})_{3}$ fällt aus Aluminiumsalzlösungen durch Ammoniak als weiße, voluminöse Gallerte.

Es verhält sich wie eine schwache Säure, vermag z. B. Alkalisalze zu bilden, indem es sich in Kali- oder Natronlauge löst: $\mathrm{K}$ ali umalumin at $\mathrm{KAlO}_{2}$.

Magnesiumaluminat kommt als Spinell in der Natur vor.

Andererseits ist das Aluminiumhydroxyd gegenüber starken Säuren eine Base; es bildet z. B. ein Sulfat etc., aber z. B. kein Karbonat.

Wenn man Aluminiumsulfat mit Natriumkarbonat versetzt, so entsteht nicht, wie zu erwarten, das Karbonat, sondern das Hydroxyd, indem $\mathrm{CO}_{2}$ entweicht.

Aluminiumsulfat $\mathrm{Al}_{2}\left(\mathrm{SO}_{4}\right)_{3}$ ist wichtig als Stammsubstanz der Alaune: gewöhnlicher Alaun (Alumen) ist ein Doppelsalz, bestehend aus Aluminiumsulfat und Kaliumsulfat, von der Formel

$$
\operatorname{AlK}\left(\mathrm{SO}_{4}\right)_{2}+12 \mathrm{H}_{2} \mathrm{O} \text {. }
$$

Der Alaun wird aus natürlichen Aluminiumverbindungen (Alaunstein, Alaunschiefer etc.) nach mannigfachen Methoden gewonnen.

Er kristallisiert in großen Oktaëdern, die sehr leicht in kaltem, namentlich aber in heißem Wasser löslich

Oppenheimer, Grundriss der anorg. Chemie. 4. Anfl. 9 
sind. Beim Erhitzen verliert er sein Kristallwasser (gebrannter Alaun).

Er wird als leichtes Antiseptikum in der Medizin und als Beizmittel in der Farbstofftechnik gebraucht.

Die Beizen sind solche Stoffe, die geeignet sind Farbstoffe auf Geweben, an denen sie sonst nicht haften, niederzuschlagen, z. B. viele Anilinfarben auf Baumwolle. Dazu dienen speziell vielfach Aluminiumverbindungen, auBer Alaun auch essigsaure T'onerde.

In dem Alaun kann das Kalium auch durch $\mathrm{Na-}$ trium, Ammonium etc. vertreten sein.

Aluminiumsilikat im Feldspat, Glimmer etc. Unreines Aluminiumsilikat ist der Ton. Mengt man Ton mit Wasser, so erhält man eine zähe, knetbare Masse (plastischer Ton). Durch Trocknen und Glühen wird sie fest, hart und feuerbeständig; darauf beruht die Verwendung des Tons zu Gefäßen.

Ganz reines kieselsaures Aluminium ist der $\mathrm{Kaolin}$ oder Porzellanton.

Porzellan wird aus einem feinen Gemenge von Kaolin, Feldspat und Quarz durch starkes Glühen hergestellt. Dadurch wird die Masse durchscheinend und undurchlässig. Die Fayence, die porös bleibt, ist weniger stark geglüht. Sie muB wegen ihrer Porosität noch mit einer Glasur von leicht schmelzbaren Silikaten überzogen werden. Der gewöhnliche Ton liefert die Ton- und Steingutgefäße.

Sie werden durch Zusatz von Kochsalz glasiert, das sich durch die heißen Wasserdämpfe in freies Natriumhydroxyd spaltet und dadurch mit dem Ton eine feste, undurchlässige Decke bildet.

Ultramarin wurde früher aus dem lapis lazuli, einem seltenen Mineral, als kostbarer blauer Farbstoff gewonnen Jetzt stellt man es im großen her, indem man Ton, Soda, Schwefel und Holzkohle zusammen glüht. Es entsteht dabei zunächst g rüner Ultramarin. Dieser gibt, nochmals mit Schwefel gemischt und an der Luft langsam erhitzt, blauen Ultramarin. Es gibt auch violetten und roten Ultramarin. Es ist eine Verbindung von Aluminiumnatriumsilikat mit Natriumpolysulfiden. 


\section{Seltene Erdmetalle.}

Aus einigen seltenen Mineralien (vor allem Cerit, Gadolinit, Monazit) hat man eine Anzahl Elemente isolieren können, die zum Teil sicher als solche charakterisiert sind und ihrem Atomgewicht nach in diese Reihe gehören, zum Teil noch nicht sicher bekannt sind. Zur ersten Kategorie gehören:

Scandium, Yttrium, Lanthan, Ytterbium, Neodym, Praseodym, Cer, Samarium, Erbium, Gadolinium, Thulium.

Unsicher sind:

Decipium, Holmium, Dysprosium, Russium, Lucium, Victorium etc.

Einige dieser Elemente spielen in der Beleuchtungstechnik eine sehr wichtige Rolle, indem sie der Torerde (s. dort) beigemengt die Giühkörper des Gasglühlichtes bilden.

\section{Gruppe des Galliums.}

Gallium Ga., Indium In., Thalli um Tl., dreiwertige Elemente, dem Aluminium verwandt. Das Thallium bildet auch als einwertiges Element Verbindungen, in denen es dem Kalium ähnlich ist, z. B. Ala une bildet:

Thalliumalaun. TlAl $\left(\mathrm{SO}_{4}\right)_{2}+12 \mathrm{H}_{2} \mathrm{O}$.

Die Thalliumverbindungen sind sehr giftig.

\section{Metalle der Fisengruppe.}

Obwohl die Metalle der Eisengruppe nach dem periodischen System erst der achten Gruppe zuzuteilen sind, erscheint es doch zweckmäßiger, sie im Anschluß an das Aluminium zu behandeln; auch das Mangan, das in seinen höheren Oxyden säurebildend auftritt und sich dem Jod ähnlich verhält, zeigt als Metall und in seinen Salzen soviel Ähnlichkeit mit dem Eisen, daß es ebenfalls hier seinen Platz finden möge.

\section{Eisen (Ferrum).}

Fe. Atomg. 56. Z wei- und dreiwertig.

Vorkommen: Gediegen nur in Meteorsteinen. Sehr weit verbreitet; die wichtigsten Erze sind: 


\section{- $132-$ \\ Magneteisenstein $\mathrm{Fe}_{3} \mathrm{O}_{4}$; \\ Roteisenstein $\mathrm{Fe}_{2} \mathrm{O}_{3}$; \\ Spateisenstein $\mathrm{FeCO}_{3}$.}

Der Brauneisenstein ist ein unreines Eisenoxydhydrat.

Darstellung: Chemisch reines Eisen erhält man aus Eisenoxyd oder oxalsaurem Eisen durch Wasserstoff.

Die Darstellung des in der Technik verwendeten Eisens, das vor allem Kohlenstoff, ferner aber auch Schwefel, Silizium, Mangan etc. enthält, geschieht im sogenannten Hochofenprozess.

Dieser beruht auf der Reduktion von sauerstoffhaltigen Eisenerzen durch Kohle. Der Hochofen, der ununterbrochen in Brand gehalten werden muB, ist ein konischer, aus feuerfestem Material gebauter Turm, der so beschickt wird, daß man abwechselnd eine Schicht Kohle und eine Schicht Erze einfüllt. Zur Beförderung des Schmelzens setzt man kalk- und kieselhaltige Substanzen zu. Die Kohle verbrennt zu Kohlenoxyd, das die Eisenerze reduziert. Während von oben immer neue Schichten nachgeschickt werden, wird unten von Zeit zu Zeit das reduzierte Eisen abgelassen. Es stellt das sogenannte Roheisen dar.

Eigenschaften: Roheisen enthält über $2,5 \% \mathrm{~K}$ ohlenstoff, außerdem stets Silizium, Phosphor, Schwefel, Mangan und Spuren anderer Metalle. Man unterscheidet:

Graues Roheisen: Es enthält den Kohlenstoff nur gelöst, meist in Form von Graphit. Es wird als Gusseisen verwendet.

W eißes Roheisen : Enthält wenig Graphit, sondern den Kohlenstoff chemisch gebunden, ferner viel Mangan. Es ist hart und spröde (Spiegeleisen).

Durch Entziehung eines Teiles des Kohlenstoffs gewinnt man zwei andere Abarten des Eisens, das Schmiedeeisen und den Stahl. 
Schmiedeeisen enthält weniger als $0.5^{0} \%_{0}$ Kohlenstoff. Es ist relativ weich, schmiedbar, schmilzt erst bei $1600^{\circ}$. Stahl enthäIt $0.5-1.6 \%$ Kohlenstoff. Der Stahl zeichnet sich durch seine große Elastizität, sowie dadurch aus, daß er härtbar ist. Wenn man ein glühendes Stück Stahl in kaltes Wasser taucht, wird es wesentlich härter. Er kann so glashart gemacht werden. Er schmilzt bei ca. $1400^{\circ}$.

Beim Erwärmen nimmt er verschiedene Färbungen an, die beim Erkalten verbleiben. Das willkürliche Hervorrufen dieser Farbentöne nennt man Anlassen des Stahls.

Zur Darstellung des Schmiedeeisens aus dem Roheisen muß dasselbe entkohlt werden. Es geschieht dies entweder durch Glühen in offenen Herden (F rischprozeß), oder in Flammenöfen (Puddelprozeß). Dabei verbrennt der größte Teil der Kohle nebst dem Phosphor und Schwefel, und es resultiert Schmiedeeisen.

Der Stahl, der in seinem Kohlenstoffgehalt zwischen dem Roheisen und Schmiedeeisen steht, kann entweder aus dem Roheisen durch teilweise En tkohlung oder aus dem Schmiedeeisen durch Zuführung von Kohle dargestellt werden. Auf letzterem Prinzip beruht die Darstellung des Zementstahls. Eisenstäbe werden in Kohlenpulver längere Zeit bei Rotglut erhitzt, bis sie durch Aufnahme von Kohle in Stahl übergegangen sind.

Die partielle Entkohlung des Roheisens geschah früher ebenfalls in $\mathrm{Puddelöfen} \mathrm{(Puddelstah} \mathrm{l}$ ); wird aber heut vorwiegend mittelst des Bessemerprozesses bewirkt.

Das flüssige Roheisen wird in eine große Retorte, den Konvertor, auch Bessemerbirne genannt, gebracht und dann Luft durchgepreßt. Dadurch verbrennt zuerst Phosphor und Schwefel, dann der Kohlenstoff. Sobald die Flamme des Kohlenstoffs allein vorhanden ist, was mittelst Spektroskop kontrolliert werden kann, wird der Prozeß unterbrochen. Durch weitere 
Verbrennung des Kohlenstoffes im Konvertor entsteht Schmiedeeisen.

Während der Bessemerprozeß früher nur fast phosphorfreies Roheisen verarbeiten konnte, gestattet neuerdings die Ausfütterung des Konvertors mit gebranntem D ol o m it (Kalziumund Magnesiumkarbonat), der die entstehende Phosphorsäure sofort bindet, auch die Verarbeitung phosphorhaltigen Roheisens. (Basischer ProzeB, ThomasprozeB.) Als sehr wertvolles Nebenprodukt entsteht dabei die den ganzen Phosphor enthaltende Thomasschlacke, ein vorzügliches Düngermittel, da sie auch Kalk enthält.

Hä r tbares Eisen, das also dem Stahl ähnlich ist, entsteht aus dem Schiedeeisen auch durch Zusatz von Mangan, Wolfram, Chrom, Nickel etc.

Chemisch reines Eisen ist ein ziemlich weiches, silberweißes Metall. Spez. G. 7,8. Schmilzt bei $1800^{\circ}$.

Eisen löst sich leicht in Salzsäure, Schwefelsäure, Salpetersäure. Kohlenstoffhaltiges Eisen entwickelt dabei den häßlichen Geruch von Kohlenwasserstoffen. Taucht man Eisen flüchtig in konzentrierte Salpetersäure und wäscht es ab, so löst es sich nicht mehr in Salpetersäure (Passivität des Eisens). Es oxydiert sich an feuchter Luft zu Eisenoxydhydrat: es rostet. Beim Glïhen an der Luft bedeckt es sich mit dem sog. $\mathrm{Hammerschlag} \mathrm{Fe}_{3} \mathrm{O}_{4}$.

Eisen läßt sich magnetisieren, doch behält nur der Stahl den Magnetismus längere Zeit bei. Das Eisen bildet zwei Reihen von Verbindungen, in denen es zweiwertig.(Ferro-) und dreiwertig (Ferriverbindungen) auftritt.

\section{Ferroverbindungen.}

Ferrochlorid, $\mathrm{FeCl}_{2}$ durch Auflösen von Eisen in Salzsäure. Grüne Prismen, leicht in Wasser löslich.

Eisenoxydui Fe0. Schwarzes Pulver.

Eisenoxyduhydrat $\mathrm{Fc}(\mathrm{OH})_{2}$ aus Eisenoxydulsalzen und Kalilauge. Grünlieher Niederschlag.

Ferrosulfat, Eisenvitriol. Aus Eisen und Schwefel- 
säure. Große grüne Prismen. Verwittern an der Luft und oxydieren sich gleichzeitig.

Ferrokarbonat $\mathrm{FeCO}_{3}$ kommt als Spateisenstein in der Natur vor.

Schwefeleisen, Ferrosulfid, FeS durch Zusammenschmelzen von Schwefel mit Eisen. Dunkelgraue Masse, gibt mit Salzsäure $\mathrm{H}_{2} \mathrm{~S}$.

\section{Ferriverbindungen.}

Eisenchlorid, Ferrum sesquichloratum, $\mathrm{FeCl}_{3}$, aus Eisenchlorür und Chlor. Kristallisiert kristallwasserhaltig als gelbbraune, zerfließliche, in Wasser und Alkohol leicht lösliche Masse. Wasserfrei aus Eisen und Chlor. In der Medizin als Blutstillungsmittel verwendet.

Eisenoxyd, FeO kommt als Roteisenstein in der Natur vor. Rotes, hartes Pulver, das als Polier mittel benutzt wird. Es wird auch zur Denaturierung des Steinsalzes verwendet (Viehsalz, Staßfurter Salz).

Eisenoxydhydrat $\mathrm{Fe}(\mathrm{OH})_{3}$ fällt aus Eisenoxydsalzlösungen als tiefbraune gallertige Masse, kommt in unreinem Zustande als Brauneisenstein und im Lehm vor.

Eisenoxyduloxyd $\mathrm{Fe}_{3} \mathrm{O}_{4}$ kommt als $\mathrm{Magneteisen-}$ stein in schwarzen Kristallen in der Natur vor; es hat magnetische Eigenschaften.

Ferrisulfat $\mathrm{Fe}_{2}\left(\mathrm{SO}_{4}\right)_{3}$ braunes Pulver. Entsteht aus Eisenvitriol bei Luftzutritt. Mit Alkalisulfaten bildet es den Eisenalaun. $\mathrm{FeK}\left(\mathrm{SO}_{4}\right) \pm+12 \mathrm{H}_{2} \mathrm{O}$.

Zweifach-Schwefeleisen $\mathrm{FeS}_{2}$ kommt als Schwefelkies in der Natur vor.

Eisensaures Kalium $\mathrm{K}_{2} \mathrm{FeO}_{4}$. vom Eisentrioxyd $\mathrm{FeO}_{3}$, in dem das Eisen sechswertig ist, bildet sich beim Schmelzen von Eisenfeile mit Salpeter in roten Prismen; die freie Säure ist nicht bekannt.

Die Cyanverbindungen des Eisens, das gelbe und rote Blutlaugensalz (Kaliumferrocyanid $\mathrm{K}_{2} \mathrm{Fe}(\mathrm{CN})_{6}$ und Kaliumferricyanid $\mathrm{K}_{3} \mathrm{Fe}(\mathrm{CN})_{6}$ ) werden in der organischen Chemie abgehandelt (s. d.) 


\section{- $136-$}

Nachweis: Die Ferroverbindungen geben mit rotem, die Ferriverbindungen mit gelbem Blutlaugensalz blane Niederschläge (Berliner Blau). Rhodankalium färbt Ferrisalzlösungen blutrot.

\section{Nickel.}

Ni. Atomg. 58.7. Zweiwertig.

Es kommt als Nickelglanz $\mathrm{NiS}_{2}$.NiAs 2 und in Silikaten vor. Es ist stets mit Kobalt vergesellschaftet.

Es ist ein silberweißes, stark glänzendes Metall, unveränderlich an der Luft; ist in Salzsäure und Schwefelsäure schwer löslich, leicht dagegen in Salpetersäure.

Es bildet nur Salze des Oxyduls NiO, das Oxyd $\mathrm{Ni}_{2} \mathrm{O}_{3}$ selbst ist indessen auch bekannt.

Das Nickel wird seiner Beständigkeit und seines Glanzes wegen vielfach angewandt, z. B. zu Kochgefäßen etc. Ferner überzieht man eiserne oder kupferne Gegenstände ebenfalls mit einer Nickelschicht, man vernickelt sie; meist auf galvanischem Wege. Von Legierungen sind wichtig:

Das Neusilber (Argentan). Es besteht aus 50\% Kupfer, 25\% Nickel und $25 \%$ Zink. Wichtig ist auch der Nickelstahl (Eisen und Nickel). Die deutschen Nickelmünzen bestehen aus $75^{\circ} \%$ Kupfer und $25^{\%} \%$ Nickel.

Die Nickelsalze, wie z. B. $\mathrm{NiSO}_{4}, \mathrm{Ni}\left(\mathrm{NO}_{3}\right)_{2}$ etc. sind $\mathrm{g} r$ ün gefärbt. Sie bieten kein weiteres Interesse.

\section{Kobalt.}

Co. Atomg. 59.3. Z $\mathrm{Z}$ eiw ertig.

Es kommt als Speiskobalt CoAs2 und Glanzkobalt $\mathrm{CoAs}_{2}, \mathrm{CoS}_{2}$ vor. Das Metall erhält man aus dem Oxydul durch Kohle. Es ist dem Nickel sehr ähnlich, bildet vorwiegend Oxydulverbindungen, doch ist das Oxyd selbst bekannt. 


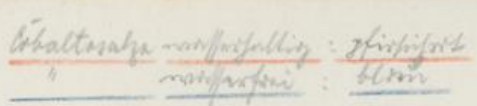

137

Die Salze des Kobalts lösen sich mit rosenroter Farbe und entsprechen völlig denen des Nickels.

Kobaltnitrat $\mathrm{Co}\left(\mathrm{NO}_{3}\right)_{2}$ ist in festem Zustande fast farblos (schwach grünlichblau); in Lösung rot. Man benutzt es deshalb zu Schriftzügen, die beim Trocknen verschwinden, aber beim Anfeuchten hervortreten (symp athetis che Tinte).

Ein Kobaltkaliumsilikat ist die Smalte, die durch Schmelzen von Kobalterzen mit Pottasche und Quarzsand hergestellt und fein gepulvert als prächtiger blauer Farbstoff angewendet wird.

Nachweis: Kobalt und Nickel geben in saurer Lösung mit $\mathrm{H}_{2} \mathrm{~S}$ keinen Niederschlag; auf Zusatz von Ammoniak fällt schwarzes Schwefelmetall, das $\mathrm{nun}$ in $\mathrm{HCl}$ unlöslich ist. Zur Trennung von $\mathrm{Co}$ und Ni benutzt man z. B. die Eigensehaft der Co-Verbindungen, mit Kaliumnitrit einen gelben Niederschlag von Kobaltikaliumnitrit $\left.\mathrm{K}_{3} \mathrm{Co}\left(\mathrm{NO}_{2}\right)_{6}\right) \mathrm{zu}$ geben.

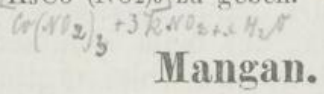

Mn. Atomg. 55.

Das Mangan, das nach seiner Stellung im periodischen System den Halogenen nahe steht, zeigt diese Ähnlichkeit nur in seiner höchsten Oxydationsstufe, wo es siebenwertig auftritt: Übermangansäure $\mathrm{HMnO}_{4}$ ist der Überjodsäure $\mathrm{HJO}_{4}$ sehr ähnlich; sonst steht es namentlich dem Eisen sehr nahe, mit dem es häufig verbunden auftritt.

Es findet sich gediegen nur in Meteorsteinen. Sonst Bramit hauptsächlich als Braunstein (Pyrolusit) $\mathrm{MnO}_{2}$, Whe $\mathrm{O}_{3}$ Manganit $\mathrm{Mn}_{2} \mathrm{O}_{3}+\mathrm{H}_{2} \mathrm{O}$ etc. Man stellt es aus den Oxyden durch Kohle dar. Es ist ein dem Eisen sehr ähnliches Metall, das sich leicht an der Luft zersetzt und in Säuren leicht löslich ist.

Es bildet vier Reihen von Verbindungen:

Manganosalze von $\mathrm{MnO}$ (zweiwertig), Manganoxydsalze von $\mathrm{Mn}_{2} \mathrm{O}_{3}$ (dreiwertig), Mangansäure $\mathrm{H}_{2} \mathrm{NnO}_{4}$ von $\mathrm{MnO}_{3}$ (sechswertig), Übermangansäure $\mathrm{HMnO}_{4}$ von $\mathrm{Mn}_{2} \mathrm{O}_{7}$ (siebenwertig). 
Außerdem bildet es noch die isoliert stehenden Oxyde $\mathrm{MnO}_{2} \mathrm{Manganperoxyd}$ und $\mathrm{Mn}_{3} \mathrm{O}_{4}$ Manganoxydoxydul.

Manganoverbindungen.

Manganoxydul MnO. Grünliches Pulver. Manganoxydulhydrat $\mathrm{Mn}(\mathrm{OH})_{2}$ aus den Salzen durch Kalilauge.

xy/-Manganchlorür $\mathrm{MnCl}_{2}$ | durch Auflösen von Mangan in ri- Mangansulfat $\left.\mathrm{MnSO}_{4}\right\}$ Salzsäure resp. Schwefelsäure. Mangansulfid MnS. Fleischfarbener Niederschlag.

Manganiverbindungen.

Manganoxyd $\mathrm{Mn}_{2} \mathrm{O}_{3}$ kommt als Braunit in der Natur vor. Das Hydrat ist ein brauner Niederschlag.

Die Salze, z. B. das Sulfat sind wenig beständig.

Manganoxydoxydul $\mathrm{Mn}_{3} \mathrm{O}_{4}$ kommt als $\mathrm{Hausmannit}$ vor.

Mangandioxyd $\mathrm{MnO}_{2}$, Manganperoxyd, Braunstein, ist ein brauner Körper, der beim Erhitzen Sauerstoff entwickelt und mit Salzsäure Chlor ergibt.

Schmilzt man Braunstein mit Kaliumchlorat oder Salpeter, so erhält man eine grüne Schmelze, aus der man grüne Kristalle von mangansaurem $\mathrm{Kali} \mathrm{K}_{2} \mathrm{MnO}_{4}$ erhalten kann, die sich von der Mangansäure resp. dem Mangantrioxyd $\mathrm{NnO}_{3}$ ableiten:

$$
\mathrm{MnO}_{3}+\mathrm{H}_{2} \mathrm{O}=\mathrm{H}_{2} \mathrm{MnO}_{4} \text {. }
$$

Wenn man das Salz in Wasser löst oder schneller bei Einwirkung von Chlor oder Säuren, entsteht:

Übermangansaures Kali, Kaliumpermanganat, $\mathrm{KMnO}_{4}$, Xolub infor

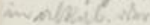
mentrale tas das aus der Lösung in grünlich schillernden, schwarz$3_{3}$ Attmuve r roten Prismen kristallisiert.

2vars löst sich ziemlich leicht in Wasser zu einer tief-

2an yioletten Flüssigkeit. Wird als kräftiges A n tisepti$4.550 \mathrm{mum}$ und fäulniswidriges Mittel vielfach angewendet. Es leitet sich her von dem Manganheptoxyd $\mathrm{Mn}_{2} \mathrm{O}_{7}$ : x. vipunganoialy.

$$
\mathrm{Mn}_{3} \mathrm{O}_{7}+\mathrm{H}_{2} \mathrm{O}=2 \mathrm{HMnO}_{\text {s. }} \text {. }
$$

Dies ist aus dem Kaliumpermanganat durch abgekühlte konz. Schwefelsäure als ölige Flüssigkeit erhältlich, die äußerst energiseh oxydie rend wirkt. 
$\mathrm{N}$ a chw ei s: Alle Manganverbindungen geben mit Salpeter eine grüne Schmelze.

Chlor, Molybdän, Wolfram, Uran.

Diese Elemente, die der sechsten Gruppe des periodischen Systems angehören, stehen in ähnlicher Beziehung zur Schwefelgruppe, wie das Mangan zu den Halogenen, d. h. diese Ahnlichkeit zeigt sich nur in den höheren Sauerstoffverbindungen, die der Schwefelsäure verwandt sind; dagegen zeigt das Chrom in seinen niederen Oxydationsstufen und als Metall nahe Verwandtschaft zurEiseng r up pe; die übrigen schließen sich dann etwas weniger nahe an das Eisen an.

\section{Chrom.}

Cr. Atomg. 52.

Findet sich in der Natur hauptsächlich als Chromeisenstein (Chromoxyd und Eisenoxyd). Ferner als chromsaures Blei: Chrombleierz.

Das Chrom erhält man durch Glühen von Chromoxyd mit Kohle als ein dem Eisen ähnliches, sehr hartes und schwer schmelzbares Metall, das sich leicht in Salzsäure und Schwefelsäure, nicht in Salpetersäure löst (wie Aluminium). Es bildet drei Reihen von Verbindungen.

Chromoverbind ungen (zweiwert.) v. CrO, $\mathrm{Chromiverbindungen} \mathrm{(dreiwert.)} \mathrm{von} \mathrm{Cr}_{2} \mathrm{O}_{3}$, Chromsäu re $\mathrm{H}_{2} \mathrm{C}_{1} \mathrm{O}_{4}$ (sechswertig) von $\mathrm{CrO}_{3}$.

Die Chromoxydulverbindungen sind sehr unbeständig und gehen leicht in die Oxydverbindurgen über.

Chromchlorür $\mathrm{CrCl}_{2}$

\section{Oxydverbindungen.}

Chromoxyd $\mathrm{Cr}_{2} \mathrm{O}_{3}$. Grünes, amorphes Pulver, in Säuren unlöslich.

Chromhydroxyd $\mathrm{Cr}(\mathrm{OH})_{3}$ aus Chromoxydsalzen durch Ammoniak als blaugrauer Niederschlag. 
Chromichlorid $\mathrm{CrCl}_{3}$. Aus Chromoxyd und Kohle dureh Glühen im Chlorstrom.

Das Chromoxyd ist wie das Aluminiumoxyd eine schwache Base, die nur mit starken Säuren Salze bildet, z. B. Chrom isulfat $\mathrm{Cr} 2\left(\mathrm{SO}_{4}\right)_{3}$; andererseits bindet es sich auch an starke Basen, bildet also als Säure Salze, die den Aluminaten entsprechen. Das Chromoxydsulfat bildet auch, wie das Aluminiumsulfat, mit Kaliumsulfat einen Alaun, den Chromalaun:

$$
\mathrm{CrK}\left(\mathrm{SO}_{4}\right)_{2}+12 \mathrm{H}_{2} \mathrm{O} \text {. }
$$

Chromsäure. Die Chromsäure, $\mathrm{H}_{2} \mathrm{CrO}_{4}$, entspricht in ihren Salzen völlig der Schw efelsäure, ist aber nicht in freiem Zustande zu erhalten, da sie sogleich in ihr Anhydrid $\mathrm{CrO}_{3}$ und Wasser zerfällt. Sie hat also die Konstitution:

$$
\mathrm{CrO}_{2}<\underset{\mathrm{OH}}{\mathrm{OH}}
$$

Chromtrioxyd $\mathrm{CrO}_{3}$, Chromsäureanhydrid, entsteht aus Kaliumdichromat und konz. Schwefelsäure in roten, langen Nadeln, die sehr heftig oxydierend wirken und in der Medizin als A etzmittel verwendet werden (Acidum chromicum). Es gibt bei ca. $250^{\circ}$ Sauerstoff ab und geht in Chromoxyd über.

Kaliumchromat, $\mathrm{K}_{2} \mathrm{CrO}_{1}$, gelbes chromsaures Kalium, entsteht durch Schmelzen von Chromeisenstein mit Salpeter. Gelbe, rhombische Kristalle.

Beim Erwärmen mit Säuren geht es in Kaliumdichromat, rotes, chromsaures Kalium $\mathrm{K}_{2} \mathrm{Cr}_{2} \mathrm{O}_{7}$ über. Große, rote Kristalle. Es verhält sich zum normalen Kaliumchromat wie Pyroschwefelsäure zur Schwefelsäure.
$\begin{aligned} & 2 \mathrm{SO}_{2}< \\ & \text { OH }\end{aligned}$
Schwefelsäure
$\mathrm{CrO}_{2}<\mathrm{OK}$
Kaliumchromat$$
\mathrm{SO}_{2}<\mathrm{OH}+\mathrm{H}_{2} \mathrm{O}
$$$$
\mathrm{SO}_{2}<\mathrm{OH}
$$$$
\text { Pyroschwefelsäure }
$$$$
\begin{aligned}
& \mathrm{CrO}_{2}<\mathrm{OK} \\
& \mathrm{CrO}_{2}<\mathrm{OK}
\end{aligned}
$$
Kaliumdichromat.

Es 1 wicl 


\section{1}

Wie die Schwefelsäure bildet auch die Chromsäure Chlorverbindungen:

$$
\begin{aligned}
\text { Chlorchromsäure } \mathrm{CrO}_{2}< & \mathrm{Cl} \\
\text { Chromylchlorid } \mathrm{CrO}_{2}< & \mathrm{Cl}
\end{aligned}
$$

Nachweis: Alle Chromverbindungen sind lebhaft gefärbt. Die Chromoxydverbindungen geben mit Salpeter die Schmelze der Chromate. Die Lösungen der Chromate werden durch etwas Wasserstoffperoxyd schön blau gefärbt. Diese Färbung läßt sich mit Äther ausziehen.

\section{Molybdän.}

Mo. Atomg. 96.

In der Natur als Molybdänglanz MoS2.

Das Molybdän hat eine anßerordentlich wechselnde Valenz. Es kann zwei-, drei-, vier-, fünf-, sechs- bis achtwertig sein. Am wichtigsten ist das

Molybdäntrioxyd $\mathrm{MoO}_{3}$, das Anhydrid der Molybdänsäure $\mathrm{H}_{2} \mathrm{MoO}_{4}$, die der Schwefelsäure ähnlich ist.

\section{Wolfram.}

W. Atomg. 184.

In der Natur in Form wolframsaurer Salze: Wolfram (wolframsaures Eisen) etc.

Es erscheint zwei-, vier-, fünf- und sechswertig.

Wolframsäureanhydrid $\mathrm{WO}_{3}$, das sowohl die der Sehwefelsäure entsprechende Säure $\mathrm{H}_{2} \mathrm{WO}_{4}$, als auch die $0 \mathrm{rth}$ th olframsäure $\mathrm{WO}(\mathrm{OH})$ s bildet.

Wolfram wird zur Erzielung großer Härte dem Stahl zugesetzt (Wolframstahl). Kaliummetaw olf ramat dient zum Imprägnieren verbrennlicher Gegenstände.

\section{Uran.}

\section{U. Atomg. 239.}

Kommt als Uranpecherz $\mathrm{U}_{3} \mathrm{O}_{8}$ vor.

Es bildet als vierwertiges Element Oxydulverbindungen und als sechswertiges Oxydverbindungen. Hierbei reagiert das zweiwertige Radikal $\mathrm{UO}_{2}$ als Base, die man Uranyl nennt.

$\mathrm{UCl}_{4}$ Uranchlorür.

$\left(\mathrm{UO}_{2}\right) \mathrm{Cl}_{2}=\mathrm{UO}_{2}<\mathrm{Cl}$ Urany chlorid.

$\mathrm{UO}_{3}$ Uranoxyd $=\mathrm{UO}_{4}-0$.

Uranylnitrat $\mathrm{UO}_{2}\left(\mathrm{NO}_{3}\right)_{2}$. 
Uranoxyd färbt Glas schön grüngelb (Uranglas). Seine

sich Salze fluoreszieren stark.

\section{Radium Ra. \\ Atomg. 225.}

Dem Uran verwandt ist ein in seiner chemischen Stellung wenig anfgeklärtes Element, das höchst merkwürdige Eigenschaften besitzt. Es findet sich in Spuren fast überall; in darstellbarer Menge, aber auch in ungemein geringem Prozentsatz, in der Pechblende (einem Uranerz). Es sind bisher nur wenige co. hergestellt. Es findet sich schließlich an Baryum gebunden. Immerhin hat man seine wichtigsten chemischen Eigenschaften, wie Atomgewicht und Spektrum feststellen können. Seine auffallendste Fähigkeit ist die, daß es dauernd Strahlen verschiedener Art ( $\alpha, \beta, \gamma$-Strahlen) aussendet, die sehr intensive Wirkungen (Wärmeentwicklung, Beeinflussung lebenden Gewebes etc.) entfalten. Dabei entsteht ein rätselhaftes Gas, die Emanation, die ebenfalls Strahlen abgibt. Schließlich entsteht dabei Helium, ein früher nur auf der Sonne spektralanalytisch gefundenes Gas, das aber von Ramsay auch auf der Erde vielfach gefunden worden ist. Die Frage nach der Herkunft der Strahlen ist noch dunkel. Die Ansicht, daß sie durch einen Zerfall des Ra d i uma toms entstehen, ist gut gestützt, führt indessen zu äußerst weittragenden Konsequenzen, die unsere gesamten chemischen Grundanschauungen modifizieren müssen. Außer dem Radium kennt man noch einige andere "radioaktive" Stoffe, wie das aktive Uran, das aktive Thorium und das Pol onium (Radiotellur), die noch wenig untersucht sind.

\section{Germanium, Zinn, Blei.}

Auch in der vierten Gruppe des periodischen Systems, deren Anfangsglieder die Metalloïde Kohlenstoff und Silizium sind, sind die höheren Glieder Elemente von metallischem Charakter, ebenso, wie auf die Nichtmetalle Sauerstoff und Schwefel die Metalle Chrom und Molybdän, auf die Halogene das Mangan folgen. Es sind dies die Metalle Germanium, Zinn, Blei. Auch hier zeigt

Grur

die

$\mathrm{Clel}$ und

$\mathrm{SnC}$

mit

Das

Eist

G.

eine

Ger

and

deh:

Es ]

Sal]

säu

ver:

Koc

ist

Tee

ster

$\sin \mathrm{c}$

das

Ant

es

we1 
sich die Ähnlichkeit vorwiegend in den höheren Sauerstoffverbindungen, die Säurebildner sind.

\section{Germanium.}

Ge. Atomg. 72.

Die Existenz des Germanium war 1871 von Mendelejeff auf Grund des periodischen Systems schon vorhergesagt, ebenso wie die des Scandiums und Galliums. Es wurde dann 1886 von Clemens Winkler in einem Zinnerz aufgefunden. Das Metall und seine Verbindungen sind dem Zinn sehr ähnlich.

\section{Zinn (Stannum).}

Sn. Atomg. 119. Zwei- und vierwertig.

Es kommt in der Natur hauptsächlich als Dioxyd $\mathrm{SnO}_{2}$ (Zinnstein) vor, Es wird daraus durch Glühen mit Kohle dargestellt und durch Umschmelzen gereinigt. Das gewöhnliche Zinn enthält meist noch Arsen und Eisen.

Es ist ein silberweißes, glänzendes Metall vom spez. G. 7.3. Es hat kristallinische Struktur: beim Biegen eines Zinnstabes entsteht ein eigentümlich knirschendes Geräusch, das von der Reibung der Kriställchen aneinander herrührt (Zinngeschrei). Es ist weich und sehr dehnbar. Es schmilzt bei 2310 und siedet bei Weißglut. Es löst sich in kochender Salzsäure und Schwefelsäure. Salpetersäure löst es entweder oder oxydiert zu Zinnsäure, je nach der Temperatur. Es ist an der Luft unveränderlich und wird deshalb zum Verzinnen von Kochgeschirren etc. verwendet. Dünn ausgewalztes Zinn ist das sog. Stanniol, das als Verpackungsmittel für Tee, Schokolade etc. viel benutzt wird. Es darf höchstens $1 \%$ Blei enthalten. Legierungen des Zinns sind die mit Kupfer (Bronzen, s. b. Kupfer), ferner das Britanniameta 11 , das aus $90 \%$ Zinn und $10 \%$ Antimon besteht.

Es bildet zwei Reihen von Verbindungen, in denen es zweiwertig (Stannoverbindungen) oder vierwertig (Stanniverbindungen) auftritt. 


\section{- $144-$ \\ Stannoverbindungen.}

Zinnchlorür, $\mathrm{SCl}_{2}$, beim Auflösen von Zinn in Salzsäure. Es löst sich leicht in Wasser und wirkt stark reduzierend, indem es in Zinnchlorid übergeht. Es wird als Beizmittel in der Färberei angewendet.

Zinnoxydulhydrat $\mathrm{Sn}\left(\mathrm{OH}_{2}\right)$ aus dem Chlorür durch Alkalien. Geht beim Erwärmen in

Zinnoxydul SnO über.

Zinnsulfür SnS aus Zinnchlorürlösung durch $\mathrm{H}_{2} \mathrm{~S}$ als brauner Niederschlag.

Stanniverbindungen.

Zinnchlorid $\mathrm{SnCl}_{4}$ aus Zinn oder Zinnchlorür und Chlor. Farblose rauchende Flüssigkeit.

Zinnehloridammoniumehlorid $\mathrm{SnCl}_{4}\left(\mathrm{NH}_{4} \mathrm{Cl}\right)_{2}$ dient als Zinnsalz zur Beize in der Kattundruckerei.

Zinnoxyd $\mathrm{SnO}_{2}$ Zinnsäureanhydrid kommt in der Natur als Zinnstein vor. Dargestellt wird es durch Erhitzen von Zinn an der Luft. Weißes Pulver, unlöslich in Säuren und Alkalien.

Kocht man eine alkalische Lösung von Zinnhydroxydul, so zersetzt sie sich in metallisches Zinn und zinnsaures Natrium. Aus diesem erhält man durch Salzsäure die Zinnsäure $\mathrm{H}_{2} \mathrm{SnO}_{3}$ als weißen Niederschlag, der in Säuren und Alkalien leicht löslich ist. Durch Aufbewahren unter Wasser wandelt sie sich in die sog. Metazinnsäure um, die dieselbe Zusammensetzung hat, aber in Säuren und Alkalien unlöslich ist. Die Zinnsäure ist der Kohlensäure $\mathrm{H}_{2} \mathrm{CO}_{3}$ und der Kieselsäure $\mathrm{H}_{2} \mathrm{SiO}_{3}$ analog.

Zinnsulfid $\mathrm{SnS}_{2}$ aus Zinnchloridlösung durch $\mathrm{H}_{2} \mathrm{~S}$ als gelber Niederschlag. Man erhält es auch aus Zinn und Schwefel durch Zusammenschmelzen unter Zusatz von Salmiak als goldgelbe, kristallinische Masse, die als Musivgold zum Bronzieren verwendet wird. Es löscht sieh in Sehwefelnatrium zu Natriumsulfostannat $\mathrm{Na}_{2} \mathrm{SnS}_{3}$.

Nachweis: HeS fällt gelbes Sulfid, das in Schwefelammonium löslich ist. 


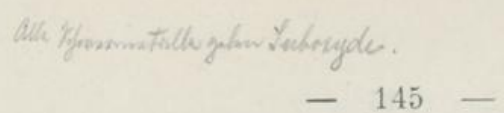

\section{Blei (Plumbum).}

lz-

rk

Es

en.

aer

nd

alz

er

ch

n-

lr-

nd

z-

$\lg$,

ch

g.

ng

lie

el-

ser

ch

be,

er-

II-

Im

Pb. Atomg. 206. Zweitwertig.

Findet sich hauptsächlich als Bleiglanz PbS.

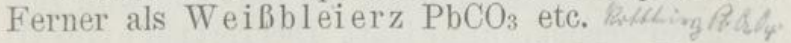

Zur Darstellung des Bleies wird der Bleiglanz an der Luft geröstet, wodurch er direkt in Blei verwandelt wird, indem der Schwefel verbrennt. Der Vorgang ist folgender:

7h/4mkik: Das Sehwefelblei wird erst zum Teil zu Bleioxyd, zum Teil zu schwefelsaurem Blei oxydiert, zum Teil bleibt es unverändert. Glüht man nun nochmals stark, /so reagiert sowohl das Bleioxyd, als auch das Bleisulfat mit dem unveränderten Bleisulfid und es resultiert Blei und Schwefeldioxyd:

1) $2 \mathrm{PbS}+70=\mathrm{PbO}+\mathrm{PbSO}_{4}+\mathrm{SO}_{2}$

2) $2 \mathrm{PbO}+\mathrm{PbS}=3 \mathrm{~Pb}+\mathrm{SO}_{2}$

$\mathrm{PbSO}_{4}+\mathrm{PbS}=2 \mathrm{~Pb}+2 \mathrm{SO}_{2}$.

Oder man glüht Bleiglanz mit Eisen.

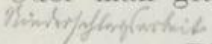

$$
\mathrm{PbS}+\mathrm{Fe}=\mathrm{FeS}+\mathrm{Pb} .
$$

Das so dargestellte Blei enthält zahlreiche Verunreinigungen, von denen es durch umständliche Prozesse

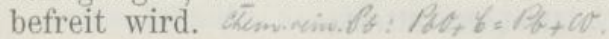

Das Blei ist ein Metall von bläulich weißer Farbe, sehr weich und leicht schmelzbar (bei $330^{\circ}$ ). Spez. G. 11.4. Es besitzt auf frischer Schnittfläche hohen Glanz, wird aber an der Luft schnell matt. Beim Erhitzen an der Luft verbrennt es zn Bleioxyd.

In reinem Wasser ist Blei etwas löslich, in gewöhnlichem, kohlensäurehaltigem Wasser bedeckt es sich sehr bald mit einer Schicht von unlöslichem Karbonat und wird nun nicht weiter angegriffen. Nur wenn das Wasser viel Kohlensäure enthält, ist auch das Karbonat etwas löslich. Dies Verhalten ist für die Hygiene von großer Bedeutung, da Blei sehr viel zu Wasserleitungsröhren verwendet wird, und wenn es in Lösung geht, das Wasser vergiftet. Durch Salzsäure resp. Schwefelsäure wird Blei nur wenig angegriffen. Sal-

Oppenheimer, Grundriss der anorg. Chemie, 4. Aufl. 10 
petersäure löst es leicht. Zink und Eisen scheiden es aus seinen Verbindungen metallisch ab (Bleibaum).

Legierungen: Eine Legierung aus gleichen Teilen Zinn und Blei schmilzt schon bei $186^{\circ}$ und wird zum Löten verwendet (Schnellot). Das Letternmetall B, okish bisk besteht aus $4-5$ Teilen Blei und 1 Teil Antimon.

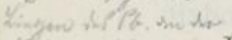

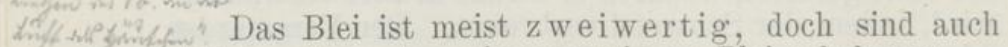

Abkömmlinge des vierwertigen Bleies bekannt.

Ziktangysman Bleioxyd, Bleiglätte, $\mathrm{PbO}$ entsteht durch Erhitzen Bes, ara $_{\text {von }}$ Blei. Es ist eine starke Base, zieht an der Luft

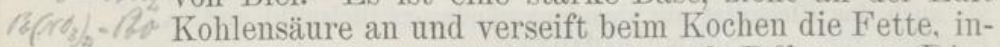

$+V_{2} b_{3}+b_{3}$. dem es fettsaures Blei bildet, das als Pflaster (Diachylonpflaster) vielfach in der Medizin verwendet wird.

Bleihydroxyd $\mathrm{Pb}(\mathrm{OH})_{2}$. Aus Bleisalzen durch Kalilauge als weißer Niederschlag. Etwas löslich in Wasser.

Bleichlorid $\mathrm{PbCl}_{2}$ fällt aus Bleisalzlösungen durch Salzsäure. Ziemlich leicht löslich in heißem, fast unlöslich in kaltem Wasser.

Bleijodid $\mathrm{PbJ}_{2}$. Goldgelbe Blättchen.

Bleinitrat $\mathrm{Pb}\left(\mathrm{NO}_{3} / 2\right.$. Durch Auf lösen von Blei in Salpetersäure.

Bleisulfat $\mathrm{PbSO}_{4}$. Unlöslich in Wasser, leicht in Natronlauge.

Bleichromat $\mathrm{PbCrO}_{4}$ kommt als Rotbleierz in der Natur vor. Entsteht als rotgelber Niederschlag aus Bleinitrat und Kaliumchromat. Wird als Anstrichfarbe benutzt.

Bleikarbonat $\mathrm{PbCO}_{3}$ kommt als Weißbleierz vor. Ein basisches Bleikarbonat $\left(2 \mathrm{PbCO}_{3}, \mathrm{~Pb}(\mathrm{OH})_{2}\right)$ ist das Bleiweiss, das eine wichtige Malerfarbe ist. Man stellt es jetzt dar, indem man Bleioxyd in Essigsäure löst und das entstandene basisch-essigsaure Blei durch Kohlensäure zersetzt. Das Bleiweiß schwärzt sich an der Luft unter Bildung von Schwefelblei und wird deshalb jetzt mehr und mehr durch Zinkweiß und Baryumsulfat verdrängt. 
Bleisulfid $\mathrm{PbS}$ kommt als Bleiglanz vor. Es fällt aus Bleisalzlösungen dureh Schwefelwasserstoff als schwarzer Niederschlag.

Von den sich vom vierwertigen Blei ableitenden Verbindungen sind nur wenige bekannt. Durch Er-3r-4m '

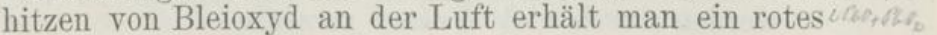
Pulver, die sog. Mennige, die die Zusammensetzung $\mathrm{Afm}_{3} \mathrm{O}_{4}$ hat und als rote Malerfarbe benutzt wird. Sie ist eine Verbindung von Bleioxyd $\mathrm{PbO}$ mit dem Bleiperoxyd $\mathrm{PbO}_{2}$. Behandelt man nämlich Mennige mit Salpetersäure, so löst das Bleioxyd sich auf und es bleibt das Bleiperoxyd als braunes Pulver zurück, das sich in Kalilauge zu bl ei sa urem Kalium, Kaliumplumbat $\mathrm{KPbO}_{3}$ löst, das dem zinnsauren Kalium analog ist.

Das Bleiperoxyd ist also als das Anhydrid der Bleisäure aufzufassen.

Auch das $\mathrm{Bleitetrachlorid} \mathrm{PbCl}_{4}$ ist bekannt.

Alle Bleiverbindungen sind sehr giftig. Arbeiter, die viel mit Blei zu tun haben (Maler, Schriftsetzer), leiden oft an chronischen Bleivergiftungen, die sich in Koliken (Bleikolik), Gicht und Lähmungen äußern.

Nachweis: $\mathrm{H}_{2} \mathrm{~S}$ fällt schwarzes Schwefelblei, Schwefelsäure weißes Bleisulfat, das sich in Natronlauge löst.

\section{Wismut (Bismutum).}

Bi. Atomg. 208.

Das Wismut, welches das letzte Glied der sonst metalloïden Stickstoffgruppe darstellt, zeigt seinen metallischen Charakter darin, daß es keine Wasserstoffverbindung mehr bildet, und daß seine Oxyde zum Teil nur sehr schwache Säuren sind, wie das Pentoxyd $\mathrm{Bi}_{2} \mathrm{O}_{3}$, oder sogar basischer Natur, wie das Trioxyd $\mathrm{Bi}_{2} \mathrm{O}_{3}$.

Vorkommen: Hauptsächlich gediegen. Dann als Wismutglanz $\mathrm{Bi}_{2} \mathrm{~S}_{3}$; ferner in manchen Erzen.

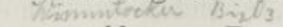

Darstellung: Das Schwefelwismut wird geröstet und das entstehende Wismutoxyd durch Kohle reduziert. 


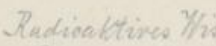

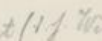

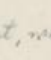

\section{$-148-$}

Eigenschaften: Rötlich weißes Metall. Spez. G. $10^{*}$ Spröde, leicht pulverisierbar. Schmilzt bei 267". Verbrennt beim Erhitzen an der Luft. Unlöslich in Salzsäure, leicht in Salpetersäure löslich. Seine Salze werden durch viel Wasser zersetzt.

Die Legierungen des Wismuts zeichnen sich durch leichte Schmelzbarkeit aus: Roses Metall (Sn, Pb, Bi) bei $94^{\circ}$; Woodsehes Metall ( $\mathrm{Sn}, \mathrm{Pb}, \mathrm{Cd}, \mathrm{Bi})$ bei $65^{\circ}$; letzteres ist die am leichtesten schmelzbare aller Legierungen.

Wismutchiorid $\mathrm{BiCl}_{3}$ aus Wismut und Chlor. Pulver.

Wismutoxyd $\mathrm{Bi}_{2} \mathrm{O}_{3}$ Durch Verbrennung von Wismut. Gelbes

Wismutpentoxyd $\mathrm{Bi}_{2} \mathrm{O}_{5}$. Anhydrid der Wismutsäure $\mathrm{HBiO}_{3}$.

Wismutnitrat $\mathrm{Bi}\left(\mathrm{NO}_{3}\right)_{3}$. Durch Auflösen von Wismut in Salpetersäure. Wasser fällt einen käsigen, weißen Niederschlag (Bismutum subnitricum), der in der Medizin verwendet wird. $2 B_{i}(O H) \frac{B}{3}\left(r_{3}\right)_{3}$

Wismutsulfid $\mathrm{Bi}_{2} \mathrm{~S}_{3}$ fällt aus Wismutsalzlösungen durch Schwefelwasserstoff als schwarzer Niederschlag.

\section{Metalle der Platingruppe.}

\section{Platin, Palladium, Rhodium, Ruthenium, Osmium, Iridium.}

Die Platinmetalle gehören zur achten Gruppe des periodischen Systems, zu der auch das Eisen gehört, und zeigen auch eine gewisse Analogie zu den Metallen der Eisengruppe. Man teilt sie in zwei Gruppen: die leichten Platinmetalle:

$$
\text { Ru } 101 \quad \text { Rh } 103 \quad \text { Pd 106, }
$$

die ein spez. G. von ca. 12 haben; und die schweren:

$$
\text { Os } 189.5 \text { Ir } 192,50 \quad \text { Pt } 194 \text {, }
$$

die ein spez. G. von ca. 22 besitzen. Doch gehören $\mathrm{chem}$ isch die untereinander stehenden zusammen.

Ruthenium und Osmium sind sehr schwer schmelzbar, an der Luft sehr veränderlich. Sie bilden Säuren, die sich 


\section{Ruthenium.}

Ru. Atomg. 101.5.

Stahlgraues Netall, hart, schmilzt bei $1800^{\circ}$. Löst sich schwierig in Königswasser. Bildet ein Oxydul RuO, ein Oxyd $\mathrm{Ru}_{2} \mathrm{O}_{3}$ und gibt mit Ätzkali geschmolzen rutheniumsaures Kalium $\mathrm{K}_{2} \mathrm{RuO}_{4}$, Auch überrutheniumsaures Kalium $\mathrm{KRuO}_{4}$, analog dem übermangansaurem Kalium, ist bekannt.

\section{Osmium.}

Os. Atomg. 189.5.

irt,

Schmilzt erst bei $2500^{\circ}$. Unlöslich selbst in Königswasser. Bildet ebenfalls das $\mathrm{Oxydul} O \mathrm{~s} O$, das $\mathrm{Oxyd} \mathrm{Os}_{2} \mathrm{O}_{3}$, und osmiumsaures Kalium $\mathrm{K}_{2} \mathrm{OsO}_{4}$.

Beim Glühen an der Luft geht es in $\mathrm{OsO}_{4}$ Uberosmiumsäureanhydrid, sogen. Osmiumsäure über. Farblose Prismen, die sich in Wasser lösen und heftig oxydierend wirken, indem sie dabei metallisches Osmium abscheiden. Die Lösung hat einen durchdringenden Geruch. Durch Oxydation färbt die Lösung F e tt e schwarz und wird deshalb in der mikroskopischen Technik angewendet (Flemmingsehe Lösung). Es bildet keine Salze. Osmium wird an Stelle des Kohlenfadens in der neuen Auerschen elektrischen Glühlampe verwendet.

1) $\mathrm{Me}=$ Metall, also $\mathrm{Ru}$ oder Os etc., einzusetzen. 
Rhodium, Iridium.

Rh. $=103$, Ir. $=192.5$.

Sind etwas leichter schmelzbar wie Osmium. Unlöslich in Königswasser. Geben Oxydule, Oxyde und Superoxyd $\mathrm{MeO}_{2}$, die kein e Säuren bilden. Das Iridium wird als Legierung mit Platin verwendet. Das Metall des Normalmeterstabes der ,internationalen Maß- und Gewichtskommission" in Paris besteht aus einer Legierung von $90 \%$ Platin und $10 \%$ Iridium.

\section{Palladium.}

\section{Pd. Atomg. 106.}

Schmilzt bei $1400^{\circ}$. Löst sich sogar in Salzsäure; Schwefelsäure und Salpetersäure, wenn auch schwer. Es absorbiert sein neunhundertfaches Volumen Wasserstoff, den es beim Erwärmen wieder abgibt. Man faßt diese Reaktion jetzt als eine ,feste Lösung “ von Wasserstoff in Palladium auf.

Es bildet 2 Reihen von Verbindungen, Oxydulverbindungen $\mathrm{PdO}$ und Oxydverbindungen $\mathrm{PdO}_{2}$.

Palladiumchlorür $\mathrm{PdCl}_{2}$ ans Palladium durch Auflösen in Königswasser.

Palladiumjodür PdJँ, schwarzes, in Wasser unlösliches Pulver das zum Nachweis von Jod dient

Palladiumchlorid $\mathrm{PdCl}_{4}$ geht leicht in das Chlorür über.

\section{Platin.}

\section{Pt. Atomg. 194.}

Grauweißes Metall vom spez. G. 21.4. Sehr zähe, läßt sich zu dünnem Draht und Blech verarbeiten. Schmilzt bei $1770^{\circ}$. Fein verteiltes Platin, Platinschwamm oder Platinmohr, absorbiert reichlich Sauerstoff. Daher wirkt Platinschwamm an der Luft stark oxydierend, entzündet z. B. W as serstoff.

Infolge seiner ungemein großen Beständigkeitgegen alle chemischen Einflüsse ist Platin ein außerordentlich wertvolles Material zur Anfertigung von Schalen, Tiegeln, sowie von Präzisionsinstrumenten (Wagen, Gewichten etc.). Noch widerstandsfähiger ist seine Legierung mit Iridium. Alkalien greifen es in der Hitze an; ferner löst es sich in $\mathrm{K}$ ö nigswasser. Es bildet ebenfalls Oxydulverbindungen und Oxydverbindungen. 


\section{$-151-$}

Platinchlorür $\mathrm{PtCl}_{2}$ gibt mit Kalilauge das K-Salz der Platinochlorwasserstoffsäure $\mathrm{H}_{2} \mathrm{PtCl}_{4}$.

Platinchlorid. $\mathrm{PtCl}_{4}$ entsteht beim Auflösen von Platin in Königswasser. Gibt mit Salzsäure eine additionelle Verbindung, die Platinchlorwasserstoffsäure, eine zweibasische Säure $\mathrm{H}_{2} \mathrm{PtCl}_{6}$, die Salze, die sog. Chloroplatinate bildet:

Kaliumchloroplatinat $\mathrm{K}_{2} \mathrm{PtCl}$.

Ammoniumchloroplatinat $\left(\mathrm{NH}_{4}\right)_{2} \mathrm{PtCl}$ ist der $\operatorname{sog}$. Platinsalmiak.

Piatinhydroxyd $\mathrm{Pt}(\mathrm{OH})_{4}$ gibt sowohl mit Säuren Salze, z. B. $\mathrm{Pt}\left(\mathrm{SO}_{4}\right)_{2}$ Platinsulfat, als auch mit Basen, z. B.

$\mathrm{Pt}<\underset{\mathrm{O}_{2} \mathrm{Ba}}{(\mathrm{OH})_{2}}$ Baryumplatinat.

Es hat also auch saure Eigenschaften.

\section{Qualitative Analyse.}

Es ist hier natürlich nicht der Ort, eine ausführliche Auseinandersetzung der Methodender Analyse zu geben; die genaue Bestimmung der Gewichtsverhältnisse der einzelnen Elemente, die quantitative An alys e, ist ein besonderer Zweig unserer Wissenschaft geworden, und selbst ein kurzer Abriß derselben würde schon ein stattliches Bändchen füllen. Wir können hier nur ein ganz kurzes Schema der qualitativen Analyse geben, d. h. derjenigen Methoden, die man anzuwenden hat, um das V or han densein eines Elementes in einer Verbindung nachzuweisen. Diesem Zwecke zu dienen, hat man für die einzelnen Elemente Erkennungsreaktionen ausfindig gemacht und diese einzelnen Reaktionen in ein bestimmtes Schema gebracht. Doch auch hier muß für den Rahmen dieses Büchleins noch die Einschränkung gemacht werden, daß die zu untersuchende Verbindung, nur aus zwei Bestandteilen, einem basischen und einem sauren bestehen soll; daß wir also ein einfaches Salz untersuchen wollen. Die beiden Haupttypen der Erkennungsreaktionen sind die Fällungsreaktionen, die uns Niederschläge von bestimmter eindeutiger Art, und F ar ben reaktionen, die uns bestimmte Farbennüancen liefern. Nur aus- 


\section{$-152-$}

uahmsweise wenden wir andere, z. B. Geruchsreaktionen an.

Nehmen wir nun an, wir hätten einen einheitlichen Körper, z. B. ein Metallsalz zu untersuchen, so geben uns schon dessen physikalische Verhältnisse gewisse Anhaltspunkte für seine Beurteilung. Haben wir z. B. ein farbloses Salz, so sind damit schon die Kupfer-, Chrom- und Mangan-Verbindungen ausgeschieden, die sämtlich gefärbt sind: ist der Körper in Wasser löslich, so ist er jedenfalls nicht ein Karbon at oder Phosphat eines Schwermetalls, da diese sämtlich in Wasser unlöslich sind $\mathrm{u}$. dergl. $\mathrm{m}$.

Wir versuchen also zunächst den Körper in Wasser zu lösen. Ist er in Wasser nicht löslich, so versuchen wir ihn in verdünnter Salzsäure zu lösen; versagt auch diese, so versuchen wir es mit Sal petersäure und schließlich mit Königswasser. Ist der Körper auch in diesem unlöslich, so gibt es andere Methoden, um ihn doch noch in lösliche Form überzuführen. Nehmen wir also an, der Körper hätte sich gelöst, so ist der Gang der Untersuchung nun folgender:

I. Man versetzt einen Teil der erhaltenen Lösung mit einigen Tropfen Salzsäure. Ein weißer Niedersehlag deutet auf Blei, Quecksilberoxydul, Silber. Man behandelt diesen Niederschlag mit Ammoniak.

1) Er bleibt unverändert, löst sich aber in kochendem Wasser ............ Blei.

2) $\mathrm{Er}$ löst sich auf ........ Silber.

3) Er wird schwarz . . . . . . Quecksilberoxydul.

II. Man versetzt, auch wenn Salzsäure einen Niederschlag erzeugt ${ }^{1}$, die salzsaure Lösung mit Schwefelwasserstoff. Es entsteht ein Niederschlag:

1) Dieser ist schwarz oder braunschwarz.

Man kocht mit Salpetersäure:

a) er löst sich

a) die Lösung gibt mit Ammoniak:

1) einen weißen Niederschlag .... Wismut.

2) eine Blaufärbung ......... Kupfer ${ }^{2}$.

$\beta$ ) Mit Schwefelsäure einen

weißen Niederschlag. ........ Blei.

y) mit Salzsäure einen weißen

Niederschlag $(\mathrm{s}$, o.). . . . . . . . Silber.

1) Dies geschieht 1) weil auch Antimonsäure und antimonige Säure mit Salzsäure Niederschläge ergeben; 2) weil Blei nur aus konzentrierten, kalten Lösungen durch Salzsäure gefällt wird.

2) Dann muß die ursprüngliche Lösung blau gewesen sein. 
b) Er löst sich nicht.

Man löst ihn in Königswasser, Zinnchlorür gibt einen weißen Niederschlag ...... Quecksilber.

2) $\mathrm{Er}$ ist $\operatorname{rot} \ldots \ldots \ldots \ldots$ Antimon. . . . . . . .

3) er ist gelb oder braun.

Man behandelt mit erwärmtem Schwefelammonium.

a) Er löst sich nicht ......... Kadmium.

b) Er Iöst sich.

Yan fällt ihn dureh Salzsäure wieder:

๙) Er löst sich in kochender Salzsäure, Quecksilberchloridlösung gibt einen weißen Niederschlag ............... Zinn.

B) Eine Probe der Substanz gibt die Marshsche A rsen probe (s. d.) .......... Arsen.

III. Schwefelwasserstoff bringt in saurer Lösung keinen Niedersehlag hervor. Man versetzt mit Ammoniak und Schwefelammonium.

Es fällt ein Niederschlag:

1) Dieser ist weiß.

a) Er löst sich in Ammoniak ...... Zink.

b) Er löst sich nicht........... Aluminium.

2) $\mathrm{Er}$ ist fleischfarben .......... Mangan.

3) $\mathrm{Er}$ ist graugrün (Chromhydroxyd) ..... Chrom').

4) $\mathrm{Er}$ ist schwarz.

a) Er löst sich in Salzsäure . . . Eisen ${ }^{2}$ ).

b) Er löst sich nicht.

a) die ursprüngliche Lösung des Salzes gibt mit Kaliumnitrit einen gelben Niederschlag. . Cobalt.

B) keinen Niederschlag . . . . . . Nickel.

IV. Wenn Schwefelammonium keinen Niederschlag gibt, setzt man zur ursprünglichen Lösung Natriumkarbonat. Es entsteht ein weißer Niederschlag; dieser wird in Essigsäure gelöst.

Einige Tropfen Kalium chromatlösung geben

1) Einen gelben Niederschlag. ...... Baryum.

1) Mangan- und Chromverbindnngen werden ferner daran erkannt, daß sie, mit Salpeter geschmolzen, eine grüne (Mangan) oder gelbe Schmelze (Chrom) ergeben.

2) Die speziellen Erkennungsreaktionen des Eisens, die seinen Nachweis ohne weiteres gestatten, sind bei seiner Besprechung im speziellen Teil angegeben (s. S. 136). 
2) Keinen Niederschlag.

In einer andern Probe gibt Gypslösung

a) einen Niederschlag ......... Strontium.

b) keinen Niederschlag.

Oxalsäure gibt

a) einen Niederschlag . . . . . . . Kalzium.

ß) keinen Niederschlag.

Phosphorsaures Natrium mit Ammoniak gibt einen

Niederschlag .............. Magnesium ${ }^{1} \%$.

V. Das Salz kann, wenn auch Natriumkarbonat keinen Niederschlag gibt, nur noch Kalium, Natrium und Ammonium enthalten.

1) Eine Probe der Substanz gibt mit Kalilauge gekocht den charakteristischen Ammoniakgeruch ... Ammonium.

2) Das Salz färbt die Bunsenflamme
a) gelb ................... Natrium.
b) violett ................ Kalium.

Für die Bestimmung des sauren Anteils gibt es kein so festes schema. Man verfährt gewöhnlich folgendermaßen:

1. Die Substanz braust mit Salz äure auf. Es entweicht
a) ein geruchloses Gas .......... Kohlensäure.
b) Schwefeldioxyd ............ schweflige Säure.
c) Schwefelwasserstoff ......... Schwefelmetall.

II. Eine Probe der Lösung gibt mit Salpetersäure und Silbernitrat

a) einen weißen Niederschlag, der in Ammoniak löslich ist . . . . . . . . . . Salzsäure.

b) Einen gelben Niederschlag, der in Ammoniak a) löslich ist . . . . . . . . Bromwasserstoff.

B) nicht löslich ist . . . . . . . . Jodwasserstoff.

III. Gibt Silbernitrat keinen Niederschlag, so wird eine andere Probe mit Chlorbaryumlösung versetzt. Sie gibt einen weißen Niederschlag. Er ist in Salzs äure

1) unlöslich ............. Schwefelsäure

2) $10 ̈$ slich

a) Eine Probe der Lösung wird mit Essigsäure und $\mathrm{Gi}$ pswas ser versetzt. Ein Niederschlag zeigt . ............ Oxalsäure.

b) Eine Probe der Substanz verkohlt beim Erhitzen ............... Weinsäure.

c) Eine andere Probe mit Alkohol übergossen brennt mit grüngesäumter Flamme . . . . . . Borsäure.

d) Eine Probe der Lösung mit Salpetersäure und A mmoniummolybdat versetzt, gibt einen gelben Nieder schlag ............. Phosphorsäure.

1) Für Erkennung dieser vier Elemente gibt es auch mannigfache andere Methoden. 
IV. Versagt auch diese Reaktion, so erhitzt man

1) eine Probe der Substanz mit Kupfer und konz. Schwefelsäure. Rote Dämpfe von Stickstoffdioxyd beweisen . . . . . . . . . . Salpetersẩure.

2) Eine andere Probe mit konz. Schwefelsäure und Alkohol. Ein Apfelgeruch von Essigäther zeigt . . Essigsäure.

Diese hier angegebenen Reaktionen werden mitunter durch andere ersetzt, zumal, wenn es sich darum handelt, mehrere Stoffe nebeneinander zu finden. Dadurch wird die Untersuchung natürlich ungleich komplizierter. Ich kann hier darauf nicht näher eingehen.

\section{Spektralanalyse.}

Eine ganz eigenartige Methode der Untersuchung und des Nachweises von Elementen wurde im Jahre 1859 von Bunsen und Kirchhoff in die Wissenschaft eingeführt, die Spektralanalyse.

Das weiße Licht wird bekanntlich durch ein Prisma re. in ein kontinuierliches Farbenband, das Spektrum, zerlegt, dessen Farben von vi olett über bla u, g rün, gelb, orange in rot übergehen. Analog verhält sich das Licht, das glühende feste Körper, z. B. glühende Netalle, Kalk etc. ausstrahlen. Dagegen besteht das Spektrum glühender Gase aus einzelnen Linien, die für jedes Element bestimmt charakterisiert sind und stets dieselbe Stellung im Spektrum inne haben. Diese Linie nennt man auch Spektra der Gase. So besteht das Spektrum des Natriumdampfes aus 2 gelben Linien, das des Kaliums aus einer roten und blauen Linie etc. Wenn man also die Spektra von Gasen untersucht, so kann man durch die bestimmten Linien bestimmte Elemente erkennen. Dazu dient der Spektralapparat, dessen wesentlichster Bestandteil das lichtbrechende Prisma ist, welches das Licht, das von den glühenden Gasen ausgeht, auf eine empirische Skala projiziert, wo man die Linien durch ein kleines, am Apparat befindliches Fernrohr beobachtet.

Oft genügt zur Erzielung von glühendem Gas die Einführung der zu untersuchenden Substanz in die 


\section{$-156-$}

Bunsenflamme. Bei schwerer flüchtigen Stoffen läßt man den elektrischen Funken zwischen Elektroden aus dem zu untersuchenden Stoff durchsehlagen; so kann man z. B. das Spektrum des Goldes etc. bestimmen. Die el e mentaren Gas e werden in Geißlerschen Röhren durch elektrische Entladungen zum Leuchten gebracht und geben so ihr Spektrum.

Die Spektralanalyse hat schon mehrfach zur Entdeckung neuer Elemente geführt: Bunsen selbst entdeckte das Rubidium und Caesium (charakterisiert durch eine sehr helle rote resp. blane Linie); ferner wurde so das Gallium, Germanium u. a. entdeckt.

Sie dient jetzt auch als sehr wichtiges Hilfsmittel der Astronomie, nicht nur für die Bestimmung von Elementen auf fernen Fixsternen 1), sondern sie ist sogar für die messende Astronomie dienstbar geworden, die aus den Verschiebungen der Spektrallinien von Fixsternen ihre Bewegungen auf uns zu oder von uns weg: $\mathrm{zu}$ berechnen gelernt hat.

\section{Geschichtlicher Rückblick.}

Den Völkern des Altertums waren nur sieben Met alle bekannt: Eisen, Blei, Zinn, Kupfer, Silber, Gold, Quecksilber; ferner kannten sie allerdings den S ch w efe l und einige andere chemische Stoffe. Im Laufe des Mittelalters waren es zunächst die Araber, die die Chemie pflegten, namentlich Geber. Ihnen gelang die Darstellung der'Schwefelsäure, des Alkohols etc. Weiterhin entwickelten sich im wesentlichen zwei Richtungen der angewandten Chemie, die Alchymisten, die chemische Studien in der Hoffnung trieben, aus unedlem Material Gold zu erzeugen, und die Jatrochemiker, die die Chemie der Heilkunst dienstbar machten. Der Alchymistik verdankt die Chemie u. a. die Entdeckung des Phosphors. Unter den Jatro-

1) Mit Hilfe der Fraunhoferschen Linien, s. in den Lehrbüchern der Physik. 
chemikern ragte namentlich $\mathrm{P}$ ar acelsus um die Mitte des sechzehnten Jahrhunderts hervor, namentlich durch seine Arbeiten über das kürzlich entdeckte A ntimon. Zur selbständigen Wissenschaft erhob die Chemie Boy le. Yit ihm beginnt die Zeit der Gasuntersuchungen. die zu der Entdeckung der Kohlensäure, des Wasserstoffs etc. führten. Mit Lavoisiers klassischen Arbeiten über das Wasser beginnt die moderne Chemie. die quantitative Forschung. Dalton (1808) begründet die Atomtheorie, Berzelius schaftt die quantitative Analyse und bestimmt von vielen Elementen die Atomgewichte. Dazn werden zahlreiche neue Elemente entdeckt. Die organische Chemie beginnt sich zu entwickeln: Chevreuil klärt die Konstitution der Fette auf; Wöhlers Harnstoffsynthese schafft neue Bahnen für die Synthese der Kohlenstoffverbindungen; die Su bstitutionsth eorie die Grundlagen dafür. Die Benzolderivate werden bekannt. Farbstoffe von großem technischen Werte, wie F uchsin, entdeckt das schöpferische Genie A. W. H ofmanns, nicht minder wichtige liefern die von Grieß entdeckten Diazokörper; es beginnt der Aufbau der komplizierten Pflanzen- und Tier stoffe: E. Fischer stellt Zucker und Harnsäure synthetisch her. Unterdessen hatten Mendelejeff und Lothar Meyer die anorganische Chemie durch ihr periodisches System ebenfalls auf neue Fundamente gestellt. Ende der siebziger Jahre beginnt dann mit den klassischen Arbeiten von Arrhenius, van t'Hoff, Ostwald und Nernst das gewaltige Aufblühen der theoretischen oder physikalischen Chemie, die die Gesetze der chemischen Reaktionen und die dabei vor sich gehenden Energieumsetzungen in neues Licht gerückt haben. Aus neuester Zeit sind besonders die Entdeckungen neuer Elemente in der atmosphärischen Luft durch Raighley und Ramsay hervorzuheben, sowie Emil Fischers Arbeiten über die Konstitution der Eiweißstoffe. Aus jüngster Zeit endlich sei die Auffindung des Radiums durch das Ehepaar Curie erwähnt, deren theoretische Folgen noch gar nicht abzusehen sind. 


\section{Register.}

Abraumsalze

Absorption

Achat

Ätzkali

Ätznatron

Alabaster

Alaun

Aluminium

- -bronze

- -salze

Algarotpulver

Amethyst

Ammoniak

$$
\text { - Soda-Prozeß }
$$

A mmonium

$$
\text { - - salze }
$$

Analyse

Anhydride

Anhydrit

Anlassen d. Stahls

Anthrazit

Antimon

Antimonyl

Antimonverbind.

Apatit

Argentum

Argon

Arragonit

Arsen

$$
\begin{aligned}
& \text { — -ige Säure } \\
& \text { — -säure } \\
& \text { - -spiegel }
\end{aligned}
$$

A.

Seite

Asbest

A tmosphäre

A tome

A tomgewicht

Auripigment

Aurum

Avogadrosches Gesetz 10

Azote

B.

$128-129$

128

128

Baryum

- -verbind.

Base

Bergkristall

Beryll

Beryllium

Bessemerprozeß

$108-109$

103

108

4

40

111

133

85

82

83

83

111

123

68

112

80

82

82

81
Bismutum

Blattgold

Blei

Bleibaum

Bleiglätte

Bleikammerprozeß

Bleikolik

Bleiverbind.

Bleiweiß

Bor

Borax

Borverbind.

Boyle-Mariottesches Gesetz

Brauneisenstein

Braunstein

Britanniametall
Seite

115

67

12

82

26

67

113

$113-114$

$25 \mathrm{f}$

92

114

114

133

147

121

145

146

146

64

147

145

146

94

94,104

94

12

132

138

143 
Brom

- -verbind.

- -wasser

- - -stoff

Bronze

Butyrum Antimonii

c.

Caesium

Carnallit

Cassius Purpur

Cer

Chalzedon

Chilisalpeter

Chlor

- -chromsäure

- -goldkalium

— -ige Säure

- -kalk

- -knallgas

- oxyde

— -säure

- -stickstoff

- -wasser

- - -stoff

Chrom

_. -bleierz

- -eisenstein

- -verbind.

- -ylchlorid

Chrysopras

Cuprum

D.

Dampfdichte

Decipium

Dialysator

Diaman $t$

Diffusion

Dissoziation

Döbereinersche Zündmaschine

Dolomit

Doppelspat

Dulong-Petitsches Gesetz

Dysprosium
E.

Seite

Edelmetalle $\quad 97$

Eisen 131

Eisensäure 135

Eisenverbind. 134

Eisenvitriol 134

Elektrolyse 31

Elemente

Energie, Erhalt. d.

Erbium

131

F.

Fayence 130

Ferriverbind. $\quad 135$

Ferroverbind. $\quad 134$

Ferrum 131

Feuerstein $\quad 91$

Flamme 58

Flemmingsche Lösung $\quad 149$

Fluor 48

- -wasserstoffsäure $\quad 52$

Flußsäure $\quad 52$

Flußspat 45

Frischprozeß 134

G.

Gadolinium 131

Gallium 131

Galmei $\quad 115$

Gasglühlicht $\quad 93$

Gay-Lussaesches

Gesetz

Germanium 143

Gips 111

Glanzkobalt $\quad 136$

Glas $\quad 112$

- -ätzung 52

Glaubersalz 101

Glockenmetall $\quad 121$

Gold 126

- -verbind. 127

Gradierhäuser $\quad 101$

Graphit 84

Grauspießglanzerz $\$ 2$

GuBeisen 132 
Halogene

H.

Hammerschlag

Helium

Hoch of en prozeß

Höllenstein

Holmium

Holzkohle

Hydrargyrum

Hydrate

praecip. album

Hydrazin

Hydroschweflige S.

Hydroxylamin

Seite

I.

Indium

131

Iridium

Kippseher App.

Knallgas

Knallgolc

Kohlendioxyd

- oxyd

- oxysulfid

— -säure

- -stoff

Koaks

Kobalt

- -salze

Königswasser

Konstante Proportionen 11

Konvertor

Korund

Kreide

Kristalle

- -wasser

Kritische Temperatur

Kryolith

Jod

J.

- -stickstoff

- -wasserstoff

Krypton

Kupfer

- -kies

- -oxyd

- -oxydul

- -salze

Kadmium

K.

Kalium

- -chromat

- -dichromat

- -oxyd

- - hydrat

- -salze

- -wasserglas

Kalk

- -gelöschter

Kalkspat

Kalomel

Kalzium

- -karbid

- oxyd

- - hydrat

- -salze

Kaolin

Karat

Karborundum

Kelp

KienruB

Kieselsäure

116
105
140
140
105
105
$106-108$
107
110
111
112
118
109
112
109
110
1112
130
127
91
102
85
92

- -vitriol

Lachgas

L.

Lanthan

Lapis lazuli

Lasurstein

LeblaneprozeB

Legierungen

Leuchtgas

Lithium

- -verbind.

Luftballon

Magnesit

II.

Magnesium

132

Malachit

Mangan

122

197 


\section{$-161$}

Seite

Manganverbind.

Marienglas

Marmor

Marshscher App.

Mauersalpeter

Meerschaum

Mennige

Merkur

- -iverbind.

- overbind.

Messing

Metaphosphors.

Mörtel

Moleküle

Molekulargewich t

Molybdän

$$
\text { - -glanz }
$$

Musivgold

137

111

112

81

111

115

147

117

118

118

121

79

110

7

14

141

141

141

144

N.

Natrium
- -oxyd
- -salze
- -peroxyd
Neusilber
Neon
Nickel
Niob-glanz

0.

Opal

Osmium

- -säure
Oxydation
0zon

P.

Palladium - verbind.

Parkessches Verfahren

Passivität d. Eisens

Pattinsonsches Verf.

Periodisches System

Peroxyde

101-103

101

121,136

68

136

136

84

149

24

56

150
Phosphor

- bronze

- -chloride

- -ige Säure

- -it

— -säure

- -sulfide

- -wasserstoff

Photographie

Platin

- -verbind.

Porzellan

Pottasche

Puddelproze $h$

Pyrophosphorsäure

0.

Quecksilber

- -verbind.

$118-119$

R.

Radikal

Radium 142

Rauchende Salpeters.

Rauchtopas

Realgar

Reduktion

Rhodium

Roheisen

Roheisenstein

Rotkupfererz

Rubidium

Rubin

Ruthenium

Säuren

S.

- -anhydride

Salpeter

- -säure

Salpetrige Säure

$\mathrm{Salz}$

— -säure

Samarium

Saphir

$39 \quad$ Sauerst of $f$

Oppenheimer, Grundriss der anorg. Chemie, 4. Anfl.
117

23

Seito

74
111

76

78

111
79

79

75

150

151

130

107

133

79

65

91

82

24

150

132

133

122

108

129

149

25

40

107

72

72

25

53

131

129

129
54 
Saure Salze

Scandium

Schießpulver

Sehmiedeeisen

Schnelloth

Schwefel

$$
\begin{aligned}
& \text { - -bäder } \\
& \text { - -blumen } \\
& \text { - -dioxyd } \\
& \text { - -kohlenstoff } \\
& \text { - -leber } \\
& \text { - -milch } \\
& \text { - - säure } \\
& \text { - -trioxyd } \\
& \text { - -wasserstoff }
\end{aligned}
$$

Schweflige Säure

Schweizers Reagens

Schwerspat

Selen

Serpentin

Siedepunkt

Silber

$$
\begin{aligned}
& \text { - -glanz } \\
& \text { - -oxyd } \\
& \text { - -salze }
\end{aligned}
$$

Silizium

- -karbid

Smalte

Smaragd

Smirgel

Soda

Solvay-ProzeB

Spateisenstein

Speiskobalt

Spezif. Wärme

Spiegeleisen

Spinell

Stahl

Stanniol

Stannum

Status nascendi

Steinkohle

Stickoxyd

Stickoxydul

Stickst off

- -wasserstoffsäure

- -dioxyd

Sei te
Strontium

Seite

- -verbind.

113

Strukturformel

Sublimat $\quad 118$

Substitution $\quad 23$

Sulfurylchlorid $\quad 62$

Superoxyde $\quad 40$

Superphosphat $\quad 111$

Sylvin

Synthese

106

4

Talk

T.

Talmi

Tantal

Tellur

Terbium

Thallium

Thermochemie

Thionsäuren

Thionylchloryd

Thiosehwefels.

Thomasschlacke

Ton

Tonerde

Thorium

Thulium

Thyreoglobulin

Tinctura Jodi

Titan

Tomback

Torf

Trass

Triphyllin

Typischer Wasserstoff

U.

Überchlorsäure

Überrutheniums.

Übersättigte Lösung

Überschwefelsäure

Ultrama rin

Unguent. cinereum

Unterchlorige S.

Unterphosphorige S.

Uran

— -glas
115

121

84

66

131

131

30

61

62

65

112,134

130

129

93

131

51

51

92

121

85

110

100

28

54

149

91

61

130

117

54

78

141

142 


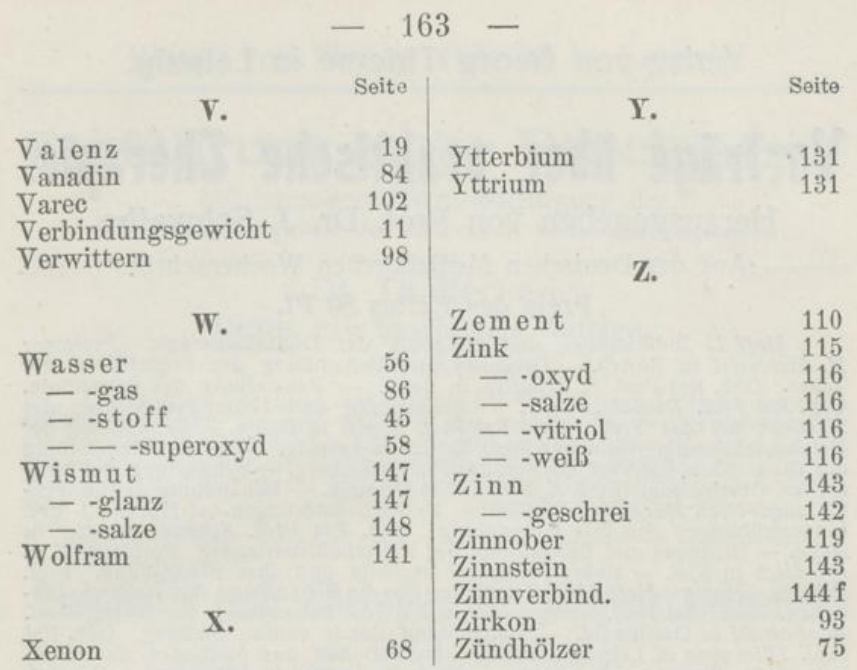




\title{
Verlag von Georg Thieme in Leipzig.
}

\section{Vorträge ïber praktische Therapie.}

\author{
Herausgegeben von Prof. Dr. J. Schwalbe.
}

(Aus der Deutschen Medizinischen Wochenschrift.)

Preis des Heftes $80 \mathrm{Pf}$.

Heft I. Indikationen und Methodik der Digitalistherapie. Professor H. Eichhorst in Zürich. - Diagnose und Behandlung der Frühstadien der Tabes. Geh. Rat Prof. F. Schultze in Bonn. - Behandlung des Panaritium. Geh. Rat Prof. Riedel in Jena. - Behandlung und Heilungsaussichten der Sterilität bei der Frau. Geh. Rat Prof. Bumm in Berlin. - Behandlung der Netzhautablösung. Geh. Rat Prof. Sattler in Leipzig. Heft II. Behandlung des Ileus. Geh. Rat Prof. Czerny, Exz., in Heidelberg. - Behandlung der habituellen Obstipation. Prof. A. Schmidt in Dresden. - Behandlung der Lungenblutung. Prof. Hochhaus in Cöln. - Ueber Sehstörungen bei Hornhaut- und Linsentrübungen und ihre Behandlung. Geh. Rat Prof. Schmidt-Rimpler in Halle, - Diagnose und Behandlung der Kieferhöhleneiterung. Professor $E$. $P$. Friedrich in Kiel. - Ueber Phimosis acquisita und ihre Behandlung. Prof. Rille in Leipzig. Heft III. Grundzüge für die Behandlung der Geisteskrankheiten. Geh. Rat Prof. Binswanger in Jena. - Behandlung der Gicht. Prof. Minkowski in Greifswald. - Behandlung durch venöse Stauung. Geh. Rat. Prof. Tillmanns in Leipzig. - Ueber Indikationen und Methoden der fakultativen Sterilisierung der Frau. - Prof. $O$. Sarwey in Tübingen. - Behandlung der nervösen Ohrerkrankungen. Prof. K. Bürkner in Göttingen. - Prophylaxe und Abortivbehandlung der Genorrhoe. Prof. Finger in Wien. Heft IV. Behandlung der Angina pectoris und des Asthma cardinale. Prof. A. Fränkel in Berlin. - Prognose und Behandlung der Albuminurie. Geh. Rat. Prof. Fürbringer in Berlin. - Behandlung des Puerperalfiebers. Geh. Rat Prof. Rosthorn in Heidelberg. - Behandlung der Katarrhe der weiblichen Genitalorgane. Prof. Dührssen in Berlin. - Behandlung der Ekzeme. Prof. Lassar in Berlin. Heft $\boldsymbol{V}$. Behandlung des Diabetes mellitus. Geh. Rat Prof. Naunyn in Straßburg. - Behandlung der Abmagerung. Geh. Rat Professor Ebstein in Göttingen. - Behandlung der Fettleibigkeit. Prof. von Noorden in Wien. - Behandlung der Herzinsuffizienz. Prof. Aug. Hoffmann in Duissel dorf. - Behandlung der Prostatahypertrophie. Prof. F. M. Oberländer in Dresden. - Heft VI. Behandlung der Arteriosklerose. Prof. E. Romberg in Tübingen. - Diagnose und Therapie der nervösen Magenerkrankungen. Dr. J. Boas in Berlin. - Die orthopädische Behandlung der Lahmungen. Geh. Rat Prof. Hoffa in Berlin. - Prognose und Behandlung der Uterusmyome. Prof. Knauer in Graz. - Diätetik des vorgeschrittenen Kindesalters. Professor Monti in Wien. Heft VII. Zur Diagnose, Prognose und Therapie der Paralysis agitans. Prof. H. Oppenheim in Berlin. - Die Behandlung der Gallensteinkrankheit. Prof. Th. Rosenheim in Berlin. - Die chirurgische Behandlung von Krankheiten des Gehirns. Prof. F. Krause in Berlin. - Die geburtshilfliche Behandlung bei Placenta praevia. Geh. Rat Prof. Fritsch in Bonn. Grundzüge einer Therapie der akuten Verdauungsstörungen des Săuglingsalters. Dr. Hochsinger, I. offentliches Kinder-Krankeninstitut in Wien. Heft VIII. Die diagnostisch-therapeutische Bedeutung der Lumbalpunktion. Geh. Rat Prof. Quincke in Bonn. - Die Behandlung der Herzneurosen. Prof. Rumpf in Bonn. - Die Leistungen und Grenzen der Lokalanästhesie. Prof. Braun in Zwickau. - Die Behandlung des chronischen Mittelohrkatarrhs. Prof, Urbantschitsch in Wien. - Therapie des Psoriasis. Prof. $v$. Düring in Kiel. Heft IX. Behandlung der Lähmungen. Geh. Rat Prof. $R$. Stintzing in Jena. - Behandlung des Pleuraempyems. Geh. Rat Prof. Braun in Göttingen. Behandlung der Skoliose. Prof. O. Vulpius in Heidelberg. - Ueber Klystiere und Irregationen. Prof. $M$. Sternberg in Wien. Heft $X$. Ueber Expektorantien. Prof. Dr. Hermann Eichhorst in Zürich. - Die Migräne. Prof. Dr. E. Mendel in Berlin. - Zur Frühdiagnose und Behandlung des Kehlkopfkrebses. Prof. Dr. B. Baginsky in Berlin. - Die Diagnose und Behandlung des Plattfußes. Prof. Dr. G. Ledderhose in Straßburg. 


\section{Einführung in die Psychiatrie.}

Mit besonderer Berücksichtigung der

Differentialdiagnose der einzelnen Geisteskrankheiten von

Dr. Th. Becker.

Dritte, neu bearbeitete Auflage.

M. 3.-

Das treffliche Büchlein, auf das wir bei seinem ersten Erscheinen empfehlend hinweisen konnten, hat sich das Bürgerrecht in der didaktischen Literatur erworben. Für den Anfänger gibt es kaum etwas Besseres, es ist kurz und doch gehaltvoll, es bereitet aut das wissenschaftliche Erfassen der Psychiatrie vor und macht mit der praktischen Handhabung derselben vertraut... Deutsche Medizinal-Zeitung.

\section{Diagnostik und Cherapie der N(agenkrankheiten} von Dr. I. Boas,

Spezialarzt für Magen- und Darmkrankheiten in Berlin. Allgemeiner Teil. Mit 54 Abbildungen.

Finnfte, veränderte und neu bearbeitete Auflage.

M. 10.50, geb. M. 11.50 .

Spezieller Teil. Mit 7 Abbildungen.

Vierte, gänzlich neu bearbeitete Auflage.

M. 8.-, geb. M. 9.-

Da die erste Auflage 1893 herauskam, so kann man wohl von einem immensen Erfolge des Buches sprechen .... Die übrigen Vorzüge des Werkes sind so bekannt, daß es Eulen nach Athen tragen hieße, wollte man noch viel Worte darüber äußern. Excerpta medica.

\section{Diagnostik und Cherapie der Darmkrankheiten} von Dr. I. Boas,

Spezialarzt für Magen- und Darmkrankheiten in Berlin.

Zweite, unveränderte Auflage.

Mit 46 Abbildungen.

M. 18.- geb. M. 19.-

Wenn ein Lehrbuch bereits im zweiten Jahre nach seinem ersten Erscheinen in zweiter Auflage vorliegt, so spricht das allein so beredt für seine Vortrefflichkeit, daß es unnötig erscheint, dieselbe noch besonders hervorzuheben. Das Boas'sche Werk verdankt seine Beliebtheit vor allem der klaren Disposition und der gut gelungenen Sichtung des praktisch Brauchbaren von der Spreu des Nebensächlichen, entsprechend seinem Leitworte: „nec ultra, nec infra scire". Das Buch ist für die Bedürinisse des Praktikers geschrieben und wird denselben in voller Weise gerecht.

Deutsche medizinische Wochenschrift. 


\title{
Lehrbuch der Hydrotherapie
}

von Dr. B. Buxbaum.

Polik1. Assistent d. Hofr. Prof. Dr. W. Winternitz u. ord. Arzt d. Fango- u. Wasserheilanstalt Wien.

Mit einem Vorwort des Hofrat Prof. Dr. W. Winternitz. Mit 34 Abbildungen und 24 Tabellen. Zweite, vermehrte Auflage.

$$
\text { M. 8.-, geb. M, 9.- . }
$$

Innerhalb zweier Jahre ist eine Neuauflage dieses ausgezeichneten Werkes notwendig geworden. Es ist dies Beweis genug. wie sehr dasselbe ein Bedürfnis war, auBerdem aber erfreulicherweise ein Beweis dafür, da $\beta$ in der Aerztewelt immer mehr und mehr die einzige richtige Auffassung sich Bahn bricht, daß die Hydrotherapie einen der wichtigsten Zweige unseres ärztlichen Könnens darstellt. Diese zweite Auflage ist wesentlich vermehrt und ergänzt worden. Vor allem ist die eingehende Würdigung der thermotherapeutischen Methoden mit Freuden zu begrußBen. Zahlreiche neue Abbildungen bringen die Methoden zur klarsten Entscheidung.

Medizinische Woche.

\section{Technik der Wasseranwendungen}

\author{
von Dr. B. Buxbaum.
}

Mit 36 Abbildungen.

M. 2.20 , geb. M. $3 .-$

. Der Student, der praktische Arzt, die keine Zeit haben, aus großen wissenschaftlichen Spezialwerken die erforderlichen Kenntnisse sich anzueignen, finden hier eine mit Illustrationen erläuterte vortreffliche Schilderung der gesamten hydriatischen Technik...

Blätter für Klin. Hydrother.

\section{Kompendium \\ der physikalischen Therapie für praktische Ärzte und Studierende von Dr. B. Buxbaum. \\ poliklin. Assist. des Hofrats Prof. Winternitz, \\ ordin. Arzt an der Fango- und Wasserheilanstalt in Wien} mit Beiträgen von

Dr. L. Herzl und Dr. F. Winkler. Mit 73 Abbildungen. M. 8.-, geb. M. 9.- .

Dieses Werk des rühmlichst bekannten Verfassers bietet dem ärztlichen Publikum ein Lehrbuch der physikalischen Heilmethoden, in dem Technik, allgemeine Wirkungsweise und spezielle Medikationen in scharf umschriebener Form klar abgehandelt worden sind... Auch dieses Buch wird bald große Verbreitung finden und dazu beitragen, die physikalischen Heilmethoden zum Allgemeingut der Aerzte zu machen.

Monatsschrift für orthopåd. Chirurgie. 
Verlag von Georg Thieme in Leipzig.

\title{
Handbuch der Cystoskopie
}

\author{
Prof. Dr. Leopold Casper,
} Zweite, umgearbeitete Auflage. Mit 116 Abbildungen und 13 Tafeln.

M. 16.-, geb. M. 17.20.

....Wir machen uns wohl keiner Obertreibung schuldig, wenn wir das Caspersche Handbuch in seiner jetzigen Form als das beste der gegenwärtigen Literatur der Cystoskopie bezeichnen.

Medizin. Centralzeitung.

\section{Die Impfstoffe und Sera.}

Grundriß der ätiolog. Prophylaxe und Therapie der Infektionskrankheiten für Ärzte etc.

von

Dr. L. Deutsch, Priv.-Doz. u. Leiter des „Jenner.Pasteur-Institutes zu Budapest.

$$
\text { M. 6.-, geb. M. 7.- }
$$

Die gemeinverständliche, klare, sachliche Darstellungsweise ist ein besonderer Vorzug des Buches, welches es jedem unschwer ermöglicht, sich aber die bedeutungsvollen Fortschritte der Impfheilmethoden zu informieren und praktischen Nutzen daraus zu ziehen.

Monatsschrift für Tierheilkunde.

\section{Leitfaden für Den geburtshilflichen Operationskurs

\author{
von
} \\ Dr. A. Döderlein,}

o. ö. Professor der Geburtshilfe u. d. Gynäkologie an d. Universität Tübingen. Mit 150 zum Teil farbigen Abbildungen. Sechste Auflage.

Geb. M. 4.- -

. . So ist in der Tat dieses Buch ein unentbehrliches Hilfsmttel des Unterrichts und ein trefflicher Ratgeber für den praktischen Arzt geworden. (Zentralbl. f. Gynäkologie.) 
Verlag von Georg Thieme in Leipzig.

\title{
Operative Gynäkologie
}

\author{
Prof. Dr. A. Döderlein und . Prof. Dr. B. Krönig \\ (Tübingen). \\ (Freiburg).
}

Mit 182 farbigen Abbildungen und einer farbigen Tafel.

Zweite erweiterte Auflage erscheint Anfang 1907.

Geb. ca.' M. 21.-

. Hier wie in allen anderen Teilen ist die zeichnerische und anderweitige Ausstattung glänzend, so wie wir sie bisher kaum in einem anderen deutschen wissenschaftlichen Werke gefunden haben

(Deutsche medizinische Wochenschrift.)

\section{Die Descendenztheorie.}

Gemeinverständliche Vorlesungen über den Auf- und Niedergang = einer naturwissenschaftlichen Hypothese, gehalten vor Studierenden aller Fakultäten

\section{Prof. Dr. A. Fleischmann \\ (Erlangen).}

Mit 124 Abbildungen.

M. 6.一, geb. M. 7.-.

Das Buch ist trotz alledem zu empfehlen, da es Freund wie Feind in gleicher Weise durch Gegenüberstellung der einzelnen Ursachen und der an sie geknüpften Spekulationen den Wert unserer stammesgeschichtlichen $\mathrm{Ab}$. handlungen der letzten 30 Jahre deutlich hervortreten läBt und zeigt, wie wenig wir auf dem bisherigen Wege erreicht haben. Alig. Literaturblatt.

\section{Die Darwinsche Theorie.}

Gemeinverständliche Vorlesungen über die Naturphilosophie der Gegenwart für Studierende aller Fakultäten.

\section{Prof. Dr. A. Fleischmann (Erlangen).}

Mit 26 Abbildungen.

M. 7.50, geb. M. 8.50.

Der bekannte Erlanger Zoologe vernichtet in diesen Vorlesungen vor Studierenden aller Fakultäten den Darwinismus von Grund aus, indem er Darwin fortwährend selbst zitiert und dann sofort Kritik übt. Das Buch ist die schärfste und exakteste Kritik des Darwinismus, die seit Wigand erSchienen ist. Wir begrüßen sie auf das lebhafteste und empfehlen ihr Studium angelegentlichst jedem, der von Darwin angekränkelt ist. Glaube und Wissen. 
Verlag von Georg Thieme in Leipzig.

\section{Grundriss der gerichtlichen NGedizin}

(ink1. Unfallfürsorge)

Mit besonderer Berücksichtigung der einschlägigen Entscheidungen des Reichsgerichts und des Reichsversicherungsamtes.

$$
\begin{gathered}
\text { Med.-Rat Dr. R. Gottschalk, } \\
\text { Kreisarzt in Rathenow. }
\end{gathered}
$$

Zweite vermehrte und verbesserte Auflage.

Geb. M. $\mathbf{5 . 5 0 \text { . }}$

Wie der Verfasser im Vorwort selbst sagt, soll sein Handbuch nicht die großen Lehrbücher ersetzen, sondern in Kürze das Wissenswerte der gerichtfichen Medizin dem Leser vor Augen führen; diesen Zweck erfüllt das Buch in ganz vorzïglicher Weise... Der Kinder-Arzt.

\section{Das physikalische Praktikum des Jichtphysikers.}

Theorie und Praxis der vorkommenden Aufgaben

für alle, denen Physik Hilfswissenschaft ist. Von

Dr. F. Grünbaum und Ingenieur R. Lindt.

Mit 123 Abbildungen.

Geb. M. 6.- .

Zweifelsohne wird das sehr empfehteswerte Buch auch seinen Weg in die phisikalischen Arbeitsräume machen.

(Naturwissenschaftliche Rundschau.)

\section{Einführung in das Studium der Bakteriologie.}

Mit besonderer Berücksichtigung der mikroskopischen Technik

Prof. Dr. Carl Günther,

Geh. Med.-Rat in Berlin.

Mit 93 Photogrammen.

Sechste vermehrte u. verbesserte Auflage.

$$
\text { M. 13.-, geb. M. } 15.80 \text {. }
$$

Seit dem ersten Erscheinen des Güntherschen Lehrbuches sind nur acht Jahre verflossen, und schon erscheint es in fünfter Auflage, ein redender Beweis dafür, daß es in vollem Maße den Ansprüchen gerecht geworden ist, die an ein Lehrbuch der Bakteriologie und der bakteriologischen Technik für Ärzte und Studierende zu stellen sind ...

Deutsche medizinische Wochenschrift. 
Verlag von Georg Thieme, in Leipzig.

\title{
Grundriss der Physik für Jrediziner
}

Stabsarzt Dr. med. Walter. Guttmann.

Mit 132 Abbildungen.

Vierte Auflage.

M. $\overline{3 .-,}$ geb. M. 3.80 .

Dies kleine Physikbuch gibt in knappester Form alles, was der Mediziner aus der Physik wissen muß. Es eignet sich besonders zur Vorbereitung für das Physikum und kann für diesen Zweck den geplagten Kandidaten viel Zeit ersparen. Es ist außerdem mit Takt und Verständnis für die schwebenden wissenschaftlichen Fragen geschrieben. Die Definitionen sind in ihrem Wortlaut sorgfältig erwogen und klar ausgedrückt. Die Grenzen physikalischer Erkenntnis sind stets angedeutet. Es hält mehr, als es verspricht und ist inhaltreicher, als nach seinem Umfange zu urteilen...

Áerztlicher Praktiker.

\section{Elektrizitätslehre für Jrediziner.}

Einführung in die physikalischen Grundlagen

der Elektrodiagnostik, Elektrotherapie und Röntgenwissenschaft von

Stabsarzt Dr. med. W. Guttmann.

Mit 263 Abbildungen und 2 Tafeln.

M. 4.80 , geb. M. 5.80

. Das äusserst klare und anschaulich praktische Buch sei nicht nur jedem fertigen Arzte, sondern ganz besonders jedem Medizinstudierenden angelegentlichst empfohlen. (Berlin, Klinischer Werkverkauf.)

\section{Einfithrung in die flugenheilkunde}

\author{
Prof. Dr. J. Hirschberg, \\ Geh. Medizinalrat in Berlin.
}

Erste Hälfte.

Mit 112 Abbildungen.

M. 8.- .

Zweite Hälfte. 1. Abt.

Mit 113 Abbild. und 1 Tafel.

M. 9.-.

Pflegt der Titel medizinischer Lehrbücher gewöhnlich den Zusatz zu tragen "für Ärzte und Studierende", so könnte hier dem Titel mit vollstem Rechte "für Studierende und Dozierende" beigefügt werden. Wer so die Ophthalmoskopie lehrt, wer danach lernt, muß zum Ziele kommen. Auch jeder mit der Anwendung des Augenspiegels vertraute Arzt wird mit Freude und Nutzen dieses durchaus eigenartige, von großem Wissen und großer Erfahrung zeugende Werk durchlesen, dessen scharfe, klare, theoretische Erörterungen mit vielen wertvollen praktischen Beispielen und auch noch mit manchen guten Ratschlägen für sprachliche Darstellung und den richtigen Gebrauch der Termini technici verbunden sind

(Schmidt's Jahrbücher der Medizin.) 
Verlag von Georg Thieme in Leipzig.

\title{
Lehrbuch der Ohrenheilkunde
}

von

\author{
Prof. Dr. L. Jacobson und Dr. L. Blau. \\ Mit 345 Abbildungen auf 19 Tafeln. \\ Dritte, neubearbeitete Auflage. \\ Geb. M. 18.- .
}

Wir glauben mit gutem Gewissen Jacobson's Lehrbuch zum besten zählen" zu dürfen, was auf dem Gebiete der Ohrenheilkunde in den letzten Jahren erschienen ist, und empfehien den Kollegen die Lektüre desselben aufs angelegentlichste."

Petersburger medizinische Wochenschrift.

\section{Sehrbuch Der Faut- und Geschlechtskrankheiten}

für Ärzte und Studierende.

Von

Dr. Max Joseph in Berlin.

lift

I. Teil: Hautkrankheiten. 51 Abbildungen und 2 Tafeln.

Vierte, vermehrte und verbesserte Auflage. M. 7.-, geb. M. 8.-.

II. T eil: Geschlechtskrankheiten. 38 Abbildungen u. 1 farbige Tafel.

Dritte. vermehrte und verbesserte Auflage. M. 7.-, geb. M. 8.-.

... Das Joseph'sche Lehrbuch stellt alles in allem ein Werk dar, welches dem praktischen Arzte und speziell dem Studierenden eine knappgefaßte, doch außerordentlich klar geschriebene und alle neueren Errungenschaften der Gebiete kritisch beleuchtende Darstellung gibt. Trotz der zahlschaften Ner Gerscheinungen von Lehrbüchern der Dermato-Syhilodologie darf dem Werke, das speziell die Interessen des Praktikers und Studenten berücksichtigt, eine günstige Prognose bezüglich weiterer Auflagen gestellt werden. Es verdient unsere vollste Empfehlung."

(Reichs-Mediz.-Anzeiger.)

\section{Der Militärarzt.}

\section{Ein Ratgeber bei der Berufswahl}

von

\section{Stabsarzt Dr. Lobedank.}

\section{1.50 .}

Es handelt sich nicht mehr um einen einzelnen militärischen Dienstzweig, sondern um die ganze Tätigkeit des Sanitätsoffiziers, wobei mit Recht zweig, sondern un werter Teile dieses Titels hingewiesen wird... Das Buch liest sich gut, und wird sich gewiß viele Freunde erwerben, hoffentlich auch durch Belehrung und Aufklärung manchen Nutzen stiften.

Deutsche medizinische Wochenschrift. 
Verlag von Georg Thieme in Leipzig.

\section{Kompendium \\ der \\ Entwickelungsyeschichte des jrenschen.}

Mit Berücksichtigung der Wirbeltiere

Prof. Dr. L. Michaelis.

Mit 50 Abbildungen und 2 Tafeln.

Zweite Auflage.

Geb. M. 4.-

Das Kompendium erhält in nuce alles Wissenswerte aus dieser täglich mehr in den Vordergrund tretenden Disziplin und steht, was man bekanntlich den Kompendien oft nicht nachsagen kann, auf ganz modernem wissenschaftlichen Standpunkt.... Deutsche medizinische Wochenschrift.

\section{Seitfaden für den gynäkologischen Opperationskurs.}

Mit Beräcksichtigung

der Operationen an der Lebenden für Ärzte und Studierende

von

Dr. E. G. Orthmann, Berlin.

Mit einem Vorwort von Prof. Dr. A. Martin.

95 zum Teil farbige Abbildungen.

Zweite Auflage.

Geb. M. 4.50 .

... Es ist gewiss nicht leicht, den Gang einer Operation klar und kurz darzustellen. Die sehr geschickte Schreibweise des Verfassers, verbunden mit einfachen, aber auf den ersten Blick verständiıchen und dabei nicht zu schematischen Zeichnungen wird auch dem Anfänger sehr schnell das Verstehen selbst komplizierter. Operationen ermöglichen ... Das kleine Werk wird sicherlich seitens der Ärzte und Studierenden die Beachtung finden, die es im vollen Masse verdient!

(Zentralblatt für Gynäkologie.)

\section{Sehrbuch Der allyemeinen physiologie.}

Eine Einführung in das Studium der Naturwissenschaft und der Medizin von J. Rosenthal.

o. ö. Professor der Physiologie an der Universität Erlangen. Mit 137 Abbildungen.

M. 14.50 , geb. M. 16.50 .

Wenn ein Forscher wie Rosenthal, der nicht nur ein großer Physiologe, sondern auch ein feinsinniger Gelehrter von tiefer, umfassender Bildung ist, als einer der letzten Mitstreiter aus der großen Zeit der deutschen Physiologie sich entschließt, der lernenden Jugend die Schätze eines reichen Wissens und die Klarheit seines langen Lebens in einer Allgemeinen Physiologie zu schenken, so muB etwas Ausserordentliches herauskommen. Und es ist ein monumentales Buch! Ein erstaunlich reiches Material ist hier verwertet, ohne je durch zu spezielles Daraufeingehen vordringlich zu werden...

(Medizinische Woche.) 
Verlag von Georg Thieme in Leipzig.

\section{Roth's klinische Jerminologie.}

Zusammenstellung der zur Zeit in der klinischen Medizin gebräuchlichen technischen Ausdrücke, mit Erklärung ihrer Bedeutung und Ableitung

von weil. Dr. Otto Roth.

Sechste, vielfach verbesserte und stark vermehrte Auflage.

Geb. M. 9.-

Von diesem Werke kann man mit vollem Recht behaupten, daß es einem tiefgefühlten Bedürfnisse entspricht und daß wir guten Grund haben, dem Verfasser für seine Gabe dankbar zu sein. Ein vortrefflicherer Führer durch dasselbe, als Roth's klinische Terminologie, dïrfte wohl schwer gefunden werden können, und stehen wir nicht an, das inhaltsreiche Buch jedem Arzte aufs angelegentichste zu empfehlen. $\quad$ (Excerpta medica.)

\section{Masern, Keuchhusten, Scharlach, Diphtherie.}

Bild und Behandlung.

Merkworte für Studierende und Praktiker

von

Prof. Dr. O. Soltmann, Leipzig.

M. -.75 .

Die Merkworte werden bei dem eminent praktischen Interesse des behandelten Gegenstandes für den Studierenden und Arzt freundliche Aufnahme finden.

\section{finatomische Tabellen \\ für Präparierübungen und Repetitionen \\ von Dr. med. C. Walther.}

Heft I. (Bänder, Muskeln, Schleimbeutel und Schleimscheiden,

Kanäle und Öffnungen etc.) Geb. M. 3.-

Heft II. (Arterien und Nerven.) Geb. M. 3.40.

Diese anatomischen Tabellen sollen in erster Linie den Studierenden der Medizin beim Arbeiten auf dem Präpariersaale zur bequemen und raschen Orientierung dienen. AuBerdem dürfen sie sich auch, wie das Vorwort richtig bemerkt, für häusliche Repetitionen - und Ref, möchte hinzusetzen, auch für bemerkt, für häusliche Repetitionen - und ollen - nützlich erweisen. Außer den von der anatomischen Gesellschaft angenommenen "Baseler" Namen sind auch die gebräuchlichsten früheren Bezeichnungen aufgenommen, was in Hinsicht auf die klinischen Semester und die Ärzte sehr zweckmäßig erscheint.... sicht auf die klinischen Semester und die Arzte sehr zweckmä forig ers Arzt wird durch solche Zusammenstellungen natürlich sehr erleichtert.

(Deutsche Medizinische Wochenschrift.) 


\title{
Seitfaden für die Schwangeren-lintersuchung
}

von

\author{
Dr. E. Winternitz.
}

a. o. Professor an der Universität Tübingen.

Mit 39 Abbildungen und 4 farbigen Tafeln.

Geb. M. 3.-

E. Winternitz's bekannte dialektische Begabung und langjährige Erfahrung im Lehrfache ließ von vornherein erwarten, daß sein Leitfaden für Studierende den beabsichtigten Zweck, diesen das Erlernen der SchwangerenUntersuchung leicht fasslich zu erläutern, voll und ganz erfillen würde. Dem Büchlein, welches sich bereits einen festen Freundeskreis erworben hat, steht vermöge seines gediegenen Wertes der Weg, sich nach Verdienst zu verbreiten, offen. (Monatsschrift f. Geburtsh. u. Gynäkol.)

\section{v. Ziemssens Rezepttaschenbuch für Jlinik und Praxis. Achte, neu bearbeitete Auflage von \\ Prof. Dr. H. Rieder (München) \\ Taschenformat. - Geb. M. 3.50.}

Das Büchlein will den oft mangelhaften Kenntnissen der jungen Ärzte in der Arzneiverordnungslehre, Drogenlehre und Arzneimittellehre zu Hilfe kommell und ihnen eine Anleitung zur Ordination geben. Durch Angabe der Preise bei den Drogen und eine Pharmacopoea oeconomica ist den Sparsamkeitsrücksichten Rechnung getragen, dabei aber die Pharmacopoea elegans nicht vergessen .... Papier, Druck und Einband sind vorzüglich.

(Sächs. Korrespondenzblatt.)

\section{Grundriss der Psychiatrie in klinischen Vorlesungen \\ von}

C. Wernicke, Zweite, revidierte Auflage.

Mit einem Bildnis des Verfassers

M. 14.-, geb. M. 15.20 .

Das Buch Wernickes gehört zu jenen, leider so wenigen Lehrbüchern der Psychiatrie, die verständlich geschrieben sind. Es ist dies ein Lob, welches an die Spitze der Besprechung gestellt werden muB... Wernicke ist einer der bedeutendsten Psychiater und ein hervorragender Kliniker, das zeigt sich auch in seinen vorliegenden klinischen Vorlesungen. Wir wollen hoffen und wünschen, daß das Buch in die weitesten ärztlichen Kreise gelange, Vermöge seiner gediegenen Form und seines vortrefflichen Inhaltes ist es dazu selten wie eines geschaffen. (Allgemeine Wiener medizinische Zeitung.) 
Verlag von Georg Thieme in Leipzig.

\section{Rauber's Lehrbuch}

der

\section{Anatomie des Menschen.}

VII. neu ausgestattete Auflage

bearbeitet von

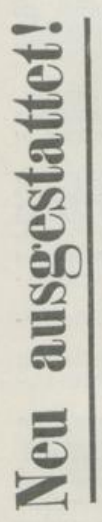

Dr. Fr. Kopseh,

Privat-Dozent und I. Assistent am Anatomischen Institut zu Berlin.

Abt. 1. Allgemeiner Teil. 221 farbige Abbild. Gebunden M. 5.-

\# 2. Skelett, Bänder. 424 farbige Abbild. Gebunden M. 8.-

\#. Muskeln, Gefässe. ca. 542 teils farbige Abbildungen. Gebunden ca. M. 10.-

4. Eingeweide erscheint Mitte November.

5. Nervensystem, erseheint Ende d. J.

6. (Sehluss), Sinnesorgane, Hirn- und

Rückenmark, Generalregister Anfang 1907.

Das altberiilımte Werk bietet mit seiner von keinem anderen Lehrbuch erreichten reichhaltigen illustrativen Ausgestaltung das vollkommenste, was die moderne Technik schafft. Durch Vergrösserung des Formates war es möglich, die Abbildungen so gross herzustellen, wie sie keiner der neueren Atlanten bringt.

Die neue Auflage macht daher die Ansehaffung eines Atlas ïberflïssig, vereinigt also in sich die Vorziige eines Lehrbuehs und eines Atlas. 


\section{Deutsche medizinische Wochenschrift.}

Begründet von Dr. Paul Börner.

Redakteur: Prof. Dr. Julius Schwalbe. - Vierteljährlich 6 Mark.

Die Deutsche Medizinische Wochenschrift hat sich während ihres 3rjährigen Besthehens zu einem der angesehensten und verbreitesten Fachblätter des In- und Auslandes entwickelt. Ihren Ruf verdankt sie in erster Linie ihren gediegenen Originalaufsätzen. In den meisten bedeutungsvollsten Fragen hat sie durch die veröffentlichten bahnbrechenden Arbeiten die Führung innegehabt, so namentlich auf dem Gebiete der TuberkuloseDiphtherie-, Cholera- und Syphilisforschung; sehr zahlreiche neue Mittel und Methoden der gesamten Heilkunde, die sich dauerndes Bürgerrecht in unserer Wissenschaft erworben haben, sind in der Deutschen Medizinischen Wochenschrift zuerst mitgeteilt worden. $\mathrm{Zu}$ ihren Mitarbeitern zähit die Deutsche Medizinische Wochenschrift die hervorragendsten Aerzte des In- und Auslandes. Mit ihrem alle Zweige der Medizin umfassenden Inhalt ist die Deutsche Medizinische Wochenschrilt eine Quelle fruchtbringender Belehrung sowohl für den lediglich wissenschaftlich arbeitenden Arzt wie für den Praktiker. Namentlich die Fortbildung des praktischen Arztes im Interesse seiner Berufstätigkeit zu fördern, betrachtet die Deutsche Medizinische Wochenschrift als ihre Hauptaufgabe; ihr dienen u. a. auch die von ersten Autoritäten verfaften, fast in jeder Nummer veröffentlichten

\section{Vorträge über praktische Therapie,}

die in Tehrbuchmäßiger Darstellung die verschiedensten Thema aus dem Arbeitsgegebiet des praktischen Arztes knapp und kurz, ohne weitschweifige Erörterungen und ohne Literatur, abhandeln und sich des größten Beifalls in den Kreisen der Aerzte erfreuen.

Die Literaturbellage enthält Bücherbesprechungen und Referate von über 70 in- und ausländischen Zeitschriften. Die Deutsche Medizinische Wochenschrift enthält unter allen Wochenschriften die reichhaltigste und am zweckmäßigsten angeordnete Literaturübersicht. Außerdem wird durch Sammelreferate die jüngste Literatur über aktuelle Themata, insbesondere aus dem Gebiete der Therapie, zusammengefaBt und so dem Leser ein vollständiges Bild von dem derzeitigen Stand der Forschung entrollt.

In der Vereinsbeilage gelangen die offiziellen Berichte sowie Originalberichte zahlreicher Vereine des In- und Auslandes zum Abdruck.

Von eigenen Berichterstattern werden die Verhandlungen der inländischen. wie der internationalen Kongresse mit größter Schnelligkeit und Vollständigkeit veröffentlicht.

Eine sorgfälige Pflege wird der öffentlichen und privaten Hygiene, den Fortschritten auf dem Gebiete des deutschen Medizinalwesens, sowie der sozialen Medizin und den Standesangelegenheiten zuteil. Die wesentlichen Entscheidungen des Reichsversicherungsamts, wichtige Urteile aus dem Gebiete der ärztlichen Rechtspraxis, die neuesten technischen Erfindungen, Neuerungen auf dem Gebiete der Krankenpflege werden von hervorragenden Fachmännern in zusammenfassenden Uebersichtsartikeln berichtet. - Nene Gesetze, behördliche Erlasse, ärztliche Personalnotizen aus allen deutschen Staaten werden nach amtlichen Mitteilungen veröffentlicht.

Die Kleinen Mitteilungen geben Kenntnis von den wichtigsten ärztlichen Tagesereignissen; sie enthaiten ferner Notizen über Kongresse, Universitätsnachrichten u. dergl.

Weiterhin erscheinen Feuilletonartikel; ständige auswärtige Korrespondenzen über das medizinische Leben des In- und Auslandes, medizinische Reiseschilderungen u, dergl.

In dem Bestreben, den Abonnenten unserer Wochenschrift ständig mehr zu bieten, ist die illustrative Ausschmückung, die die Wochenschrift bisher schon - abgesehen von den wissenschaftlichen Abbildungen - durch die im Text reproduzierten Portrăts hervorragender Aerzte erfahren hat, durch die

Beigabe von wertwollen Bildern aus der Geschichte der Medizin

in Form von Kunstbeilagen erweitert worden. Geschmackvoll ausgeführte Sammelmappe kann zum billigen Preise von 1,50 Mk, bezogen werden.

Die Deutsche Medizinische Wochenschrift erscheint wöchentlich in Nummern von $5-6$ Bogen.

\section{Stud.-Abonn. 3 Mark vierteljährlich.}

Druck von J. B. Hirschfeld Leipzig. 
Verlag von Georg Thieme in Leipzig.

\section{Lehrbuch}

der

\section{Allgemeinen Pathologie}

und der

\section{Allgemeinen pathologischen Anatomie}

von

\section{Dr. med. R. 0estreich,}

Privatdozent und Prosektor am

Angusta-Vil:toria-Hospital zu Berlin.

Mit 44 Textabbildungen und 14 Abildungen auf

11 Tafeln in Dreifarbendruck.

Preis ea. 12 Mark. 



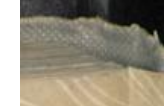




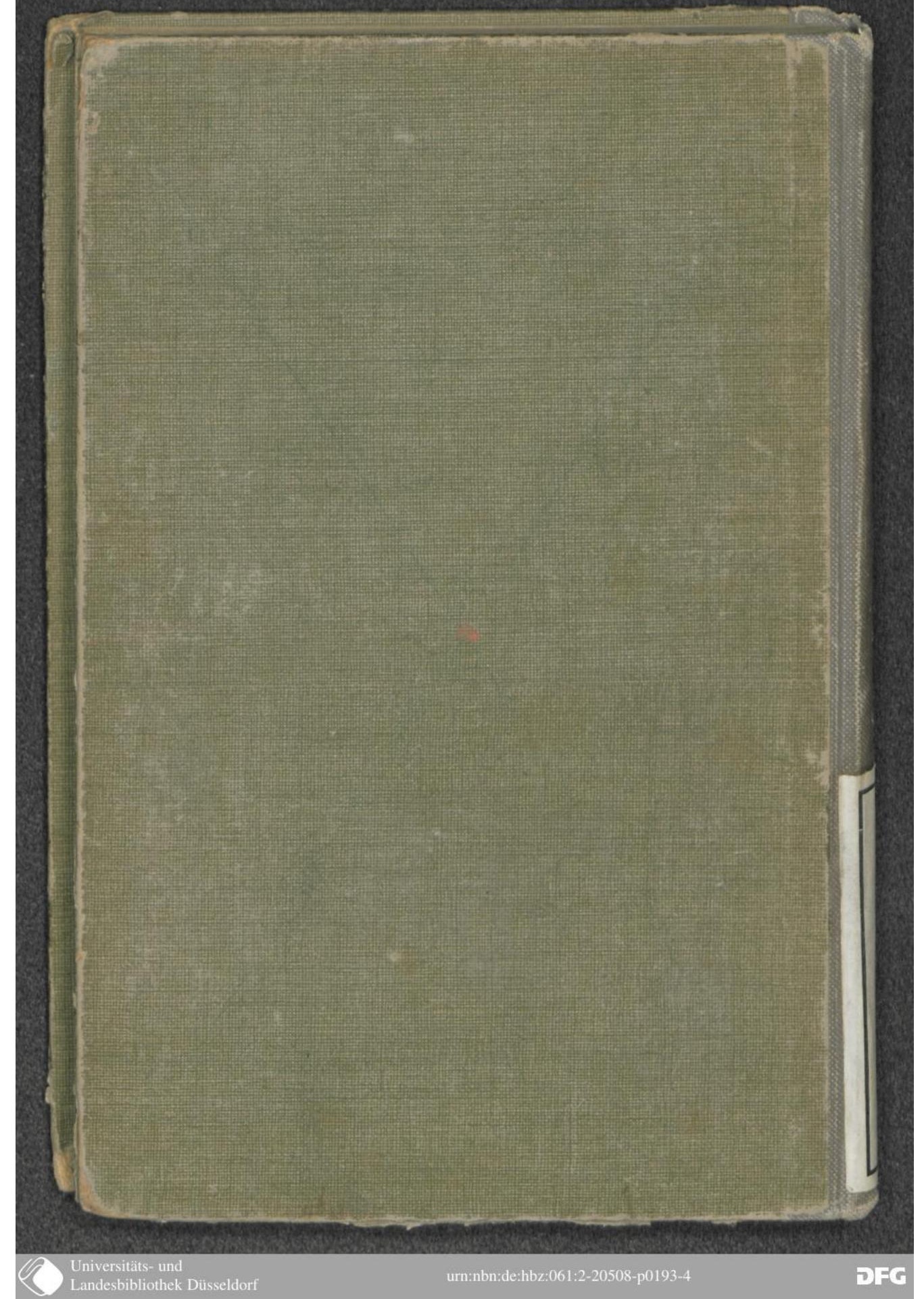

